\title{
O problema integrado de dimensionamento e sequenciamento de lotes no processo de fabricação da cerveja: modelos e métodos de solução
}





\title{
O problema integrado de dimensionamento e sequenciamento de lotes no processo de fabricação da cerveja: modelos e métodos de solução
}

\author{
Tamara Angélica Baldo
}

Orientador: Prof. Dr. Reinaldo Morabito

Co-orientadora: Profa. Dra. Maristela Oliveira dos Santos

Tese apresentada ao Instituto de Ciências Matemáticas e de Computação - ICMC-USP, como parte dos requisitos para obtenção do título de Doutor em Ciências - Ciências de Computação e Matemática Computacional. VERSÃO REVISADA. 
Ficha catalográfica elaborada pela Biblioteca Prof. Achille Bassi e Seção Técnica de Informática, ICMC/USP, com os dados fornecidos pelo(a) autor(a)

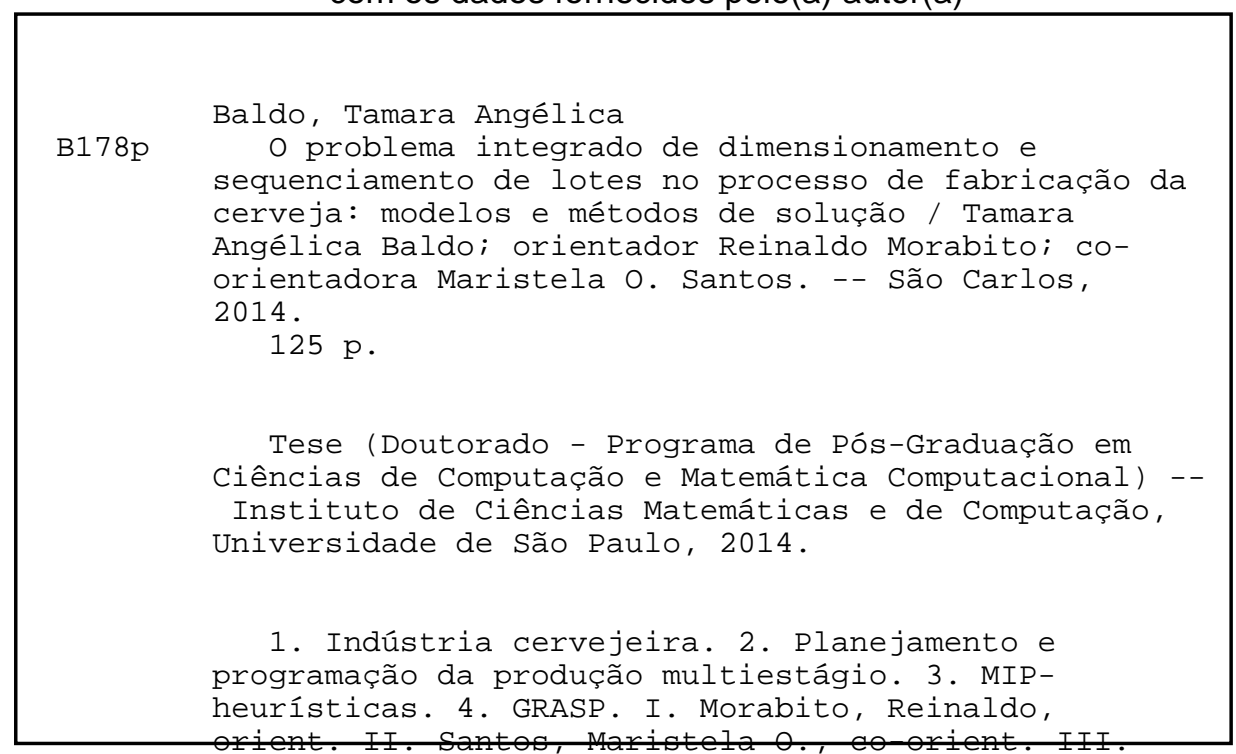

Título. 
Aos meus pais Denivaldo e Francisca,

à minha irmã Thaísa e ao meu noivo João. 


\section{Agradecimentos}

A conclusão de um trabalho não requer apenas esforço e paciência de uma única pessoa. Temo cometer a injustiça de esquecer alguém, pois são muitos aqueles que fizeram e fazem parte de minha vida, que contribuíram direta e/ou indiretamente durante estes anos de doutorado.

Gostaria de começar agradecendo aos meus pais, Francisca e Denivaldo, que dia-a-dia mostram-me o quão a família é nosso alicerce. Por vários momentos de dificuldades, graças ao carinho e ao incentivo constante, eu consegui (e consigo) me fortalecer e seguir em frente. Acredito que o mais difícil destes anos de doutorado foi a distância. Principalmente em 2011, onde um oceano separava os nossos braços e não permitia que um abraço se concretizasse fisicamente. Neste mesmo parágrafo, gostaria de incluir minha irmãzinha (Thaísa), que engradece ainda mais este laço familiar e quem eu amo demais também.

Agradeço aos meus familiares: avós (Elisa e Maria), avôs (Antônio e Pedro), tios, tias, primos e primas, por todo o carinho e paciência durante esta etapa, que mesmo com as tormentas que a vida nos trouxe, mantiveram-se fortes, enfrentando tudo sempre com muito respeito, amor e companheirismo. Estes gestos mostram-me que a maior riqueza terrena que tenho é cada um de vocês, juntamente com meus pais e minha irmã.

Ao meu querido noivo, João Francisco, pela paciência, compreensão, incentivo e, principalmente, pelo amor e carinho incondicional durante estes anos juntos.

Aos meus orientadores, Reinaldo e Maristela, que acreditaram em mim e neste trabalho, incentivaram, aconselharam e foram os tutores desta tese. Reinaldo, obrigada pelos seus sábios conselhos e seu otimismo. Mari, obrigada por ter sido a minha mãe dentro do mundo acadêmico, pelas broncas (que mereci ouvir) e conselhos, pois estes me fizeram engrandecer, fortalecer e lutar ainda mais pelo meu objetivo. Esta tese não é o fim de uma parceria, mas a continuação de muitos trabalhos que ainda hão de vir.

Aos meus amigos que me apoiaram. Em especial, à minha querida amiga Diana, esta que fez toda a diferença em minha vida não só durante a minha estada em Portugal. À minha amiga Elsa, que com seu jeitinho português, ajudou-me a entender um pouco a Europa e os portugueses.

Aos alunos e professores do Laboratório de Otimização do Instituto de Ciências Matemáticas e de Computação (LOT - ICMC/USP), Laboratório de Investigação Operacional da Faculdade de Engenharia da Universidade do Porto (FEUP - Portugal) e do Grupo de Pesquisa Operacional do departamento de Engenharia de Produção (GPO - UFSCar). Especialmente, à professora Franklina pelos conselhos e pela amizade.

Aos funcionários do ICMC-USP e do DEP-UFSCar .

Ao grande músico Raul Santos Seixas, que mesmo não estando fisicamente neste plano, sempre esteve presente com sua voz em meus fones de ouvido durante as inúmeras horas de estudos, implementações, escrita da tese, lazer, viagens, enfim, em inúmeros momentos.

À CAPES (processo: BEX 6198/10-4) pelo apoio financeiro durante o período que fiquei em Portugal desenvolvendo o doutorado-sanduíche. Ao CNPq (processo: 143295/2009-8) pela colaboração durante todo o período que estive desenvolvendo o doutorado no Brasil.

E, por fim, uma pessoa de extrema importância na execução desta tese: à Tamara do passado, pois sem ela, seu esforço, sua dedicação e sua persistência, este trabalho não estaria aqui e eu (a Tamara do presente) não teria engrandecido o suficiente.

Gostaria de deixar explícito o imensa satisfação que foi o desenvolvimento desta pesquisa e o quão prazeroso foi (e continua sendo) poder aprender um pouco mais sobre cerveja. 
"Há três métodos para ganhar sabedoria: primeiro, por reflexão, que é o mais nobre; segundo, por imitação, que é o mais fácil; e terceiro, por experiência, que é o mais amargo." (Confúcio) 
Este trabalho aborda o problema multiestágio de planejamento e programação da produção em indústrias cervejeiras. O processo de fabricação de cerveja pode ser dividido em duas etapas principais: preparação do líquido e envase. A primeira etapa ocorre, na maior parte do tempo, dentro de tanques de fermentação e maturação. A segunda ocorre nas linhas de envase, podendo ter início assim que o líquido estiver pronto nos tanques. O tempo de preparação do líquido demora vários dias, enquanto que na maioria das indústrias de bebidas carbonatadas este tempo é de no máximo algumas horas. O objetivo deste estudo é obter planos de produção viáveis que visam otimizar as decisões de programação envolvidas nestes processos. Visitas a cervejarias no Brasil e em Portugal foram realizadas para uma maior familiaridade do processo de produção e dados foram coletados. Modelos de programação inteira mista para representar o problema foram desenvolvidos, baseados em abordagens CSLP (The Continuous Setup Lot-Sizing Problem), GLSP (General Lot Sizing and Scheduling Problem), SPL (Simple Plant Location Problem) e ATSP (Asymmetric Travelling Salesman Problem). Os resultados mostram que os modelos são coerentes e representam adequadamente o problema, entretanto, mostram-se difíceis de serem resolvidos na otimalidade. Esta dificuldade de resolução dos modelos motivou o desenvolvimento de procedimentos MIP-heurísticos, como também de uma metaheurística GRASP (Greedy Randomized Adaptive Search Procedure). As soluções obtidas pelos procedimentos heurísticos são de boa qualidade, quando comparadas ao melhor limitante inferior encontrado por meio da resolução dos modelos matemáticos. Os testes computacionais foram realizados utilizando instâncias geradas com base em dados reais.

Palavras-chave: Indústria cervejeira, Planejamento e programação da produção multiestágio, Dimensionamento de lotes e sequenciamento, Programação inteira mista, MIP-heurísticas, GRASP. 

This study deals with the multistage lot-sizing and scheduling problem in breweries. The brewing process can be divided into two main stages: preparation and filling of the liquid. The first stage occurs most of the time in fermentation and maturation tanks. The second stage occurs in the filling lines and it can start as soon as the liquid gets ready. The preparation time of the liquid takes several days, while in the carbonated beverage industries this time is at most a few hours. The purpose of this study is to obtain feasible production plans aimed at optimizing the decisions involved in these processes. Visits to brewery industries in Brazil and Portugal were held to a greater familiarity of the production process and data were collected. Mixed integer programming models have been developed to represent the problem, based on approaches for the CSLP (The Continuous Setup Lot-Sizing Problem), GLSP (General Lot Sizing and Scheduling Problem), SPL (Simple Plant Location Problem) and ATSP (Asymmetric Travelling Salesman Problem). The results show that the models are consistent and adequately represent the problem; however, they are difficult to be solved at optimality. This motivated the development of MIP-heuristic procedures, as well as a meta-heuristic GRASP (Greedy Randomized Adaptive Search Procedure). The obtained solutions by the heuristics are of good quality, when compared to the best lower bound found by solving the mathematical models. The tests were conducted using generated instances based on real data.

Keywords: brewery industry, multistage lot-sizing and scheduling problem, mixed integer mathematical model, MIP-heuristic, GRASP. 



\section{Sumário}

Resumo i i

Abstract iii

\begin{tabular}{lll}
\hline 1 & Introdução & 1
\end{tabular}

1.1 Objetivos e justificativa $\ldots \ldots \ldots \ldots \ldots \ldots \ldots \ldots \ldots$

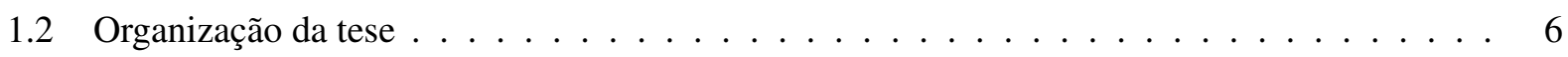

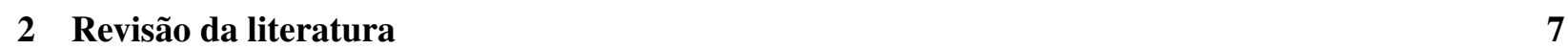

2.1 Dimensionamento de lotes . . . . . . . . . . . . . . . . . . . . . . . 12

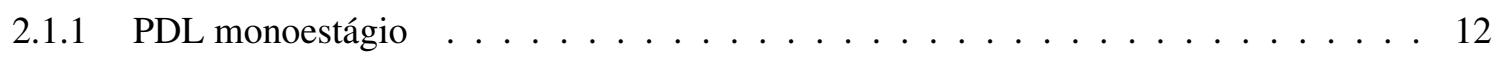

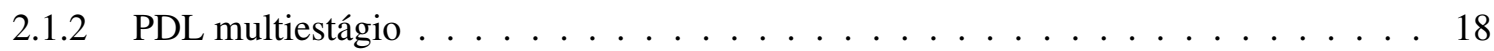

2.2 Problema de sequenciamento da produção $\ldots \ldots \ldots \ldots \ldots \ldots \ldots$

2.3 Problema integrado de dimensionamento e sequenciamento . . . . . . . . . . . . . . 21

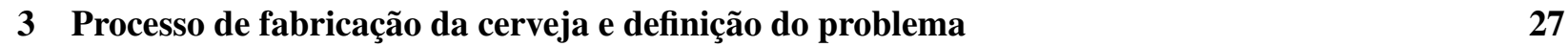

3.1 Histórico . . . . . . . . . . . . . . . . . . . . . . . . . . 27

$3.1 .1 \quad$ A história da cerveja no Brasil . . . . . . . . . . . . . . . . . . . . . . . . . . . 29

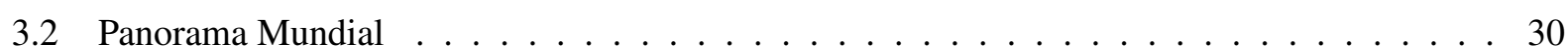

3.3 Processo de fabricação da cerveja $\ldots \ldots \ldots \ldots \ldots \ldots \ldots$

3.3 .1 Etapas do processo de produção de cerveja $\ldots \ldots \ldots \ldots \ldots \ldots$

3.3 .2 Cerveja sem álcool . . . . . . . . . . . . . . . . . . . . . . . . 34

3.3 .3 Classificação das cervejas . . . . . . . . . . . . . . . . . 34

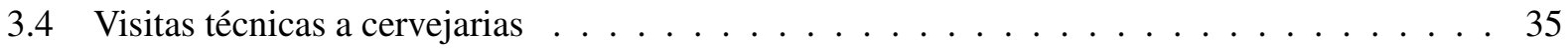

3.4 .1 Empresa brasileira . . . . . . . . . . . . . . . . 36

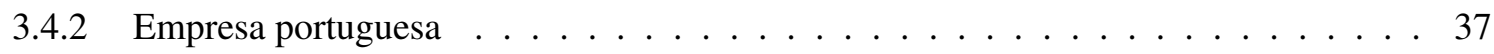

3.5 Definição do problema $\ldots \ldots \ldots \ldots \ldots \ldots$

4 Modelagem matemática do problema $\quad 41$

$4.1 \quad$ Modelo matemático: T1LM . . . . . . . . . . . . . . . . . . . . . . . . 43

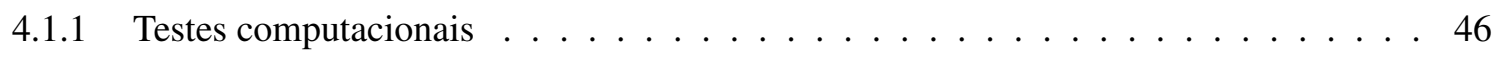




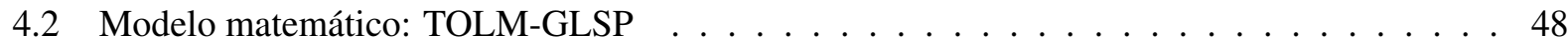

$4.2 .1 \quad$ Exemplo numérico: modelo TOLM-GSLP $\ldots \ldots \ldots \ldots \ldots \ldots$

4.2 .2 Influência do tempo de fermentação e maturação $\ldots \ldots \ldots$. . . . . . . . . . 54

4.2 .3 Gerador de dados . . . . . . . . . . . . . . . . . . . . . . . 55

4.2 .4 Características das instâncias de teste $\ldots \ldots \ldots \ldots$. . . . . . . . . . . 58

4.2 .5 Testes computacionais utilizando o modelo TOLM-GLSP $\ldots \ldots \ldots$. . . . . . . . 59

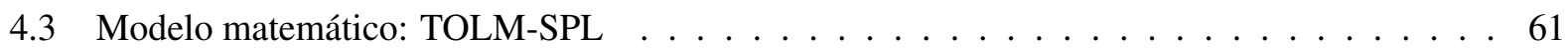

$4.3 .1 \quad$ Testes computacionais (TOLM-SPL) $\ldots \ldots \ldots \ldots \ldots$. . . . . . . . . . 64

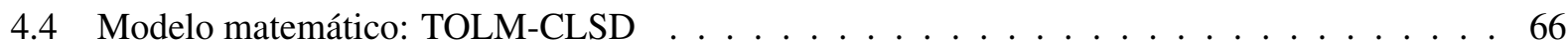

$4.4 .1 \quad$ Restrições MTZ . . . . . . . . . . . . . . . . . . . . . . . . . . . . 68

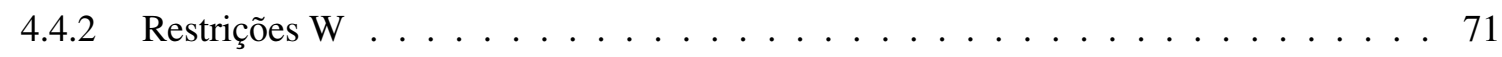

4.5 Conclusões sobre os modelos TOLM $\ldots \ldots \ldots \ldots \ldots \ldots \ldots$

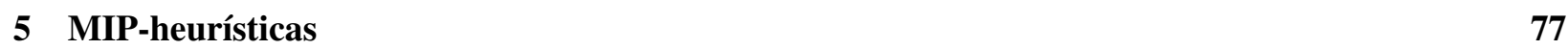

5.1 MIP-heurísticas: relax-and-fix e fix-and-optimize $\ldots \ldots \ldots \ldots \ldots$

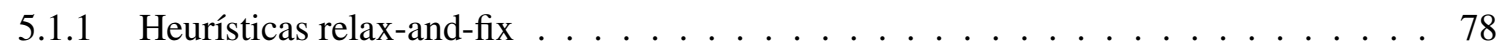

5.1 .2 Heurísticas de melhoria: fix-and-optimize $\ldots \ldots \ldots \ldots$. . . . . . . . 82

5.1 .3 Testes (iniciais) computacionais: MIP-heurísticas relax-and-fix e fix-and-optimize . . 83

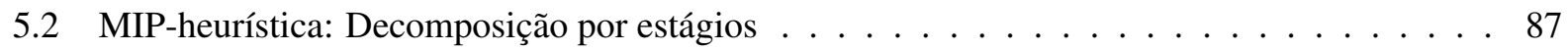

5.3 Resultados das MIP-heurísticas $\ldots \ldots \ldots \ldots$. . . . . . . . . . . . . . . 89

5.4 Análise de sensibilidade $\ldots \ldots \ldots \ldots \ldots \ldots \ldots$. . . . . . . . . . . . . . . . . . .

$\begin{array}{lll}6 & \text { Meta-heurística } & 95\end{array}$

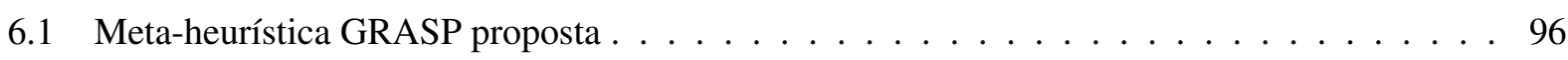

6.1 .1 Heurística Construtiva . . . . . . . . . . . . . . . . . . . . . . . . . . 97

6.1 .2 Heurística de busca local . . . . . . . . . . . . . . . . . . . 107

6.2 Resultados . . . . . . . . . . . . . . . . . . . . . . . . . . . . 109

\begin{tabular}{lll}
\hline 7 & Conclusões & 113
\end{tabular}

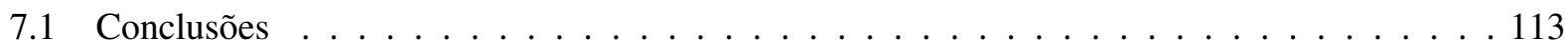

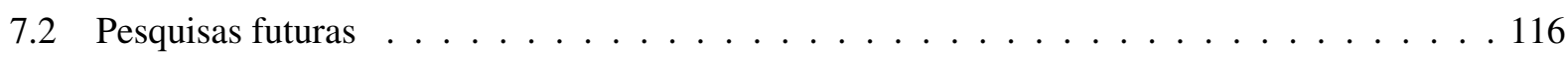




\section{Lista de Figuras}

2.1 Tipos de estrutura dos produtos em problemas multiestágios. . . . . . . . . . . . . . . . . 10

2.2 Linha do tempo para o horizonte de planejamento em problemas BPP (Charnprasitphon: 2007) . . . . . . . . . . . . . . . . . . . 16

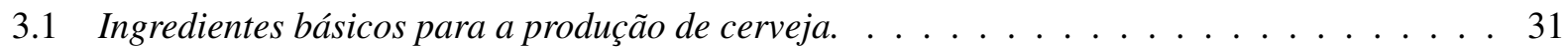

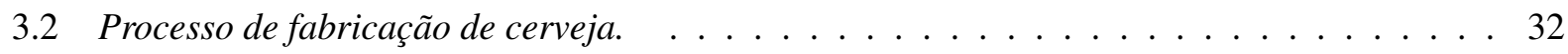

$3.3 \quad$ Sincronização entre os estágios. $\ldots \ldots \ldots \ldots \ldots \ldots$

4.1 Divisão do horizonte de planejamento. . . . . . . . . . . . . . . . . . . . . . . . . . . . . . 49

4.2 Tanque vazio ao receber um novo líquido e começar o período de fermentação/maturação $\left(K_{o l t}=0\right)$, estando pronto e disponível após $\Delta_{l}+1$ dias. $\ldots \ldots \ldots \ldots \ldots$

$4.3 \quad$ Ilustração de plano de produção de uma cervejaria, utilizando dados fictícios. . . . . . . . . 53

4.4 Influência do tempo de fermentação e maturação, analisando: (I) o GAP (veja a equação (4.16)); (II) o percentual de contribuição para a função objetivo do custo de estoque e do atraso. . . . . . . . . . . . . . . . . . . . . . . 55

$4.5 \quad$ Ilustração da função objetivo (4.34). . . . . . . . . . . . . . . . . . . . . . . . . . 63

4.6 Ilustração das restrições (4.39) e (4.40). . . . . . . . . . . . . . . . . . . . . . . 64

$4.7 \quad$ Horizonte de planejamento para os modelos TOLM-CLSD. . . . . . . . . . . . . . . . . . 66

$4.8 \quad$ Possíveis configurações de setup - figura extraída de Almada-Lobo et al.](2007). . . . . . . 68

$5.1 \quad$ Ilustração das iterações da heurística relax-and-fix forward. . . . . . . . . . . . . . . . 80

$5.2 \quad$ Ilustração das iterações da heurística relax-and-fix backward. . . . . . . . . . . . . . . 80

5.3 Ilustração das iterações da heurística relax-and-fix forward por estágios. . . . . . . . . . . . 80

5.4 Ilustração das iterações da heurística relax-and-fix por tanques. . . . . . . . . . . . . . . . . 81

$5.5 \quad$ Ilustração das iterações da heurística relax-and-fix por líquidos e itens. . . . . . . . . . . . 82 



\section{Lista de Tabelas}

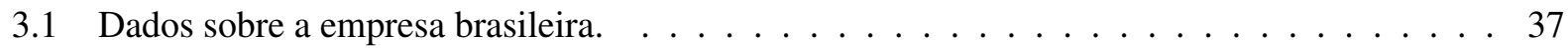

3.2 Especificações dos tanques de fermentação e dos tanques de armazenamento do líquido

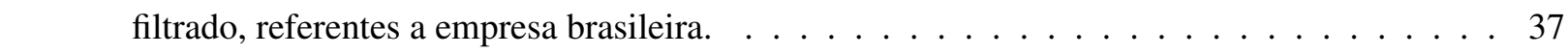

3.3 Dados sobre a empresa portuguesa. . . . . . . . . . . . . . . . . 38

3.4 Especificações dos tanques de fermentação e dos tanques de armazenamento do líquido

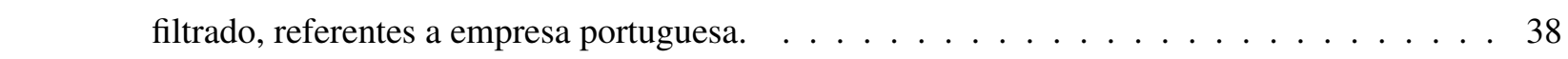

4.1 Dados utilizados para a geração das classes de instâncias (modelo T1LM). . . . . . . . . . . . 47

4.2 Resumo dos resultados obtidos com a resolução do modelo T1LM utilizando os exemplos

da Classe-A1 a Classe-B3 (analisando o GAP e tempo de execução). . . . . . . . . . . . . 48

4.3 Dados referente ao exemplo numérico utilizado para a explicação de TOLM-GLSP. . . . . . 52

4.4 Dados utilizados para a geração de instâncias teste durante explicação da influência do tempo de fermentação e maturação. . . . . . . . . . . . . . . . . . . 55

4.5 Exemplo de como estabelecer a relação de contribuição de produção de cada máquina. . . . 56

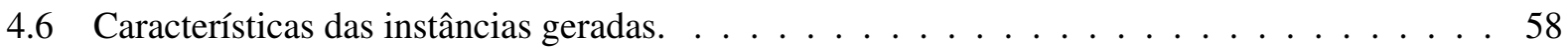

4.7 Resultados computacionais obtidos por meio da resolução do modelo TOLM-GLSP. . . . 60

4.8 Resultados computacionais obtidos por meio da resolução do modelo TOLM-SPL, utilizando as instâncias cujas características estão definidas na Seção 4.2 .4$]$. . . . . . . . . . . 65

4.9 Resultados computacionais obtidos por meio da resolução do modelo TOLM-CLSD_MTZ. . 70

4.10 Resultados computacionais obtidos por meio da resolução do modelo TOLM-CLSD_W, utilizando as instâncias cujas características estão definidas na Seção|4.2.4 $\ldots$. . . . . . . . 73

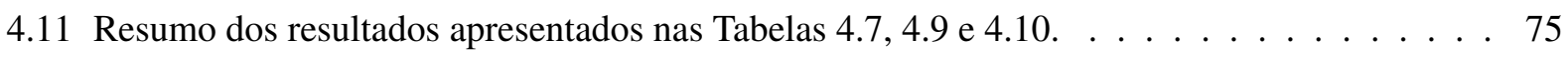

5.1 Comparação dos resultados resolvendo o modelo e as estratégias relax-and-fix, em (A) fixa\begin{tabular}{|c|c|}
\hline se apenas as variáveis inteiras e em $(\boldsymbol{B})$ fixa-se as variáveis inteiras e limita-se as variáveis \\
\hline
\end{tabular}

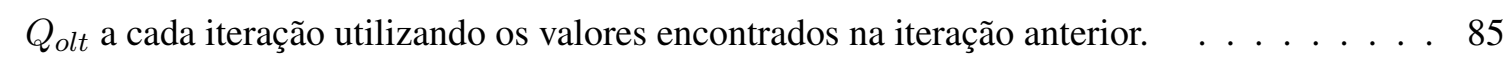

5.2 Resultados das estratégias OPT_Forw, OPT_Back, OPT_Forw_II-I, OPT_Tank e OPT_Demand.

5.3 Resultados obtidos por meio da resolução das instâncias de grande dimensão, utilizando os procedimentos: Proc_Crescente, Proc_Decrescente e Decomposição por estágios. . . . . . . 90 
5.4 Resultados da análise de sensibilidade do modelo e das MIP-heurísticas. . . . . . . . . . . . 93

6.1 Dados referentes ao exemplo numérico ilustrativo utilizado para a explicação da metaheurística GRASP. . . . . . . . . . . . . . . . . . . . . . . . . . 97

6.2 Demanda dos itens do exemplo numérico ilustrativo utilizado para a explicação da metaheurística GRASP . . . . . . . . . . . . . . . . . . . . . . . 97

6.3 Inicialização dos tanques. . . . . . . . . . . . . . . . . . . . . . . . . . . . . 99

6.4 Demanda de líquidos por períodos e respectiva ordem de processamento das demandas

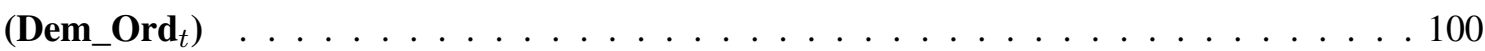

6.5 Tabela contendo a configuração inicial da linha de envase ( $0^{\mathrm{a}}$ iteração) e após as três primei-

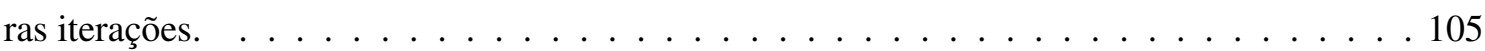

6.6 Tabela contendo a configuração das linhas de envase após a $4^{a}, 5^{a}, 6^{a}$ e $7^{a}$ iterações. . . . . . 106

6.7 Plano de produção fornecido por meio da execução da heurística construtiva para o exemplo (Algoritmo) . . . . . . . . . . . . . . . . . . . . 107

6.8 Plano de produção fornecido ao final da execução da heurística de busca local para o exemplo (Algoritmo ). . . . . . . . . . . . . . . . . . . . . . . . 108

6.9 $\quad$ GAP variando-se os valores de partial na execução da meta-heurística GRASP para as instâncias geradas. . . . . . . . . . . . . . . . . . . . 110

6.10 Comparação dos resultados do modelo TOLM-GLSP, Proc_Crescente e da meta-heurística

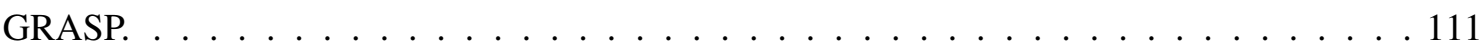




\section{Lista de abreviaturas e siglas}

$\begin{array}{ll}\text { PCP } & \text { Planejamento e Controle da Produção } \\ \text { MIP } & \text { Mixed Integer Problem } \\ \text { GRASP } & \text { Greedy Randomized Adaptive Search Procedure } \\ \text { PDL } & \text { Problema de dimensionamento de lotes } \\ \text { CLSP } & \text { PDL com limitações de capacidade } \\ \text { PLSP } & \text { Proportional Lotsizing and Scheduling Problem } \\ \text { DLSP } & \text { The Discrete Lot-Sizing and Scheduling Problem } \\ \text { BPP-SD } & \text { modelo de Charnprasitphon } \\ \text { BPP-SI } & \text { modelo de } 2007) \text { para o problema de produção de vacinas } \\ \text { EBC } & \text { European Brewery Convention } \\ \text { FIFO } & \text { First-In-First-Out } \\ \text { VNS } & \text { Variable Neighborhood Search alocação dos tanques de cerveja } \\ \text { GLSP } & \text { General Lot-sizing and Scheduling Problem (Fleischmann \& Meyr. 1997) } \\ \text { ATSP } & \text { Assymetric Travelling Salesman Problem } \\ \text { CLSD } & \text { The Capacitated Lot-Sizing Problem with Sequence Dependent Setup Costs } \\ \text { CSLP } & \text { The Continuous Setup Lot-Sizing Problem } \\ \text { SPL } & \text { Simple Plant Location } \\ \text { AmBev } & \text { Companhia de Bebidas das Américas }\end{array}$


O Planejamento e Controle da Produção (PCP) é o setor responsável por garantir a continuidade da produção em uma indústria, coordenar e administrar os recursos que estão disponíveis e que serão utilizados durante o processo produtivo. O principal objetivo do PCP é conduzir da maneira mais eficiente e eficaz possível as decisões para cada um dos níveis hierárquicos: estratégico, tático e operacional (Slack et al., 2002).

O nível estratégico envolve as decisões de longo prazo, como a definição dos objetivos mais gerais da empresa, sendo as decisões deste nível as que envolvem os mais altos investimentos. O nível tático abrange as decisões de médio prazo e está vinculado com a utilização efetiva de recursos existentes, tendo por objetivo o cumprimento das metas determinadas no planejamento estratégico, definindo como irá acontecer a produção (por exemplo: quais produtos serão produzidos em um determinado período e em quais quantidades - dimensionamento de lotes). O nível operacional está relacionado ao dia-a-dia da produção (curto prazo), cujo objetivo é definir as prioridades do nível anterior, por exemplo, quais as ordens de produção dos itens e quais as respectivas máquinas que irão fazê-los (programação da produção), entre outros (Slack et al. 2002). As decisões envolvidas durante o dimensionamento de lotes e a programação da produção em indústrias cervejeiras é o objeto principal deste trabalho.

O problema de dimensionamento de lotes consiste em planejar a quantidade de itens a ser produzida em cada período ao longo de um horizonte de tempo finito, de modo a atender uma certa demanda, respeitandose limitações dos recursos e otimizando uma função objetivo (por exemplo, minimizar custos). Os custos envolvidos podem ser os custos de produção, de estoque e de preparação de máquinas (setup cost). Os itens a serem produzidos competem pelos recursos, sendo estes recursos, na maioria das vezes, escassos (capacidade limitada). Revisões da literatura sobre tais problemas podem ser encontradas em Jans \& Degraeve (2007) e Karimi et al. (2003). O problema de dimensionamento de lotes consiste em planejar a quantidade de itens a ser produzida em cada período ao longo de um horizonte de tempo finito, de modo a atender uma certa demanda, respeitando-se limitações dos recursos e otimizando uma função objetivo (por exemplo, minimizar custos). Os custos envolvidos podem ser os custos de produção, de estoque e de preparação 
de máquinas ( $\operatorname{setup}$ cost). Os itens a serem produzidos competem pelos recursos, sendo estes recursos, na maioria das vezes, escassos (capacidade limitada). Revisões da literatura sobre tais problemas podem ser encontradas em Jans \& Degraeve (2007) e Karimi et al. (2003).

Antes do início da produção de um lote de determinado item, máquinas precisam ser preparadas. Porém, o custo e o tempo de preparo (setup) das máquinas normalmente independe do tamanho deste lote, ou seja, o tempo despendido e o custo para o preparo de uma máquina independem se a produção será de um lote pequeno ou de um lote grande. Com isto, muitas vezes torna-se vantajoso produzir quantidades maiores que a demanda e estocar, ao invés de produzir um mesmo item por diversas vezes durante o horizonte de planejamento. Entretanto, o preparo de máquina pode ser influenciado pela sequência da produção. Quando há presença de tempos de preparo dependentes da sequência, a capacidade disponível para a produção dependerá tanto do tamanho quanto do sequenciamento dos lotes de produção. Por exemplo, durante a fase de envase da cerveja, o líquido precisa estar pronto para ser envasado e, ainda, a linha de envase preparada para o início da produção. Se o item for uma garrafa retornável de 600ml, esta linha deve estar preparada para lavar e esterilizar a embalagem, enchê-la de líquido, fechar a garrafa, pasteurizar o produto e rotular a embalagem. Se for uma lata de $350 \mathrm{ml}$, esta já vem esterilizada, então deve-se encher, fechar a lata e pasteurizar o líquido. O tempo de preparo das linhas de envase são influenciadas pela sequência de produção, por exemplo, se o produto anterior for uma cerveja de puro malte e a próxima cerveja contenha grits 1 de milho, o tempo de preparação é de 20 minutos, aproximadamente. Porém, se considerarmos a sequência contrária, o tempo de preparo é de 1,5 horas, supondo o mesmo tipo de embalagem para ambas.

Na literatura, há diversos trabalhos que abordam modelos matemáticos para o problema de dimensionamento de lotes (Billington et al., 1986; Eppen \& Martin, 1987, Trigeiro et al., 1989; França et al., 1997; Toledo \& Armentano, 2006; Jans \& Degraeve, 2007; Baldo, 2009; Wu et al., 2013; Toledo et al., 2013) e que integram a este o sequenciamento da produção (Fleischmann \& Meyr, 1997; Salomon et al., 1997; Ferreira et al., 2009; Luche et al., 2009; Toledo et al., 2009; Lang \& Shen, 2011; Meyr \& Mann, 2013, Santos \& Almada-Lobo, 2012, Seeanner et al., 2013). Os problemas integrados de dimensionamento e sequenciamento da produção são comumente encontrados em processos industriais e estes envolvem enormes desafios, pois cada indústria possui suas peculiaridades (por exemplo, sazonalidade de demanda e insumos, perecibilidade, produtos que disputam recursos em comum, entre outros). Alguns trabalhos que abordam o problema integrado em ambientes industriais são: Araujo et al. (2007) (fundições), Almada-Lobo et al. (2008) (produção de recipientes de vidro), Toso et al. (2008) (suplementos para nutrição animal), Figueira et al. (2013) (indústria papeleira), Toledo et al. (2012) (refrigerantes) e Baldo et al. (2014) (cervejeira).

Suerie (2005) discute alguns modelos clássicos de planejamento da produção presentes na literatura que utilizam configurações de setup independente e dependente da sequência. $\mathrm{O}$ autor define as principais características destes problemas, principalmente em termos de modelagem matemática, e em quais situações são considerados (in)dependentes da sequência. De acordo com o autor, tais modelos são apresentados de acordo com a escala de tempo do horizonte de planejamento. Se a escala de tempo discreta é escolhida, o bucket de tempo pode ser grande (big-bucket) ou pequeno (small-bucket). A distinção entre problemas big-bucket e small-bucket está relacionada ao tamanho do período e ao lote de produção dos itens. Nos problemas small-bucket é geralmente assumido que em cada período somente um, ou no máximo dois lotes de produtos podem ser produzidos, sendo assim, no máximo um setup é permitido. Logo, os problemas smallbucket integram decisões de dimensionamento de lotes e programação da produção, ou seja, não somente

\footnotetext{
${ }^{1}$ farinha grosseira (Dicionário Michaelis: Inglês-Português. Editora Melhoramentos.)
} 
determinam o tamanho dos lotes, mas também a sequência em que a produção ocorre. Por conseguinte, os problemas big-bucket permitem produção de vários lotes de produtos em cada período de tempo, podendo (ou não) fazer asserção a respeito da sequência da produção dentro do período, sendo o CLSP (The Capacitated Lot-Sizing Problem) o problema big-bucket mais básico estudado. O problema CLSP considera o processamento de vários produtos por um mesmo recurso, cuja capacidade é limitada. Cada item possui uma demanda dinâmica determinística (previamente conhecida) durante o horizonte de tempo finito, dividido em períodos, tendo por objetivo a minimização da soma dos custos de estoque e os custos de preparação (quando existente).

Existem diversas formulações matemáticas que representam problemas small-bucket, onde cada uma possui diferentes graus de liberdade, no que diz respeito às variáveis de decisão. Dentre os problemas e seus respectivos modelos, destacam-se (Suerie, 2005): DLSP, CSLP, PLSP e o GLSP. O DLSP (Discrete Lot-Sizing and Scheduling Problem) tem por pressuposto a divisão de cada período, denominado agora macro-período; esta divisão resulta em vários micro-períodos de tamanhos pré-definidos (Fleischmann. 1994). O DLSP assume a produção 'tudo-ou-nada': um item será produzido por micro-período somente se esta produção utilizar toda a capacidade disponível. Os modelos que representam os problemas CSLP (Continuous Setup Lot-Sizing Problem) descartam a produção 'tudo-ou-nada', ou seja, os lotes podem ter tamanhos variados, entretanto, os demais pressupostos fundamentais são os mesmos do DLSP. Os problemas PLSP (Proportional Lot-Sizing and Scheduling Problem) permitem a utilização da capacidade dos recursos por mais de um item durante o mesmo micro-período. O GLSP (General Lot-Sizing and Scheduling Problem) considera o tamanho de cada micro-período flexível. Revisões da literatura e comparações sobre estes problemas, como também seus modelos matemáticos, podem ser encontradas em Drexl \& Kimms (1997) e Suerie (2005).

Dependendo da estrutura dos itens demandados, a produção pode acontecer em um único estágio (monoestágio) ou em vários estágios (multiestágio). Na produção monoestágio, a demanda é classificada como independente. Neste caso, os itens finais não dependem da produção dos itens intermediários, que são considerados como parte ou peças (e/ou não passam por estágios intermediários de fabricação). Na produção multiestágio, um item final necessita de vários itens intermediários, que também devem ter suas produções planejadas, ou passam por estágios intermediários.

Nesta tese estuda-se o problema de planejamento e programação da produção na indústria cervejeira. $\mathrm{O}$ problema integrado de dimensionamento e sequenciamento de lotes de produção no processo de fabricação de cerveja pode ser classificado como multiestágio, de modo que no primeiro estágio ocorre a preparação (fermentação e maturação) do líquido - ou seja, a produção da cerveja; e, na sequência, o líquido está disponível para iniciar o processo de envase das embalagens (segundo estágio). No estágio I, tem-se um problema independente da sequência de produção, enquanto no estágio II a ordem de produção é considerada. Para melhor entendimento dos processos envolvidos durante a produção de cerveja, foram realizadas visitas a algumas cervejarias no Brasil e em Portugal. As empresas apresentam diversas semelhanças, não apenas durante o processo produtivo, como também na forma como tentam prever a demanda. As cervejarias visitadas fazem o planejamento e a programação da produção de cada um dos estágios de maneira desacoplada, onde primeiramente há o planejamento do estágio I (preparação dos líquidos) e depois a programação do estágio II (envase). Esta estratégia de desacoplar os problemas simplifica suas soluções na prática, porém pode perder oportunidades de melhorar as soluções ao considerar o problema de maneira integrada, pois qualquer decisão em um dos estágios pode interferir diretamente no outro. Logo, o intuito deste trabalho 
é apresentar modelos e métodos de solução que considerem ambas as etapas simultaneamente para gerar planos de produção.

\subsection{Objetivos e justificativa}

Embora a cerveja seja um produto apreciado mundialmente e os principais fabricantes sejam grandes potências econômicas e tecnológicas, como China e Estados Unidos, não há relatos de estudos referentes ao planejamento e controle da produção em indústrias cervejeiras, assim como desenvolvido no decorrer desta pesquisa, o qual considera de maneira integrada as decisões de médio (dimensionamento de lotes ao longo dos períodos) e curto prazo (sequenciamento da produção dentro de cada período). Há poucos artigos que descrevem a otimização de partes do problema considerado. Logo, entre as justificativas deste estudo, destacam-se a escassez e a oportunidade de novos estudos na literatura do problema multiestágio de dimensionamento e programação da produção em indústrias cervejeiras. O problema tem relevância científica e destaca-se também a importância técnica e econômica em determinar planos de produção viáveis reduzindo os custos envolvidos, considerando as decisões não só de dimensionamento e sequenciamento, como também, de cada um dos estágios envolvidos durante a produção de cerveja (preparação do líquido e envase), de maneira acoplada.

Sobre a literatura envolvendo a indústria cervejeira, além de Baldo et al. (2014), que é produto desta tese, o único trabalho encontrado na base de dados pesquisada e que mais assemelha-se a este é o de Guimarães et al. (2012). Em Guimarães et al. (2012) descreve-se um estudo de caso em uma indústria de bebidas portuguesa (cerveja e refrigerante), considerando o ambiente multi-planta. Este trabalho é focado no planejamento tático e explora três modelos matemáticos monoestágio. Diferindo-se, assim, do que se propõe nesta tese, que são as decisões envolvidas no nível tático-operacional. Com relação aos problemas presentes nas demais indústrias de bebidas (água, sucos, refrigerantes, etc), notam-se inúmeras diferenças, das quais destacamos o tempo, relativamente longo, necessário para se completar o estágio I, ou seja, o período de fermentação e maturação tem duração de 3 a 41 dias, enquanto que na indústria de refrigerantes o tempo de preparação dos líquidos ocorre em minutos (no máximo poucas horas) estando disponível para o envase. $\mathrm{E}$, ainda, na indústria cervejeira, o líquido pronto pode permanecer nos tanques durante algum tempo antes de ser envasado, enquanto que na indústria de bebidas carbonatadas, esta possibilidade é inexistente. Outra característica analisada é a troca de líquidos nos tanques de fermentação e maturação que independe da sequência em que são alocados. Isso ocorre pois, antes de um tanque receber o mosto cervejeiro, este passa por um processo de limpeza cujo tempo médio é conhecido previamente e independe de qual líquido estava no tanque anteriormente. Esta especificidade também não está presente na indústria de refrigerantes.

O objetivo deste trabalho é apresentar alternativas que auxiliem as tomadas de decisões do planejamento e controle da produção, presentes nos níveis tático e operacional, do problema de dimensionamento de lotes e programação da produção em indústrias cervejeiras. Para tanto, modelos matemáticos são propostos, utilizando programação inteira mista (em inglês, Mixed Integer Programming - MIP), com o objetivo de fornecer planos de produção factíveis e otimizados para este tipo de indústria. Os problemas de dimensionamento de lotes de grandes dimensões são, em geral, NP-difíceis (Florian et al., 1980, Bitran \& Yanasse, 1982), sendo complicados de serem resolvidos na otimalidade ou próximo a ela. Esta dificuldade motiva o desenvolvimento e a proposta de novos métodos de resolução à literatura, principalmente métodos (meta)heurísticos. Neste trabalho apresentam-se métodos heurísticos baseados em modelagem matemática (MIP-heurísticos, 
Wolsey (1998)) e uma meta-heurística baseada em GRASP (Greedy Randomized Adaptive Search Procedure, Feo \& Resende (1989)) para a resolução do problema.

Seguindo a classificação proposta em Bertrand \& Fransoo (2002) e Morabito \& Pureza (2010), este trabalho trata-se de uma pesquisa quantitativa, normativa, com componentes tanto empíricos quanto axiomáticos. Quantitativa por apresentar modelos abstratos descritos em linguagem matemática e computacional. Empírica quantitativa por basear-se diretamente na realidade encontrada nas empresas cervejeiras visitadas e axiomática quantitativa por ter forte apelo a modelos de problemas idealizados da literatura cuja preocupação é obter soluções para o problema em questão e assegurar que tais soluções ajudem a esclarecer a estrutura do problema descrito no modelo. A pesquisa empírica normativa está interessada em criar um modelo que representa de forma adequada as relações causais presentes na realidade que envolve o problema e prescreva ações e decisões para otimizar este problema.

Em suma, os principais objetivos deste trabalho são:

- caracterização e definição do problema na prática: para isso coletaram-se informações e dados reais no processo de produção de indústrias cervejeiras no Brasil e em Portugal, ressaltando-se as semelhanças e divergências entre elas. Como consequência, um gerador de instâncias para o problema baseado em informações reais é proposto, pois até a presente data, não há instâncias na literatura para tal problema;

- desenvolvimento de modelos matemáticos considerando particularidades presentes nos estágios I e II (preparação do líquido e envase, respectivamente) do problema. Nos modelos permite-se que, por exemplo, o líquido fique armazenado durante vários dias dentro dos tanques de fermentação/maturação enquanto espera para ser envasado. O tempo de preparação das máquinas de envase é dependente da sequência, há sincronização entre tanques e linhas de envase (porém, de maneira diferente ao que é proposto na indústria de refrigerante, veja Ferreira et al. (2012)) e o problema envolve multiprodutos, multimáquinas, multiperíodos, entre outros. Os modelos de programação matemática propostos neste trabalho para representar o problema são descritos resumidamente a seguir:

- T1LM: trata-se de um modelo de programação inteira mista, cujo estágio II foi construído com base nos problemas CSLP. Este modelo representa a situação de apenas um tanque e diversas linhas de envase. Sendo assim, a extensão deste modelo foi necessária (com algumas ressalvas na modelagem) para considerar vários tanques (modelo TOLM-GLSP);

- TOLM-GLSP: considera vários tanques e linhas de envase, e o estágio II foi construído com base nos problemas GLSP (Fleischmann \& Meyr, 1997), semelhante ao modelo de Ferreira (2007) para as indústrias de refrigerantes. O modelo proposto considera o horizonte de planejamento dividido em duas partes disjuntas, sendo a primeira parte mais detalhada que a segunda;

- TOLM-SPL: é uma reformulação do modelo TOLM-GLSP, utilizando estratégias de modelagem dos problemas SPL (Simple Plant Location, Rosling (1986)). As formulações matemáticas de ambos os estágios (I e II) foram reescritas utilizando tal estratégia;

- TOLM-CLSD: o modelo TOLM-GLSP foi reformulado baseado nos problemas CLSD (The Capacitated Lot-Sizing Problem with Sequence Dependent Setup Costs, Haase (1996)). Para evitar a presença de subciclos, foram exploradas duas estratégias de eliminação destes subtours, assim como nos problemas ATSP (Asymmetric Travelling Salesman Problem). 
- proposta de métodos de resolução: os modelos propostos para o problema de dimensionamento de lotes e programação da produção em indústrias cervejeiras são difíceis de serem resolvidos na otimalidade ou, até mesmo, próximo a ela. Assim, com o objetivo de obter soluções de boa qualidade, neste trabalho são propostos e implementados diversos métodos heurísticos baseados em formulação matemática (MIP-heurísticas) e numa meta-heurística, sendo estes descritos brevemente a seguir:

- MIP-heurísticas:

$\nabla$ São propostas cinco heurísticas relax-and-fix para a resolução dos modelos e, também, cinco procedimentos de melhoria fix-and-optimize. Estes procedimentos foram testados e dois métodos resultantes da combinação destes, denominadas, Proc_Crescente e Proc_Decrescente, foram explorados;

$\nabla$ Decomposição por estágios: consiste na resolução de cada um dos estágios envolvidos durante o processo produtivo de maneira desacoplada. Primeiramente, resolve-se o estágio I e, na sequência, o estágio II. Este último recebe informações obtidas pela resolução do anterior e estas devem ser respeitadas. O estágio I fornece ao estágio II informações sobre qual líquido, qual período e a respectiva quantidade deste líquido que está pronta em cada um dos tanques, durante o decorrer do horizonte de planejamento.

- desenvolvimento e implementação de uma meta-heurística GRASP, cujo objetivo da fase construtiva é produzir o mais cedo possível a demanda, evitando o atraso na entrega. Após a construção de uma solução viável, esta passa por uma fase de melhoria por meio de uma heurística de busca local, que visa deslocar a produção no horizonte de planejamento.

\subsection{Organização da tese}

Esta tese contém 7 capítulos, sendo os demais estruturados conforme a seguir.

No Capítulo 2, 'Revisão da literatura', apresenta-se uma revisão da literatura de trabalhos que abordam o problema de dimensionamento de lotes e os que integram, conjuntamente com o dimensionamento e o sequenciamento da produção, apresentando modelos clássicos da literatura, como também trabalhos aplicados a algumas indústrias.

O Capítulo 3, 'Descrição do problema', traz uma descrição detalhada dos processos envolvidos durante a produção de cerveja e define o problema estudado no doutorado, com base na revisão da literatura e, também, visitas realizadas em empresas cervejeiras no Brasil e em Portugal.

O Capítulo 4, 'Modelos matemáticos', apresenta os modelos matemáticos desenvolvidos para o problema de dimensionamento e sequenciamento de lotes em indústrias cervejeiras.

O Capítulo 5, 'Métodos de solução', descreve as MIP-heurísticas desenvolvidas para a resolução dos modelos. As MIP-heurísticas consistem na combinação de heurísticas construtivas (relax-and-fix) e procedimentos de melhoria (fix-and-optimize).

No Capítulo 6, 'Meta-heurística', apresenta-se a meta-heurística proposta baseada no GRASP (Greedy Randomized Adaptive Search Procedure).

O Capítulo 7, 'Conclusões', aborda as conclusões do trabalho, trazendo uma breve discussão dos resultados das abordagens propostas e ressaltando as vantagens e as desvantagens de cada uma delas. Neste capítulo também discutem-se perspectivas interessantes para pesquisas futuras. 
O PCP (Planejamento e Controle da Produção) tem o propósito de garantir que os processos envolvidos durante a produção ocorram eficaz e eficientemente, como também que produzam produtos e serviços conforme requeridos, assegurando que as decisões tomadas sejam as mais acertadas possíveis, resultando em altas taxas de produtividade e qualidade, baixos índices de falhas e menor custo de produção (Slack et al. 2002). Nesta definição, o planejamento é a formalização do que pretende-se que ocorra em um determinado momento no futuro; estas formalizações são feitas por meio de plano de produção, sendo estes expectativas a serem implementadas. Entretanto, como são expectativas, obviamente não há garantia de que tudo ocorra conforme o esperado. Logo, o controle da produção tem o propósito de lidar com possíveis imprevistos, fazendo ajustes (quando necessários) que permitam que a operação atinja os objetivos estabelecidos previamente, podendo até refazer os planos que precisarem de alterações a curto prazo.

As necessidades do planejamento e controle da produção são diferentes para cada empresa, como também ao longo do horizonte de tempo. A longo prazo (estratégico) são necessárias definições mais gerais, relativas a metas, recursos a serem utilizados e adquiridos, enfim, uma visão mais ampla do que fazer e como implementar os objetivos da empresa ao longo do(s) próximo(s) ano(s), ou até mesmo da(s) próxima(s) década(s). A médio prazo (tático), preocupa-se em especificar como irá acontecer (ou até mesmo um replanejamento) o que foi estabelecido pelo nível estratégico, por exemplo: qual o produto será produzido em cada período e em quais quantidades (dimensionamento de lotes), quais recursos serão necessários para a execução do plano de produção, entre outras. A curto prazo (operacional) encontram-se as decisões voltadas para a programação da produção e estão relacionadas ao dia-dia da empresa, abrangendo um maior detalhamento de como as tarefas/produtos serão executados. As decisões envolvidas no dimensionamento de lotes e programação da produção em indústrias cervejeiras é o objeto principal deste trabalho, tendo um dos seus objetivos o desenvolvimento de modelos matemáticos, cuja resolução produza planos de produção viáveis e eficazes. 
O trabalho pioneiro tratando o problema de dimensionamento de lotes é de Ford W. Harris, intitulado "How many parts to make at once?" (Harris, 1913). A partir de então começa a surgir uma vasta corrente de pesquisas na literatura para tratar diversas aplicações do problema de dimensionamento de lotes. Para Suerie (2005), estes problemas podem ser classificados de acordo com o tempo, os recursos e os itens outras classificações podem ser encontradas em Kuik et al. (1994), Wolsey (2002) e Karimi et al. (2003). O primeiro conjunto de classificações relaciona-se com a estrutura do tempo e aos dados utilizados:

Horizonte de planejamento: o horizonte de planejamento pode ser finito ou infinito. Modelos com um horizonte de planejamento infinito geralmente assumem uma taxa de demanda constante, como o clássico trabalho de Harris: EOQ model (Economic Order Quantity model). Exemplos de trabalhos que utilizam o horizonte de planejamento finito aparecem, por exemplo, em Wagner \& Whitin (1958) e Trigeiro et al. (1989).

Escala de tempo: a escala de tempo pode ser discreta ou contínua. Se for discreta, o número de períodos (buckets) são limitados, onde cada um pode ter tamanho grande ou pequeno e, ainda, os buckets podem classificados como uniforme ou não uniforme. A maioria dos modelos de dimensionamento de lotes assume a escala de tempo discreta e uniforme. A distinção entre buckets pequenos ou grandes diz respeito ao comprimento relativo dos períodos de tempo. Nos problemas small-bucket, ou seja, com períodos pequenos, geralmente assume-se que em cada período apenas um ou, no máximo, dois produtos podem ser produzidos. Portanto, os modelos que representam os problemas small-bucket integram as decisões de dimensionamento e sequenciamento da produção. Por outro lado, os problemas big-bucket permitem que vários produtos possam ser produzidos a cada período, sem fazer qualquer afirmação com relação a sequência da produção. Contrariamente, quando contínua, não há limitações e definições de períodos pré-definidos.

Disponibilidade e conhecimento prévio dos parâmetros: os parâmetros podem variar ao longo do tempo (dinâmico) ou não (estático). Estes distinguem-se de acordo com a evolução temporal dos valores destes parâmetros (por exemplo, a capacidade de produção, os parâmetros de custo e coeficientes de produção) que podem variar - dinâmico (Guimarães et al., 2012), ou não - estático (Salomon et al., 1991; Kuik et al., 1994), ao longo do tempo.

Função objetivo: normalmente o objetivo de um problema de dimensionamento de lotes é minimizar a soma de vários componentes que resultam nos custos de produção (Wagner \& Whitin, 1958; Trigeiro et al. 1989; Araujo et al. 2008: Baldo, 2009). No entanto, outras funções objetivos também podem ser definidas. Estas podem envolver tanto questões monetárias (maximização de lucros ou vendas) ou não (por exemplo, em uma indústria de móveis pode ser interessante a minimização número de padrões de corte, devido ao tempo de preparação das serras a cada troca de padrão).

Componentes de custo: a função objetivo comumente encontrada em problemas de dimensionamento de lotes é a minimização dos custos de produção (assim como dito anteriormente). Os custos unitários variáveis de produção são frequentemente desconsiderados, visto que a demanda é fixada, previamente conhecida e atendida no decorrer do horizonte de planejamento, e que estes custos unitários em geral não variam ao longo deste horizonte. Dentre os demais custos envolvidos durante a produção tem-se os custos de estoque, atraso e preparação de máquinas.

- Custos de estoque: os custos de estoque normalmente são considerados como custos lineares na função objetivo e, economicamente, consistem principalmente dos custos de capital estagnados em estoques, calculados proporcionalmente a quantidade de produtos em estoque em determinado mo- 
mento. Outros custos que podem ser inclusos ao custo de estoque são os custos de operações de manutenção, impostos, obsolescência e/ou encolhimento do produto.

- Custos de atraso: outro custo também comumente utilizado é o custo associado a falta de produtos para cumprir a demanda no período requisitado, acarretando no atraso da entrega, ou até mesmo, o não cumprimento da demanda. Este custo é difícil de ser estimado, pois consideram-se não apenas a perda da venda, como também, dependendo da situação, a insatisfação do cliente ao não ser entregue o pedido na data.

- Custos de preparação: custos de setup são incorridos pelo processo de produção, pois sempre que um lote de produto é produzido, o(s) recurso(s) envolvidos no processo de produção precisam estar preparado(s) para produzir este produto específico. Custos de setup consistem em custos diretos (por exemplo, materiais de limpeza) e em custos de oportunidade. E, estes custos de oportunidade são difíceis de calcular, uma vez que dependem fortemente da escassez de capacidade disponível e que podem variar ao longo do tempo, e muitas vezes só são conhecidos após o dimensionamento de lotes feito.

O segundo conjunto de atributos diz respeito, principalmente, aos recursos envolvidos no problema de planejamento da produção.

Capacidade: as limitações de recursos podem ser finitas (Trigeiro et al., 1989) ou infinitas (Wagner \& Whitin, 1958). Se finitos, podem (ou não) ser prorrogados por horas extras, tendo um custo adicionado. Os recursos ainda podem ser renováveis ou apenas parcialmente renováveis. Isto significa que a disponibilidade em um determinado período de tempo depende do uso deste recurso em períodos anteriores.

Número de recursos: O problema pode ser composto de um ou mais tipos de recursos. Se uma operação específica pode ser realizada em mais de um recurso, estes recursos são chamados de recursos paralelos. Eles podem ser idênticos (com respeito aos coeficientes de produção, capacidades e conjuntos de produtos possíveis de serem processados) ou não.

Taxa mínima de produção: muitas vezes, para utilização de determinado recurso, para evitar subaproveitamento, é necessário uma taxa mínima de produção. Quando esta taxa não é atingida, tenta-se adequar utilizando-se transferência de produção entre plantas, ou utilização de outro recurso, ou transferindo a produção de período.

Operações de preparação: as preparações de máquina podem ser dependentes (Figueira et al., 2013) ou independentes (Trigeiro et al. 1989; Baldo, 2009) da sequência e esta definição não está correlacionada a quantidade do produto a ser produzido. Define-se preparação independente da sequência quando para a produção de determinado produto, o tempo de preparo do recurso é fixo e este valor sempre será o mesmo, não levando em consideração o item anterior processado no recurso. Por outro lado, na preparação dependente da sequência tem-se o tempo de preparação relacionado ao produto que estava anteriormente sendo processado neste recurso (por exemplo, na indústria cervejeira, o tempo de preparo de uma envasadora para produzir uma cerveja long neck é menor se anteriormente estivesse sendo produzida cerveja $600 \mathrm{ml}$, ao invés de lata de alumínio, supondo mesmo líquido).

O último conjunto de atributos (produtos) é dedicado a como ocorre o processo de produção.

Número de produtos: há problemas em que há um único item a ser produzido, como também há problemas que possuem vários itens (multi-produtos) distintos. 
Número de níveis de produção: os problemas podem ser de nível único (Trigeiro et al., 1989) ou multinível (Billington et al., 1986). Em problemas de um único nível, também conhecidos como monoestágio, o produto final independe de peças ou itens intermediários para ficar pronto. Porém, quando um item final possui itens predecessores, que também devem ser programados para produção ou compra, este problema é chamado de multiestágio ou multi-nível. Os itens finais possuem suas próprias demandas, chamadas demandas independentes, enquanto que os itens predecessores possuem demanda dependente (utilizados como componentes de outros itens) e demanda independente. A dependência entre os itens são facilmente visualizadas utilizando a estrutura de produto. A estrutura do processo de produção multiestágio pode ser representada por um grafo orientado $\mathrm{G}(\mathrm{V}, \mathrm{E})$, em que os nós $\mathrm{V}$ representam o conjunto de itens e, os arcos $E$ representam as relações entre eles. $\mathrm{O}$ arco $(i, j)$ existe quando o item $j$ depende da produção do item $i$, ou seja, $j$ é um sucessor imediato do item $i$ e $i>j$ (na estrutura do produto os itens são numerados de 1 a $n$, de itens finais a matérias primas, como mostra a Figura 21). Estas estruturas de produto são usualmente classificadas como em Pochet \& Wolsey (2006) (veja a Figura 2.1):

- (a) serial: todos os itens possuem apenas um sucessor e um predecessor;

- (b) montagem: um item pode ter mais de um predecessor mas um único sucessor;

- (c) estrutura geral: número indefinido de sucessores e predecessores para todos os itens.

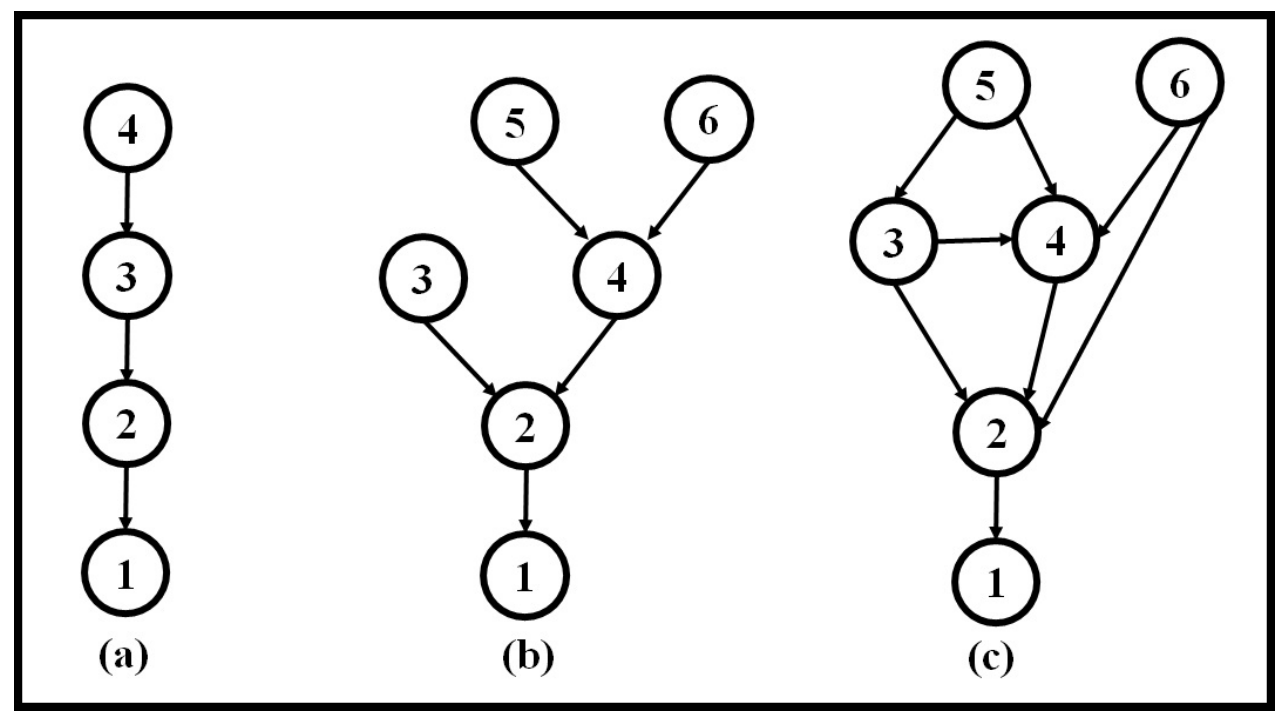

Figura 2.1: Tipos de estrutura dos produtos em problemas multiestágios.

Processo de fornecimento: diz respeito ao momento em que um produto fica disponível para outros estágios/níveis após ser processado em um estágio. A primeira opção é que cada item de um lote estará disponível imediatamente para a etapa seguinte de processamento (por exemplo, numa linha de fluxo). Outra opção é quando os produtos ficam disponíveis apenas se o lote completo foi concluído, ou depois de um tempo de espera definido.

Lead time: o lead time em um problemas de dimensionamento de lotes pode ser endógeno ou exógeno. Lead times endógenos são fatores controláveis pela empresa, podendo ser mensurado o tempo de produção. Por outro lado, os tempos de lead times exógenos são dados pelas circunstâncias do processo de produção 
(por exemplo, tempo de transporte entre os recursos sucessivos ou simplesmente de secagem de pintura), resultam em prazos mínimos que devem ser respeitados.

Restrições de estoque: as restrições sobre os níveis de estoques de produtos são impostas em algumas situações. Estas podem ser limitadas superiormente devido a capacidade máxima de armazenamento ou limitada inferiormente para garantir que um determinado estoque de segurança seja mantido. Além disso, restrições de prazo de validade podem ser incluídas para evitar a obsolescência dos produtos, sendo comumente encontradas nas indústrias de alimentos.

Política de serviços: as políticas de serviço da empresa consideram a preocupação com o cumprimento da demanda. Na maior parte dos problemas de dimensionamento de lotes conhece-se a demanda a priori e esta tem que ser cumprida. Há situações em que não ocorre o cumprimento da demanda no período requerido e esta é perdida (vendas perdidas) ou pode ser cumprida em períodos subsequentes (backlog).

Informações adicionais de dimensionamento de lotes: no processo industrial, a quantidade de um determinado lote de produção é frequentemente limitada e estas restrições podem ser inferiormente ou superiormente limitadas sobre o tamanho do lote. Outras condições podem ser adotadas, por exemplo, produção tudo-ou-nada.

De acordo com a classificação apresentada, o presente trabalho aborda o problema multiestágio de dimensionamento e programação da produção em indústrias cervejeiras, considerando o horizonte de tempo finito, cujos períodos discretos possuem mesmo tamanho e correspondem a um dia. A demanda é dinâmica e determinística, pois é considerada previamente conhecida; e, a função objetivo visa minimizar os custos envolvidos durante a produção (estoque, atraso e número de trocas nas linhas de envase). A capacidade dos recursos é limitada (número de tanques e linhas de envase predefinidos, em que as capacidades de cada um destes recursos são respeitadas). Para utilização de cada tanque de fermentação há uma capacidade mínima (devido aos sensores de temperatura) e máxima a ser respeitada. A preparação dos tanques de fermentação/maturação é independente da sequência; entretanto, as preparações das linhas de envase são dependentes da sequência. Cada linha mantém um coeficiente de produção constante durante todo o horizonte de planejamento. Não são considerados os níveis de estoque mínimo e máximo; porém, nas cervejarias estudadas, alguns produtos possuem estoque mínimo. O lead time considerado é endógeno, entretanto, na prática, o lead time pode ser exógeno, tendo um tempo médio pré-estabelecido para o período de fermentação/maturação que pode variar de um a dois dias a mais ou a menos. Se a temperatura for rigorosamente controlada, as incertezas são praticamente inexistentes, logo neste trabalho, trataremos o lead time como sendo endógeno e respeitando o tempo de duração necessário para completar o ciclo de fermentação e maturação.

Os problemas de dimensionamento de lotes envolvem um horizonte de planejamento considerando restrições de demanda, capacidade de máquina(s), entre outros fatores, e o objetivo é minimizar os custos totais de produção no processo produtivo (por exemplo: produção, preparação de máquina, estocagem, etc), de forma que sua resolução forneça planos de produção factíveis. O problema de dimensionamento de lotes (PDL), ao ser resolvido, obtém um plano de produção que fornece informações de quando e quanto de cada produto será produzido, de forma a satisfazer uma demanda previamente conhecida. O problema de sequenciamento da produção tem por objetivo estabelecer uma ordem de produção para os lotes. O problema integrado de dimensionamento de lotes e sequenciamento da produção considera ambos os problemas simultaneamente. 
Para o problema de produção em uma indústria cervejeira, foram encontrados poucos estudos abordando o tema na literatura, seguindo a mesma linha de pesquisa deste doutorado. Um dos trabalhos que mais se assemelham, porém, ainda bastante distante de nossos objetivos, é o de Guimarães et al. (2012). Guimarães et al. (2012) aborda o problema da produção anual em uma empresa de bebidas de Portugal, considerando um ambiente multi-planta, a sazonalidade da demanda, entre outras especificidades desta empresa, permitindo transferência de produção entre plantas; os autores propõem um algoritmo VNS (Variable Neighborhood Search) para a resolução do problema.

Este capítulo tem o intuito de revisar alguns trabalhos presentes na literatura que foram úteis como fundamentação teórica para o desenvolvimento deste doutorado. Assim, as próximas seções trazem uma revisão da literatura para os problemas de dimensionamento, sequenciamento e problemas integrados. Então, considere os conjuntos, parâmetros e variáveis definidos a seguir.

\section{Conjuntos}

$N$ : conjuntos dos itens a ser produzidos $(i, j \in N)$;

$T$ : conjunto dos períodos do horizonte de planejamento $(t \in T)$;

\section{Parâmetros}

$d_{i t}$ : quantidade demandada do item $i$ no período $t$;

$a_{i}$ : quantidade de recurso necessária para produzir uma unidade do item $i$;

$C_{t}$ : quantidade do recurso disponível no período $t$;

$b_{i}$ : quantidade consumida de recursos na preparação da máquina para a produção do item $i$;

$q_{i t}$ : custo de preparação para produção do item $i$ no período $t$;

$c p_{i t}$ : custo de produzir uma unidade do item $i$ no período $t$;

$h_{i t}^{+}$: custo de estocagem, de um período para outro, de uma unidade do item $i$ no período $t$;

$h_{i t}^{-}$: custo de atraso, de um período para outro, de uma unidade do item $i$ no período $t$.

\section{Variáveis}

$X_{i t}$ : quantidade do item $i$ produzida no período $t$;

$I_{i t}^{+}$: quantidade estocada do item $i$ no final do período $t$;

$I_{i t}^{-}$: quantidade atrasada do item $i$ no final do período $t$;

$Y_{i t}: 1$ se o recurso está preparado para o item $i$ ser produzido no período $t ; 0$ caso contrário.

\subsection{O problema de dimensionamento de lotes}

Esta seção está organizada segundo os níveis de produção e primeiramente são apresentados trabalhos para o problema de dimensionamento de lotes (PDL) monoestágio e, na sequência, para o caso multiestágio.

\subsubsection{PDL monoestágio}

O trabalho pioneiro sobre modelos para representar o problema de dimensionamento de lotes é o de Harris (1913) - EOQ model (Economic Order Quantity model). Este trabalho considera um único item, sem restrições de capacidade, horizonte de planejamento infinito, períodos contínuos e demanda estacionária. 
Demanda estacionária é aquela cujos valores ocorrem a uma taxa constante e contínua durante o horizonte de planejamento.

O problema de Wagner \& Whitin (1958) é uma extensão do EOQ, considerando a demanda dinâmica e horizonte de planejamento finito. Considera a produção de um único item e assume o horizonte de planejamento finito divido em vários períodos discretos. Além disso, considera os custos de estoque, preparação e o preço de venda do item. Os custos unitários de produção são desprezados $\left(c_{i t}=c_{i}\right)$, visto que independente do período que ocorra a produção, este terá um valor previamente conhecido, tendo a demanda determinística e dinâmica $\left(\sum_{i \in N} c_{i} \sum_{t \in T} d_{i t}=\sum_{i \in N} c_{i} \sum_{t \in T} X_{i t}=\right.$ Custo $)$. Logo, apenas os custos de estoque podem variar de acordo com o período que tem-se a produção dos itens demandados. Cabe salientar que, apesar de sua simplicidade, o problema de Wagner \& Whitin (1958) é de grande importância, visto que muitos problemas complexos podem ser relaxados, tendo como resultado vários subproblemas mais simples, iguais a este. Wagner \& Whitin (1958) apresentaram um algoritmo de programação dinâmica para resolver o problema em $O\left(T^{2}\right)$.

O PDL com limitações de capacidade (CLSP) é o problema big-bucket mais básico estudado no contexto de dimensionamento de lotes com múltiplos itens e limitações de capacidade. Neste problema, segundo Suerie (2005), algumas suposições são fundamentais:

- vários itens $i$ são produzidos com um recurso compartilhado;

- o recurso tem um limite de capacidade;

- o horizonte de planejamento é finito e dividido em $|T|$ períodos;

- todos os produtos possuem demanda dinâmica e determinística;

- se um item é produzido em um determinado período, o recurso tem que estar preparado para este item neste período;

- as preparações consumem capacidade do recurso e incorrem em um custo;

- o objetivo é minimizar a soma dos custos de estoque e preparação.

Manne (1958) foi um dos precursores a utilizar o CLSP considerando uma única máquina, veja o modelo (2.1)-2.5.

Minimizar

$$
\sum_{i \in N} \sum_{t \in T}\left(q_{i t} Y_{i t}+h_{i t}^{+} I_{i t}^{+}\right)
$$

Sujeito a:

$$
\begin{array}{cl}
I_{i t}^{+}=I_{i, t-1}^{+}+X_{i t}-d_{i t} & i \in N ; t \in T \\
\sum_{i \in N}\left(b_{i} Y_{i t}+a_{i} X_{i t}\right) \leq C_{t} \quad & t \in T \\
X_{i t} \leq \min \left\{\frac{C_{t}-b_{i}}{a_{i}}, \sum_{t^{\prime} \in T} d_{i t^{\prime}}\right\} Y_{i t} & i \in N ; t \in T \\
X_{i t} \geq 0 ; I_{i t}^{+} \geq 0 ; Y_{i t} \in\{0,1\} & i \in N ; t \in T
\end{array}
$$


O objetivo deste problema é minimizar os custos de preparações e de estocagens, dado por 2.1. Em 2.2) estão as equações de balanço de estoque e garantem que as quantidades estocadas em cada período para cada item devem ser iguais as quantidades em estoque do período anterior, adicionadas as produções no período e subtraídas as demandas para o referido período. As inequações (2.3) garantem que o recurso disponível no período seja respeitado. As inequações (2.4) asseguram que se houver produção $\left(X_{i t}>0\right)$, então, $Y_{i t}=1$. As restrições 2.5 forçam a não negatividade das variáveis $X_{i t}$ e $I_{i t}^{+}$; e $Y_{i t}$ é binário. A não negatividade de $I$ com as restrições 2.2 garantem que as demandas são atendidas sem atraso.

Florian et al. (1980) mostraram que quando o tempo de preparação de máquina é considerado, encontrar a solução ótima para o problema com um único item é NP-hard. Bitran \& Yanasse (1982) ressaltam vários casos de problemas com um único item que podem ser resolvidos em tempo polinomial, entretanto ao adicionar o segundo item o problema é NP-hard. E em Maes et al. (1991), quando considerado limitações de recursos, o problema é NP-completo. Por isso, os procedimentos de resolução para o problema de dimensionamento de lotes com limitações de capacidade são, na grande maioria, heurísticos.

Nos trabalhos seguintes encontram-se procedimentos heurísticos de resolução para problema de dimensionamento de lotes monoestágio com múltiplos itens e com limitações de capacidade: Trigeiro et al.(1989), Araujo \& Arenales (2000), Toledo \& Armentano (2006) e Baldo (2009). O método heurístico proposto por Trigeiro et al. (1989), mesmo após décadas, ainda é muito estudado e utilizado para a resolução do problema em questão devido a sua eficiência, rapidez e, de certa forma, simplicidade. Araujo \& Arenales (2000) propuseram uma pequena modificação no método proposto por Trigeiro et al. (1989). Em Baldo (2009) estudou-se as abordagens propostas por Trigeiro et al. (1989) e Araujo \& Arenales (2000), utilizando algumas estratégias destes trabalhos durante a fase de factibilização da solução obtida por meio de procedimentos de geração de colunas.

Tonaki \& Toledo (2010) abordaram o problema de dimensionamento de lotes com limitações de capacidade aplicado a fundições de pequeno porte, ou seja, realizaram um estudo de caso numa empresa do interior do estado de São Paulo, buscando um plano de produção de ligas metálicas e peças com o menor custo, atendendo a demanda dos itens sem exceder a capacidade do forno. Este trabalho decompõe o modelo proposto por Araujo et al. (2008) em dois subproblemas menores: um para a produção das ligas metálicas e outro para a produção dos itens (peças metálicas). Os subproblemas são resolvidos utilizando heurísticas lagrangianas.

Toledo \& Armentano (2006) consideram um problema com várias máquinas, relaxam as restrições de capacidade e propõem uma heurística para a resolução do problema relaxado. A solução inicial é obtida por meio da minimização do problema lagrangiano, normalmente inviável. Realiza-se deslocamento da produção entre períodos e máquinas na tentativa de factibilizá-la, pois deslocam a produção que excede a capacidade, procurando soluções factíveis que minimizam o custo.

Os problemas de programação inteira mista de grandes dimensões são, em geral, difíceis de serem resolvidos na otimalidade ou próximo a ela. A possibilidade de (re)formular tais problemas pode "reduzir" drasticamente o caminho para se chegar a uma solução. Entretanto, alguns destes avanços ou sofisticadas reformulações não são genéricas, no sentido que elas dependem de uma estrutura específica no problema para sua aplicabilidade. Em outras palavras, a identificação da estrutura no planejamento da produção é importante durante a construção do modelo, especificamente para usar técnicas de reformulação (Pochet \& Wolsey, 2006). A decomposição de Dantzig \& Wolfe (1960) consiste em reescrever as variáveis do problema como combinação convexa de pontos extremos (e raios extremos, se existirem) de um subconjunto 
do conjunto de restrições do problema original. Pimentel (2005) e Baldo (2009) tratam em suas respectivas dissertações o problema em questão utilizando a decomposição de Dantzig \& Wolfe (1960) e a geração de colunas. Algumas ideias do trabalho de Pimentel (2005) e de Baldo (2009) foram baseadas no trabalho de Jans (2002), porém, consideram também uma outra decomposição (por períodos) não abordada em Jans (2002). Em Jans (2002) apresenta-se um algoritmo branch-and-price e discute-se a formulação proposta por Manne (1958).

Em Charnprasitphon (2007) abordam-se processos monoestágio de produção de uma variedade de produtos perecíveis. Dentre estes produtos perecíveis, há a abordagem de alocação de tanques de fermentação de cerveja. Por se tratar de produto perecível e, também, da produção de cerveja, que é o foco deste trabalho, abrimos uma subseção especialmente para relatarmos esta pesquisa.

\section{PDL monoestágio com produto perecível}

A tese de Charnprasitphon (2007) está motivada em auxiliar tomadas de decisões para indústrias de produtos com prazos de validade curtos, determinando um plano de produção para o problema de dimensionamento de lotes monoestágio, considerando várias questões, tais como: tempos de setup (independente ou dependente da sequência), tamanho do lote (discreto ou contínuo), capacidade das máquinas, tempo de processamento fixo, a vida útil dos produtos, a demanda determinística e o número de máquinas disponíveis, a fim de minimizar o custo total, incluindo os custos de estoque, deterioração, produção, preparação e multas para demanda não atendida. Este trabalho apresenta inovações para a abordagem integrada de problemas de dimensionamento de lotes e sequenciamento da produção para produtos perecíveis, considerando tempo de setup e máquinas paralelas. Foram tratados dois tipos de problema: o caso da sequência de tempos de setup independentes (BPP-SI, abreviação para Batch Production Problem for Perishable Products with Sequence-Independent Setup Times): o problema de alocação dos tanques de cerveja, e o caso de uma sequência dependente (BPP-SD, abreviação para Batch Production Problem for Perishable Products with Sequence-Dependent Setup Times): problema de produção de vacinas. Este último não será mais citado aqui; para maiores detalhes, veja o respectivo trabalho. Charnprasitphon (2007) implementou cinco algoritmos heurísticos para resolução dos modelos com tempos de setup de sequência independente (BPP-SI). De acordo com os resultados computacionais, as heurísticas desenvolvidas obtiveram boas soluções para os problemas de grandes dimensões, utilizando pouco tempo computacional.

Os produtos perecíveis considerados em Charnprasitphon (2007) compartilham os mesmos recursos que possuem capacidade limitada. Ele considera tempos de preparação e, também, produção em bateladas. A produção em bateladas é usada em diversos ambientes de produção, por exemplo: produtos de polímeros, produtos farmacêuticas, indústrias alimentícias, entre outras. A característica chave da produção dos lotes são as operações não-preemptivas, cada máquina pode processar todos os produtos, porém, no máximo, um de cada vez, e cada lote de produto requer uma configuração sempre que um novo lote for processado na máquina. Como os produtos são perecíveis, o primeiro a ser processado é o primeiro a ficar pronto, ou seja, a política FIFO (First-In-First-Out) é utilizada para controlar o estoque. Como o tempo de setup em uma máquina é independente da sequência de produtos produzidos, pode ser incorporada no tempo de processamento fixo. Para o problema $B P P$-SI, o intuito foi determinar o programa mestre de produção (MPS), considerando a configuração de sequência independente. Os custos associados com este problema incluem: os custos fixos de setup de preparação, os custos variáveis de produção, custos de estoque, os custos variáveis de eliminação de produtos estragados, e, os custos variáveis de demanda não atendida. Para 
exemplificar o modelo BPP-SI, o autor utilizou o problema de fabricação de cerveja, mais especificamente o processo de fermentação. Para o modelo matemático proposto, considere:

- cada máquina $(m \in M)$ pode ser usada para produzir qualquer um dos $|N|$ produtos perecíveis;

- cada máquina pode ser usada para produzir apenas um produto por período;

- se a máquina for utilizada, consequentemente toda sua capacidade será utilizada (produção tudo-ounada);

- se a máquina está sendo preparada para produzir o produto $i$, não haverá interrupção do processo, e esta máquina voltará a ficar disponível apenas quando a produção do lote acabar;

- pode ocorrer apenas um setup por período;

- as máquinas paralelas são semelhantes;

- a demanda é dinâmica e determinística.

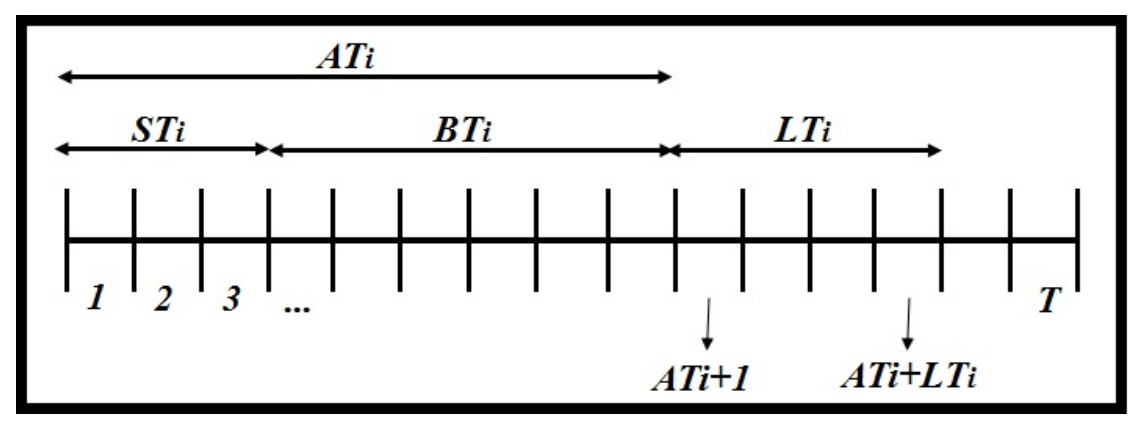

Figura 2.2: Linha do tempo para o horizonte de planejamento em problemas BPP (Charnprasitphon. 2007).

Para a apresentação dos modelos matemáticos a seguir, considere as especificações apresentadas anteriormente e, ainda:

\section{Dados:}

$c p_{i t}$ : custo de produção de uma unidade do item $i$ no período $t$;

$c_{i}$ : custo de preparação da máquina para produzir o item $i$;

$d c_{i t}$ : custo de desperdício de uma unidade do item $i$ por ter estragado;

$L T_{i}$ : tempo de vida útil (limitado) a cada produto $i$, onde $i \in N$ (veja a Figura 2.2);

$S T_{i}$ : quantidade de períodos utilizados para preparar cada máquina para o processamento do produto $i$ (veja a Figura 2.2);

$B T_{i}$ : quantidade de períodos utilizados para a produção de uma batelada do produto $i$ (veja a Figura 2.2);

$A T_{i}$ : quantidade total de períodos que a máquina fica dedicada ao produto $i$, desde a preparação até a produção, efetivamente ( $=B T_{i}+S T_{i}$, veja Figura 2.2);

$N M_{t}$ : número total de máquinas disponíveis para uso no período $t$;

$I_{i 0}$ : estoque inicial do produto $i$ 
$C p$ : para uma unidade de lote a ser processada, cada uma das $M$ máquinas paralelas possuem uma capacidade de $C p$ unidades de produtos.

\section{Variáveis:}

$S_{i t}$ : montante de produtos estragados do tipo $i$ no período $t$;

$O_{t}$ : número total de máquinas usadas no período $t$;

$w_{\text {imt }}$ : variável binária para designar o status da máquina, indicando se máquina $m$ está ocupada com o produto $i$ no período $t\left(w_{i m t}=1\right)$ ou não $\left(w_{i m t}=0\right)$.

$r_{\text {imt }}$ : variável binária para setup da máquina $m$ para o produto $i$ começando no período $t$, sendo que a batelada estará pronta no período $A T_{i}+t\left(r_{i m t}=1\right)$, caso contrário, $r_{i m t}=0$.

\section{Modelo matemático BPP-SI}

Minimizar

$$
\sum_{t \in T} \sum_{i \in N}\left(h_{i t}^{+} I_{i t}^{+}+h_{i t}^{-} I_{i t}^{-}\right)+\sum_{t \in T} \sum_{i \in N} c p_{i t} X_{i t}+\sum_{t \in T} \sum_{i \in N} d c_{i t} S_{i t}+\sum_{t \in T} \sum_{m \in M} \sum_{i \in N} c_{i} r_{i m t}
$$

Sujeito a:

$$
\begin{aligned}
& I_{i t}^{+}-I_{i t}^{-}=I_{i, t-1}^{+}+X_{i t}-S_{i t}-d_{i t} \quad i \in N ; t \in T \\
& X_{i t}=C p \sum_{m \in M} r_{i m, t-A T_{i}} \quad i \in N ; A T_{i}+1 \leq t \leq T \\
& S_{i t} \geq I_{i, t-1}^{+}-C p \sum_{\tau=1}^{L T_{i}-1} X_{i, t-\tau} \quad i \in N ; L T_{i}+1 \leq t \leq T \\
& \sum_{\tau=1}^{A T_{i}} r_{i m, t+\tau-1} \leq 1 \quad i \in N ; m \in M \\
& 1 \leq t \leq T-A T_{i}+1 \\
& \sum_{i \in N} r_{i m t} \leq 1 \quad m \in M ; t \in T \\
& \sum_{i \in N} \sum_{m \in M} w_{i m t}=O_{t} \quad t \in T \\
& O_{t} \leq N M_{t} \quad t \in T \\
& A T_{i} r_{i m t} \leq \sum_{\tau=1}^{A T_{i}} w_{i m, t+\tau-1} \quad i \in N ; t \in T ; \\
& 1 \leq t \leq T-A T_{i}+1 \\
& \sum_{i \in N} w_{i m t} \leq 1 \quad m \in M ; t \in T \\
& r_{i m t}=0 \quad i \in N ; T-A T_{i}+1 \leq t \leq T \\
& P_{i t}=0 \quad i \in N ; 1 \leq t \leq A T_{i} \\
& I_{i t}^{+}, I_{i t}^{-}, S_{i t}, P_{i t} \geq 0 \quad i \in N ; t \in T \\
& O_{t} \in\{0,1, \ldots\} \quad t \in T \\
& w_{\text {imt }}, r_{\text {imt }} \in\{0,1\} \quad i \in N ; m \in M ; t \in T
\end{aligned}
$$


A função objetivo 2.6 minimiza os custos totais durante o horizonte de planejamento, sendo estes: custo de estocagem, penalidade se houver atraso, produção, penalidade se algum produto estragar e custo de preparação. Existem dois grupos de restrições: 2.7)-2.17) são as referentes a produção, enquanto que 2.18)-2.20 são as definições de domínio, ou seja, as variáveis reais (estoque, atraso, produtos estragados e produção), inteiras (quantidade de máquina utilizada) ou binárias (se a máquina está ocupada e se houve preparação), respectivamente. Explicando mais detalhadamente o primeiro grupo de restrições: 2.7) são as equações de balanço de estoque de cada produto para cada período; observe que $I_{i t}^{-}$representa a quantidade de demanda não atendida do produto $i$ no período $t$; 2.8 garantem que a quantidade de produto no início do período $t$ é obtido através da liberação do lote total no início do período $t-A T_{i}$ para cada máquina; (2.9) são usadas para calcular a quantidade de produto estragado no começo de cada período $t$, assim, para determinar a quantidade de $i$ estragada no início de período $t\left(S_{i t}\right)$, basta saber quantos produtos estão em estoque e retirar deste valor a quantidade de produtos produzidos não estragados, ou seja, que estão dentro dos $L T_{i}$ períodos após a produção; 2.10) garantem que a máquina pode ser programada para produzir o produto $i$ só uma vez durante o tempo de produção dos períodos de $A T_{i} ; 2.11$ representam que a máquina pode ser programada para produzir no máximo um produto em cada máquina e em cada período; 2.12 são usadas para determinar o número total de máquinas utilizadas em cada período; 2.13) representam que, em cada período, o número total de máquinas em uso não pode exceder o número total de máquinas disponíveis; 2.14 asseguram que, se uma máquina é inicialmente configurada para produzir o produto $i$ no início do período $t$, a máquina deve ser ocupada pelo produto $i$ do período $t$ até o período $t+A T_{i}-1$; 2.15): asseguram que, no máximo, um produto pode ocupar cada máquina em cada período; e, por fim, 2.16) e 2.17) são restrições lógicas na liberação de lote e de produção.

\subsubsection{PDL multiestágio}

Assim como descrito anteriormente, quando um item final possui itens predecessores, que também devem ser programados para produção ou compra, tem-se o problema multiestágio. Os itens finais possuem suas próprias demandas, chamadas demandas independentes, enquanto que os itens predecessores possuem demanda dependente (utilizados como componentes de outros itens) e demanda independente. Para a apresentação do modelo matemático do PDL multiestágio, considere os seguintes dados adicionais:

$p_{i j}$ : número de itens $i$ necessários para a produção do item $j$;

$S_{i}$ : conjunto de sucessores imediatos do item $i$.

Minimizar

$$
\sum_{i=1}^{N} \sum_{t=1}^{T}\left(q_{i t} Y_{i t}+h_{i t} I_{i t}^{+}\right)
$$


Sujeito a:

$$
\begin{aligned}
& I_{i t}=I_{i, t-1}+X_{i t}-\sum_{j \in S_{i}} p_{i j} X_{j t}-d_{i t} \quad i=1, \ldots, N ; t=1, \ldots, T \\
& \sum_{i}^{n}\left(b_{i} Y_{i t}+a_{i} X_{i t}\right) \leq C_{t} \quad t=1, \ldots, T \\
& X_{i t} \leq \min \left\{\frac{C_{t}-b_{i}}{a_{i}}, \sum_{j=t}^{T} d_{i j}\right\} Y_{i t} \quad i=1, \ldots, N ; t=1, \ldots, T \\
& X_{i t} \geq 0 ; I_{i t} \geq 0 ; Y_{i t} \in\{0,1\} \quad i=1, \ldots, N ; t=1, \ldots, T
\end{aligned}
$$

Este problema é semelhante ao problema 2.1]-2.5], diferindo-se apenas em 2.22], pois há a inclusão da produção dos itens intermediários.

Existem vários trabalhos sobre técnicas de resolução para o problema de dimensionamento de lotes multiestágio considerando variações na estrutura do produto e/ou na limitação de capacidade. Dentre as muitas pesquisas que envolvem este problema, destacamos as seguintes: Billington et al. (1983), Afentakis et al. (1984), Billington et al. (1986), Maes et al. (1991), Clark \& Armentano (1995), Tempelmeier \& Derstroff (1996), França et al. (1997), Santos (2000), Berretta et al. (2005), Toledo et al. (2009) e Toledo et al. (2013).

Billington et al. (1983) fazem uma breve revisão bibliográfica para o problema multiestágio ressaltando trabalhos que utilizam tal modelo. Apresentam um método para reduzir o tamanho do problema, sem perder a solução ótima do problema original, cujo princípio do método é a análise da estrutura do produto.

Billington et al.(1986) apresentam um método heurístico baseado nos métodos de relaxação lagrangiana para problemas de dimensionamento de lotes multiestágio que possuem um estágio com um único centro gargalo. Um gargalo é um centro de trabalho que limita a produção para um sistema. O método heurístico tem duas fases de resolução. Na primeira, as restrições de capacidade e balanceamento de estoque são dualizadas e incluídas na função objetivo, resultando em um problema lagrangiano para cada item e estes são resolvidos heuristicamente. Ao final deste procedimento, verifica-se se a solução obtida é factível para o problema original. Caso não seja, há remanejamento de produção entre períodos com o intuito de viabilizar a solução. Na fase dual, atualizam-se os custos duais e este procedimento é repetido até encontrar uma boa solução. Esta atualização dos custos duais tenta desfavorecer a produção no estágio onde a capacidade é limitada. A solução do procedimento é primeiro testada em dois casos especiais: no problema com e sem limitações de capacidade e no problema monoestágio com múltiplos itens. Os resultados mostram que as soluções dos procedimentos podem fornecer soluções melhores que algumas heurísticas designadas, especialmente para os problemas conhecidos para a época.

Em Clark \& Armentano (1995) é apresentado uma heurística para a resolução do problema multiestágio considerando a capacidade de produção e de preparação limitada. Para facilitar o funcionamento da heurística, usaram a formulação do problema com base no conceito de estoque de escalão e horizonte rolante. A heurística consiste na aplicação sequencial do algoritmo de Wagner-Whitin (Wagner \& Whitin, 1958) ao problema sem restrições de capacidade e, em seguida, executam-se transferências de uma certa quantidade de produção entre períodos com o objetivo de obter a factibilidade. Em França et al. (1997) é desenvolvida uma heurística baseada na apresentada em Clark \& Armentano (1995). A heurística é composta por quatro procedimentos: solução inicial, factibilização, alteração e melhoria. Os testes executados mostraram que 
os resultados obtidos em Clark \& Armentano (1995) foram melhorados. Berretta et al. (2005) propõem um método heurístico baseado em Clark \& Armentano (1995) e Tempelmeier \& Derstroff (1996), somando a uma meta-heurística híbrida proposta para a resolução do problema.

Tempelmeier \& Derstroff (1996) apresentam um procedimento baseado na relaxação lagrangiana das restrições de capacidade e de balanço de estoque. O problema considerado neste trabalho difere de Billington et al. (1986), pois consideraram restrições de capacidade em todas operações (níveis). Com a relaxação destas restrições, se obtém um problema decomponível por item, o qual pode ser resolvido eficientemente por um algoritmo de programação dinâmica, para obtenção de um limitante inferior para o problema. $\mathrm{O}$ procedimento para obtenção de uma solução factível parte de uma solução inicial, a qual é factível para as restrições de balanço de estoques, executando transferências de produção dos recursos com sobrecarga, em determinados períodos. Santos (2000) mostrou que este procedimento é equivalente a tradicional relaxação lagrangiana, aplicada ao problema reformulado por estoque de escalão.

Em Toledo et al. (2009) apresenta-se um algoritmo genético multi-populacional para um problema dois estágios, comumente encontrado em indústrias de refrigerantes. Em Toledo et al. (2013) apresenta-se um algoritmo memético para o mesmo problema. Entretanto, estes trabalhos também consideram o sequenciamento da produção. Logo, serão melhor descritos na seção de problemas integrados de dimensionamento e sequenciamento de lotes.

\subsection{Problema de sequenciamento da produção}

Ao ser determinada a quantidade de itens, seja em um único estágio ou em vários, que será produzida a cada período do horizonte de planejamento, num próximo passo deve-se determinar qual a ordem que estes itens serão processados em cada uma das máquinas. O problema de sequenciamento da produção consiste em estabelecer qual a ordem em que determinadas tarefas (já preestabelecidas) serão processadas em uma ou mais máquinas, cujo objetivo, por exemplo, pode ser minimização do tempo de processamento. Algumas revisões bibliográficas destes problemas podem ser encontradas em Błażewicz et al. (1996) e um bom livro de referência no assunto é Pinedo (1995).

A dissertação de mestrado de Guimarães (2009) é um trabalho preliminar de Guimarães et al. (2012), também desenvolvido em uma empresa de bebidas situada a noroeste de Portugal. Em Guimarães (2009) foram utilizados três modelos matemáticos. O primeiro trata o problema dimensionamento de lotes e, os dois outros, o sequenciamento da produção, sendo estes desenvolvidos de maneira desacoplada. O modelo de dimensionamento de lotes proposto é uma extensão da formulação clássica do CSLP (Continuous Setup Lotsizing Problem), onde o autor considera máquinas paralelas, setup carry-over e estoque de segurança, tendo seu horizonte de planejamento baseado em seis semanas. $\mathrm{O}$ autor teve por objetivo fornecer planos de produção definindo para cada linha de envase, os produtos e as quantidades a serem produzidas referentes a cada semana do horizonte de planejamento, sem considerar a sequência, para cada uma das plantas. Para o sequenciamento, o primeiro modelo apresentado considera apenas uma linha de envase e este foi desenvolvido utilizando preceitos do problema PLSP (Proportional Lotsizing and Scheduling Problem) considerando o tempo de preparação dependente da sequência, backloging, e lotes mínimos de produção para a família de produtos. Para o modelo com múltiplas linhas, foram feitas extensões do modelo anterior. As instâncias testadas correspondem ao período entre $18^{a}$ semana até a $23^{a}$ do ano de 2009. Os problemas foram resolvidos utilizando o software de otimização CPLEX 11.2 da ILOG, cujo tempo foi limitado em 1 hora. 
Estudos mais recentes mostram que o problema de sequenciamento tem sido tratado de forma conjunta aos problemas de dimensionamento (Drexl \& Kimms, 1997; Staggmeier \& Clark, 2001; Suerie, 2005). Assim, a próxima seção aborda o problema de forma integrada.

\subsection{Problema integrado de dimensionamento e sequenciamento dos lotes}

Em contraste com a maioria dos modelos para os problemas big-bucket, os modelos para os small-bucket consideraram as decisões de dimensionamento de lotes e sequenciamento simultaneamente. Entretanto, algumas considerações são feitas, como, por exemplo, no máximo uma operação de preparação de máquina é permitida a cada (sub)período. Diferentes formulações, com vários graus de liberdade no que diz respeito às variáveis de decisão do modelo, são conhecidas nesta área e podem ser encontradas em Suerie (2005). Revisões da literatura sobre tais modelos podem ser encontradas em Drexl \& Kimms (1997) e Staggmeier \& Clark (2001).

Como dito anteriormente, a grande maioria dos trabalhos da literatura que estuda problemas integrados de dimensionamento e sequenciamento dos lotes tem por objetivo minimizar os custos de estoque, atrasos, preparação de máquina e produção, fornecendo a quantidade, o período e a sequência em que cada item deve ser produzido. Aplicações destes modelos podem ser encontradas em diversos setores industriais: como programação da produção de grãos eletro fundidos (Luche et al. 2009), planejamento e programação da produção a partir de uma fundição (Araujo et al., 2007), suplementos para nutrição animal (Toso et al., 2008, 2009: Clark et al. 2010), fabricação de embalagens de vidro (Almada-Lobo et al. 2008), indústria de papéis (Santos \& Almada-Lobo, 2012; Figueira et al., 2013), refrigerantes (Ferreira et al., 2012; Toledo et al., 2012), entre outros.

Toso et al. (2008), Toso et al. (2009) e Clark et al. (2010), abordam um estudo de caso em uma indústria de nutrição animal do interior do estado de São Paulo. Este setor industrial depara-se com alguns problemas particulares, sendo alguns destes: sazonalidade da demanda dos produtos, sazonalidade dos insumos (períodos de entre-safra), perecibilidade dos insumos e dos produtos, tempos de preparação de máquinas (utilizadas no decorrer do processo produtivo) dependentes da sequência. Estes problemas são tratados separadamente (habitualmente) na prática, o que torna difícil a adequação às mudanças caso ocorram imprevistos. Assim, os trabalhos de Toso et al. (2008), Toso et al. (2009) e Clark et al. (2010), tratam o problema de maneira integrada utilizando um modelo de programação inteira mista, para representar as decisões envolvidas, cujo objetivo é minimizar os custos de produção. A empresa onde foi feito o estudo de caso produz suplementos vitamínicos (sais minerais, núcleos, premixes), promotores para bovinos, equinos, suínos e aves, além de alguns produtos para animais de estimação (linha pet). O processo produtivo ocorre basicamente em duas etapas, sendo a primeira a dosagem das matérias-primas e, a segunda, a mistura dos ingredientes. O processo de produção é intermitente e ocorre em bateladas. A quantidade produzida em cada batelada limita-se ao tamanho do misturador. O misturador possui uma capacidade máxima e uma quantidade mínima, para que a mistura consiga ficar homogênea. Embora o processo produtivo ocorra, basicamente, em duas etapas, este é considerado monoestágio.

Em Toso et al. (2008) apresentam-se abordagens para encontrar soluções viáveis para o problema integrado na indústria de nutrição animal, combinando as formulações do problema General Lot-sizing and Scheduling Problem (GLSP, de Fleischmann \& Meyr (1997)), conjuntamente com formulações do problema 
do caixeiro viajante assimétrico (Assymetric Travelling Salesman Problem - ATSP). Este último é utilizado para modelar a representação das decisões de sequenciamento, sendo esta formulação também explorada em Clark et al. (2010). O problema é abordado de duas maneiras diferentes. Inicialmente o modelo considera cada período do horizonte de planejamento independente, ou seja, ao final de cada período haverá uma limpeza da máquina, assim, a máquina estará limpa ao início do próximo período. Depois, considera-se os períodos de maneira dependente, ou seja, inclui-se novas variáveis ao modelo anterior para que seja guardada a sequência entre os períodos (carryover). Estes modelos são resolvidos utilizando duas estratégias: eliminação de sub-rotas e eliminação e combinação de sub-rotas.

Em Toso et al. (2009), assim como em Toso et al. (2008), o primeiro modelo apresenta períodos independentes e o segundo com períodos dependentes (carryover). Cada período do horizonte de planejamento é dividido em número fixo de subperíodos, sendo estes subperíodos de tamanhos flexíveis e determinados de acordo com o tamanho de cada lote de produção (produzido ou não). Para resolução dos modelos foi utilizado o solver AMPL/CPLEX (versão 9). Devido a dificuldade do problema, em geral, nenhum dos modelos é resolvido até a otimalidade; ou seja, a execução do programa é interrompida ao atingir o limite de tempo pré-estabelecido (1 hora). As soluções encontradas possuem um alto valor de GAP, ou seja, estão distantes do melhor limitante encontrado para problema. Para amenizar tal situação, é utilizado, neste artigo, três diferentes abordagens relax-and-fix para a resolução dos modelos. Os testes computacionais mostram que a utilização da abordagem relax-and-fix é eficiente por encontrar boas soluções. O primeiro método (Method $R F$ on the lot sizes, sendo RF abreviação de relax-and-fix) relaxa a variável que determina o número de bateladas que deve ser produzido de cada produto em cada subperíodo, fixando-se as variáveis de produção e preparação. O segundo método (Method RF forwards over the periodst) relaxa as variáveis de produção e as variáveis referentes a preparação de máquina, entretanto, a estratégia consiste em resolver o problema diversas vezes, sendo que na primeira vez mantem-se a integralidade destas variáveis apenas no primeiro período. Encontrando uma solução viável para o primeiro período, de acordo com a solução obtida, resolvese o problema novamente mantendo a integralidade das variáveis inteiras do primeiro período, que estão fixadas no segundo período, e assim sucessivamente até o último período do horizonte de planejamento. $\mathrm{O}$ último método de resolução (Method RF backwards over the periodst), é semelhante ao método anterior, porém o início do método acontece no final do horizonte de planejamento e prossegue interativamente até o primeiro período.

Outro problema integrado de dimensionamento de lotes e sequenciamento da produção é encontrado na indústria de bebidas, tais como refrigerantes. Nestas indústrias, em geral, a produção é dividida em dois estágios. No primeiro estágio, as matérias-primas são colocadas em tanques para que sejam misturadas a outros componentes, resultando nos xaropes. No segundo estágio, os xaropes são escoados pelas linhas de envase resultando na bebida ou produto final. Um tanque pode armazenar apenas um tipo de matéria-prima de cada vez e somente pode ser reabastecido quando estiver vazio. Um tanque pode abastecer mais de uma linha de envase, entretanto, uma linha pode receber líquido de apenas um tanque por vez. Tanto na linha de envase quanto no tanque, quando há troca de líquidos ou matéria-prima, existe uma limpeza, sendo o tempo de duração vinculado a sequência. Por exemplo, o tempo de limpeza quando há troca de um refrigerante diet para um refrigerante normal é menor que o contrário. Todos os tanques envolvidos possuem uma capacidade máxima (tamanho do tanque) e mínima (para que a mistura fique homogênea, há uma quantidade mínima de matéria-prima que deve ser colocada em cada tanque). Os xaropes nos tanques devem suprir as demandas das linhas de produção e, vice-versa, caracterizando o problema em estágios e, ainda, a interdependência 
desses estágios. Portanto, torna-se importante a resolução do problema de dimensionamento e programação de matérias-primas e bebidas, respectivamente, nos tanques e nas linhas, de maneira integrada. Descrições pormenorizadas sobre o processo de produção de bebidas podem ser encontradas em Ferreira (2007) e Ferreira et al. (2008b). Este problema requer modelos específicos para representá-lo, sendo abordado em Ferreira (2007), Toledo et al. (2007), Ferreira et al. (2008b), Ferreira et al. (2008a), Ferreira et al. (2009), Toledo et al. (2009) e Ferreira et al. (2012).

Em Ferreira (2007) são apresentados dois modelos para o dimensionamento e o sequenciamento da produção de bebidas. Neste trabalho, resume-se a produção de refrigerantes em quatro estágios: tratamento da água, preparo dos xaropes, envase e empacotamento. Além do mais, são necessários: xaropes de diversos sabores, vasilhames, tampas, rótulos variados e água gaseificada, que são chamados de insumos. Os modelos propostos determinam a quantidade e a ordem que os refrigerantes devem ser produzidos nas máquinas, de forma a satisfazer a demanda de cada período do horizonte de planejamento, levando em consideração as limitações de capacidade e insumos. Os modelos consideram também os estágios de envase, xaroparia, tempo e custo de troca de refrigerantes nas linhas de produção. O primeiro modelo (modelo Multi Máquinas - MMM) considera o tempo e o custo de troca de refrigerantes nos tanques integrando o dimensionamento e o sequenciamento da produção, mas faz uma simplificação do problema onde cada máquina possui um tanque dedicado, o que pode não ser verdade na prática, pois um tanque pode atender mais de uma linha de produção. O segundo modelo (modelo Super Tanque - MST) não considera o sequenciamento da produção do tanque, uma relaxação do modelo MMM, no entanto a xaroparia agrega a capacidade de todos os tanques considerando que o gargalo da produção é o estágio de envase. Os modelos foram resolvidos com o AMPL/CPLEX (versão 9). Os resultados obtidos são um pouco inesperados, pois o primeiro modelo obtém soluções melhores e em menos tempo que o segundo modelo.

No trabalho de Toledo et al. (2007), tanto os tanques como as linhas são interpretados como máquinas dispostas em paralelo processando xaropes e produtos, respectivamente. O referido artigo propõe um modelo matemático para representar o problema em questão. O horizonte de planejamento foi divido em períodos de tamanho fixo, cada período foi subdividido em micro-períodos de mesmo tamanho e é atribuído a cada micro-período um lote referente (para o tanque ou para a linha), sendo que este lote pode, não necessariamente, ocupar todo o micro-período. O objetivo do modelo é minimizar os custos de produção, preparação, estocagem e atrasos respeitando as restrições do problema. Este modelo possui 64 grupos de restrições. As instâncias testadas no modelo foram geradas aleatoriamente e os intervalos utilizados para geração dos parâmetros podem ser encontrados em Toledo et al. (2007). Os modelos foram resolvidos utilizando o GAMS/CPLEX (versão 7), com limite máximo de tempo de execução em 1 hora. Para os modelos de pequenas dimensões, em várias instâncias, chegou-se ao ótimo dentro do tempo pré-estabelecido. Para instâncias de maior dimensão, dentro do tempo pré-estabelecido, foi inviável encontrar soluções exatas, portanto, foram avaliadas três versões relaxadas do modelo, que mostrou-se viável: Relax1 (todas as variáveis binárias do modelo são relaxadas), Relax2 (matem-se a condição de integralidade das variáveis de utilização dos tanques para armazenar o lote de determinado xarope e se há produção de um lote em determinada linha, sendo as demais variáveis relaxadas) e Relax3 (semelhante a Relax2, exceto, ao manter a condição de integralidade das variáveis que indicam qual produto de um determinado lote está reservado em determinada linha e tanque). Sendo estas três versões relaxadas também resolvidas pelo GAMS/CPLEX.

Ferreira et al. (2008a) ressaltam algumas estratégias heurísticas e meta-heurísticas, presentes na literatura, para a resolução do problema em questão. Devido a dificuldade de resolução dos modelos, estas 
estratégias estão sendo exploradas para obtenção de soluções do problema. Como, por exemplo, em Toledo et al. (2009) que apresenta um algoritmo genético que utiliza a ferramenta NPOpt (Mendes, 2003).

Em Ferreira et al. (2009) estuda-se a produção de refrigerantes de sabores diversificados envasados em garrafas de diferentes tamanhos, dividindo o processo em dois estágios: preparação do líquido (estágio I) e envase (estágio II). O modelo proposto considera sincronização entre os estágios de produção e integra as decisões do modelo de dimensionamento de lotes e sequenciamento da produção, assim como em Toledo et al. (2009). O modelo considera o gargalo da produção, alternativamente, tanto no estágio I quanto no II em cada macro-período. Quando o gargalo é no estágio I, o tamanho de cada micro-período é limitado pela capacidade mínima e máxima do tanque, bem como a capacidade de máquina. Uma relaxação é proposta para a resolução do problema e utiliza-se a estratégia baseada na heurística relax-and-fix para obteção da solução.

Existem diferenças entre o problema encontrado na indústria de refrigerante e na indústria cervejeira, estes estão principalmente relacionados ao estágio I. Como também, notou-se que o estágio II (envase) descrito por Ferreira (2007), apresenta semelhanças com o processo de envase presente na produção de cerveja. Logo, apresenta-se o modelo proposto pelos autores a seguir, também baseado no trabalho de Fleischmann \& Meyr (1997).

\section{Modelagem matemática com dois estágios}

Para a apresentação do modelo matemático, considere as especificações citadas anteriormente conjuntamente com as citadas a seguir. $\mathrm{O}$ autor considerou o índice superior (I) para especificar o primeiro estágio, e o (II) para o segundo. Aqui, também, manteremos esta nomenclatura.

\section{Conjuntos:}

$S_{t}$ : conjunto de micro-períodos no período $t ;$

$\lambda_{i}$ : conjunto de envasadoras que podem produzir o item $i$;

$\alpha_{m}$ : conjunto de itens que podem ser produzidos na máquina de envase $m$;

$\beta_{m}$ : conjunto de líquidos diferentes (sabores) que podem ser produzidos no tanque $m$;

$\gamma_{m l}$ : conjunto de itens que podem ser produzidos na envasadora $m$ e necessitam do líquido $l$.

\section{Dados:}

$c_{k l}^{I}$ : custo para trocar o líquido do tipo $k$ para $l$;

$c_{j i}^{I I}$ : custo para trocar o item do tipo $j$ para $i$;

$b_{k l}^{I}:$ tempo de troca do líquido $k$ para o $l$;

$b_{j i}^{I I}$ : tempo de troca do item $j$ para o $i$;

$a_{m l}^{I I}:$ tempo consumido para escoar uma unidade do líquido $l$ do tanque $m$;

$a_{m i}^{I I}$ : tempo necessário para produzir uma unidade do item $i$ na envasadora $m$;

$C_{m t}^{I}$ : capacidade total do tanque $m$ (tempo);

$C_{m t}^{I I}$ : capacidade (tempo) da envasadora $m$ para o período $t$;

$r_{i l}$ : quantidade de líquido $l$ necessária para produção de um item $i$;

$I_{i 0}^{+}$: estoque inicial para o item $i$;

$I_{i 0}^{-}:$atraso inicial para o item $i$;

$Y_{m l 0}^{I}: 1$ se o tanque $m$ está inicialmente preparado para o líquido $l ; 0$ caso contrário; 
$Y_{m i 0}^{I I}: 1$ se a envasadora $m$ está inicialmente preparado para o item $i ; 0$ caso contrário;

\section{Variáveis:}

$X_{m l s}^{I}$ : produção do tanque $m$ do xarope $l$ no micro-período $s$;

$X_{m i s}^{I I}$ : quantidade de itens $i$ produzidos na envasadora $m$, no micro-período $s$;

$Y_{m l s}^{I}: 1$ se existe produção no tanque $m$ do líquido $l$, no micro-período $s ; 0$ caso contrário;

$Y_{m i s}^{I I}: 1$ se a máquina de envase $m$ é preparada para o item $i$ no micro-período $s ; 0$ caso contrário;

$Z_{m k l s}^{I}: 1$ se existe troca do líquido $k$ para o $l$ no tanque $m$ no micro-período $s ; 0$ caso contrário.

$Z_{m j i s}^{I I}: 1$ se existe troca do item $j$ para o $i$ na envasadora $m$ no micro-período $s ; 0$ caso

O modelo dois estágios de dimensionamento e sequenciamento da produção com múltiplas máquinas de envase é então:

\section{Minimizar}

$$
\sum_{m=1}^{M} \sum_{l \in \beta_{m}} \sum_{k \in \beta_{m}} \sum_{s=1}^{S} c_{k l}^{I} Z_{m k l s}^{I}+\sum_{m=1}^{M} \sum_{i \in \alpha_{m}} \sum_{j \in \alpha_{m}} \sum_{s=1}^{S} c_{j i}^{I I} Z_{m j i s}^{I I}+\sum_{i=1}^{N} \sum_{t=1}^{T}\left(h_{i t}^{+} I_{i t}^{+}+h_{i t}^{-} I_{i t}^{-}\right)
$$

\section{Sujeito a:}

\section{Estágio I (Xaroparia)}

$$
\begin{array}{cl}
\sum_{i \in \gamma_{m l}} r_{l i} X_{m i s}^{I I}=X_{m l s}^{I} & m=1, \ldots, M ; l \in \beta_{m} ; \\
\sum_{l \in \beta_{m}} \sum_{s \in S_{t}} a_{l m}^{I} X_{m l s}^{I}+\sum_{k \in \beta_{m}} \sum_{l \in \beta_{m}} \sum_{s \in S_{t}} b_{k l}^{I} Z_{m k l s}^{I} \leq C_{m t}^{I} & m=1, \ldots, S \\
X_{m l s}^{I} \leq \frac{C_{m t}^{I}}{a_{l m}^{I}} Y_{m l s}^{I} & m=1, \ldots, M ; l \in \beta_{m} ; \\
Y_{m l s}^{I}=\sum_{i \in \gamma_{m l}} Y_{m i s}^{I I} & t=1, \ldots, T ; s \in S_{t} \\
Z_{m k l s}^{I} \geq Y_{m k, s-1}^{I}+Y_{m l s}^{I}-1 & m=1, \ldots, M ; s=, \ldots, S ; l \in \beta_{l} \\
& m=1, \ldots, M ; k, l \in \beta_{m} ; \\
& s=1, \ldots, S
\end{array}
$$

\section{Estágio II (Envase)}

$$
\begin{array}{rl}
I_{i(t-1)}^{+}+I_{i t}^{-}+\sum_{m=1}^{M} \sum_{s \in S_{t}} X_{m i s}^{I I}=I_{i(t-1)}^{-}+I_{i t}^{+}+d_{i t} & i=1, \ldots, N ; \\
t & =1, \ldots, T \\
\sum_{i \in \alpha_{m}} \sum_{s \in S_{t}}\left[a_{i m} X_{m i s}^{I I}+\sum_{j \in \alpha_{m}} b_{j i} Z_{m j i s}^{I I}\right] \leq C_{m t}^{I I} & t=1, \ldots, T ; \\
& m=1, \ldots, M
\end{array}
$$




$$
\begin{array}{cl}
X_{m i s}^{I I} \leq \frac{C_{m t} I I}{a_{i m}^{I I}} Y_{m i s}^{I I} & i \in \alpha_{m} ; s=1, \ldots S ; \\
Z_{m j i s}^{I I} \geq Y_{m j(s-1)}^{I I}+Y_{m i s}^{I I}-1 & \\
\sum_{i \in \alpha_{m}} Y_{m i s}^{I I}=1 & s, j \in \alpha_{m} ; m=1, \ldots, M ; \\
& m=1, \ldots, S . \ldots, M ; \\
X_{m l s}^{I} \geq 0 ; X_{m i s}^{I I} \geq 0 ; I_{i t}^{+} \geq 0 ; I_{i t}^{-} \geq 0 ; & s=1, \ldots, S \\
Z_{m k l s}^{I} \in\{0,1\} ; Z_{m j i s}^{I I} \in\{0,1\} ; Y_{m l s}^{I} \in\{0,1\} ; Y_{m i s}^{I I} \in\{0,1\} ; & \\
s=1, \ldots, S ; t=1, \ldots, T ; i, j=1, \ldots, N ; m=1, \ldots, M ; l \in \beta_{m} . &
\end{array}
$$

A função objetivo (2.26) minimiza a soma dos custos de trocas de xaropes nos tanques, trocas de líquidos nas envasadoras, de estocagem e backorder da demanda. No estágio I, a demanda para o líquido $l$ é computada em função das variáveis de produção do estágio II. Isto é, a demanda para o líquido $l$ em cada tanque $m$ no micro-período $s$ é dada por $\sum_{i \in \gamma_{m l}} r_{i l} X_{m i s}^{I I}$ de acordo com as restrições 2.27). As restrições (2.28) garantem que o tempo gasto para escoar o xarope do tanque $m$, mais o tempo necessário para as trocas de xaropes, não ultrapasse a capacidade de tempo disponível do tanque $m$. As restrições 2.27) e (2.30) interligam os dois estágios, sendo que as últimas garantem que para cada xarope $l$, o número de preparos no micro-período $s$ da máquina $m$ seja igual ao número de preparos no micro-período $s$ do tanque $m$. As restrições 2.31) capturam a troca de xaropes no tanque.

No segundo estágio, tem-se que as restrições (2.32) representam as equações de balanço de estoque para cada item em cada período. Observe que as variáveis de produção são definidas para cada microperíodo do período $t(t \in T)$, logo para se obter a produção total do item $i$ no período $t$, é necessário somar a produção associada a todas as máquinas capazes de produzir este item $\left(m \in \lambda_{i}\right)$ nos micro-períodos $\left(s \in S_{t}\right.$ ) pertencentes ao macro-período $t$. As restrições 2.33 representam a capacidade da máquina em cada período. As restrições 2.34 garantem que haverá produção apenas se a linha estiver preparada para o item. As restrições 2.35 capturam as trocas realizadas nas linhas. As restrições 2.36 asseguram que cada linha está preparada para um líquido a cada micro-período. E, pro fim, as restrições 2.37) definem o domínio das variáveis.

Conforme mencionado, o modelo (2.26)- 2.37) foi um dos pontos de partida para o desenvolvimento de uma das abordagens de modelagem matemática do presente trabalho, apresentada no Capítulo 4. 


\section{Processo de fabricação da cerveja e definição do problema}

A primeira cerveja surgiu acidentalmente devido as condições precárias de armazenamento dos grãos. Com a evolução humana, o entendimento do processo agrícola, e também do armazenamento de produtos, a cerveja começou a tomar características tais como se conhece atualmente. A história da cerveja misturase de tal forma com a história da humanidade que torna-se difícil falar de cerveja separadamente. Então, para que se possa compreender como deu-se origem ao atual processo de fabricação, este capítulo conta um pouco dessa história e, depois, descreve como a cerveja é fabricada atualmente. Ao final, define-se como este problema é abordado no presente trabalho. As informações históricas que constam neste capítulo baseiam-se no livro de Morado(2009).

\subsection{Histórico}

O início da vida humana sobre a Terra é marcada por povos nômades, que extraíam e usufruíam dos recursos provindos da natureza. Quando estes ficavam escassos, migravam para outros locais menos explorados. Ao perceber a escassez de alimentos, começaram a cultivar e criar seu próprio sustento e, assim, a se fixar em locais previamente escolhidos. Ao desenvolver as primeiras técnicas agrícolas, o homem deixa de ser nômade e organiza-se em grupos, começando a desenvolver técnicas para o plantio agrícola e armazenamento das colheitas. Estudiosos afirmam que a cerveja tenha sido descoberta por acaso, pois acredita-se que agricultores tenham armazenado a colheita dos grãos de cereais em vasos, para utilizá-los posteriormente. Entretanto, por alguma razão, até mesmo por uma chuva, estes grãos tenham ficado úmidos e, em seguida, colocados para secar. O que se assemelha ao primeiro processo de fabricação de cerveja, os grãos de cevada são amolecidos, colocando-os de molho em água, provocando, então, o processo químico da quebra da molécula de amido em açúcares. Para interromper o processo de germinação dos grãos, estes precisam 
ser secados; assim, com a secagem e torrefação dos grãos, obtêm-se o malte. O próximo passo foi preparar uma "sopa" com este malte. Esta, ao ser abandonada, sofreu um processo de fermentação, pois foi atacada por micro-organismos presentes na atmosfera. Assim, surge a cerveja! Há possibilidade de que este fato tenha acontecido, pois há registros de desenhos rupestres (símbolos primitivos), que descrevem o processo de preparação de uma bebida semelhante a cerveja.

No museu do Louvre, na França, há uma peça em exposição, conhecida como Pedra Azul, que marca o início da civilização suméria (população mesopotâmica, que habitava a região entre os rios Tigres e Eufrates, atualmente o Iraque). Esta peça contém dados sobre a produção de cerveja. O líquido era usado para honrar os deuses e também servia-se aos doentes. Assim, acredita-se que a arte de fabricar cerveja teve seu início com os assírios e os sumérios há 5000 anos atrás. Em 3400 a.C., em Tebas (Egito), segundo consta nos hieroglifos, passou-se a produzir variedades como a Cerveja dos Notáveis e a Cerveja de Tebas. Os egípcios difundiram a cerveja no Oriente e Mediterrâneo. Do Mediterrâneo, chegou à Europa e depois ao mundo.

Outros historiadores acreditam que a cerveja tenha surgido no Egito. Este fato deve-se à descoberta de arqueólogos, durante escavações de tumbas de faraós, onde encontraram vasos, tesouros em ouro e especiarias, sendo que nestes vasos haviam resquícios de cevada. Os gregos e romanos aprenderam a fabricar cerveja com os egípcios, entretanto, na época, o vinho era a bebida mais popular e também considerada sagrada. Outros registros comprovam que por volta de 2000 a.C., os chineses produziam o tsiou, cerveja de painço (painço: planta gramínea, cujo grão assemelha-se a um milho miúdd ${ }^{1}$, para oferecer aos ancestrais.

O vinho, por ser uma bebida cara e depender exclusivamente de uvas para fabricação, começa a perder seu prestígio para a cerveja, pois esta pode ser fabricada a partir de diversos grãos: milho, sorgo, cevada, arroz e trigo, sendo estes de cultivo mais fáceis que a uva e, também, por serem mais resistentes e abundantes. Já no início da Idade Média, a produção de cerveja era uma atividade exclusivamente caseira. As esposas eram as responsáveis pela produção com a finalidade de suprir o consumo da família. O líquido era bebido principalmente no desjejum e também utilizado como medicamento.

Em vários mosteiros do mundo, os monges católicos se alimentavam basicamente de cerveja durante todo o período da quaresma. Os próprios monges fabricavam a cerveja e adicionavam diversas ervas para aromatizá-la, como mírica, rosmarinho, louro, sálvia, gengibre e o lúpulo. Este último, introduzido no processo entre os anos 700 e 800 , é utilizado até hoje. Os religiosos foram os primeiros pesquisadores de cerveja. Eram alfabetizados e possuíam capacidade de trabalho, o que contribuiu para o aprimoramento dos métodos de fabricação. Foram eles os precursores da conservação a frio do líquido. A partir do século VI, os mosteiros tiveram as primeiras iniciativas de produção em grande escala da bebida. Por serem organizados e terem desenvolvido receitas (guardadas em segredo), se tornaram os únicos com capacidade para produzir cerveja em grande escala. A bebida era destinada aos monges e aos pobres, comercializada para peregrinos e camponeses da região. Assim, os mosteiros desenvolveram receitas, técnicas e equipamentos exclusivos para a fabricação da cerveja de boa qualidade.

Desde os primórdios, a cerveja tem seu sabor, aroma e cor enriquecidos com especiarias ou raízes, por exemplo, mel, anis, canela, tomilho, gengibre e alecrim. Entretanto, o uso do lúpulo na produção de cerveja tornou-se comum a partir do século IX, sendo registrado apenas alguns séculos depois pela monja beneditina alemã Hildegard von Bingen (1098-1179) no livro Physica sive Subtilitatum. O lúpulo foi adotado, principalmente, devido as suas propriedades de conservação da bebida. No decorrer dos séculos XII e XIII ocorreu a urbanização, em outras palavras, a concentração dos consumidores, contribuindo para

\footnotetext{
${ }^{1}$ Dicionário Michaelis. Moderno dicionário da língua portuguesa. Editora Melhoramentos.
} 
criação do negócio especializado de cerveja. Durante este período, várias instituições e estabelecimentos começam a produzir e comercializar cerveja. Em 1040, o Mosteiro de Weihenstephan, na Alemanha, obteve a primeira licença para produzir cerveja comercialmente, sendo a cervejaria mais antiga do mundo, ainda hoje em atividade.

A descoberta da América e a Reforma Protestante marcam o início da Idade Moderna. Neste período da história, a produção de cerveja começou a ser mais controlada, principalmente devido a Reforma Protestante. Esta desencadeou muitas mudanças na Europa, afetando e desestruturando os mosteiros cervejeiros. As medidas de controle da produção cervejeira tinham por objetivo questões econômicas (arrecadação de impostos) e/ou qualidade dos produtos. Com estas novas medidas de controle, surge a necessidade de regulamentação de forma a estabelecer padrões para o processo de produção da bebida. Em 1487, o Duque Albrecht IV, da Baviera, decretou a primeira regulamentação sobre a fabricação da cerveja, que serviu como inspiração para a promulgação da Lei da Pureza, em 1516. A Lei da Pureza tornou-se a mais famosa referência que estabeleceu padrões de produção cervejeira da história.

Resumidamente, segundo historiadores, a cerveja que conhecemos hoje teve seus primórdios no Egito, difundindo-se na Europa, durante a Era Cristã, levada pelos romanos. No século I d.C., a cerveja já era produzida pelos antepassados dos alemães e dos franceses, logo espalhando-se para outras regiões do continente. Na idade das trevas, mais precisamente nos anos de 700 a 800 , a cerveja passou a ser produzida nos mosteiros e, consequentemente, tomou o status de bebida nobre. Os monges medievais foram os responsáveis pela adição do lúpulo à cerveja obtendo uma maior durabilidade do líquido e, assim, atribuindo o sabor amargo até hoje apreciado. As primeiras cervejas tinham uma durabilidade curta, devido ao seu preparo rudimentar. Eram feitas com malte, acrescido de água e alguns aromatizantes (canela, coentro, gengibre, etc.). A mistura era reservada para que fermentasse, formando o álcool e o gás carbônico. Com a adição do lúpulo, observou-se que a durabilidade de tal líquido era maior, além de sofisticar o sabor.

No Brasil, ou melhor, Pindorama, nome do nosso país muito antes da colonização, o líquido era obtido a partir da fermentação da mandioca. A cerveja que conhecemos hoje tem estreita relação com a vinda da família real ao Brasil. A próxima seção descreve tal evento mais detalhadamente.

\subsubsection{A história da cerveja no Brasil}

A cerveja tardou a chegar no Brasil, pois os portugueses temiam perder o principal comprador de seus vinhos. A família real portuguesa, quando se exilou no Brasil em 1808, foi a primeira a trazer a cerveja, cujo sabor é semelhante ao que se tem hoje, muito embora se tenha evoluído e alterado muita coisa desde os primeiros barris descarregados na costa brasileira no início do século XIX. Consta que Dom João era apreciador de cerveja. Assim, decorrente da abertura dos portos às nações amigas de Portugal, a Inglaterra foi o primeiro país a introduzir a cerveja em nosso país.

Até 1830 a bebida alcoólica mais popular consumida no Brasil era a cachaça. Os nobres consumiam também licores importados da França e vinhos portugueses. Nesta época a produção de cerveja no Brasil era insignificante, de feitio artesanal, e apenas abasteciam o próprio consumo das famílias de imigrantes que as fabricavam. No período de 1840 a 1889, época correspondente ao Segundo Reinado, o enfoque comercial era, exclusivamente, a venda de cerveja e não a fabricação. O contrário ocorreu na década seguinte, quando os imigrantes (os fabricantes) alocaram escravos e trabalhadores livres à produção de cerveja e depois distribuíam o produto no comércio local. 
É bem difícil, segundo os próprios historiadores, dizer ou descrever à(s) primeira(s) fábrica(s). O estudo dessa época é difícil, pois não se produzia cerveja com marca e geralmente era vendida em barris para os depósitos (comércios que nem sempre eram só de cerveja). Segundo a AmBev (Companhia de Bebidas das Américas), a primeira cerveja "de marca" produzida no Brasil foi em 1853, a Bohemia. A Bohemia era, e é até os dias de hoje, produzida com ingredientes importados (AmBev, 2013).

\subsection{Panorama Mundial}

Kirin Institute of Food and Lifestyle elaborou um relatório analisando o consumo mundial de cerveja relativo ao ano de 2011. Segundo Kirin (2012), o consumo mundial de cerveja durante o ano de 2011 foi de aproximadamente 188,78 milhões de quilolitros (um aumento de 3,8\%, comparado ao ano anterior). Isto marcou o $26^{\circ}$ ano consecutivo de crescimento. Neste respectivo ano, o consumo total da população brasileira teve um aumento de 3,5\% em relação ao ano anterior, ocupando o terceiro lugar no ranking mundial. O consumo per capita da nossa população encontra-se em $26^{\circ}$ lugar, subindo uma posição no ranking em relação ao ano anterior. Com relação à produção mundial, o Brasil é o terceiro maior produtor de cerveja, perdendo apenas para a China e Estados Unidos. Em quarto lugar encontra-se a Rússia, seguida da Alemanha, México e Japão, respectivamente.

\subsection{Processo de fabricação da cerveja}

As seções anteriores mostram o prestígio da cerveja e o quão antiga é a produção deste líquido no mundo. Com o decorrer dos anos, surgiram várias técnicas de produção que foram se aprimorando e tornando-se cada vez mais automatizadas, auxiliadas pelas novas tecnologias. Esta seção tem o intuito de descrever como ocorre atualmente a produção de cerveja dentro das cervejarias. Existem diversos tipos de cerveja e estas são classificadas de acordo com a fermentação, cor, extrato primitivo, teor alcoólico, entre outros fatores. Para cada tipo de cerveja, existe um processo de fabricação diferente. As próximas seções abordam algumas diferenças entre as cervejas e o que as diferem durante o processo de fabricação.

Como dito anteriormente, para cada tipo de cerveja existe um processo de produção distinto e específico. Porém, pode-se dizer que todas passam pelas mesmas etapas de produção, distinguindo-se, principalmente, na utilização de determinadas matérias-primas e tempos de processamento em cada uma das etapas, como, por exemplo, tempo de fermentação, mostura, cozimento, etc. A seguir é descrito o processo de fabricação da cerveja de forma geral, porém, os ingredientes são os mesmos utilizados em cervejas do tipo Lager, a mais popular aqui no Brasil. Para tal, há quatro ingredientes fundamentais (veja Figura 3.1):

Água: exerce grande influência no sabor final da cerveja. Além de passar por um processo de purificação e filtragem, se houver excesso de sais minerais, estes também devem ser extraídos.

Malte: o malte é o grão de cevada que sofre um processo de germinação controlada, desenvolvendo enzimas que tornam o amido do grão mais solúvel e macio. Este processo é conhecido como malteação. A cevada é uma planta da família das gramíneas e seu cultivo dá-se em climas temperados.

Lúpulo: responsável pelo toque amargo no sabor das cervejas. A planta é uma espécie de trepadeira perene com flores fêmeas que possuem grandes quantidades de resinas amargas e óleos essenciais. Cultivável em climas frios. 
Leveduras: a levedura utilizada é da espécie Saccharomyces Cerevisiae e cada cervejaria possui sua própria cep: $2^{2}$. Todas as cepas executam basicamente o trabalho de transformar açúcar em álcool e gás carbônico. O sabor do produto obtido difere de uma cepa para outra, em virtude de pequenas diferenças de metabolismo e consequente formação de substâncias capazes de conferir aroma e sabor ao produto, mesmo em quantidades muito pequenas. Portanto, o fermento é um elemento essencial para a produção de cerveja.

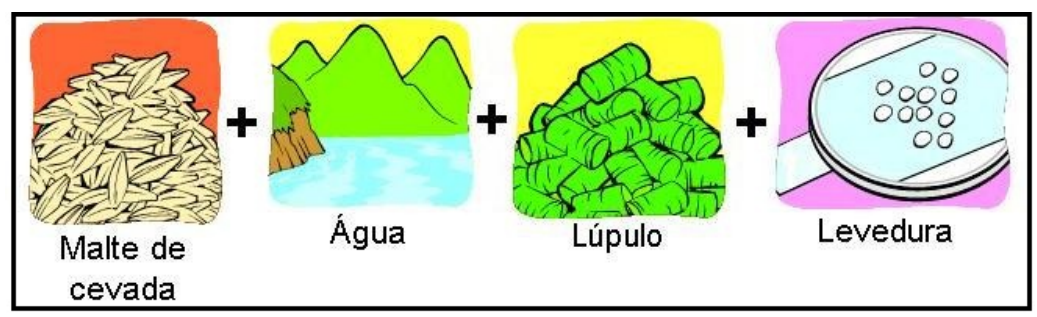

Figura 3.1: Ingredientes básicos para a produção de cerveja.

\subsubsection{Etapas do processo de produção de cerveja}

O processo de fabricação de cerveja consiste basicamente em dois estágios: preparação do líquido e envase do líquido pronto. Em cada um destes estágios existem etapas intermediárias que serão descritas nesta seção. Para facilitar a compreensão das etapas do processo de fabricação de cerveja, vamos considerar a Figura 3.2 .

Maltagem: é o processo de transformação da cevada em malte. Normalmente, este processo ocorre fora da cervejaria, ou seja, compra-se o malte pronto de alguma outra indústria especializada (maltaria). Pode ser dividido em três etapas:

- Maceração: tem duração entre 6 a 12 horas. Os grãos de cevada são umedecidos para que se inicie a germinação;

- Germinação: tem duração de 5 a 6 dias. Os grãos de cevada sofrem modificações físicas (formação de radículas e acrospira) e químicas (formação de enzimas para quebrar o amido).

- Secagem: nesta etapa, as radículas são eliminadas e os grãos de cevadas são secados, ou seja, eliminase a umidade, favorecendo, também, a estocagem.

I(A) Brassagem: este processo tem por objetivo a obtenção do mosto cervejeiro (transformação do amido e das proteínas em uma solução de açúcares e outras substâncias). A duração média de todo o processo é de 4 a 6 horas. Ele é uma composição de várias outras etapas:

- Moagem: quebra o grão de malte e adjuntos, expondo o amido contido no interior.

- Mostura: adiciona-se água ao malte moído, obtendo uma substância adocicada chamada mosto. No decorrer deste processo, a temperatura sofre variações.

- Filtragem do mosto: tem o intuito de separar o mosto líquido e o bagaço do malte.

\footnotetext{
${ }^{2}$ Linhagem, família, estirpe (Dicionário Michaelis. Moderno dicionário da língua portuguesa. Editora Melhoramentos.)
} 


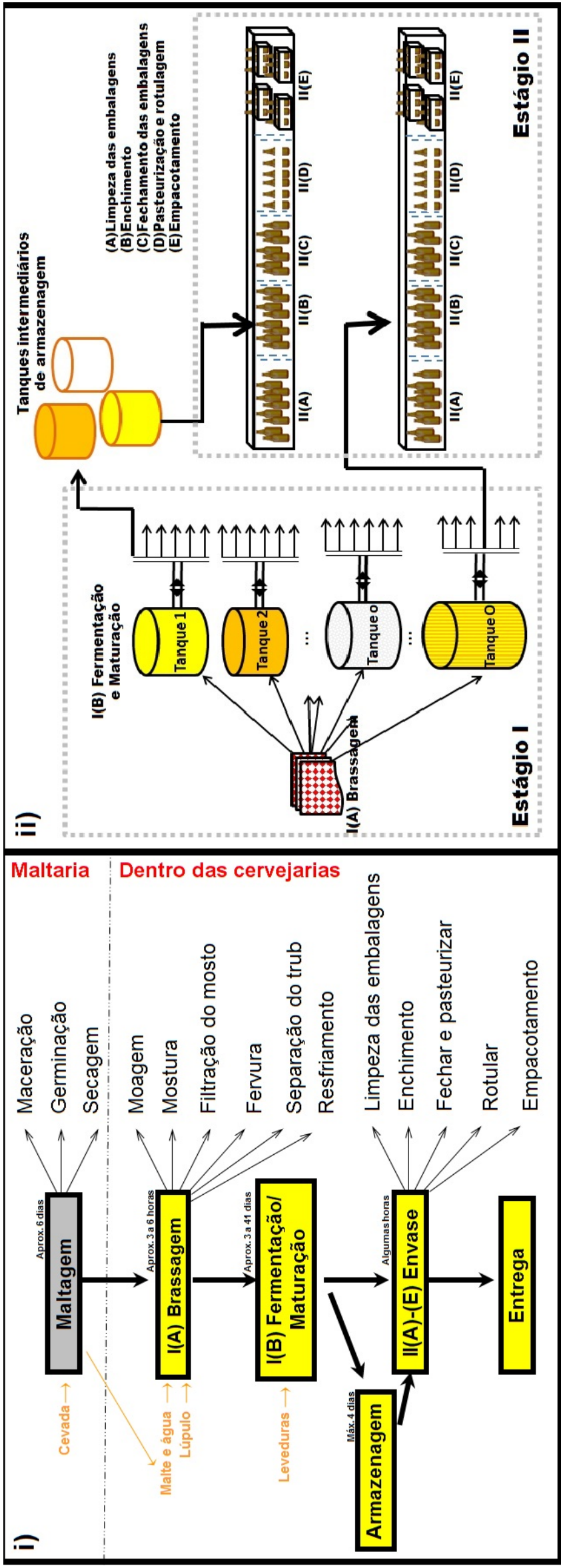

Figura 3.2: Processo de fabricação de cerveja. 
- Fervura: responsável pela esterilização do mosto. É neste processo que ocorre a lupagem, ou seja, a adição do lúpulo. Este processo estabiliza o mosto nos aspectos biológico, químico e coloidal e, também, contribui com o sabor da cerveja.

- Separação do trub: trub é parte das proteínas contidas no mosto que aglutinam-se durante a fervura. A separação do trub pode ser feita de várias formas, a mais utilizada é a sedimentação.

- Resfriamento do mosto: é necessário para que o mosto atinja a temperatura desejada antes do início da fermentação, sendo feito o mais rápido possível para evitar a formação de aromas indesejáveis e risco de contaminação.

I(B) Fermentação: são adicionadas leveduras (Saccharomyces cerevisiae) ao mosto e estas transformam os açúcares em dióxido de carbono e álcool. A temperatura é controlada e mantida em torno de $10^{\circ} \mathrm{C}$ a $13^{\circ} \mathrm{C}$. Os fatores mais importantes a serem controlados são: temperatura de fermentação, duração, contrapressão, escolha das leveduras e a quantidade de leveduras a ser utilizada. Ao término, a levedura flocula (sedimentando ou flutuando) é recolhida e pode ser usada novamente em outro processo. Porém, as leveduras podem ser usadas durante um período máximo de gerações, sendo considerada cada geração a soma dos tanques que ela foi adicionada para o processo. A fermentação é considerada o gargalo da produção, pois a duração média é de 3 a 41 dias, dependendo da cerveja a ser produzida.

I(B) Maturação: o processo de maturação tem início logo após a retirada das leveduras e ocorre no mesmo tanque utilizado para o processo de fermentação. Esta etapa é responsável pelo "afinamento" da cerveja e sua duração média é entre 2 a 4 dias. Ao término da maturação, a cerveja precisa ser filtrada. O processo de filtragem tem por objetivo dar o acabamento "brilhante" eliminando quase que totalmente as leveduras. Após o término da filtração, o líquido já está pronto para ser envasado. Porém, às vezes é necessário armazená-lo em tanques (tanques intermediários de armazenagem), entretanto, o líquido dura poucos dias após ter sido filtrado e não pasteurizado.

II(A)-(E) Envase: esta é a fase final do processo de produção, onde a cerveja será envasada em garrafas de vidro, latas de alumínio e barris. Ou seja, a cerveja é a mesma em qualquer uma das embalagens, não alterando seu paladar e aroma. O processo de envase ocorre sobre uma esteira rolante, conduzindo embalagens em todo seu curso para as etapas:

- Limpeza das embalagens: as embalagens retornáveis precisam ser lavadas e esterilizadas, antes de receber o líquido pronto em seu interior. As embalagens descartáveis, por exemplo, latas de alumínio, chegam prontas para serem cheias de líquido e não precisam passar por esta etapa.

- Enchimento: nesta etapa as embalagens são preenchidas com líquido pronto.

- Fechar e pasteurizar: após o enchimento, a embalagem precisa ser fechada e, na sequência, dá-se início a pasteurização, principalmente quando são envasadas em garrafas ou latas (no barril, normalmente não é pasteurizada e, por isso, recebe o nome de chope). A pasteurização é um processo térmico no qual a cerveja é submetida a um aquecimento a $60^{\circ} \mathrm{C}$ e posterior resfriamento, para garantir maior estabilidade e uma maior durabilidade ao produto (algo em torno de 6 meses).

- Rotular: o rótulo do produto e especificações, como validade e lote de fabricação, são adicionados nesta etapa. 
- Empacotar: as embalagens são agrupadas em packs.

Entrega: com a término da produção, os itens (cervejas) estão prontas para serem entregues às distribuidoras.

Concluindo, tem-se que a cerveja é um produto natural, fabricado com cereais e água. Tem sua normatização e controle subordinados ao Ministério da Agricultura, tanto no Brasil como na maioria dos demais países. Estas normatizações que definem a classificação, padronização e produção da cerveja (no Brasil) foram feitas por meio da lei federal número 8.918 de 1994 e regulamentada pelo Decreto 2314 de 1997.

\subsubsection{Cerveja sem álcool}

A cerveja é considerada sem álcool quando seu teor alcoólico não ultrapassar mais de 0,5\% relativo ao seu volume. Para obtenção da cerveja sem álcool existem duas estratégias: a primeira é baseada na remoção do álcool após a produção normal da cerveja, e a segunda é suprimir o processo de produção do álcool durante a fabricação. Dentre os processos citados, o primeiro é considerado mais caro segundo Lehnert et al. (2006), pois são necessários equipamentos especiais para a remoção do álcool. Neste trabalho, o objetivo é focar o processo produtivo da cerveja, por isso, não iremos nos preocupar com a cerveja sem álcool. Esta foi citada apenas a título de curiosidade.

\subsubsection{Classificação das cervejas}

Segundo o SINDCERV (2013), as cervejas podem ser classificadas conforme especificidades abaixo:

- Fermentação:

- Alta fermentação (denominada Ale): são aquelas cujas leveduras flutuam, durante o processo, em temperatura de $20^{\circ} \mathrm{C}$ a $25^{\circ} \mathrm{C}$, após fermentar o mosto, gerando um produto de cor cobreavermelhada, de sabor forte, ligeiramente ácido e com teor alcoólico entre 4\% e 8\% (por exemplo, as cervejas alemãs). Algumas cervejas do tipo Ale:

* Altbier: incluem em seu ingrediente um pouco de cacau proveniente do malte torrado, e a característica mais peculiar é a grande quantidade de lúpulo. A cor tende para os tons mais escuros.

* Barley Wine: esta cerveja pode ser guardada por muitos anos, diferindo-se das demais cervejas. É forte e tem sabor intenso de malte e de lúpulo.

* Belgian Ale: geralmente o processo de fabricação é artesanal. Tem cores e sabores variados e divide-se em vários tipos.

* Bitter: é muito amarga. Essa característica fica mais acentuada à medida que aumenta a quantidade de lúpulo na receita. Sua cor varia do âmbar ao cobre.

* Brown Ale: é escura, tem pouco teor de lúpulo (portanto, pouco menos amarga) e sabor adocicado de nozes.

* Abadia: é uma cerveja de alta fermentação. Seu aroma lembra especiarias e tem um sabor bem diferente, resultante do equilíbrio ideal entre o amargor, a doçura e o teor alcoólico. 
- Baixa fermentação (denominada Lager): as cervejas de baixa fermentação só começaram a ser produzidas em larga escala no século passado, com a descoberta de Carl Paul Gottfried von Linde (quem inventou a máquina frigorífica). Alguns dos principais tipos de cerveja do tipo Lager são descritos a seguir:

* Bock: cerveja de cor escura, originalmente da Alemanha, de sabor adocicado, levemente amarga e alto teor alcoólico.

* Münchener: cerveja escura ou preta e pode ser bem leve. Tem um sabor forte, de malte, assemelhando-se ao café.

* Pilsen: originária da região da Boêmia. Com cor dourada e translúcida. Em sua fórmula original, seu sabor é suave e um aroma acentuado de flores, acentuada concentração de lúpulo.

- Teor de extrato primitivo (densidade original do mosto antes da fermentação):

- Leve: mais de $5 \%$ e menos de $10,5 \%$ de extrato primitivo;

- Comum: menor que $10,5 \%$ e maior que $12 \%$;

- Extra: entre $12,0 \%$ e $14 \%$;

- Forte: mais de $14 \%$.

- Cor:

- Clara: menos de 20 unidades EBC (European Brewery Convention);

- Escura: 20 ou mais unidades EBC.

- Teor alcoólico:

- Sem álcool: menos de 0,5\% em volume de álcool;

- Alcoólica: igual ou maior que $0,5 \%$ em volume de álcool.

- Teor de extrato final (corresponde ao percentual de extrato que foi fermentado):

- Baixo: até $2 \%$;

- Médio: 2\% a 7\%;

- Extra: maior que $12,0 \%$ e menor que $14 \%$;

- Alto: mais de $7 \%$.

\subsection{Visitas técnicas a cervejarias}

Para o desenvolvimento deste trabalho, por tratar-se de uma pesquisa quantitativa empírica, de acordo com a classificação de Morabito \& Pureza (2010), foram realizadas visitas às cervejarias, tanto portuguesas, quanto brasileiras. Estas visitas foram importantes para o entendimento, na prática, do processo produtivo e, também, para a identificação de quais são as maiores dificuldades durante o processo, sob o ponto de vista das indústrias. Desta forma, descrevemos as principais características da empresa brasileira e, na sequência, da empresa portuguesa. 


\subsubsection{Empresa brasileira}

A empresa brasileira localiza-se no interior do estado de São Paulo. Trata-se de uma empresa de médio/grande porte quando analisa-se a quantidade de produção, entretanto não há muita diversidade de produtos produzidos. A empresa em questão tenta prever a demanda por meio de estudos baseados em dados históricos, ou seja, em informações de vendas anteriores e, também, um estudo do mercado atual. Os dados são manipulados e armazenados em um sistema computacional específico. A previsão de demanda considera o estoque mínimo tanto para produtos, quanto para insumos, sendo o horizonte de planejamento rolante, com tamanho de 3 meses (mês subsequente e os próximos). Por meio desta previsão de demanda, o planejamento ocorre do final para o início do horizonte, ou seja, primeiramente detecta-se quantos produtos finais serão necessários ao final de cada período, depois, calcula-se a quantidade de líquido necessária para que, ao ser envasado, resulte na quantidade de itens finais. Desta forma, ao saber a quantidade necessária de líquido, estamos no processo anterior ao envase, assim, verifica-se a disponibilidade dos tanques e como alocá-los para receber o mosto. Para a produção do mosto cervejeiro, é necessário que este passe pelo processo de brassagem, alocando, assim, todo o recurso necessário para efetuar esta etapa. Ao final destas etapas descritas anteriormente, o programador já sabe quais as datas em que irão ocorrer cada um dos processos de fabricação e suas respectivas quantidades demandadas.

$\mathrm{Na}$ empresa, o PCP (planejamento e controle da produção) é baseado em informações fornecidas pelo SAP 3 que oferece uma visão de quanto e quando produzir. O gerente responsável ajusta as informações determinando quanto, quando e qual a sequência da produção, montando assim o MRP (Material Resource Planning). O planejamento permanece fixo durante um horizonte de 15 dias.

Dentre todas as programações, as mais preocupantes ocorrem antes do processo de filtragem, pois há receio que não haja líquido dentro dos tanques para a fabricação dos itens, visto que o processo de fermentação/maturação é o mais demorado; e, sem líquido pronto, não há como envasar. Na empresa, o processo de preparação do mosto demora algo em torno de 4 a 6 horas. Porém, o processo de fermentação dura aproximadamente 14 dias. Os tanques de fermentação têm capacidades iguais, somando um total de 18 tanques. Nestes tanques também ocorrem o processo de maturação, que tem duração entre 2 a 4 dias. Após a maturação a cerveja é filtrada. Há 6 tanques para armazenar a cerveja filtrada. Após filtrada, o líquido está pronto para ser envasado. A empresa possui 3 linhas de envase.

São fabricados 9 tipos de itens diferentes, ou seja, cervejas prontas e envasadas. Há 3 diferentes líquidos fermentados e cada cerveja é composta por apenas um tipo de líquido. Uma linha pode receber qualquer um dos 3 líquidos, porém, não consegue envasar qualquer um dos tipos de produto devido as embalagens de diferentes tamanhos (veja Tabela 3.1. O tempo e o custo de preparação (setup) das linhas são dependentes da sequência, podendo durar de 20 minutos (ou menos) até 8 horas. A demora ocorre principalmente quando há mudança de tamanhos de embalagem numa mesma linha, ou ainda, quando há mudança para cervejas de puro malte. Na Tabela3.2 há especificações dos tanques de fermentação/maturação e de armazenamento dos líquidos prontos para o envase, sendo que cada tanque possui uma capacidade mínima (devido a sensores de temperatura, pois abaixo deste nível eles não funcionam como o esperado) e máxima de armazenamento (tamanho máximo do tanque).

\footnotetext{
${ }^{3}$ SAP é um Software de Gestão de Negócios que possui o mesmo nome da empresa que o desenvolveu (http://www.sap.com).
} 
Tabela 3.1: Dados sobre a empresa brasileira.

\begin{tabular}{|ccc|}
\hline Linhas & Itens & Líquidos \\
\hline 3 & 9 & 3 \\
\hline
\end{tabular}

Tabela 3.2: Especificações dos tanques de fermentação e dos tanques de armazenamento do líquido filtrado, referentes a empresa brasileira.

\begin{tabular}{|c|ccc|}
\hline Tanques & $\begin{array}{c}\text { Quantidade } \\
\text { (unidades) }\end{array}$ & \multicolumn{2}{c|}{ Capacidade (litros) } \\
& Mínima & Máxima \\
\hline Fermentação/Maturação & 18 & 30.000 & 600.000 \\
\hline Armazenagem & 6 & 30.000 & 300.000 \\
\hline
\end{tabular}

\subsubsection{Empresa portuguesa}

A empresa portuguesa está localizada a noroeste do país. É uma empresa de grande porte, tanto em volume de produção, quanto em diversidade de produtos produzidos, sendo este último aspecto, a principal diferença entre as empresas estudadas. Esta empresa possui duas plantas localizadas em diferentes cidades, porém, relativamente próximas. Para facilitar, denomina-se as plantas de 'A' e 'B'. De maneira análoga a empresa brasileira, esta faz a previsão de demanda por meio de estudos baseados em históricos e do mercado atual. Por meio desta previsão, o planejamento ocorre do final para o início, ou seja, primeiramente detectase quantos produtos finais serão necessários ao final de cada período, depois, calcula-se a quantidade de líquido necessária.

$\mathrm{Na}$ empresa portuguesa, o PCP é baseado em informações fornecidas por um software de gestão empresarial, onde estão armazenadas as informações relativas às previsões de demanda. O gerente responsável ajusta as informações determinando quanto, quando e qual a sequência da produção. Um plano de enchimento dos tanques é feito com 6 semanas de antecedência. Quando um tanque fica vazio, demora 3 a 4 horas, no mínimo, para receber líquido novamente, devido ao CIP (Clean-in-Place). Esta limpeza tem que ser feita no máximo 24 horas antes do tanque receber líquido, caso contrário, um novo processo de limpeza é necessário. Na prática, limpa-se um tanque no final do dia para enchê-lo no dia seguinte. O enchimento é feito com 3 semanas de antecedência ao envase, pois é o tempo estimado para que o líquido fique pronto.

Há prioridade de utilização dos tanques maiores, pois é menos oneroso quando utilizado próximo a sua capacidade máxima. Isto ocorre devido a relação custo/litro, visto que o custo para manter o tanque praticamente independe da sua dimensão.

O principal gargalo da produção encontra-se na etapa de envase. Outra peculiaridade, é que a Planta A envia líquido para ser envasado em B, e vice-versa. Por exemplo, a Planta A não envasa latas, mas B sim, entretanto B não produz todos os líquidos necessários para a produção de cervejas em latas. O transporte de líquido entre as plantas é feito por meio rodoviário e utiliza-se caminhões próprios para transporte de produtos perecíveis, pois o líquido deve ser mantido a baixas temperaturas. Na Planta A, são produzidos 66 itens diferentes. Para produção destes itens, são necessários 17 tipos diferentes de líquidos e, cada item final, é composto por apenas um tipo de líquido. Nesta planta, há 5 linhas de envase. A Planta B possui 5 linhas de envase, produz 47 itens diferentes e 7 tipos de líquidos, como mostra a Tabela 3.3 As informações sobre os tanques de fermentação/maturação e armazenagem estão na Tabela 3.4

A produção do mosto cervejeiro tem duração média entre 2 a 3 horas, mas pode ocorrer situações onde a duração é de até 6 horas. Durante o processo de brassagem, o maior custo, além dos ingredientes, é a geração 
do calor para as caldeiras. Portanto, a empresa tenta aproveitar o máximo de tempo possível para produzir quando a caldeira está funcionando. Em um único dia, é possível fazer o enchimento de até 14 tanques. A empresa em questão, mais especificamente na Planta $\mathrm{A}$, possui dois espaços dedicados à fabricação do mosto. Entretanto, apenas um deles permanece ativo, devido a minimização dos custos de geração de calor para as caldeiras. O processo de brassagem é rápido, logo, não é o gargalo da produção. Durante a fase de mostura existem poucas operações manuais. Os tanques grandes recebem até 4 lotes de mosto fabricado, ocupando totalmente sua capacidade, os pequenos 1,5 lotes. O enchimento do mosto nos tanques demora aproximadamente 1 hora. A partir do momento que o tanque está cheio, este demora aproximadamente 3 semanas para estar disponível novamente.

O processo de fermentação e maturação ocorre dentro do mesmo tanque. Após o término do período de fermentação/maturação, o líquido precisa ser filtrado. Entretanto, na empresa não há a possibilidade do líquido ser filtrado e imediatamente ser envasado, pois não existe sincronia entre as linhas de envase e os tanques. Neste aspecto, difere-se da empresa brasileira, pois a velocidade de escoamento do líquido pode ser sincronizada com as linhas de envase. Sendo assim, há a necessidade de tanques intermediários para armazenagem de líquido filtrado. A cerveja filtrada pode ficar nos tanques de 3 a 5 dias. Caso fique mais tempo, é necessário analisar a qualidade do líquido. Nas plantas, os tanques destinados a armazenagem de líquido filtrado possuem capacidade máxima de 150 mil litros e são imprescindíveis. Na Planta A, são 18 tanques de armazenagem e, em B, são 9. Estes tanques demoram aproximadamente 2 horas para encher e de 6 a 8 horas para esvaziar, dependendo da(s) linha(s) de envase que estão abastecendo. Na etapa de escoagem do líquido, as mangueiras responsáveis pelo transporte do líquido de um lugar para outro, são encaixadas manualmente e, assim, obtém a ligação, ou seja, o percurso que o líquido irá fluir. Esta etapa, na empresa brasileira, é automatizada.

Um dos maiores problemas da empresa é a fabricação dos lotes mínimos. Há itens cuja demanda é muito baixa, porém, é necessário uma quantidade mínima de líquido nos tanques. Uma das principais consequências geradas pelo lote mínimo é a fabricação de itens além do demandado, ficando em estoque durante vários períodos, gerando custos de armazenagem.

Tabela 3.3: Dados sobre a empresa portuguesa.

\begin{tabular}{|c|ccc|}
\hline Planta & Linhas & Itens & Líquidos \\
\hline $\mathrm{A}$ & 5 & 66 & 18 \\
\hline $\mathrm{B}$ & 5 & 47 & 7 \\
\hline
\end{tabular}

Tabela 3.4: Especificações dos tanques de fermentação e dos tanques de armazenamento do líquido filtrado, referentes a empresa portuguesa.

\begin{tabular}{|c|c|c|c|c|}
\hline \multirow[b]{2}{*}{ Planta } & \multirow[t]{2}{*}{ Tanques } & \multirow{2}{*}{$\begin{array}{l}\text { Quantidade } \\
\text { (unidades) }\end{array}$} & \multicolumn{2}{|c|}{ Capacidade (litros) } \\
\hline & & & Mínima & Máxima \\
\hline \multirow{3}{*}{ A } & Fermentação/Maturação & 48 & 10.000 & 100.000 \\
\hline & Fermentação/Maturação & 40 & 30.000 & 300.000 \\
\hline & Armazenagem & 18 & 15.000 & 150.000 \\
\hline \multirow{3}{*}{ B } & Fermentação/Maturação & 24 & 10.000 & 100.000 \\
\hline & Fermentação/Maturação & 20 & 30.000 & 300.000 \\
\hline & Armazenagem & 9 & 15.000 & 150.000 \\
\hline
\end{tabular}




\subsection{Definição do problema}

Nas cervejarias pesquisadas, notou-se que o principal gargalo encontra-se, durante o estágio I, no processo de fermentação e maturação, responsável por mais de $95 \%$ do tempo despendido para a preparação do líquido. Isso ocorre quando um tanque é alocado para receber o mosto cervejeiro, pois este fica durante vários dias dedicado somente a este mosto, até que se complete o processo de fermentação e maturação. Por outro lado, na indústria de refrigerantes (assim, como também, indústrias de bebidas carbonatadas) esta etapa tem duração de apenas alguns minutos e, em alguns casos, algumas horas.

O gargalo no estágio II é a etapa de enchimento das embalagens, pois quando ocorre a alocação dos líquidos prontos às suas embalagens, acontece o esvaziamento dos tanques, ou seja, quanto mais rápido for o envase, mais brevemente os tanques são liberados. Sendo assim, para o desenvolvimento dos modelos matemáticos desta pesquisa, partimos do pressuposto que se há uma programação da produção para as etapas de fermentação/maturação e envase, o programa de produção para as demais etapas pode ser facilmente derivado. Logo, para o estágio I, assumiu-se (sem perda de generalidade) que os demais processos não envolvidos no gargalo fossem desprezados, pois não interferem diretamente nas decisões necessárias a serem tomadas durante a programação da produção.

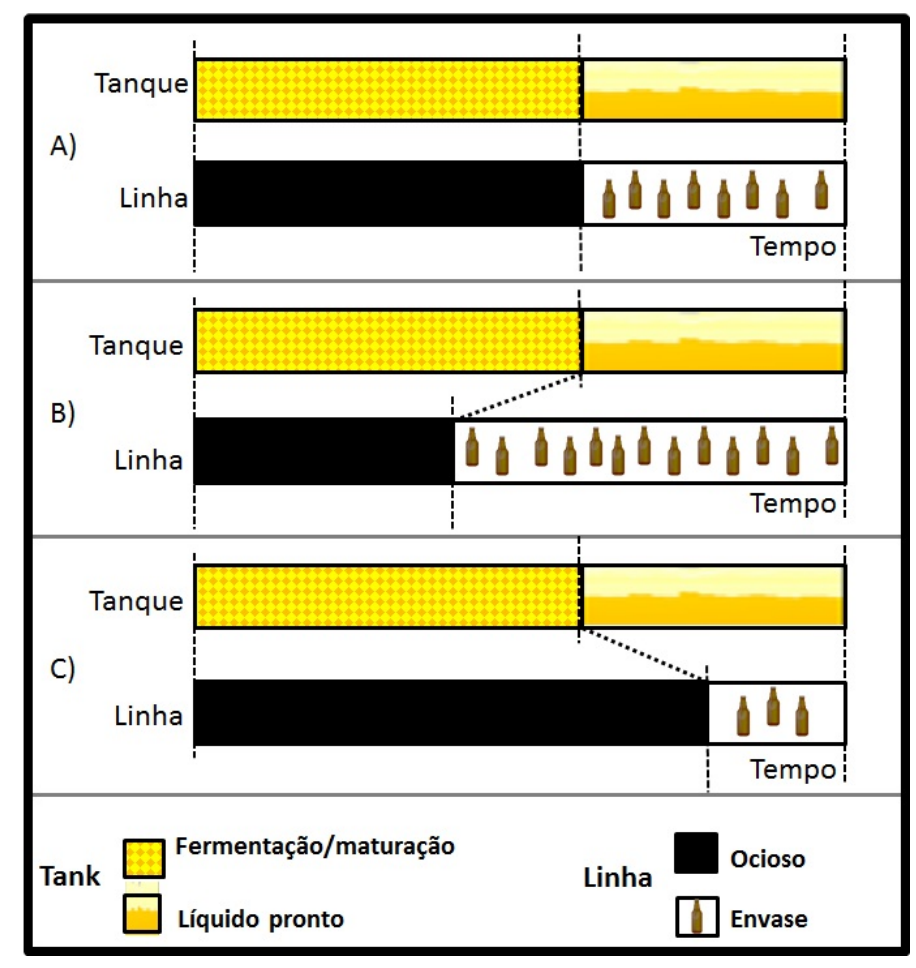

Figura 3.3: Sincronização entre os estágios.

Nas indústrias cervejeiras (assim como nas indústrias de bebidas em geral), o estágio II (linha de enchimento) só pode começar depois que o líquido estiver pronto. A Figura 3.3 ilustra três situações sobre as interdependências entre tanques e linhas presentes na indústria cervejeira, sendo apenas duas delas viáveis na prática. Em cada caso, a produção dos tanques (superior) e as linhas de enchimento (inferior) são representadas por gráficos de Gantt. Na Figura 3.3.A), ilustra-se um cenário ideal onde o líquido fica pronto, completando o processo de fermentação/maturação, e no mesmo instante começa a ser envasado. A situa- 
ção (B) é impraticável, pois o líquido começa a ser envasado antes de concluir o processo de fermentação e maturação. Finalmente, em (C) o líquido pronto espera um tempo dentro do tanque até começar a ser envasado. Além desta particularidade, sobre a sincronização e espera entre os estágios, o processo de produção de cerveja possui algumas outras especificidades, sendo estas:

- um tanque pode abastecer de líquido mais de uma linha de envase ao mesmo tempo;

- uma linha não pode receber líquido de dois ou mais tanques ao mesmo tempo, mesmo que estes tanques possuam o mesmo líquido;

- um item é composto apenas por um líquido (tipo de cerveja);

- os tanques possuem um limite máximo (a capacidade) e mínimo, pois cada tanque possui sensor de temperatura que funciona adequadamente somente quando o tanque está com líquido acima deste limite;

- o líquido pronto pode esperar dentro dos tanques de fermentação e maturação até o processo de envase começar (diferentemente das demais indústrias de bebidas);

- assim como também podem ser filtrados e esperarem nos tanques de estocagem de líquido pronto (não existe esta possibilidade nas demais indústrias de bebidas). Entretanto, esta última situação, a filtragem, não é abordada nesta pesquisa;

- a troca de líquido nos tanques independe da sequência em que são alocados. Isso ocorre pois, antes de um tanque receber o mosto cervejeiro, este passa por um processo de limpeza cujo tempo médio é conhecido previamente e independe de qual líquido estava no tanque anteriormente. Esta especificidade também não está presente na indústria de refrigerantes.

Todas estas características do problema são consideradas durante o desenvolvimento dos modelos matemáticos e métodos de solução propostos, que visam à obtenção de planos de produção viáveis e efetivos para a indústria cervejeira. Então, tem-se que o problema considerado é:

- multiestágio, cujo estágio I, corresponde as decisões relativas aos tanques de fermentação/maturação; e estágio II, decisões sobre as linhas de envase;

- horizonte de planejamento finito, cujos períodos discretos possuem mesmo tamanho e correspondem a um dia;

- demanda dinâmica e determinística, pois admite-se previamente conhecida;

- o objetivo é minimizar os custos envolvidos durante a produção: estoque, atraso e número de trocas nas linhas de envase;

- os recursos são limitados: número de tanques e linhas de envase predefinidos, com as capacidades de cada um destes recursos tendo que ser respeitadas;

- a preparação dos tanques de fermentação/maturação é independente da sequência;

- as preparações das linhas de envase são dependentes da sequência;

- cada linha mantém um coeficiente de produção constante durante todo o horizonte de planejamento. 


\section{Modelagem matemática do problema}

Os modelos apresentados neste capítulo visam representar adequadamente o problema de dimensionamento de lotes e programação da produção em indústrias cervejeiras. Como descrito anteriormente, o processo de produção de cerveja por ser dividido em dois principais estágios: preparação do líquido (estágio I) e envase (estágio II). Os gargalos presentes em cada um destes estágios são o foco deste trabalho, visto que, as decisões de programação da produção dos demais processos envolvidos durante a produção são deriváveis a partir das decisões da programação da produção estabelecidas para cada um dos processos gargalo em cada um dos estágios. O gargalo da produção no estágio I é o processo que ocorre dentro dos tanques (fermentação/maturação), pois os tanques ficam ocupados durante vários dias até a cerveja ficar pronta e disponível para o envase. Com relação ao estágio II, o gargalo do processo encontra-se no envase, pois a velocidade em que as embalagens são cheias com líquidos influencia diretamente na liberação (ou não) dos tanques.

Como já dito anteriormente, existem diferenças entre os problemas de dimensionamento de lotes e programação da produção presentes nas indústrias de bebidas (sucos, água, refrigerantes, etc) e nas indústrias cervejeiras; principalmente quando refere-se ao estágio I, preparação do líquido. O tempo de preparação dos líquidos nas indústrias de bebidas, em geral, é de no máximo algumas horas. Por outro lado, na fabricação de cerveja, o estágio I (fermentação/maturação) necessita de vários dias para se completar (de 3 a 41 dias, dependendo do tipo de cerveja). Outra diferença é que na indústria cervejeira, após o período de fermentação e maturação, o líquido pronto pode permanecer armazenado nos tanques durante vários dias, enquanto espera para ser envasado; o que não ocorre na indústria de refrigerantes devido a perecibilidade dos xaropes. Quando analisa-se o estágio II de ambas as indústrias, notam-se semelhanças nas indústrias de refrigerantes e cervejeiras; portanto, para o estágio II (envase), dois dos modelos propostos neste capítulo (T1LM e TOLM-GLSP) baseiam-se nos modelos propostos em Ferreira et al. (2009). E, ainda, outros dois modelos (TOLM-CLSD_MTZ e TOLM-CLSD_W) foram motivados pela iniciativa de Ferreira et al. (2012) de reescrever o modelo GLSP utilizando estratégias ATSP para a indústria de refrigerantes. 
A resolução de cada um dos modelos fornece um plano de produção, que estabelece a quantidade, a sequência e o tempo que cada um dos líquidos/itens requer em cada um dos estágios e suas respectivas utilizações dos recursos, com a finalidade de atender a demanda. Os modelos consideram os requisitos de demanda determinística e dinâmica, a quantidade de recursos finita, o horizonte de tempo finito, cujos períodos discretos possuem mesmo tamanho e correspondem a um dia. A preparação dos tanques de fermentação/maturação é independente da sequência; entretanto, as preparações das linhas de envase são dependentes da sequência. Cada linha mantém um coeficiente de produção constante durante todo o horizonte de planejamento, entre outras características, a fim de proporcionar planos de produção viáveis que minimizem os custos envolvidos no processo de produção (estoque e atraso) e o número de trocas de itens em linhas de enchimento. Para os modelos propostos, considerou-se:

- contrariamente às indústrias de refrigerantes, os líquidos podem ficar dentro dos tanques enquanto esperam o início do envase. Ou seja, a sincronização presente na indústria cervejeira é diferente da indústria de refrigerantes, em que os xaropes estragam se permanecerem durante algum tempo dentro dos tanques depois de preparados. Com isso, não é mais necessária a sincronização completa entre produção de líquido pronto nos tanques e itens nas linhas de envase;

- não há custos de estoque dos líquidos dentro dos tanques devido ao curto período de tempo em que o líquido pronto permanece estocado;

- não há custos de preparação dos tanques, pois em cada troca de líquido, os tanques precisam ser limpos e o tempo consumido é conhecido previamente e independe da sequência; portanto, o tempo necessário para limpeza dos tanques estão inclusos na definição de tempo de fermentação/maturação utilizada nos modelos;

- não se considera a possibilidade dos líquidos serem filtrados e esperarem em outros tanques (buffers).

Os modelos matemáticos propostos são descritos neste capítulo, que está divido em cinco seções. As quatro primeiras descrevem as diferentes abordagens de modelagem propostas utilizando programação matemática. Na primeira seção apresenta-se um modelo mais simplificado (T1LM), onde considera-se apenas um tanque de fermentação/maturação. As demais seções trazem modelos que consideram vários tanques e várias linhas de envase (TOLM), onde a elaboração de cada um foi inspirada em modelos clássicos da literatura (GLSP, SPL e ATSP). A análise de todos os resultados obtidos pelos modelos TOLM encontra-se na última seção. Para a descrição dos modelos matemáticos, as definições de conjuntos, parâmetros e variáveis seguem abaixo.

\section{Conjuntos:}

$N$ : conjunto de itens ( $i$ e $j \in N$ );

$L$ : conjunto de líquidos $(l \in L)$;

$M$ : conjunto de linhas de envase $(m \in M)$;

$O$ : conjunto dos tanques $(o \in O)$;

$T$ : conjunto dos períodos $(t \in T)$;

$\gamma_{l}$ : conjunto de itens que utilizam $l$ em sua composição;

$\mu_{m}$ conjunto de itens que podem ser produzidos em $m$. 


\section{Parâmetros:}

$\Delta_{l}$ : quantidade de períodos que o líquido $l$ utiliza durante seu processamento (tempo de fermentação/maturação e limpeza dos tanques);

$d_{i t}$ : demanda do item $i$ no período $t$;

$h_{i}^{+}$: custo de estoque de uma unidade do item $i$ ao final do período;

$h_{i}^{-}$: custo de atraso do $i$ ao final do período $t$;

$a_{m i}$ : tempo de produção de uma unidade do item $i$ na linha de envase $m$;

$C_{m t}$ : tempo disponível da envasadora $m$ no período $t$;

$r_{l i}$ : quantidade de líquido $l$ necessária para produzir uma unidade do item $i$;

$b_{m j i}$ : tempo de preparação da envasadora $m$ ao trocar a preparação do item $j$ para $i$;

Cap ${ }_{\text {min }}^{o}$ : capacidade mínima do tanque $o$;

Cap ${ }_{\text {max }}^{o}$ : capacidade máxima do tanque $o$;

$\Omega$ : número máximo de preparações em uma envasadora durante um período;

$\alpha$ : número suficientemente pequeno;

$B$ : número suficientemente grande;

$I_{i 0}^{+}=0$ : não há estoque inicial do item $i$;

$I_{i 0}^{-}=0$ : não há atraso no início do horizonte de planejamento.

\section{Variáveis: Estágio I}

$Q_{l t}:$ quantidade total de líquido $l$ pronto no período $t$;

\section{Estágio II}

$I_{i t}^{+}$: quantidade do item $i$ em estoque no final do período $t$;

$I_{i t}^{-}$: quantidade do item $i$ em atraso no final do período $t$;

\subsection{Modelo matemático: T1LM (1 tanque e $|M|$ linhas de envase)}

Devido à complexidade do problema abordado e às diversas informações a serem consideradas simultaneamente, fizemos algumas simplificações durante a elaboração deste primeiro modelo. Considera-se apenas um tanque de fermentação/maturação e várias linhas de envase. Estas simplificações permitiram o desenvolvimento de um modelo inicial. Nas seções subsequentes, acoplam-se múltiplos tanques e uma nova representação deste problema é proposta .

Este modelo matemático considera o horizonte de planejamento dividido em dias para o estágio I (macroperíodos). Para o estágio II, cada macroperíodo foi subdividido em $S_{t}$ microperíodos, cujo tamanho de cada um é fixo. A estratégia de considerar o tamanho do microperíodo fixo foi inspirada nos problemas CSLP - The Continuous Setup Lot-Sizing Problem-Salomon (1991). A comunicação entre os estágios é importante, pois estes são modelados de maneira acoplada. Logo, a referência que fornece a ligação entre o macroperíodo $t$ (estágio I) e os seus respectivos microperíodos $s$ (estágio II) é feita por meio de $S_{t}$ (subconjunto de microperíodos $s$ que pertencem ao macroperíodo $t$ ), ou seja, para um determinado $t$, os microperíodos $s$ correspondentes estão no subconjunto $S_{t}\left(s \in S_{t}\right)$. A motivação desta divisão do horizonte 
de planejamento baseia-se na empresa que possui jornadas de trabalho de 8 horas, ocorrendo no máximo uma troca de produtos em cada uma das linhas de envase por jornada. Como este modelo considera apenas um tanque, o índice $o$ das variáveis e parâmetros que o possuem foi suprimido. Os demais parâmetros e variáveis são definidos a seguir.

\section{Conjuntos:}

$S$ : conjunto de microperíodos $(s \in S)$;

$S_{t}$ : subconjunto de microperíodos pertencentes ao macroperíodo $t\left(S=\bigcup_{t \in T} S_{t}\right)$.

\section{Parâmetros:}

$C_{m s}$ : capacidade (tempo) disponível da envasadora $m$ no microperíodo $s$;

$c_{m j i}$ : custo de troca do item $i$ para $j$ na envasadora $m$ (estipulado proporcionalmente ao tempo de troca);

\section{Variáveis:}

$Y_{l t}^{I}: 1$ se o líquido $l$, que está no tanque, está pronto período $t, 0$ caso contrário;

$O_{l t}$ : quantidade de líquido $l$ armazenada no tanque no período $t$ (independente se este está fermentando, maturando ou pronto);

$G_{l t}: 1$ se o tanque está sendo utilizado no final do período $t$ pelo líquido $l, 0$ caso contrário;

$X_{m i s}$ : quantidade produzida do item $i$, na envasadora $m$ durante o microperíodo $s$;

$Y_{m i s}^{I I}: 1$ se a linha de envase $m$ está preparada para produzir o item $i$ no microperíodo $s, 0$ caso contrário;

$Z_{m j i s}: 1$ se existe troca, na linha de envase $m$, do item $j$ para o $i$ no microperíodo $s ; 0$ caso contrário.

Observe que as variáveis $Z_{m j i s}$ podem ter o domínio definido no conjunto dos número reais $(0 \leq$ $Z_{m j i s} \leq 1$ ), por causa da função objetivo e da forma como estas foram utilizadas nas restrições $Z_{m j i s}$, conjuntamente com as variáveis $Y_{m i s}^{I I}$.

Minimizar

$$
\sum_{i \in N} \sum_{t \in T}\left(h_{i t}^{+} I_{i t}^{+}+h_{i t}^{-} I_{i t}^{-}\right)+\sum_{m \in M} \sum_{i \in N} \sum_{j \in N} \sum_{s \in S} c_{m j i} Z_{m j i s}
$$

Sujeito a:

\section{(Estágios I e II)}

$$
\begin{array}{cl}
O_{l t}=O_{l, t-1}-\sum_{m \in M} \sum_{i \in \gamma_{l}} \sum_{s \in S_{t}} r_{l i} X_{m i s}+Q_{l, t+\Delta_{l}} & l \in L ; t \in\left\{1, \ldots,|T|-\Delta_{l}\right\} \\
O_{l t}=O_{l, t-1}-\sum_{m \in M} \sum_{i \in \gamma_{l}} \sum_{s \in S_{t}} r_{l i} X_{m i s} & l \in L ; t \in\left\{|T|-\Delta_{l}+1, \ldots,|T|\right\}
\end{array}
$$


(Estágio I)

$$
\begin{array}{cl}
O_{l, t-t^{\prime}} \geq Q_{l t} & l \in L ; t \in T ; t^{\prime} \in\left\{1, \ldots, \Delta_{l}-1\right\} ;\left(t-t^{\prime} \geq 0\right) \\
\sum_{t^{\prime}=0}^{\Delta_{l}} \sum_{l \in L} Y_{l, t-t^{\prime}}^{I} \leq 1 & t \in T \\
O_{l t} \leq \operatorname{Cap}_{\max } G_{l t} & t \in T ; l \in L \\
\sum_{l \in L} G_{l, t} \leq 1 & t \in T \\
G_{l, t-1} \leq \operatorname{Cap}_{\max }\left(1-\sum_{l^{\prime} \in L} Y_{l^{\prime}, t+\Delta_{l}}^{I}\right) & t \in\left\{1 \ldots,|T|-\Delta_{l}\right\} ; l \in L \\
\operatorname{Cap}_{\min } Y_{l t}^{I} \leq Q_{l t} \leq \operatorname{Cap}_{\max } Y_{l t}^{I} & t \in T ; l \in L
\end{array}
$$

\section{(Estágio II)}

$$
\begin{array}{cl}
I_{i(t-1)}^{+}+I_{i t}^{-}+\sum_{m \in M} \sum_{s \in S_{t}} X_{m i s}=I_{i(t-1)}^{-}+I_{i t}^{+}+d_{i t} & i \in N ; t \in T \\
\sum_{i=1}^{N}\left[a_{m i} X_{m i s}+\sum_{j=1}^{N} b_{m j i} Z_{m j i s}\right] \leq C_{m s} & m \in M ; s \in S \\
X_{m i s} \leq \frac{C_{m s}}{a_{m i}} Y_{m i s}^{I I} & m \in M ; i \in N ; s \in S \\
Z_{m j i s} \geq Y_{m j(s-1)}^{I I}+Y_{m i s}^{I I}-1 & m \in M ; i \in N ; j \in N ; \\
\sum_{i=1}^{N} Y_{m i s}^{I I}=1 & s \in S \in M ; s \in S
\end{array}
$$

$$
\begin{gathered}
I_{i t}^{+} \geq 0 ; I_{i t}^{-} \geq 0 ; Q_{l t} \geq 0 ; O_{l t} \geq 0 ; X_{m i s} \geq 0 ; 0 \leq Z_{m j i s} \leq 1 \\
Y_{l t}^{I} \in\{0,1\} ; G_{l t} \in\{0,1\} ; Y_{m i s}^{I I} \in\{0,1\} \\
l \in L ; t \in T ; s \in S ; m \in M ; i \in N ; j \in N .
\end{gathered}
$$

A função objetivo (4.1) visa minimizar a soma dos custos de preparação (a cada microperíodo), de estocagem e de atraso de cada macroperíodo. As restrições de acoplamento das variáveis dos dois estágios são dadas por 4.2) e 4.3, que representam o balanço da quantidade de líquido no tanque durante o horizonte de planejamento. O tanque enche $\Delta_{l}$ macroperíodos antes do líquido ficar pronto. Quando pronto, este está disponível para o envase, logo a quantidade de líquido no tanque será igual a quantidade vinda do macroperíodo anterior subtraindo a utilizada durante o envase. As equações (4.2) garantem que o tanque só receberá líquido até o macroperíodo $|T|-\Delta_{l}$, pois depois deste, se o tanque receber líquido, ele não ficará disponível para o envase. As equações (4.3) permitem que o envase ocorra durante $|T|-\Delta_{l}+1$ a $|T|$ apenas se houver líquido no tanque.

As restrições (4.4) a (4.9) representam as decisões envolvidas durante o estágio I. As inequações (4.4) forçam a quantidade de líquido no tanque permanecer inalterada durante $\Delta_{l}-1$ macroperíodos anteriores a $t$, evitando o escoamento durante o período de fermentação e maturação; o líquido está pronto apenas em $t\left(Q_{l t}>0\right)$. As inequações 4.5 garantem que apenas um tipo de líquido ficará pronto a cada $\Delta_{l}$ 
macroperíodos, ou seja, $Y_{l t}^{I}=1$ apenas uma vez durante (no mínimo) $\Delta_{l}$ macroperíodos. Nas inequações (4.6), $G_{l t}$ terá valor não nulo enquanto o tanque estiver sendo usado ao final do macroperíodo $t$. Em 4.7), temos a garantia de que se o tanque estiver ocupado, ele ficará ocupado apenas para um líquido. As inequações (4.8) garantem que um líquido $l$ ficará pronto em $t+\Delta_{l}$ apenas se o tanque não estiver ocupado em $t-1$ para receber o mosto cervejeiro. As inequações (4.9) garantem que a quantidade de líquido que estará pronta no macroperíodo $t$ não pode ultrapassar a capacidade máxima do tanque e, também, devido aos sensores de temperatura, a quantidade de líquido não pode ser inferior a $C a p_{\min }$.

As equações e inequações, referentes as linhas de envase, foram adaptadas de Ferreira (2007) e baseiamse em algumas considerações dos modelos CSLP. Sendo assim, no estágio II, as restrições (4.10) representam as equações de balanço de estoque para cada item em cada macroperíodo. As restrições (4.11) garantem que o tempo de troca de itens e o tempo de preparação na linha de envase não ultrapassem a capacidade disponível a cada macroperíodo. As restrições (4.12) asseguram que existirá a produção do item $i$ no microperíodo $s$ apenas se as variáveis de preparação associadas foram definidas. As restrições (4.13) referem-se a troca de itens na linha; se houver troca do item $j$ para o item $i$ no microperíodo $s \in S_{t}$, a variável $Z_{j i t s}$ terá valor igual a 1 . As restrições (4.14) asseguram que cada linha de envase esteja preparada para um item a cada microperíodo. Os domínios das variáveis estão definidos pelas restrições 4.15.

Note que se quisermos impor que toda a demanda seja atendida $\left(\sum_{i=1}^{N} \sum_{t=1}^{T} d_{i t}\right)$ dentro do horizonte de planejamento, basta fixar $I_{i|T|}^{-}=0$ (i.e. $t=|T|$ ) nas restrições 4.15 dos domínios das variáveis.

\subsubsection{Testes computacionais}

O modelo T1LM foi implementado utilizando a linguagem de programação $\mathrm{C}++$, conjuntamente com a biblioteca Concert do software de otimização CPLEX (versão 12.2). Os testes computacionais foram realizados em uma máquina com processador Intel(R) Core(TM) 2 Quad e $4 \mathrm{GHz}$, cujo sistema operacional é o Windows 7. Inicialmente, este modelo foi resolvido utilizando exemplos ilustrativos menores, para verificar a consistência e adequação das soluções ótimas obtidas. Entretanto, nenhum destes é detalhado nesta seção, visto que este processo ilustrativo é apresentado para o modelo multi-tanque TOLM-GLSP que pode ser visto na Seção 4.2 .

Os testes realizados neste trabalho estão fundamentados em instâncias geradas a partir de informações coletadas da empresa portuguesa. A empresa possui 5 linhas de envase e produz 47 tipos de produtos diferentes (variando a embalagem e o líquido). No total, são 7 líquidos diferentes de cerveja pronta. O horizonte de planejamento considerado pela empresa é de 3 meses, porém detalha-se apenas as seis primeiras semanas, e a cada 15 dias há um novo (re)planejamento da produção. Mais informações podem ser encontradas na Seção 3.4 .2 .

A partir dos dados fornecidos pela indústria, foram geradas 60 instâncias para os testes computacionais e cada uma delas possui 5 itens. Estas foram agrupadas em 6 classes, contendo 10 instâncias cada (Tabela 4.1 . Classe-A1 a Classe-B3). O tamanho do horizonte de planejamento considerado é de 2 meses. A redução no tamanho do horizonte de planejamento, comparado ao utilizado na empresa, foi motivada com o intuito de reduzir o número de variáveis do problema. A construção das demais classes de exemplares estão vinculadas às Classe-A1 e Classe-B1, logo estas serão descritas primeiro.

Para a Classe-A1 e a Classe-B1 foi escolhida aleatoriamente uma entre as 5 linhas de envase da empresa; este sorteio foi repetido para cada uma das 20 instâncias. Os 5 itens sorteados de cada instância são 
produzidos pelo mesmo líquido para a Classe-A1, enquanto para a Classe-B1 são dois líquidos diferentes. A quantidade de líquido (em litros) para cada item foi definida entre os valores da coluna $r_{l i}$ da Tabela 4.1 . O tempo de processamento da máquina é proporcional ao tamanho dos itens; o custo e o tempo de trocas nas linhas de envase, dependem da embalagem, do tamanho do item anterior e da troca de líquidos. Os valores para o $\Delta_{l}$ foram estipulados com base na média do tempo de limpeza/fermentação/maturação dos líquidos pertencentes aos dados reais (Tabela 4.1). A Classe-A2 e a Classe-B2 foram geradas pela duplicação, a Classe-A3 e a Classe-B3 foram gerados a partir da triplicação, do número de linhas de envase da Classe-A1 e da Classe-B1, respectivamente.

A demanda dos itens foi gerada proporcionalmente à contribuição da respectiva máquina escolhida para o cumprimento da demanda total. A partir desta contribuição, houve uma variação de $10 \%$ (para mais e para menos) e um valor foi sorteado neste intervalo. A demanda gerada está concentrada nas três últimas semanas do horizonte de planejamento. O tanque de fermentação/maturação tem sua capacidade calculada dependendo da demanda de cada instância e a fórmula para este cálculo está na coluna $C a p_{\max }$ e $C a p_{\min }$ da Tabela 4.1. Esta tabela contém um resumo com as especificações das classes utilizadas no problema.

Tabela 4.1: Dados utilizados para a geração das classes de instâncias (modelo T1LM).

\begin{tabular}{|c|c|c|c|c|c|c|c|c|}
\hline & Qtde $^{+}$ & $|N|$ & $|M|$ & $|L|$ & $\Delta_{l}$ & $r_{l i}$ & Cap $\max$ & $\operatorname{Cap}_{\min }$ \\
\hline Classe-A1 & 10 & 5 & 1 & 1 & 15 & \multirow{3}{*}{1,$8 ; 4$} & & \multirow{6}{*}{$0,1 \times C a p_{\max }$} \\
\hline Classe-A2 & 10 & 5 & 2 & 1 & 15 & & $0,5 \times \quad \sum d_{i t}$ & \\
\hline Classe-A3 & 10 & 5 & 3 & 1 & 15 & & $i \in N, t \in T$ & \\
\hline Clacse-B1 & 10 & 5 & 1 & & & 4,$8 ; 5 ; 6 ;$ & \multirow{3}{*}{$0,9 \times \max \left\{\sum_{i \in \gamma_{1}, t \in T} d_{i t}, \sum_{i \in \gamma_{2}, t \in T} d_{i t}\right\}$} & \\
\hline $\begin{array}{l}\text { Classe-B 1 } \\
\text { Clasce_B2 }\end{array}$ & $\begin{array}{l}10 \\
10\end{array}$ & $\begin{array}{l}5 \\
5\end{array}$ & 1 & 2 & $\begin{array}{ll}10 \text { e } 15 \\
10\end{array}$ & & & \\
\hline Classe-B3 & 10 & $\begin{array}{l}5 \\
5\end{array}$ & 3 & $\begin{array}{l}2 \\
2\end{array}$ & 10 e 15 & $7,92 ; 12\}$ & & \\
\hline
\end{tabular}

\section{Resultados do modelo T1LM}

Ao tentar resolver o modelo utilizando as 6 classes de exemplos, mantendo a configuração default do solver CPLEX e limitando o tempo de execução em 3600 segundos, mais de $85 \%$ dos testes tiveram o procedimento interrompido antes do final do tempo limite por falta de memória computacional. Logo, para evitar este tipo de problema, a memória utilizada foi limitada em $3 \mathrm{~GB}$ e, assim que alcançado este limite, os experimentos paravam a sua execução, devolvendo a resposta corrente, caso houvesse encontrado uma solução factível. Outra medida adotada foi a limitação de 15 mil nós durante a construção da árvore branchand-cut do CPLEX. Estas configurações foram consideradas para todos os testes computacionais realizados.

Para cada classe de instâncias foram analisados o GAP e o tempo de resolução (em segundos). O GAP foi estimado por meio da equação 4.16 , onde $F o$ representa o valor corrente da função objetivo analisada e Best o melhor limitante encontrado para o problema, durante a resolução da instância. Devido a grande quantidade de instâncias, os resultados foram resumidos e apresentados na Tabela 4.2. Foram calculadas as médias ponderadas do GAP e do tempo de execução do modelo, sendo estes valores apresentados conjuntamente com os respectivos valores mínimo e máximo encontrados para cada classe de instâncias. Note a dificuldade de resolução encontrada pelo CPLEX quando aumenta-se o número de variáveis, ou seja, para as classes com maior número de linhas de envase e 2 líquidos (Classe-B2 e Classe-B3).

$$
G A P=\left(\frac{F o-B e s t}{F_{o}} \times 100\right) \%
$$


Para todos exemplares foi encontrada uma solução viável, entretanto, principalmente para instâncias pertencentes à Classe-A1 e à Classe-B1, ocorreu um alto índice de demanda não atendida ao final do horizonte de planejamento, com um percentual variando entre $1 \%$ e $22 \%$ (aproximadamente). Isso ocorre devido a característica comum a estas classes de exemplos, ou seja, possuem uma única envasadora, o que provoca uma demora na produção (envase) e, consequentemente, demora para liberar o tanque para receber o mosto e dar início ao processo de fermentação e maturação.

Tabela 4.2: Resumo dos resultados obtidos com a resolução do modelo T1LM utilizando os exemplos da Classe-A1 a Classe-B3 (analisando o GAP e tempo de execução).

\begin{tabular}{|c|c|c|c|c|}
\hline & \multicolumn{3}{|c|}{ T1ML } \\
\hline & & Mínimo & Média & Máximo \\
\hline \multirow{2}{*}{ Classe-A1 } & GAP & $0,1 \%$ & $3,9 \%$ & $11,0 \%$ \\
\hline & Tempo & 1942 & 2461 & 3600 \\
\hline \multirow{2}{*}{ Classe-A2 } & GAP & $1,0 \%$ & $1,7 \%$ & $5,1 \%$ \\
\hline & Tempo & 3059 & 3448 & 3600 \\
\hline \multirow{2}{*}{ Classe-A3 } & GAP & $0,0 \%$ & $52,7 \%$ & $91,0 \%$ \\
\hline & Tempo & 1587 & 3418 & 3600 \\
\hline & & \multicolumn{3}{|c|}{ T1ML } \\
\hline & & Mínimo & Média & Máximo \\
\hline \multirow{2}{*}{ Classe-B1 } & GAP & $0,9 \%$ & $1,7 \%$ & $2,8 \%$ \\
\hline & Tempo & 1727 & 2747 & 3600 \\
\hline \multirow{2}{*}{ Classe-B2 } & GAP & $0,0 \%$ & $44,2 \%$ & $71,8 \%$ \\
\hline & Tempo & 2693 & 3306 & 3600 \\
\hline \multirow{2}{*}{ Classe-B3 } & GAP & $0,2 \%$ & $51,4 \%$ & $95,3 \%$ \\
\hline & Tempo & 1915 & 2811 & 3600 \\
\hline
\end{tabular}

\subsection{Modelo matemático: TOLM-GLSP $(|O|$ tanques e $|M|$ linhas de envase utilizando abordagem GLSP)}

Após a experiência inicial com o modelo T1LM, notou-se a necessidade em diminuir o número de variáveis e, também, reavaliar a representação de algumas delas, antes de estender tal modelo para considerar um maior número de tanques. Logo, os modelos TOLM fazem uma redefinição na representação do horizonte de planejamento, assim como, também, a supressão de algumas variáveis $\left(G_{l t}, O_{l t}\right)$ e a definição de novas variáveis. Observe que $O$, a partir deste capítulo, é definido como o conjunto de tanques, não mais uma variável como no modelo T1LM.

Os modelos TOLM consideram o horizonte de planejamento composto por algumas semanas e este é dividido em períodos correspondentes a dias. Sendo assim, durante o estágio I, os períodos somam um total de $|T|$ dias. Para conseguir controlar as decisões envolvidas no estágio II, dividiu-se os $|T|$ dias em duas partes, $T_{1}$ e $T_{2}$, possuindo uma segmentação de tempo diferente para cada. Sendo assim, a cada dia $t \in T$ há uma subdivisão em um conjunto $\lambda_{t}$ de $p$ sub-períodos de tamanho flexível (veja Figura 4.1). Para cada $t \in T_{1},\left|\lambda_{t}\right|=\Omega$ e para cada $t \in T_{2},\left|\lambda_{t}\right|=1$. O número de sub-períodos por dia varia apenas na primeira parte $T_{1}$ do horizonte de planejamento, mantendo-se semelhante a divisão utilizada para os tanques na segunda parte $T_{2}\left(T=T_{1} \cup T_{2}, T_{1} \cap T_{2}=\emptyset\right)$.

Note que as 'saídas' (outputs) do estágio I são 'entradas' (inputs) de informações para do estágio II (Figura 3.2-ii). Ao final do estágio I (isto é, depois de completar o tempo de fermentação/maturação), uma quantidade $Q_{\text {olt }}$ de líquido $l$ fica pronto no tanque $o$ no período $t$. Este montante $Q_{\text {olt }}$ de líquido $l$ pronto em $t$, pode ser usado (ou parte dele) para o enchimento das embalagens nas linhas de envase, produzindo 


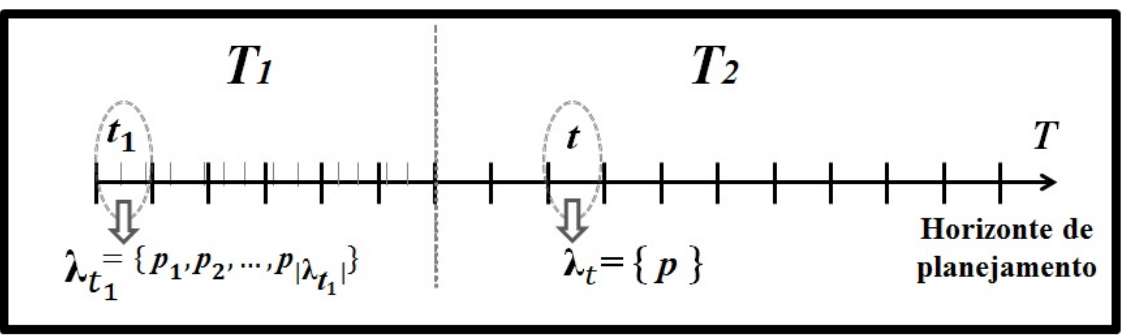

Figura 4.1: Divisão do horizonte de planejamento.

assim os itens ( $\sum_{m \in M} \sum_{i \in \gamma_{l} \cap \mu_{m}} \sum_{p \in \lambda_{t}} r_{l i} X_{\text {omip }}$ ) no mesmo período $t$; ou o líquido permanece armazenado no tanque $o\left(K_{o l t}\right)$ para a produção de itens em períodos futuros. Se algum líquido $l$ é usado para produzir itens nas linhas de enchimento, um montante equivalente $\left(X_{\text {omip }}\right)$ do item $i$ é produzido na linha $m$ no sub-período $p\left(p \in \lambda_{t}\right)$, alimentado de líquido $l$ fornecido pelo tanque $o$ (estágio II). Este montante $X_{\text {omip }}$ produzido de item $i$ (ou parte dele) é usado tanto para atender a demanda de $i$ no período $t$ ou é armazenado $\left(I_{i t}^{+}\right)$, para atender as demandas futuras deste item. Notamos que a produção nas linhas de envase (estágio II) ocorre apenas se existir líquido pronto disponível (após o final do processo de maturação, estágio I). As demais variáveis de decisão dos estágios I e II são utilizadas para controlar os demais processos $\left(Y_{o l t}^{I}, Z_{m j i p}\right.$, $Y_{\text {omip }}^{I I}$ ) ou o backlogging $\left(I_{i t}^{-}\right)$. Desta forma, o modelo coordena as decisões dos estágios I e II. A seguir, mais detalhes sobre o modelo.

\section{Variáveis:}

\section{Estágio I}

$K_{o l t}$ : quantidade (i.e., estoque) de líquido $l$ pronto e disponível no tanque $o$ no período $t$;

$Q_{o l t}$ : quantidade total de líquido $l$ que fica pronto no tanque $o$ no período $t$;

$Y_{o l t}^{I}: 1$, se o líquido $l$ fica pronto no período $t$ no tanque $o ; 0$ caso contrário.

Ambos os estágios

$X_{\text {omip }}$ : montante de item $i$ produzido na envasadora $m$ no período $p$, abastecido pelo líquido do tanque $o$;

Minimize

$$
\sum_{i \in N} \sum_{t \in T} h_{i}^{+} I_{i t}^{+}+\sum_{i \in N} \sum_{t \in T} h_{i}^{-} I_{i t}^{-}+\sum_{m \in M} \sum_{j, i \in \mu_{m}} \sum_{p \in \lambda_{t} \mid t \in T_{1}} \alpha Z_{m j i p}
$$

Subject to:

(Estágios I e II)

$$
K_{o l t}=K_{o l, t-1}-\sum_{m \in M} \sum_{i \in \gamma_{l} \cap \mu_{m}} \sum_{p \in \lambda_{t}} r_{l i} X_{o m i p}+Q_{o l t} \quad o \in O ; l \in L ; t \in T
$$




\section{(Estágio I)}

$$
\begin{array}{cl}
\sum_{l^{\prime}=1}^{L} \sum_{t^{\prime}=1}^{\Delta_{l}+1} K_{o l^{\prime}, t-t^{\prime}} \leq B\left(1-Y_{o l t}^{I}\right) & o \in O ; l \in L ; t \in T \\
\sum_{l \in L} \sum_{t^{\prime}=0}^{\Delta_{l}} Y_{o l, t-t^{\prime}}^{I} \leq 1 & o \in O ; t \in T \\
\text {Cap }_{\text {min }}^{o} Y_{\text {olt }}^{I} \leq Q_{\text {olt }} \leq \operatorname{Cap}_{\text {max }}^{o} Y_{\text {olt }}^{I} & o \in O ; l \in L ; t \in T
\end{array}
$$

\section{(Estágio II)}

$$
\begin{aligned}
& \sum_{o \in O} \sum_{\substack{m \in M \\
i \in \mu_{m}}} \sum_{p \in \lambda_{t}} X_{o m i p}+I_{i, t-1}^{+}+I_{i t}^{-}=d_{i t}+I_{i, t-1}^{-}+I_{i t}^{+} \quad t \in T ; i \in N \\
& \sum_{o \in O} \sum_{i \in \mu_{m}} \sum_{p \in \lambda_{t}} a_{m i} X_{o m i p}+\sum_{j \in \mu_{m}} \sum_{i \in \mu_{m}} \sum_{p \in \lambda_{t} \mid t \in T_{1}} b_{m j i} Z_{m j i p} \leq C_{m t} \quad t \in T ; m \in M \\
& \begin{array}{rl}
X_{\text {omip }} \leq \frac{C_{m t}}{a_{m i}} Y_{\text {omip }}^{I I} & o \in O ; m \in M ; i \in \mu_{m} ; \\
& p \in \lambda_{t} ; t \in T
\end{array} \\
& \sum_{o \in O} \sum_{i \in \mu_{m}} Y_{o m i p}^{I I}=1 \quad m \in M ; p \in \lambda_{t} ; \\
& t \in T_{1} \\
& \sum_{o \in O} \sum_{i \in \mu_{m}} Y_{o m i p}^{I I} \leq \Omega \\
& m \in M ; p \in \lambda_{t} \\
& t \in T_{2} \\
& \sum_{o \in O} Y_{o m j, p-1}^{I I}=\sum_{i \in \mu_{m}} Z_{m j i p} \\
& m \in M ; j \in \mu_{m} ; \\
& p \in \lambda_{t} ; t \in T_{1} \\
& \sum_{o \in O} Y_{o m i p}^{I I}=\sum_{j \in \mu_{m}} Z_{m j i p} \\
& m \in M ; i \in \mu_{m} \\
& p \in \lambda_{t} ; t \in T_{1} \\
& X_{\text {omip }} \geq 0 ; K_{\text {olt }} \geq 0 ; Q_{\text {olt }} \geq 0 ; Y_{\text {olt }}^{I} \in\{0,1\} ; \quad i, j \in N ; o \in O ; l \in L ; \\
& I_{i t}^{+} \geq 0 ; I_{i t}^{-} \geq 0 ; Y_{\text {omip }}^{I I} \in\{0,1\} ; 0 \leq Z_{\text {mjip }} \leq 1 \quad m \in M ; p \in \lambda_{t} ; t \in T
\end{aligned}
$$


A função objetivo (4.17) visa minimizar a soma dos custos de estoque de produto final, de atraso na entrega da demanda e um termo proporcional $(\alpha)$ ao número de trocas de itens nas linhas de envase, evitando trocas desnecessárias nas linhas de envase. As restrições (4.18), representam as equações de equilíbrio da quantidade de líquido pronto disponível nos tanques; estas integram os estágios I e II. A demanda de líquido $l$ para cada tanque $o$ no período $t$ provém da quantidade de produção de itens $\left(\sum_{m \in M} \sum_{i \in \gamma_{l} \cap \mu_{m}} \sum_{p \in \lambda_{t}} r_{l i} X_{o m i p}\right.$ ). Quando há líquido pronto no período $t\left(Q_{o l t}>0\right), K_{o l, t-1}=0$, pois não há líquido pronto no período anterior. As restrições 4.19) garantem que, para ter líquido pronto em $t\left(Y_{\text {olt }}=1\right)$, o processo de fermentação/maturação ocorre durante os $\Delta_{l}$ períodos imediatamente anteriores a $t$ e, durante este período, o líquido não está disponível. O tanque deve estar vazio antes de começar o processo de fermentação/maturação no período $t-\left(\Delta_{l}+1\right)$. As restrições (4.20) asseguram que, durante todo o período do processo de fermentação/maturação o tanque não tem líquido disponível, ou seja, $Y_{\text {olt }}^{I}$ é igual a zero, veja Figura 4.2. Finalizando o estágio I, as restrições (4.21) garantem que a quantidade de líquido pronto respeite os limites inferiores e superiores para cada tanque.

Note que, assim como no modelo T1LM, se quisermos impor que toda a demanda seja atendida $\left(\sum_{i=1}^{N} \sum_{t=1}^{T} d_{i t}\right)$ dentro do horizonte de planejamento, basta fixar $I_{i|T|}^{-}=0$ (i.e. $t=|T|$ ) nas restrições 4.15 dos domínios das variáveis.

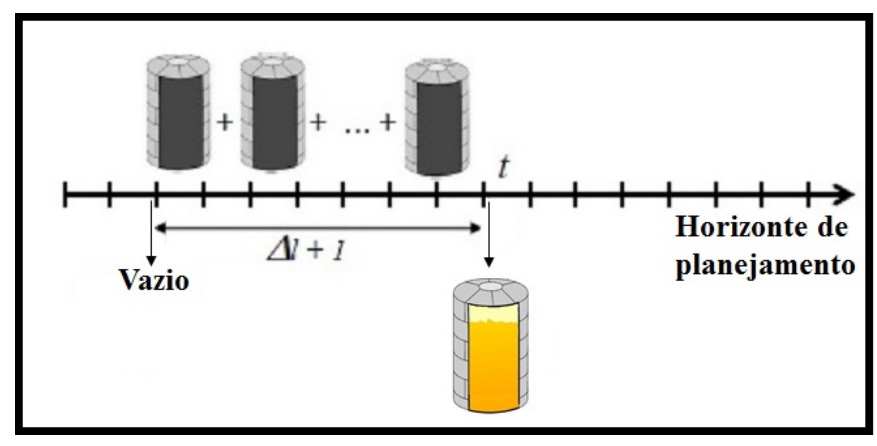

Figura 4.2: Tanque vazio ao receber um novo líquido e começar o período de fermentação/maturação $\left(K_{o l t}=0\right)$, estando pronto e disponível após $\Delta_{l}+1$ dias.

No estágio II (linhas de envase), as restrições (4.22) asseguram o equilíbrio do estoque, atraso, produção e a demanda. As restrições (4.23) garantem que a capacidade das linhas de enchimento sejam respeitadas durante $T_{1}$ e $T_{2}$, respectivamente. Durante $T_{1}$, o tempo de preparação contribui para o consumo da capacidade, o que não ocorre em $T_{2}$ (ver Figura 4.3). As restrições 4.24), garantem que a produção de $i$ ocorre apenas se a linha de envase estiver preparada para produzi-lo. De acordo com as restrições (4.25), cada linha de envase deve estar preparada para um único item para cada subperíodo $p \in \lambda_{t}, t \in T_{1}$. As restrições 4.26 limitam o número de preparações de cada linha de enchimento em $\Omega$ a cada subperíodo $p \in \lambda_{t}, t \in T_{2}$. Lembre-se que na segunda parte do horizonte $\left(T_{2}\right)$ o tamanho de cada subperíodo é maior do que em $T_{1}$, e decisões de sequenciação não são consideradas, mas vários lotes (até $\Omega$ ) podem ser produzidos na mesma linha de enchimento por subperíodo. Finalmente, as restrições 4.27) e 4.28) captam a transição de itens nas linhas de enchimento em $T_{1}$. Além disso, as restrições 4.29 definem o domínio das variáveis. Se quisermos impor que toda demanda deve ser satisfeita dentro do horizonte de planejamento, basta fixar $I_{i|T|}^{-}=0$, i.e., $t=|T|$. Ainda, deve-se observar que, no caso $\Delta_{l}=0$ para todos os $l \in L$, o 
modelo representa uma situação fictícia, onde a preparação dos líquidos ocorre no mesmo período em que os líquidos ficam prontos para o envase.

Em Ferreira (2007), ao invés das restrições (4.27) e (4.28), utilizaram-se as restrições $Z_{m j i p} \geq Y_{o m j(p-1)}+$ $Y_{\text {omip }}-1\left(o \in O, m \in M, j \in N, i \in N, p \in \lambda_{t}, t \in T\right)$. No entanto, essas expressões não são usadas neste modelo, pois em Wolsey (1997) os autores consideram estas restrições (4.27) e (4.28) menos fortes.

Para um melhor entendimento das restrições presentes no modelo TOLM-GLSP, a Seção 4.2 .1 traz um exemplo numérico ilustrativo, de pequena dimensão, que utiliza dados fictícios.

\subsubsection{Exemplo numérico: modelo TOLM-GSLP}

Para facilitar o entendimento das restrições do modelo, o gráfico de Gantt da Figura 4.3 ilustra as principais decisões presentes nos dois estágios do processo de produção ao longo do horizonte de planejamento, ou seja, as variáveis $Q_{o l t}, K_{\text {olt }}$ e $X_{o m i p}$. Uma instância pequena, com dois tanques de capacidade máxima $C a p_{\max }=10000$ cada, duas linhas de envase e três itens foi resolvida utilizando o modelo TOLM-GLSP até a otimalidade. Os tanques estão representados na parte superior, enquanto que as linhas na parte inferior da figura. O exemplo numérico foi resolvido por um solver comercial (CPLEX 12.4) em 100 segundos. O horizonte de planejamento $|T|=12$, e os primeiros três períodos são descritos detalhadamente $\left(\left|T_{1}\right|\right.$ = 3) para o processo de enchimento. O exemplo considera dois diferentes líquidos para produzir os três itens. Dois itens são feitos de 'líquido $1^{\prime}$ ( $\left(\Delta_{1}=1\right.$ para a fermentação/maturação, $r_{11}=5$ e $\left.r_{13}=7\right)$ e 'líquido 2' produz apenas um item $\left(\Delta_{2}=2\right.$ tempo de fermentação e maturação, $\left.r_{22}=4\right)$. Um resumo das características do exemplo teste pode ser visto na Tabela 4.3 .

Observe na Figura 4.3, que em $t=1$ a produção do item $i=3$ ocorre na linha $m=1$ e do item $i=1$ em $m=2$. Ambas as linhas recebem líquido pronto do tanque $o=1\left(Q_{111}=9.791\right)$. Em $t=2$, na envasadora $m=1$, há uma troca do item $i=3$ para $i=2$, utilizando parte do líquido pronto do tanque $o=2(2664)$ para produzir o último item. Consequentemente, o tanque contém $K_{223}=6.936$ de líquido pronto no período subsequente. Neste mesmo período, o tanque de $o=1$ está fermentando/maturando o líquido $l=1$, que fica pronto em $t=3$. A mesma análise é feita para os tanques durante os outros períodos. Relembre que a partir de $t=4$ até o final do horizonte de planejamento (isto é, durante $T_{2}$ ), os lotes não são sequenciados nas linhas (apesar da figura poder induzir o leitor a isso). Por exemplo, observe que em $t=4$, existe uma troca de itens, mas não há nenhum tempo de preparação.

Tabela 4.3: Dados referente ao exemplo numérico utilizado para a explicação de TOLM-GLSP.

\begin{tabular}{|r|c|l|}
\hline Itens $(\boldsymbol{N})$ & 3 & $(h=[0,02939,0,01600,0,03100])$ \\
Líquidos $(\boldsymbol{L})$ & 2 & $(\Delta=[1,2])$ \\
Períodos $(\boldsymbol{T})$ & 12 & $\left(\left|T_{1}\right|=3\right)$ \\
Máquinas $(\boldsymbol{M})$ & 2 & $(C=[500,500])$ \\
Tanques $(\boldsymbol{O})$ & 2 & $($ Cap $\operatorname{Cax}=[10000,10000])$ \\
\hline
\end{tabular}




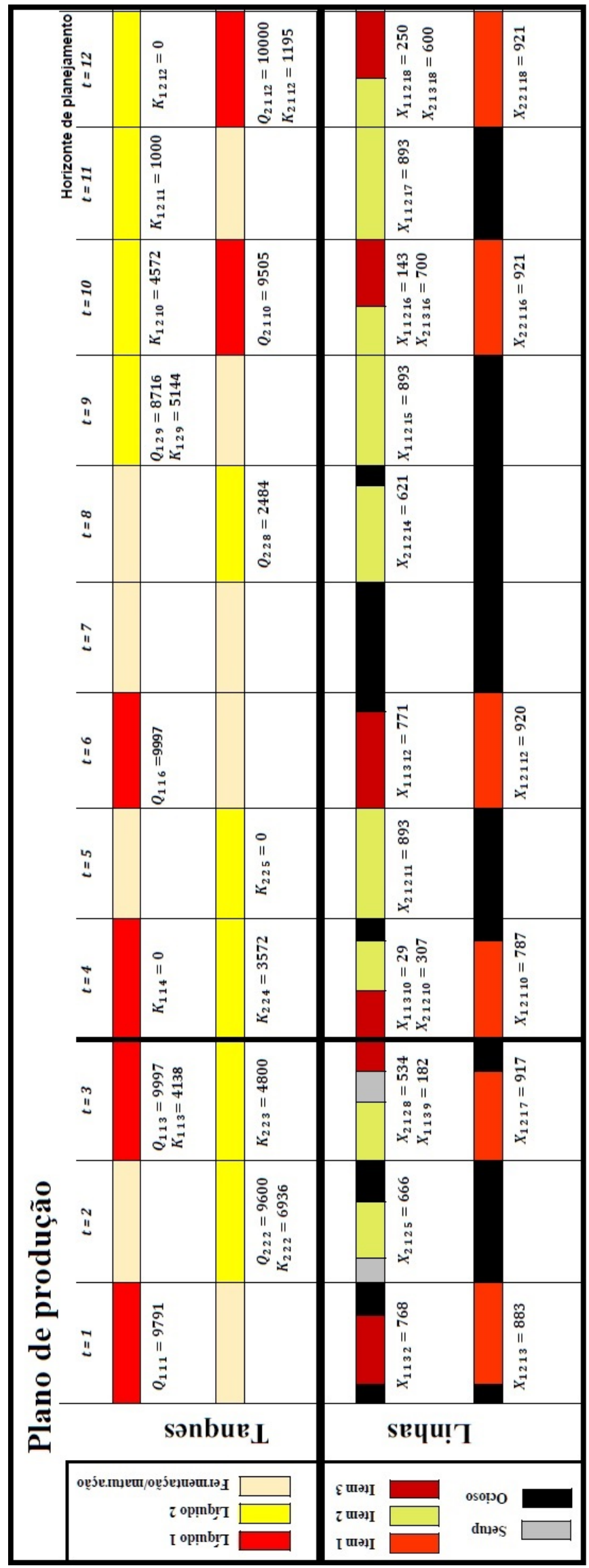

Figura 4.3: Ilustração de plano de produção de uma cervejaria, utilizando dados fictícios. 
Com o intuito de entender o quão o tempo de fermentação e maturação influencia e dificulta as decisões a serem tomadas durante a elaboração do plano de produção, testes computacionais foram realizados. Um exemplo fictício foi gerado, e os dados foram mantidos para geração de novas instâncias, exceto o tempo de fermentação e maturação. Esta análise foi realizada apenas para o primeiro modelo TOLM proposto, mas as mesmas conclusões poderiam ter sido obtidas utilizando-se qualquer um dos outros modelos TOLM propostos neste capítulo, apresentados posteriormente.

\subsubsection{Influência do tempo de fermentação e maturação}

Em geral, o estágio de preparação dos líquidos na indústria de bebidas (por exemplo, água natural e gaseificada, refrigerante, ... , suco) leva alguns minutos ou, no máximo, algumas horas. Na indústria cervejeira, o período de fermentação e maturação (estágio I) é lento. Esta característica influencia diretamente o plano de produção, até mesmo o envase (estágio II), pois este só pode começar depois que o líquido estiver pronto. O líquido pronto pode permanecer durante algum tempo nos tanques antes de ser envasado. Este fato não ocorre nas indústrias de bebidas, em que não existe a possibilidade de estocar o líquido, pois este tem de ser envasado imediatamente após a obtenção do preparo do líquido.

Para ilustrar a influência da duração da fermentação e da maturação $\left(\Delta_{l}\right)$, o modelo TOLM-GLSP foi resolvido utilizando um solver comercial (CPLEX 12.4), e um conjunto de sete instâncias artificiais com as mesmas características da utilizada na Seção 4.2.1 (veja Tabela 4.3). Os exemplos foram gerados utilizando os mesmos dados, entretanto o número de tanques considerado agora é oito, com capacidade menor que a considerada anteriormente (três tanques com capacidade máxima de 3000 e 1000 para os demais), veja a Tabela 4.4. O tempo de fermentação/maturação varia para cada uma das instâncias, de forma que a nova combinação de tempos $\left(\Delta_{1}\right.$ e $\left.\Delta_{2}\right)$ é dada: $(0,0),(0,2),(2,0),(2,2),(2,3),(2,4),(2,6),(2,7)$ e $(2,8)$, estas são apresentadas na parte inferior da Figura 4.4. O limite de tempo de execução considerado foi de uma hora. Os resultados destes testes são mostrados na Figura 4.4, em que o eixo 'x' representa as instâncias. Em 4.4-I, o gráfico mostra o GAP no eixo 'y', calculado pela equação 4.16 em \%. Na Figura 4.4, o tempo de execução é reportado (só difere de 3600 segundos nos casos em que o CPLEX provou a otimalidade antes do limite de tempo ser atingido). A Figura 4.4 II, apresenta a contribuição percentual dos custos presentes na função objetivo: estoque e atraso.

Analisando os resultados apresentados na Figura 4.4 I, apenas os casos com $\left(\Delta_{1}, \Delta_{2}\right)$ iguais a $(0,0)$ e $(0,2)$, respectivamente, foram resolvidos até a otimalidade dentro do limite de tempo. Observe também o gradual aumento do GAP quando $\Delta_{l}$ aumenta. A dificuldade de resolver os últimos exemplos da Figura 4.4 é notável. Naturalmente, com o aumento do tempo de fermentação/maturação, a flexibilidade do processo de produção diminui, provocando um impacto no atendimento da demanda, como mostrado no caso $(2,4)$. $\mathrm{O}$ atraso começa para as instâncias $(2,6)$ em diante, também com uma tendência positiva com o aumento de $\Delta_{l}=1$ (veja Figura 4.4-II).

Quando $\Delta_{l}=0$ para cada líquido, a solução ideal é encontrada em alguns segundos. Entretanto, mesmo as cervejas com os menores tempos de fermentação e maturação levam três dias para conclusão do estágio I (por exemplo, algumas cervejas sem álcool). O caso $\Delta_{l}=0$ (ou até $\Delta_{l}=1$ ) assemelhase à indústria de bebidas não alcoólicas (refrigerantes, água gaseificada, sucos, etc), onde a preparação e enchimento de líquidos ocorre dentro de 24 horas; porém, mesmo neste caso, o modelo não representa o problema desta indústria devido a possibilidade de armazenar líquido pronto no interior dos tanques de fermentação/maturação. 
Tabela 4.4: Dados utilizados para a geração de instâncias teste durante explicação da influência do tempo de fermentação e maturação.

\begin{tabular}{|c|c|c|c|}
\hline & Itens $(N)$ & 3 & $(h=[0,02939,0,01600,0,03100])$ \\
\hline \multirow{4}{*}{ (a) } & Líquidos $(L)$ & 2 & $(\Delta=[1,2])$ \\
\hline & Períodos $(T)$ & 12 & $\left(\left|T_{1}\right|=3\right)$ \\
\hline & Máquinas $(M)$ & 2 & $(C=[500,500])$ \\
\hline & Tanques $(O)$ & 8 & $\left(\operatorname{Cap}_{\max }=[3000,3000,3000,1000,1000,1000,1000,1000]\right)$ \\
\hline
\end{tabular}

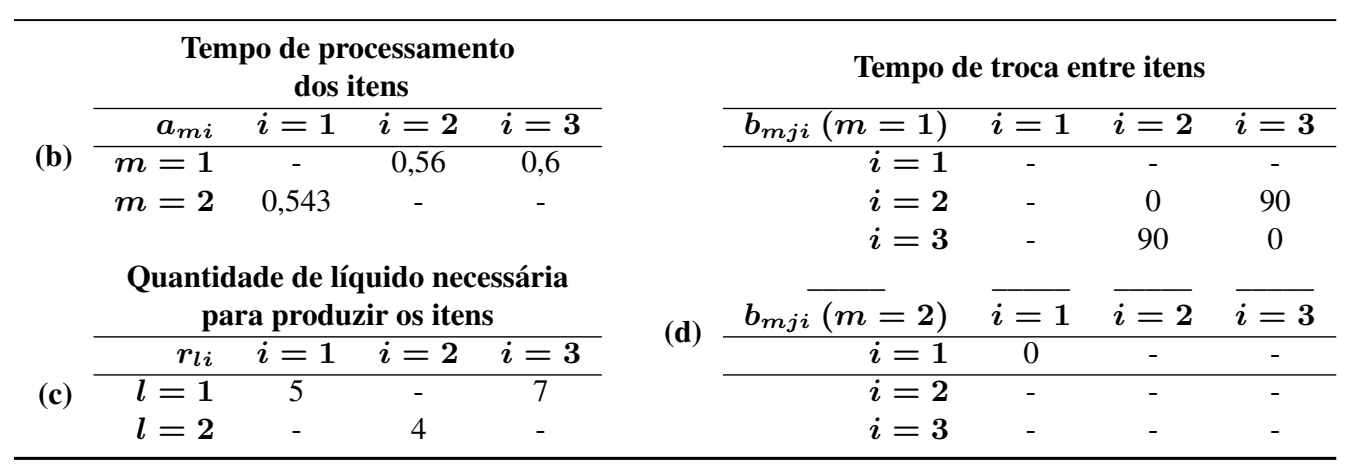
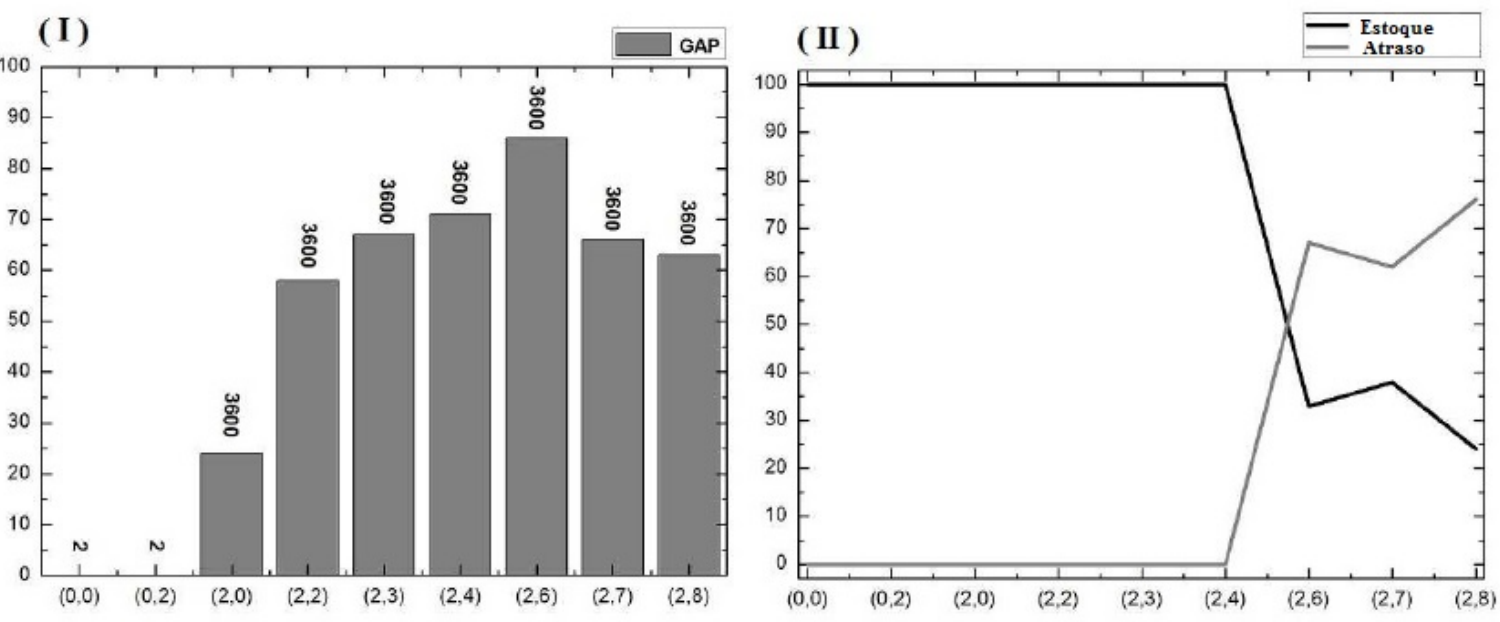

Figura 4.4: Influência do tempo de fermentação e maturação, analisando: (I) o GAP (veja a equação (4.16)); (II) o percentual de contribuição para a função objetivo do custo de estoque e do atraso.

Para uma análise mais detalhada do modelo TOLM-GSLP, assim como para os demais modelos e métodos de resolução do problema, apresentados nesta tese, precisa-se de exemplares de teste que representem situações semelhantes as encontradas nas indústrias cervejeiras. Sendo assim, as informações coletadas nas cervejarias visitadas foram analisadas e, a partir delas, elaborou-se um gerador de dados aleatórios que mantivesse características e dificuldades similares as das empresas. Este gerador de dados é descrito na seção seguinte.

\subsubsection{Gerador de dados}

O gerador de dados foi implementado baseado em dados reais, cujo Algoritmo 1 pode ser configurado utilizando dados de qualquer indústria cervejeira. Para os testes computacionais realizados neste traba- 
lho, dados de uma empresa cervejeira portuguesa foram utilizados. Porém, para proteger interesses dessa empresa, estes não puderam ser explicitamente divulgados. Sendo assim, o gerador de dados foi desenvolvido com o intuito de gerar problemas com parâmetros semelhantes aos da empresa, como, também, subproblemas menores coerente às informações da realidade, sendo as instâncias representativas quanto a complexidade real presente na empresa.

Para o gerador, algumas adaptações foram necessárias quando utilizamos os dados da empresa. A empresa forneceu a quantidade de demanda de cada item durante uma semana do horizonte de planejamento, logo, para gerarmos uma maior variabilidade de instâncias, estas demandas tiveram um coeficiente de variação de até $10 \%$. Além do mais, quando geramos os dados de maneira aleatória, não podemos permanecer com esta demanda total, se não forem utilizadas todas as envasadoras. Visto que diversas máquinas contribuem na produção de um determinado item e nem todas podem estar presentes na instância gerada, lembrando que cada máquina possui capacidade diária finita, foram feitas adaptações à demanda. Para o cálculo da demanda de cada item, a primeira informação necessária é qual a contribuição, em termos percentual, de cada máquina para satisfazer a demanda total de cada item. Esta informação foi estabelecida por meio da velocidade de produção. Ao encontrarmos tal valor, calculamos proporcionalmente a demanda do item, de acordo com a quantidade de máquinas sorteadas.

Para exemplificar o raciocínio anterior, considere a Tabela 4.5, onde as máquinas foram nomeadas na primeira linha da tabela e os itens na primeira coluna. A intersecção entre itens e máquinas fornece as informações relativas ao tempo de processamento deste respectivo item na referida máquina e, também, qual o percentual de contribuição na produção, calculado por meio da soma total da velocidade de produção de todas as máquinas para o determinado item. Este valor é o divisor e o dividendo é a velocidade de cada uma das máquinas analisadas para este item. O resultado é a relação de contribuição da máquina para a produção. Utilizando a Tabela 4.5 , o divisor do item I1 é '0,84' (a soma total do tempo), de I2 é ' 1,35 ', de I3 é ' 0,60 ' e de I4 é ' 1,59 '. A contribuição da 'Máquina A' na produção do item I1 é de $32 \%\left(\frac{0,27}{0,84}\right)$, da Máquina $\mathrm{B}$ é de $34 \%\left(\frac{0,29}{0,84}\right)$, da Máquina C é de $0 \%$ (esta máquina não produz o item I1) e assim sucessivamente.

Tabela 4.5: Exemplo de como estabelecer a relação de contribuição de produção de cada máquina.

\begin{tabular}{|c|cc|cc|cc|cc|cc|}
\hline- & \multicolumn{2}{|c|}{ Máquina A } & \multicolumn{2}{c|}{ Máquina B } & \multicolumn{2}{c|}{ Máquina C } & \multicolumn{2}{c|}{ Máquina D } & \multicolumn{2}{c|}{ Máquina E } \\
\hline Item & Tempo & Percentual & Tempo & Percentual & Tempo & Percentual & Tempo & Percentual & Tempo & Percentual \\
\hline I1 & 0.27 & $32 \%$ & 0.29 & $34 \%$ & - & $0 \%$ & 0.28 & $33 \%$ & - & $0 \%$ \\
I2 & 0.29 & $21 \%$ & - & $0 \%$ & 0.28 & $21 \%$ & 0.39 & $29 \%$ & 0.39 & $29 \%$ \\
I3 & 0.32 & $53 \%$ & - & $0 \%$ & - & $0 \%$ & 0.28 & $47 \%$ & - & $0 \%$ \\
I4 & 0.34 & $21 \%$ & 0.28 & $18 \%$ & 0.27 & $17 \%$ & 0.38 & $24 \%$ & 0.32 & $20 \%$ \\
\hline
\end{tabular}

Suponhamos que a nossa instância a ser gerada considera apenas duas envasadoras $(|M|=2)$ e dois itens $(|N|=2)$; sendo que as envasadoras escolhidas aleatoriamente são as máquinas 'A' e 'E', sorteadas dentre as máquinas 'A', 'B', 'C', 'D' e 'E'. Logo, os itens que podem ser sorteados para compor $|N|=2$ são: 'I1', 'I2', 'I3' e 'I4' (observe que todos os itens são possíveis, pois a máquina 'A' pode produzí-los, a Máquina ' $E$ ' pode produzir apenas os itens 'I2' e 'I4'). Realiza-se um sorteio, o qual os itens 'I2' e 'I4' foram escolhidos (o gerador de dados foi implementado de forma que cada máquina deve produzir ao menos um item). Logo, a demanda dos itens 'I2' e 'I4' é calculada seguindo a fórmula 4.30, sendo $d_{i t}^{\text {empresa }}$, o valor da demanda para o respectivo item fornecido pela empresa, $\pm[0,10] \%$ a variabilidade da demanda $\mathrm{e}$ Cont é a contribuição das envasadoras para a produção do respectivo item; ou seja, quando $i=$ 'I2' o valor de $C o n t=32 \%$ e quando $i=$ 'I 4 ' o valor de $C o n t=41 \%$ (resultado da soma: $21 \%+20 \%$ ). 


$$
d_{i t}=d_{i t}^{\text {empresa }} \times( \pm[0,10] \%) \times C o n t ; \forall t \in T
$$

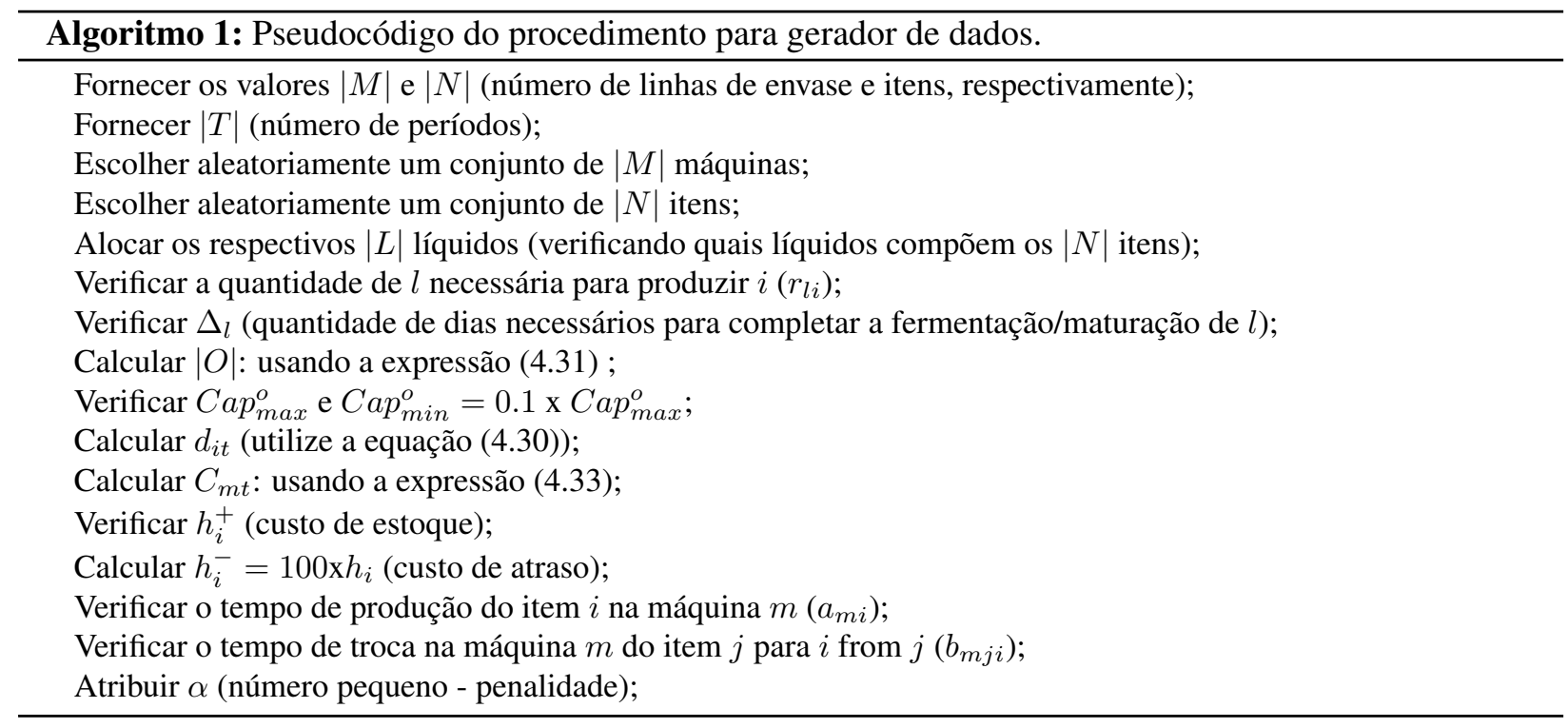

O número de tanques $(|O|)$ e a capacidade das linhas de enchimento $\left(C_{m t}\right)$ foram gerados de acordo com a necessidade e características de cada instância. O número de tanques é dado pela expressão (4.31), dividindo-se a quantidade em $75 \%$ dos tanques que tem uma capacidade $C a p_{\text {max }_{1}}^{o}=100000$, e $25 \%$ $C a p_{\text {max }}^{o}=300000$; assim como comentado na Seção 3.4.2. O valor $E_{l}$ é definido na expressão 4.32 e refere-se ao número de tanques necessário para satisfazer a demanda para cada líquido. A capacidade das linhas é calculada a partir de expressão 4.33 , que leva em conta os tempos de preparação, juntamente com a produção dos itens a serem produzidos pela linha. O tempo mínimo considerado para as linhas a serem ligadas é de 60 minutos.

$$
\begin{aligned}
& |O|=\left\lceil\frac{\sum_{l \in L} \sum_{i \in \gamma_{l}} \sum_{t \in T} d_{i t} r_{l i}}{\left(0,75 \text { Cap }_{\text {max }}^{o}+0,25 \operatorname{Cap}_{\text {max }_{2}}^{o}\right) \sum_{l \in L} E_{l}}\right\rceil \\
& E_{l}=\left\lceil\frac{T}{\Delta_{l}+1}\right\rceil, \forall l \in L \\
& C_{m t}=\max \left\{60 \text { minutes, }\left[\sum_{l \in L}\left[\frac{\sum_{t \in T} \sum_{i \in \mu_{m}}\left(a_{m i} d_{i t}+\max _{\forall j \in \mu_{m}}\left\{b_{m j i}\right\}\right)}{|T|}\right]\right]\right\}, \forall m \in M \text { and } \forall t \in T
\end{aligned}
$$

O gerador de dados descrito foi utilizado de forma a criar várias instâncias teste que são utilizadas para análise dos modelos e, também, das (meta)heurísticas apresentadas nos próximos capítulos. Estes exemplares testes têm suas características descritas na Seção 4.2.4 


\subsubsection{Características das instâncias de teste}

Geramos as instâncias utilizando o Algorimo 1, para tal fornecemos a quantidade de máquinas (utilizamos $|M| \in\{1,2,4,5\}$ ), a quantidade de itens produzidos (utilizamos $|N| \in\{5,10,15,20,35,40\}$ ) e a quantidade de períodos durante o horizonte de planejamento (utilizamos $|T|=42$, correspondente a 6 semanas, assim como na indústria em questão).

Assim, as seguintes configurações foram utilizadas para a geração das instâncias: para $|M|=1$ tem-se $|N| \in\{5\}$, para $|M|=2$ tem-se $|N| \in\{5,10\}$, para $|M|=4$ tem-se $|N| \in\{5,10,15,20\}$ (somando 7 instâncias utilizadas para os testes preliminares) e para para $|M|=5$ tem-se $|N| \in\{35,40\}$, sendo este último grupo formado por 20 instâncias diferentes, ou seja, 10 para cada combinação. Todas as $|M|$ máquinas juntas devem ser capazes de produzir os $|N|$ itens, com a ressalva de que um item necessariamente precisa ser produzido por pelo menos uma das máquinas.

Tabela 4.6: Características das instâncias geradas.

\begin{tabular}{|rrrrrr|}
\hline Instância & $|N|$ & $|L|$ & $|M|$ & $|O|$ & $|T|$ \\
\hline P_1_5_1 & 5 & 2 & 1 & 7 & 42 \\
P_2_5_1 & 5 & 3 & 2 & 7 & 42 \\
P_2_10_1 & 10 & 4 & 2 & 18 & 42 \\
P_4_5_1 & 5 & 3 & 4 & 7 & 42 \\
P_4_10_1 & 10 & 3 & 4 & 22 & 42 \\
P_4_15_1 & 15 & 5 & 4 & 27 & 42 \\
P_4_20_1 & 20 & 4 & 4 & 21 & 42 \\
& & & & & \\
D_5_35_1 & 35 & 7 & 5 & 37 & 42 \\
D_5_35_2 & 35 & 7 & 5 & 36 & 42 \\
D_5_35_3 & 35 & 7 & 5 & 46 & 42 \\
D_5_35_4 & 35 & 7 & 5 & 55 & 42 \\
D_5_35_5 & 35 & 6 & 5 & 51 & 42 \\
D_5_35_6 & 35 & 7 & 5 & 37 & 42 \\
D_5_35_7 & 35 & 7 & 5 & 47 & 42 \\
D_5_35_8 & 35 & 5 & 5 & 48 & 42 \\
D_5_35_9 & 35 & 7 & 5 & 51 & 42 \\
D_5_35_10 & 35 & 6 & 5 & 51 & 42 \\
D_5_40_1 & 40 & 7 & 5 & 57 & 42 \\
D_5_40_2 & 40 & 7 & 5 & 54 & 42 \\
D_5_40_3 & 40 & 7 & 5 & 53 & 42 \\
D_5_40_4 & 40 & 6 & 5 & 54 & 42 \\
D_5_40_5 & 40 & 6 & 5 & 58 & 42 \\
D_5_40_6 & 40 & 7 & 5 & 56 & 42 \\
D_5_40_7 & 40 & 7 & 5 & 53 & 42 \\
D_5_40_8 & 40 & 7 & 5 & 59 & 42 \\
D_5_40_9 & 40 & 7 & 5 & 53 & 42 \\
D_5_40_10 & 40 & 7 & 5 & 51 & 42 \\
\hline & & & & &
\end{tabular}

Para cada instância, os primeiros 7 dias foram discretizados em três subperíodos (para cada dia), ou seja, $\left|T_{1}=7\right| \mathrm{e}\left|\lambda_{t}\right|=3, \forall t \in T_{1}$. A seguir tem-se o intervalo dos conjuntos de dados gerados em nossos testes. A quantidade de líquidos $|L|$ para produzir uma unidade de produto $i\left(r_{l i}\right)$ varia entre $\{1,98,4,00,4,80$, $5,00,6,00,6,00,6,60,7,92,12,00,17,82,20,00,30,00,50,00$ \}. A demanda semanal está no intervalo $[60,256710]$ (demanda expressa em unidades). Os custos de estoque estão no intervalo $[0,009,0,35]$. Os tempos de processamento nas linhas de enchimento estão no intervalo $[0,018,9,6]$. Cada produto é feito a partir de um líquido com os tempos de fermentação/maturação variando entre $\{5,10,13,15,16,17,21\}$. As linhas de enchimento são capazes de produzir todos os itens. As diferentes características de cada item 
definiram os tempos de setup. Quanto maior for a diferença entre os itens, então maior é o valor do tempo de preparação entre os mesmos. Os valores variam entre $\{30,40$, 45, 60, 75 , 90, 100, $120,150,160,165$, $180,195,210,240,260,300,380,480\}$ (minutos).

\subsubsection{Testes computacionais utilizando o modelo TOLM-GLSP}

O modelo TOLM-GLSP foi implementado utilizando a linguagem de programação $\mathrm{C}++$, conjuntamente com a biblioteca Concert do software de otimização CPLEX (versão 12.4). Os testes computacionais foram realizados em uma máquina com processador Intel(R) i7 2600 (quatro núcleos, 2 threads cada) de $3.4 \mathrm{GHz}$, 16GB de memória RAM e o sistema operacional utilizado foi o Windows 7. Entretanto, para resolver cada instância, limitou-se a utilização em 4 threads.

A Tabela 4.7 apresenta os resultados obtidos por meio da resolução do modelo TOLM-GLSP, utilizando as instâncias cujas características encontram-se descritas na Seção 4.2.4. Para a leitura e interpretação da Tabela 4.7 deve-se começar pela primeira coluna, onde cada linha da tabela representa os resultados da respectiva instância discriminada nesta coluna. A segunda, terceira e quarta colunas trazem o número de linhas (' $\mathrm{N}^{0}$ de linhas', equivalente ao número de restrições após o pré-processamento), número de colunas (' $\mathrm{N}^{\mathrm{o}}$ de colunas', equivalente ao número de variáveis após o pré-processamento) e o número de nós (' $\mathrm{N}^{\mathrm{o}}$ de nós') da árvore Branch-and-cut, na resolução do modelo pelo CPLEX. Note que os números de variáveis e restrições chegam a ordem de centenas de milhares, à medida que o tamanho das instâncias cresce. As colunas 'Fo - LP' e 'Tempo - LP' apresentam os valores da função objetivo do problema relaxado e os tempos de execução (em segundos) para encontrá-las, respectivamente. Nas colunas 'FO-MIP' e 'Tempo - MIP' encontram-se os valores da função objetivo do MIP e o tempo de execução (em segundos) para encontrá-la, respectivamente. A coluna 'GAP - CPLEX' apresenta o GAP da solução fornecida pelo CPLEX, a coluna 'Status' reporta se a solução é viável ou inviável e, por fim, a coluna 'Critério' explicita o motivo pela qual a execução do modelo parou por meio da interrupção do CPLEX, podendo ocorrer: solução ótima (Ótima ou Ótima - Tol, a solução é considerada ótima se atingir o limite de tolerância estabelecido: 0,00001) e limite de tempo (quando o limite de tempo de 3600 segundos foi atingido). Todas as informações contidas na Tabela 4.7 foram extraídas do CPLEX. Pode-se notar a dificuldade durante a resolução do modelo quando analisa-se a coluna 'GAP - CPLEX'.

Analisando os resultados obtidos nesta Tabela 4.7, todas as instâncias foram resolvidas, ou seja, obtevese uma solução viável para cada uma delas (coluna 'Status') dentro do limite de tempo. Note que a resolução do problema relaxado ('Fo - LP' e 'Tempo - LP') leva menos de 6 segundos para as instâncias P_1_5_1 a P_4_20_1, observando um aumento no tempo quando aumenta-se o tamanho do problema (vide ' $\mathrm{N}^{\mathrm{o}}$ de linhas' e ' $\mathrm{N}^{\mathrm{o}}$ de colunas'). Para as demais instâncias, D_5_35_1 a D_5_40_10, o tempo de resolução do modelo relaxado também é pequeno, limitando-se a menos de 2 minutos. Observe que para os problemas menores, o valor da função objetivo do problema relaxado encontra-se próximo ao valor do MIP, entretanto, o mesmo não ocorre aos problemas de maiores dimensões. Note, também, que todas as instâncias utilizaram todo tempo limite de execução (veja a coluna 'Critério'), obtendo um GAP relativamente pequeno para os problemas P_1_5_1 a P_4_20_1, contudo, para os exemplares D_5_35_1 a D_5_40_10, o GAP manteve-se superior a 99\%, o que era esperado em função do tamanho destas instâncias.

Uma importante ressalva deve ser feita à solução obtida para P_4_5_1, embora apresente um GAP fornecido pelo CPLEX de $0,1 \%$, esta solução é ótima, o que foi provado pelo modelo TOLM-CLSD_MTZ descrito adiante. 


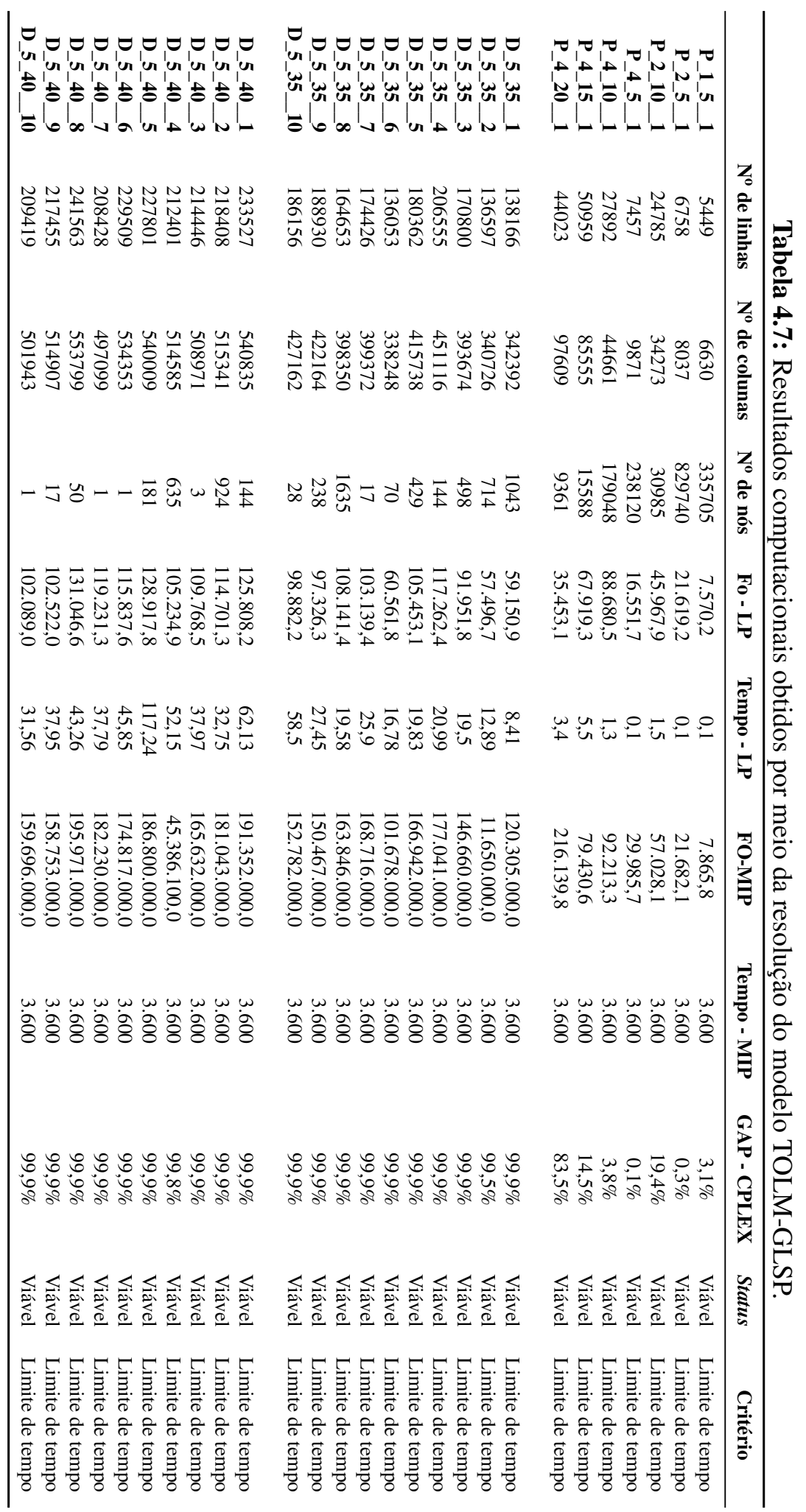




\subsection{Modelo matemático: TOLM-SPL ( $|O|$ tanques e $|M|$ linhas de en- vase utilizando abordagem SPL)}

Na literatura, é comum a prática de utilizar uma modelagem conhecida e estender ou fazer uma reformulação do modelo utilizando a substituição de variáveis ou adição de novos conjuntos de variáveis. Exemplos disso são as várias reformulações do problema de dimensionamento de lotes, uma delas proposta por Eppen \& Martin (1987) que utiliza fluxo em rede. Em Suerie (2005) mostra-se o CLSP reescrito utilizando o Simple Plan Location-SPL (Rosling, 1986). Esta última abordagem inspirou o modelo apresentado a seguir.

A abordagem SPL foi utilizada para reformular ambos os estágios do modelo TOLM-GLSP, entretanto alguns ajustes foram necessários. Esta estratégia de reformulação é baseada na reformulação do clássico Problema de Transportes para representar problemas simples de produção, conhecida de décadas anteriores (Johnson \& Montgomery, 1974). A ideia dessa reformulação do modelo consiste em substituir as variáveis $K_{o l t}, Q_{o l t}, I_{i t}^{-}, I_{i t}^{+}$e $X_{o m i p}$. A primeira substituição gera as variáveis $K_{o l t t^{\prime}}$, tendo as mesmas funções das variáveis $K_{\text {olt }}$ e $Q_{\text {olt }}$. Na segunda, tem-se as variáveis $X_{o m i p p^{\prime}}$ subtituindo $I_{i t}^{+}, I_{i t}^{-}$e $X_{o m i p}$. Sendo assim, as definições destas novas variáveis são dadas a seguir.

Estágio I

$K_{o l t t^{\prime}}$ : quantidade de líquido $l$ pronto no período $t$ no tanque $o$ utilizada para produção de itens no período $t^{\prime}$

$X_{\text {omipp }}$ : quantidade de itens $i$ produzidos no subperíodo $p\left(p \in \lambda_{t}\right.$ e $\left.t \in T\right)$ para suprir a demanda do subperíodo $p^{\prime}\left(p^{\prime} \in \lambda_{t^{\prime}}\right.$ e $t^{\prime} \in T$ ), cujo líquido vem do tanque $o$ e o item é envasado na máquina $m$.

Minimizar

$$
\begin{aligned}
& \sum_{o \in O} \sum_{m \in M} \sum_{i \in \mu_{m}} \sum_{t, t^{\prime} \in T} \sum_{\substack{t<t^{\prime} \\
p \in \lambda_{t}}} \sum_{p^{\prime} \in \lambda_{t^{\prime}}}\left(t^{\prime}-t\right) h_{i}^{+} X_{o m i p p^{\prime}} \\
& +\sum_{o \in O} \sum_{m \in M} \sum_{i \in \mu_{m}} \sum_{\substack{t, t^{\prime} \in T \\
t>t^{\prime}}} \sum_{p \in \lambda_{t}} \sum_{p^{\prime} \in \lambda_{t^{\prime}}}\left(t-t^{\prime}\right) h_{i}^{-} X_{o m i p p^{\prime}} \\
& +\sum_{m \in M} \sum_{j, i \in \mu_{m}} \sum_{\substack{p \in \lambda_{t} \\
t \in T_{1}}} \alpha Z_{m j i p}
\end{aligned}
$$

Sujeito a:

(Estágios I e II)

$$
\sum_{\substack{t \in T, t \leq t^{\prime}}} K_{o l t t^{\prime}}-\sum_{m \in M} \sum_{i \in \gamma_{l} \cap \mu_{m}} \sum_{p^{\prime} \in \lambda_{t^{\prime}}} \sum_{p^{\prime \prime} \in P} r_{l i} X_{o m i p^{\prime} p^{\prime \prime}} \geq 0 \quad o \in O ; t^{\prime} \in T ; l \in L
$$




\section{(Estágio I)}

$$
\begin{aligned}
& \operatorname{Cap}_{\min }^{o} Y_{\text {olt }}^{I} \leq \sum_{t^{\prime} \in T, t^{\prime} \geq t} K_{\text {oltt }} \leq \operatorname{Cap}_{\text {max }}^{o} Y_{\text {olt }}^{I} \quad o \in O ; t \in T ; l \in L, \\
& \sum_{\substack{l^{\prime} \in L, l^{\prime} \neq l=l}} \sum_{\substack{t^{\prime}=0, t-t^{\prime}>0}}^{\Delta_{l}} Y_{o l^{\prime}, t-t^{\prime}}^{I} \leq 1-Y_{\text {olt }}^{I} \quad o \in O ; l \in L ; t \in T \\
& \sum_{\substack{t^{\prime}=1, t-t^{\prime}>0}}^{\Delta_{l}} Y_{o l, t-t^{\prime}}^{I} \leq 1-Y_{\text {olt }}^{I} \quad o \in O, l \in L, t \in T \\
& \sum_{l^{\prime} \in L} \sum_{t^{\prime}=1}^{t-1} \sum_{\substack{t^{\prime \prime}=\max \left\{1, t-\Delta_{l}\right\}, t^{\prime \prime}>=t^{\prime}}}^{t} K_{o l^{\prime} t^{\prime} t^{\prime \prime}} \leq \operatorname{Cap}_{\max }^{o}\left(1-Y_{o l t}^{I}\right) \quad o \in O ; l \in L ; t \in T \\
& \sum_{l^{\prime} \in L} \sum_{t^{\prime}=1}^{t-1} \sum_{t^{\prime \prime}=t}^{T} K_{o l^{\prime} t^{\prime} t^{\prime \prime}} \leq \operatorname{Cap}_{\max }^{o}\left(1-Y_{o l t}^{I}\right) \quad o \in O ; l \in L ; t \in T
\end{aligned}
$$

\section{(Estágio II)}

$$
\begin{array}{cl}
\sum_{o \in O} \sum_{m \in M} \sum_{p \in P} \sum_{p^{\prime} \in \lambda_{t}} X_{o m i p p^{\prime}}=d_{i t} & i \in \mu_{m} ; t \in T \\
\sum_{j \in N} \sum_{i \in N} b_{m j i} Z_{m j i p}+\sum_{i \in N} \sum_{p^{\prime} \in P} a_{m i} X_{o m i p p^{\prime}} \leq C_{m p} & m \in M ; p \in \lambda_{t} ; t \in T_{1} \\
\sum_{o \in O} \sum_{i \in N} \sum_{p^{\prime} \in P} a_{m i} X_{o m i p p^{\prime}} \leq C_{m p} & m \in M ; p \in \lambda_{t} ; t \in T_{2} \\
X_{o m i p p^{\prime}} \leq \frac{C_{m p}}{a_{m i}} Y_{o m i p} & o \in O ; m \in M ; i \in N
\end{array}
$$

Restrições (4.25) a (4.29).

A função objetivo (4.34) visa minimizar a soma dos custos de atraso na entrega da demanda (veja Figura 4.5. 'B'), dos custos de estoque de itens (veja Figura 4.5, 'C') e o número de trocas de itens nas linhas de envase (veja Figura 4.5, 'A'). Observe que na Figura 4.5 - 'A', a linha de envase estava preparada para produzir o produto $j$ no início do horizonte de planejamento, porém foi necessária a preparação da máquina para o produto $i$ num dado instante, ou seja, houve uma troca do produto $j$ para o produto $i$ em $t$ (lembre-se que $p \in \lambda_{t}$ ). Na Figura 4.5. ' $\mathrm{B}$ ' tem-se que a demanda ocorre em $t^{\prime}$, porém a fabricação desta demanda ocorreu apenas em $t\left(t>t^{\prime}\right)$, ou seja, $X_{\text {omipp }^{\prime}}>0\left(p \in \lambda_{t}\right.$ e $\left.p^{\prime} \in \lambda_{t^{\prime}}\right)$. Analogamente faz-se a análise da figura Figura 4.5 . ' $\mathrm{C}$ ' onde há estocagem do item do período $t$ ' a $t$.

As restrições (4.35) acoplam os estágios I e II, pois garantem que haverá produção de itens no período $t^{\prime}\left(p \in \lambda_{t^{\prime}}\right)$, se houver líquido pronto disponível. As restrições pertencentes ao estágio I são representadas pelas restrições 4.36- (4.40). A capacidade máxima e mínima de cada tanque precisa ser respeitada e as restrições 4.36 garantem que esta condição seja respeitada. As restrições 4.37) e 4.38 garantem que o período de fermentação/maturação sejam respeitados, pois não permitem que durante, pelos menos, $\Delta_{l}$ períodos, mais de um líquido fique pronto dentro de um determinado tanque; possuem um raciocínio 
semelhante as restrições 4.20). As restrições 4.39) e (4.40) apresentam um raciocínio semelhante a 4.19), ou seja, garantem que para ter líquido pronto em $t\left(Y_{\text {olt }}^{I}=1\right)$, o processo de fermentação e maturação ocorre durante os $\Delta_{l}$ períodos imediatamente anteriores a $t$. A compreensão destas restrições não é trivial, logo, a Figura 4.6 tem o intuito de auxiliar a visualização de como estas foram elaboradas. Considere a ilustração da variável $K_{\text {oltt' }}$ durante o horizonte de planejamento para um determinado tanque $o$ como sendo a Figura 4.6, onde as linhas desta 'matriz' representam $t$ (período em que o líquido fica pronto) e as colunas $t^{\prime}$ (período em que o líquido é utilizado para fabricação de itens). Observe que a representação lembra uma matriz diagonal superior, pois não há como ocorrer produção se não houver líquido disponível $\left(t^{\prime} \geq t\right)$. Considere $t$ o instante em que o líquido $l$ fica pronto e disponível, logo para todos os períodos $t^{\prime} \geq t$ tem-se líquido disponível para o envase; visualmente, esta situação está representada na Figura 4.6 na linha $t+1$ (em amarelo). As restrições 4.39) garantem que o período de fermentação e maturação seja respeitado, ou seja, durante $\Delta_{l}$ períodos anteriores a $t+1$, o tanque está dedicado ao processamento do líquido $l\left(K_{o l t^{*} t^{\prime}}=0\right.$, para $\left.t^{*} \in\left\{t-\Delta_{l}, \ldots, t-1\right\}\right)$, sendo esta situação representada em verde na Figura $4.6 \mathrm{E}$, as restrições (4.40) garantem que o tanque está vazio e não ocorre produção em períodos anteriores a $t$ e $t^{\prime}$ simultaneamente, sendo esta situação representada em roxo na Figura 4.6 . Observe também que, na figura, há líquido disponível novamente em $t+8$, cujo período de fermentação e maturação correspondeu há apenas 3 períodos.

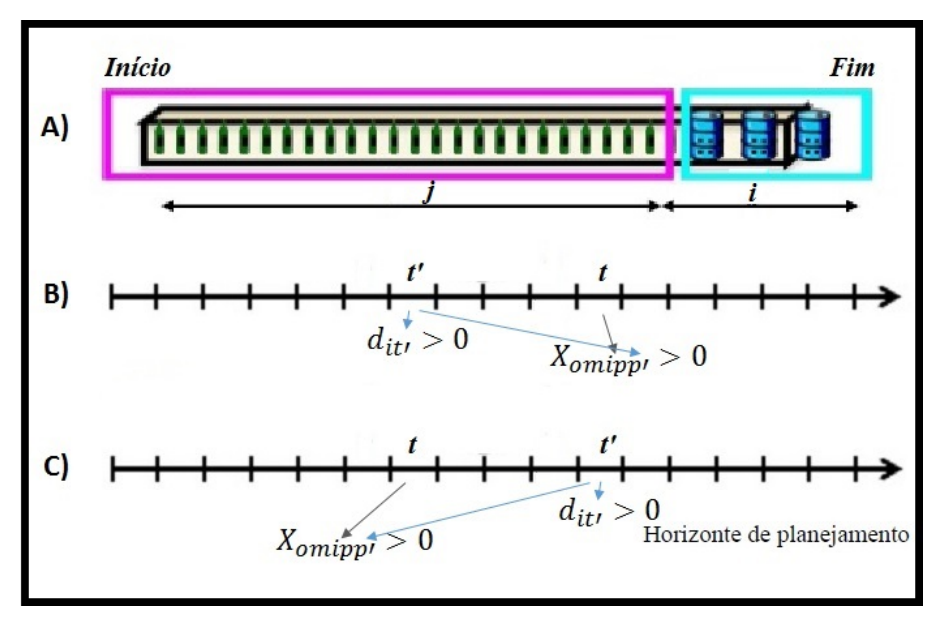

Figura 4.5: Ilustração da função objetivo (4.34).

Para o Estágio II (envase), as restrições (4.41) asseguram que toda demanda será cumprida dentro do horizonte de planejamento, mesmo que com atraso. Devido a estas restrições 4.41, este modelo não é estritamente comparável a TOLM-GLSP. Para que estes fossem estritamente comparáveis, seria necessária a inclusão da condição de $I_{i|T|}^{-}=0$ (i.e. $t=|T|$ ) ao modelo TOLM-GSLP. As restrições 4.43 garantem que o limite de capacidade da enchedora será respeitado. Nas restrições (4.44), há a garantia de que haverá produção de $i$ se a máquina estiver preparada. 


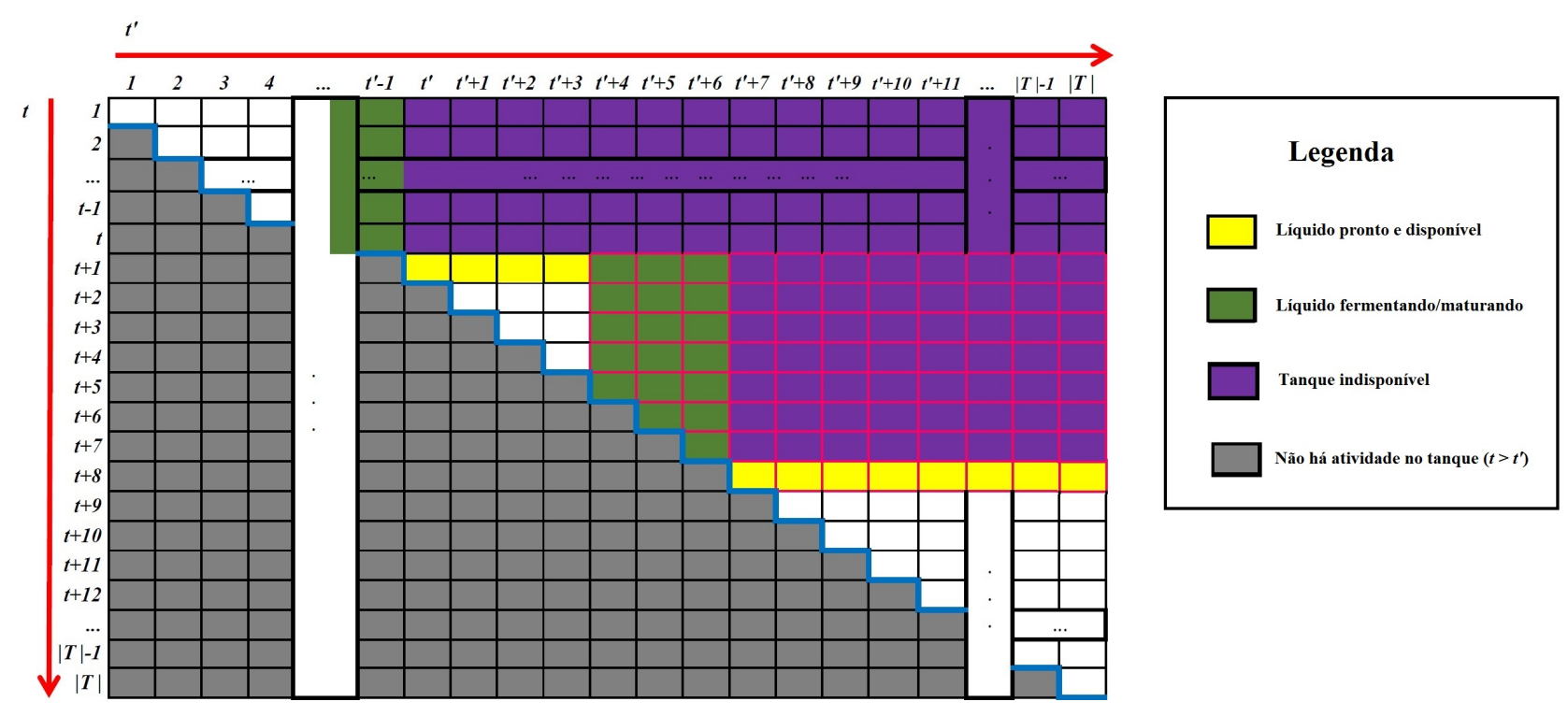

Figura 4.6: Ilustração das restrições (4.39) e (4.40).

\subsubsection{Testes computacionais (TOLM-SPL)}

A Tabela 4.8 traz os resultados obtidos ao resolver as instâncias testes (veja Seção 4.2.4) por meio do modelo TOLM-SPL. Utilizou-se as mesmas condições de testes do modelo TOLM-GLSP, descritas na Seção 4.2.5. As explicações referentes a leitura da Tabela 4.8 são as mesmas apresentadas na Seção 4.2.5. para a leitura da Tabela 4.7. Note que o número de restrições e o número de variáveis aumentaram ( $\mathrm{N}^{\mathrm{o}}$ de linhas' e ' $\mathrm{N}^{\mathrm{o}}$ de colunas') comparadas ao modelo TOLM-GLSP. Observe, também, o tempo elevado que o modelo relaxado leva para ser resolvido, principalmente para instâncias de grande dimensão (D_5_35_1 a D_5_40_10). Veja a dificuldade deste modelo até mesmo em resolver instâncias de pequena dimensão (P_2_10_1 a P_4_20_1), apresentado na coluna 'GAP-CPLEX', não encontrando uma solução viável para aproximadamente um terço destas instâncias dentro do tempo limite estabelecido. Uma outra indicação da dificuldade ao resolver as instâncias utilizando este modelo, está no número de nós utilizados durante a resolução do Branch-and-cut não conseguindo sair do nó raiz para os exemplares de maior dimensão. Entretanto, ao analisarmos o resultado obtido para a instância P_1_5_1, comparada aos demais modelos (TOLM-GLSP, TOLM-CLSD_MTZ e TOLM-CLSD_W, estes dois últimos apresentados nas próximas seções), TOLM-SPL obtém o melhor valor da função objetivo, igual a 7.799,3, mas o GAP fornecido pelo CPLEX é de 1,9\%. Este valor é superior aos GAPs obtidos pelos modelos TOLM-CLSD_MTZ e TOLMCLSD_W, ambos com valores iguais a $0,8 \%$ e função objetivo iguais a 7834,2. Isso ocorre pois o modelo TOLM-SPL, durante a resolução do Branch-and-cut pelo CPLEX para esta instância, encontrou um limitante inferior de qualidade não tão boa quanto aos dos modelos TOLM-CLSD_MTZ e TOLM-CLSD_W.

Ao fazer uma comparação rápida entre os modelos TOLM-GLSP e TOLM-SPL, nota-se que o primeiro apresentou melhores resultados que o segundo, embora, neste experimento, o segundo não tenha sido capaz de encontrar soluções viáveis dentro do tempo limite para a maioria das instâncias, o que impossibilita uma melhor análise. Logo, não serão mais reportados testes para TOLM-SPL. 


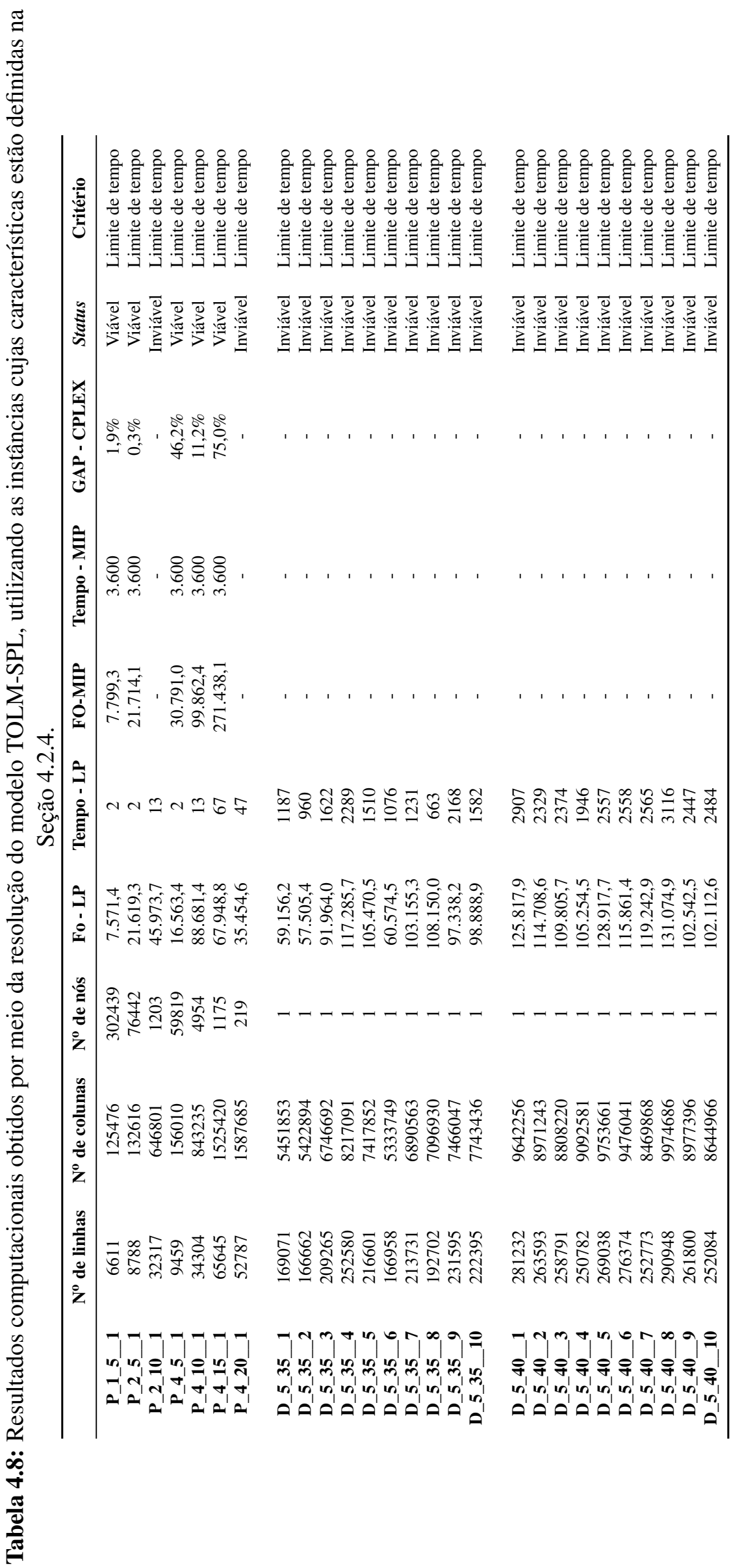




\subsection{Modelo matemático: TOLM-CLSD ( $|O|$ tanques e $|M|$ linhas de envase utilizando abordagens ATSP)}

Assim como na reformulação SPL, nesta seção o modelo apresentado é uma reformulação do TOLMGLSP utilizando o CLSD (The Capacitated Lot-Sizing Problem with Sequence Dependent Setup Costs, Haase (1996)). Maiores detalhes sobre os modelos CLSD podem ser encontrados em Suerie (2005).

Para esta reformulação, foi necessária a eliminação do conceito de subperíodos, sendo assim, no estágio II, ao tratar-se do horizonte de planejamento, este encontra-se divido em períodos correspondentes a dias (veja a Figura 4.7). Entretanto, o particionamento do horizonte de planejamento permaneça, ou seja, há um detalhamento maior para os $\left|T_{1}\right|$ primeiros períodos. Considere as definições a seguir para o modelo.

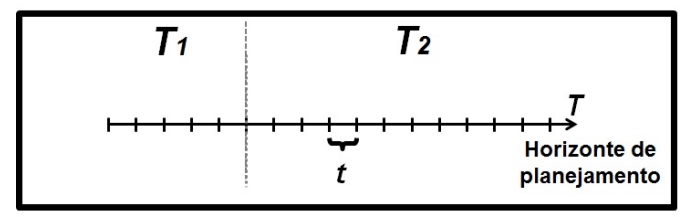

Figura 4.7: Horizonte de planejamento para os modelos TOLM-CLSD.

\section{Variáveis}

Estágio II

$Y_{m i t}^{I I}: 1$ se a envasadora $m$ está preparada para o item $i$ no início do período $t ; 0$ caso contrário;

$Z_{m j i t}: 1$ se a máquina $m$ trocou sua preparação do item $j$ para o item $i$ no início do período $t$; 0 caso contrário.

Minimizar

$$
\sum_{i \in N} \sum_{t \in T} h_{i}^{+} I_{i t}^{+}+\sum_{i \in N} \sum_{t \in T} h_{i}^{-} I_{i t}^{-}+\sum_{m \in M} \sum_{j, i \in \mu_{m}} \sum_{t \in T_{1}} \alpha Z_{m j i t}
$$

(Acoplamento e Estágio I)

Restrições (4.18)-(4.21)

\section{(Estágio II)}

$$
\begin{array}{cl}
\sum_{o \in O} \sum_{\substack{m \in M \\
i \in \mu_{m}}} X_{o m i t}+I_{i, t-1}^{+}+I_{i t}^{-}=d_{i t}+I_{i, t-1}^{-}+I_{i t}^{+} \quad & i \in N ; t \in T \\
\sum_{o \in O} \sum_{i \in \mu_{m}} a_{m i} \cdot X_{o m i t}+\sum_{i \in \mu_{m}} \sum_{j \in \mu_{m}} b_{m i j} \cdot Z_{m i j t} \leq C_{m t} & \forall m \in M ; t \in T_{1} \\
X_{\text {omit }} \leq \frac{C_{m t}}{a_{m i}} \cdot\left(\sum_{j \in \mu_{m}} Z_{m j i t}+Y_{m i t}^{I I}\right) & \forall o \in O, m \in M, i \in \mu_{m} ; t \in T_{2}
\end{array}
$$




$$
\begin{array}{cc}
\sum_{i \in \mu_{m}} Y_{m i t}^{I I}=1 & \forall m \in M ; t \in T_{1} \\
Y_{m i t}^{I I}+\sum_{j \in \mu_{m}} Z_{m j i t}=\sum_{j \in \mu_{m}} Z_{m i j t}+Z_{m i, t+1} & \forall m \in M ; i \in \mu_{m} ; t \in T_{1} \\
\sum_{i \in \mu_{m}} \sum_{j \in \mu_{m}} Z_{m i j t} \leq \Omega & \forall m \in M ; t \in T_{2} \\
X_{\text {omit }} \geq 0 ; K_{\text {olt }} \geq 0 ; Q_{\text {olt }} \geq 0 ; Y_{\text {olt }}^{I} \in\{0,1\} ; \quad & i, j \in N ; o \in O ; l \in L ; \\
I_{i t}^{+} \geq 0 ; I_{i t}^{-} \geq 0 ; Y_{\text {mit }}^{I I} \in\{0,1\} ; 0 \leq Z_{m j i t} \leq 1 & m \in M ; p \in \lambda_{t} ; t \in T
\end{array}
$$

A função objetivo (4.45) é semelhante à (4.17). As restrições 4.46) e 4.47) são semelhantes às restrições 4.22) e 4.23, respectivamente. As restrições (4.48) permitem que a produção do item $i$ ocorra no período $t$ se a envasadora estiver preparada, seja por uma operação de troca de produtos na linha (a linha estava preparada para o item $i$ e depois preparada para produzir $j, Z_{m i j t}$ ); ou se a máquina já estivesse preparada no período $t-1$ para produzir o item $i$ e esta preparação foi levada para o período $t$ ( $Y_{\text {mit }}^{I I}$ ). No final de cada período, a máquina sempre deve estar preparada para algum item $i$, restrições 4.49. As restrições 4.50) descrevem o fluxo de trocas e preparações a cada linha de envase. O lado esquerdo é igual ' 1 ' se houve preparação e a envasadora está preparada para o item $i$ no período $t\left(Y_{m i t}^{I I}=1\right)$, ou se houve alguma troca na linha de envase do item $j$ para o item $i\left(\sum_{j} Z_{m j i t}=1\right)$. Então, a preparação da máquina é 'enviada para $t+1$ ', $Y_{m i t}^{I I}=1$, ou uma troca a partir do item $i$ é realizada para qualquer outro produto $j^{\prime}$ no período $t\left(\sum_{j^{\prime}} Z_{m i j^{\prime} t}=1\right)$. O mesmo raciocínio aplica-se quando ambos os lados são iguais a zero. $\mathrm{O}$ número máximo de trocas em cada envasadora $m$ para cada período $t$ deve ser menor ou igual $\Omega$ e isto está garantido pelas restrições 4.51. O domínio das variáveis está definido pelas restrições 4.52);

As soluções fornecidas pela resolução deste modelo permitem a existência de subtours, que representam a produção de um mesmo item mais vezes durante o mesmo período. Por exemplo, a máquina estava preparada para o item ' $i_{1}$ ', houve a troca de produto nesta linha para a produção do item ' $i_{2}$ ' e, antes do final do período, voltou-se a produzir o item ' $i_{1}$ ', entretanto, apenas uma preparação foi realizada, dado que já ocorria a produção deste item neste período. O exemplo citado, não ocorre na prática, a menos que os tempos e custos de setup não obedeçam a desigualdade triangular (Toso et al., 2008). Sendo assim, restrições de eliminação de subtours são necessárias. Logo, a seguir mostra-se duas abordagens estudadas e utilizadas neste trabalho.

Antes de prosseguir para próxima seção, note que as restrições 4.27) e 4.28) do modelo TOLM-GLSP foram substituídas pelas restrições 4.50 no modelo TOLM-CLSD. Esta alteração foi motivada pelos resultados de vários testes computacionais realizados considerando ambos os conjuntos (incluindo também as restrições de eliminação de subtours no modelo), não notando nenhuma melhoria significantiva na utilização de um conjunto em relação ao outro. Então, optou-se por utilizar as restrições 4.50 . 


\subsubsection{Restrições MTZ}

Para facilitar a visualização da existência de subtours, vamos utilizar o exemplo apresentado em AlmadaLobo et al. (2007). Define-se um dígrafo $G=([N], A=[N] \times[N])$, onde os nós correspondem aos produtos e um arco $a=(j, i)$ corresponde a troca do produto $i$ para o produto $j$. Tem-se que o conjunto $\left\{(i, j) \mid Z_{m j i t}=1\right\}$ correspondendo a um conjunto de possibilidades de caminhos cíclicos e disjuntos para uma determinada máquina $m$. As restrições (4.46) - (4.51) admitem soluções que têm, no máximo, um caminho, mas potencialmente muitos ciclos, também chamado subtours, ver Figura 4.8. A configuração esquerda representa uma solução que implica em um caminho do item $i_{1}$ para $i_{4}$ e 3 subtours desconectados. A configuração direita ilustra uma solução com um ciclo que começa e termina em $i_{1}$ e 2 subtours desconectados. Logo, precisa-se, para obter uma solução factível, conseguir a ocorrência de apenas uma única componente $Y_{m i t}^{I I}$ ligada ao arco.
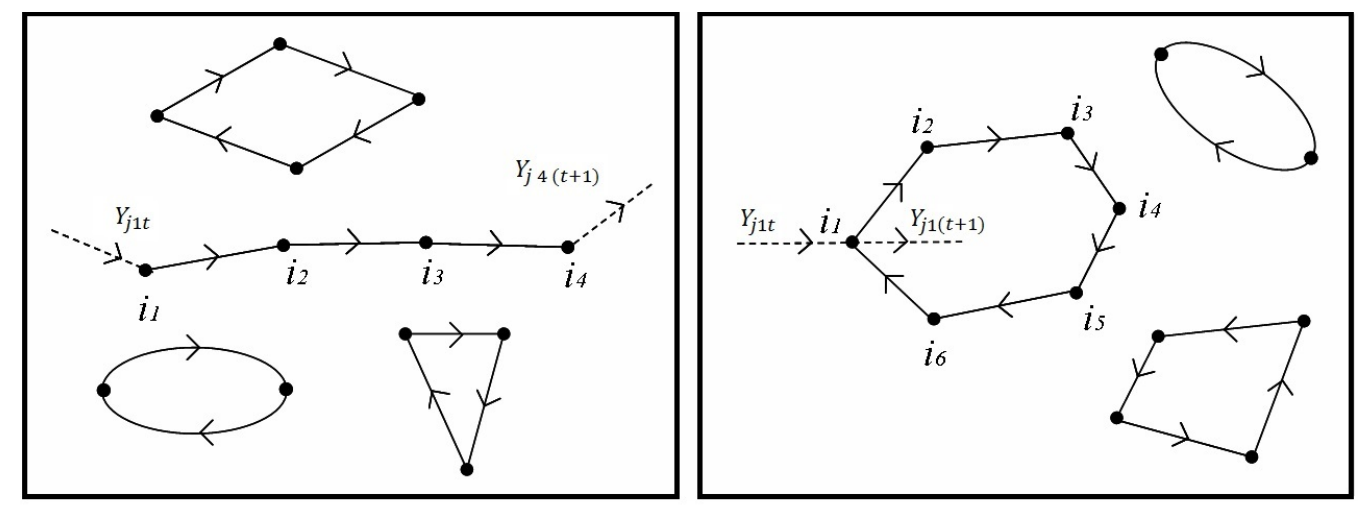

Figura 4.8: Possíveis configurações de setup - figura extraída de Almada-Lobo et al. (2007).

Uma das propostas utilizadas nesta pesquisa para eliminação de subtours são as restrições propostas por Miller, Tucker e Zemlin, dando origem ao nome da restrição: MTZ (Johnson \& Pilcher, 1988). Para gerar as restrições (4.53) - MTZ, necessita-se da definição de um conjunto de variáveis reais e não nulo, sendo este:

$V_{m i t}$ : ordem em que o item $i$ aparece na sequência da produção para a envasadora $m$ no período $t$.

$$
V_{m j t} \geq V_{m i t}+1-|N| \cdot\left(1-Z_{m i j t}\right)-|N| \cdot Y_{m i t}^{I I} \quad \forall m \in M ; i, j \in \mu_{m}, j \neq i ; t \in T_{1}
$$

De modo a obter uma solução viável, deve-se impor que exista apenas um único componente ligado ao arco, correspondendo as variáveis $Y_{m i t}^{I I}$, cujas restrições 4.53 conseguem isso usando as variáveis $V_{\text {mit }}$ que avaliam o estado da máquina através de uma sequência qualquer.

\section{Resultados TOLM-CLSD_MTZ}

A Tabela 4.9 traz os resultados obtidos pelo modelo TOLM-CLSD_MTZ, utilizando as instâncias geradas na Seção 4.2.4 Utilizou-se as mesmas condições de testes utilizadas para o modelo TOLM-GLSP, descritas na Seção 4.2.5. As explicações referentes a leitura da Tabela 4.9 são as mesmas apresentadas na Seção 4.2.5, para a leitura da Tabela 4.7 . 
Como pode-se observar na Tabela 4.9, esta modelagem possui um número menor de variáveis e de restrições que a apresentada pelo modelo TOLM-GLSP, vide as colunas ' $\mathrm{N}^{0}$ de linhas' e ' $\mathrm{N}^{\mathrm{o}}$ de colunas'. Observe o excelente desempenho deste modelo ao resolver as instâncias P_1_5_1 a P_4_20_1, com valores de GAP baixos ou inexistentes, encontrando a solução ótima para os exemplares P_2_5_1 e P_4_5_1. Entretanto, para solução dos exemplares maiores (D_5_35_1 a D_5_40_10), nota-se a dificuldade do modelo, pois para a maioria deles o modelo não consegue obter uma solução viável dentro do tempo limite estabelecido (3600 segundos). 


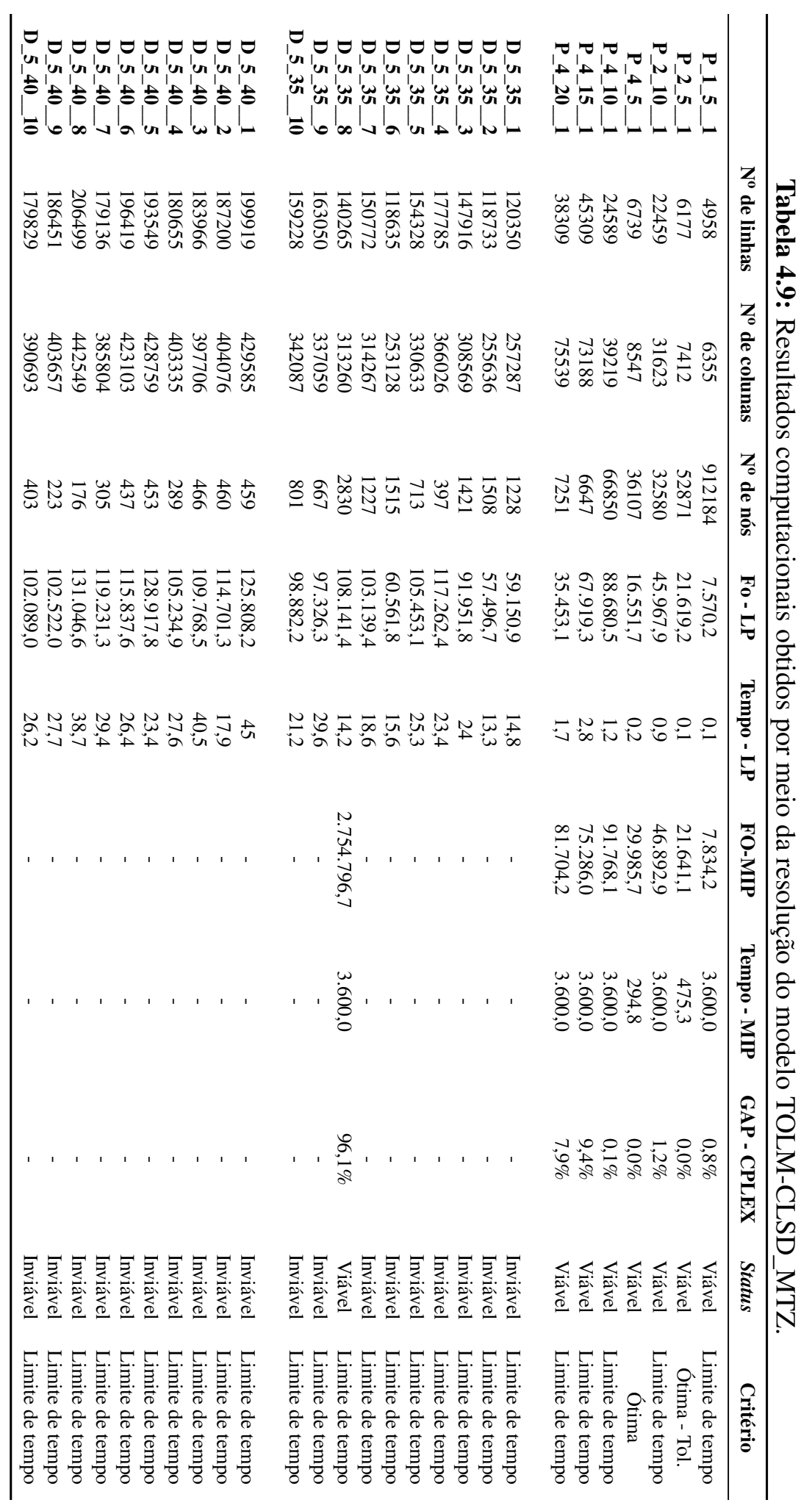




\subsubsection{Restrições W}

A segunda abordagem de eliminação de subtours deste trabalho foi motivado pelo trabalho de AlmadaLobo et al. (2007). Para tal, necessita-se da definição de uma nova variável,

$W_{m t}: 1$ se nenhuma configuração é realizada no período $t$ na máquina $m, 0$ caso contrário.

Sendo as novas restrições dadas por (4.54)-4.60).

$$
\begin{array}{cl}
\sum_{j \in \mu_{m}} Z_{m i j t} \leq 1 & \forall m \in M ; i \in \mu_{m} ; t \in T \\
\sum_{j \in \mu_{m}} Z_{m j i t} \leq 1 & \forall m \in M ; i \in \mu_{m} ; t \in T \\
Y_{m i t}^{I I} \leq \sum_{j \in \mu_{m}} Z_{m i j t}+W_{m t} & \forall m \in M ; i \in \mu_{m} ; t \in T \\
Y_{m i t}^{I I} \leq \sum_{j \in \mu_{m}} Z_{m j i, t-1}+W_{m, t-1} & \forall m \in M ; i \in \mu_{m} ; t \in T \\
1-W_{m t} \leq \sum_{i \in \mu_{m}} \sum_{j \in \mu_{m}} Z_{m i j t} & \forall m \in M ; t \in T \\
\sum_{i \in \mu_{m}} \sum_{j \in \mu_{m}} Z_{m i j t} & \\
W_{m t} \leq 1-\frac{}{|N|} & \forall m \in M ; t \in T \\
Z_{m i j t}+Z_{m j i t}-Y_{m i t}^{I I}-Z_{m j t} \leq 1 & \forall m \in M ; i, j \in \mu_{m}, j \neq i ; t \in T .
\end{array}
$$

As restrições 4.56-4.60 eliminam todos os subtours quando $\Omega$ é 3, desde que 4.56-4.59) só permitem subtours com até dois produtos, asseguradas pela restrição 4.60 .

Se a desigualdade triangular é válida para ambos os custos e tempos de troca, as restrições 4.54 e 4.55) são uma modelagem alternativa desta situação, que garantem que a desigualdade triangular seja respeitada, assim como estão sempre satisfeitas em uma solução ótima.

As restrições 4.57)-4.60 formam um conjunto de desigualdades válidas para o problema (AlmadaLobo et al., 2007). Para argumentar que são válidas, considere uma máquina $m$ e, ainda, a situação em que $Y_{m i t}=1$. Pode-se distinguir os quatro seguintes casos.

- Se $Y_{m i(t-1)}=0, Y_{m i(t+1)}=0$ : tem-se $\sum_{j \in \mu_{m}} Z_{j i(t-1)} \geq 1, \sum_{j \in \mu_{m}} Z_{j i t} \geq 1$ e $W_{t}=W_{t-1}=0$ e as desigualdades são satisfeitas;

- Se $Y_{m i(t-1)}=1, Y_{m i(t+1)}=0$ : tem-se $\sum_{j \in \mu_{m}} Z_{i j(t-1)} \geq 1$ e $W_{t}=0$. Se $\sum_{j, i \in \mu_{m}} Z_{i j(t-1)} \geq 1(\mathrm{e}$ $W_{t-1}=0$ ), então elas são válidas. E, ainda, se $\sum_{j, i \in \mu_{m}} Z_{i j(t-1)}=0$, então $W_{t-1}=1 \mathrm{e}$, novamente, são válidas.

- Se $Y_{m i(t-1)}=0, Y_{m i(t+1)}=1$ : este processo é semelhante ao descrito acima;

- Se $Y_{m i(t-1)}=1, Y_{m i(t+1)}=1$ : este processo é facilmente obtido adaptando-se o segundo caso. 


\section{Testes computacionais do modelo TOLM-CLSD_W}

Assim como para os demais modelos, utilizou-se as mesmas condições de testes descritas na Seção 4.2.5 As explicações referentes a leitura da Tabela 4.9 são as mesmas apresentadas na Seção 4.2.5. A Tabela 4.10 traz os resultados obtidos pelo modelo TOLM-CLSD_W, utilizando as instâncias geradas na Seção 4.2.4. Observe que o número de variáveis e o número de restrições são menores que as do modelo TOLM-GLSP. Observe que TOLM-CLSD_W mostra um comportamento semelhante ao modelo TOLM-CLSD_MTZ, apresentando um excelente desempenho ao resolver as instâncias menores P_1_5_1 a P_4_20_1, com valores de GAP baixos ou inexistentes, encontrando a solução ótima para as instâncias: P_2_5_1, P_4_5_1 e P_4_10_1. Entretanto, ao resolver os exemplares maiores (D_5_35_1 a D_5_40_10), nota-se a dificuldade do modelo, pois para a maioria deles não se consegue obter uma solução viável dentro do tempo limite estabelecido (3600 segundos), e obtém apenas uma solução factível a mais que o modelo TOLMCLSD_MTZ. 


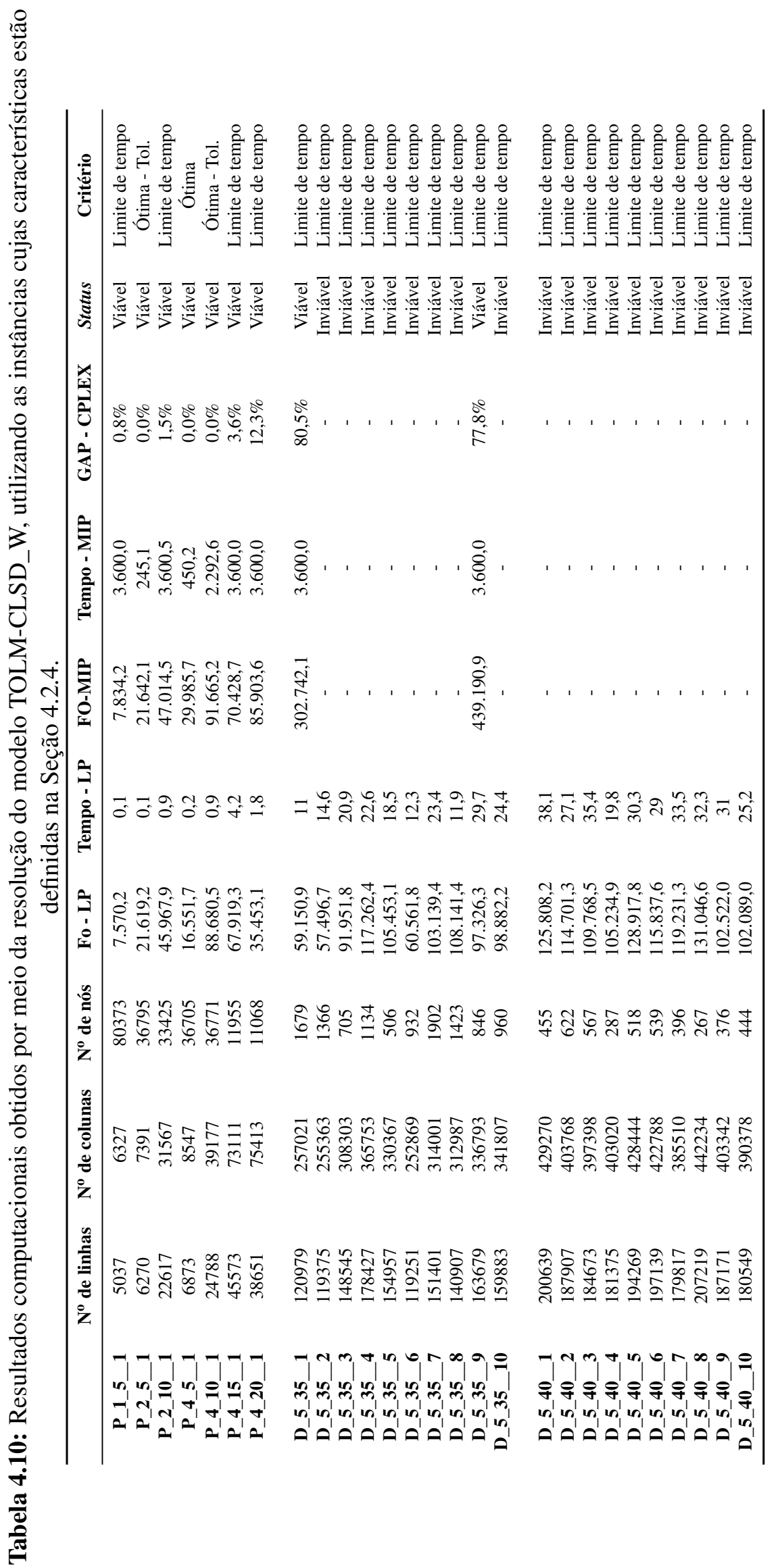




\subsection{Conclusões sobre os modelos TOLM}

A Tabela 4.11 traz um resumo dos resultados obtidos pelos modelos TOLM-GLSP, TOLM-CLSD_MTZ e TOLM-CLSD_W, apresentados nas Tabelas 4.7, 4.9 e 4.10. A coluna 'LB', da Tabela 4.11, representa o lower bound encontrado por meio da execução dos modelos TOLM-GLSP, fornecido pelo CPLEX. A coluna 'GAP' tem seu valor calculado utilizando a expressão 4.16. De maneira geral, pode-se dizer que o modelo TOLM-GLSP apresenta melhor desempenho para instâncias de grande dimensão, pois fornece pelo menos uma solução viável, mesmo que de qualidade não tão boa, como mostra os valores dos GAPs. Entretanto, nas instâncias de pequenas dimensões, os modelos que utilizam a abordagem CLSD apresentam melhores resultados.

Nas indústrias encontram-se instâncias de grande dimensão, logo pode-se dizer que o modelo TOLMGLSP apresenta melhor desempenho, visto que fornece uma solução viável, apesar desta solução em geral envolver altos custos de atraso ou faltas. Então, para os testes realizados nas MIP-heurísticas, considerou-se apenas o modelo TOLM-GLSP. Sendo assim, os demais modelos não serão mais abordados nos próximos capítulos. 


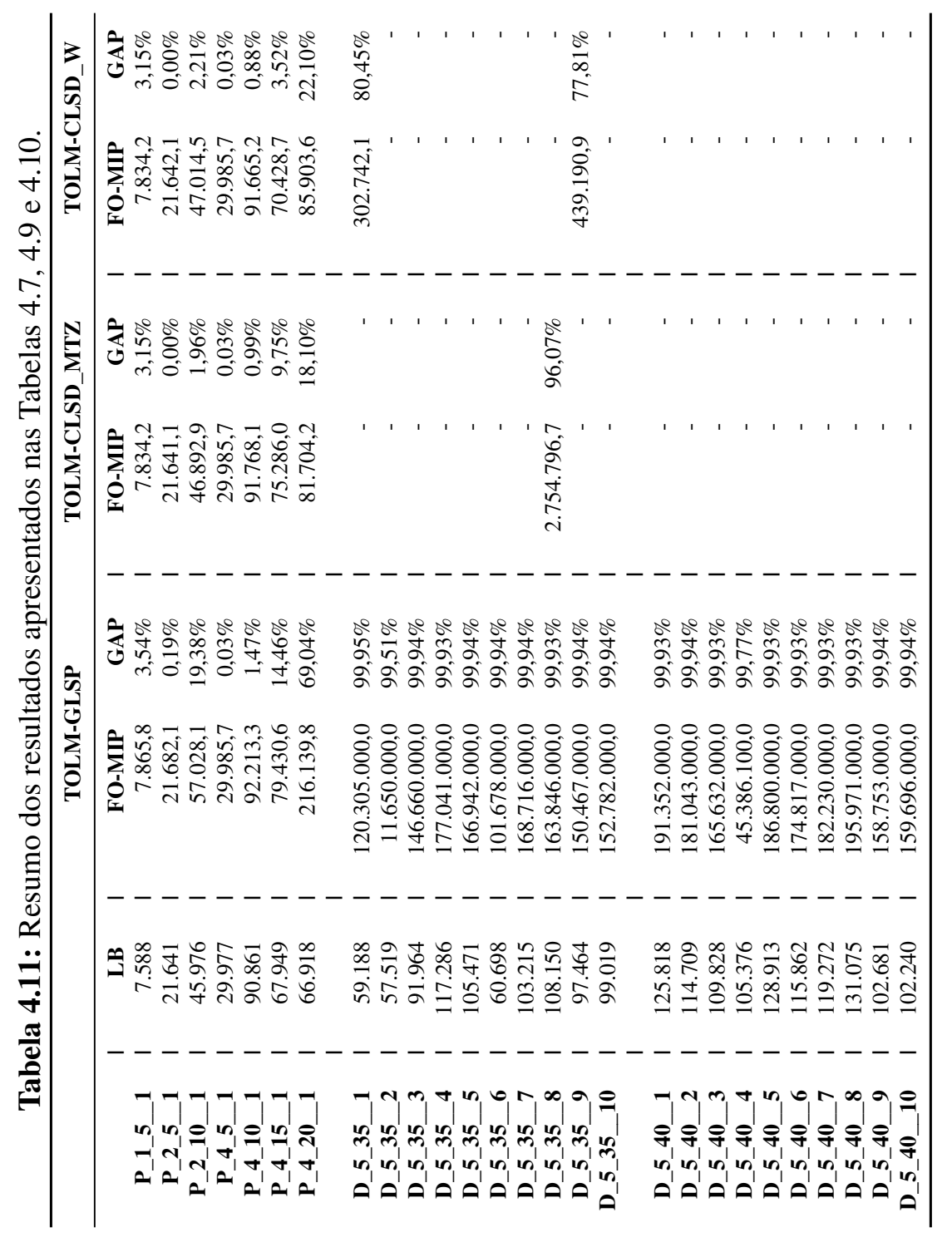



A dificuldade apresentada pelos modelos matemáticos do capítulo anterior motivou os estudos e o desenvolvimento de métodos (meta)heurísticos para a resolução do problema em questão. Os métodos heurísticos propostos (mais precisamente, MIP-heurísticas) utilizam a formulação obtida pelo modelo matemático TOLM-GLSP, pois foi o único que obteve soluções viáveis para todas as instâncias.

Diferentemente dos métodos exatos, que garantem encontrar uma solução ótima do problema, métodos heurísticos buscam alcançar uma boa solução viável, entretanto, não necessariamente a solução ótima (Martín \& Reinelt, 2011). O estudo de heurísticas para resolução de problemas de otimização combinatória vem tornando-se cada vez mais frequentes devido à dificuldade de resolução destes problemas. Existem muitos métodos heurísticos presentes na literatura, sendo difícil fornecer uma classificação total das heurísticas.

Para Martín \& Reinelt (2011), a classificação a seguir fornece uma ampla categorização, na qual conseguese alocar as heurísticas mais conhecidas presentes na literatura:

- heurística construtiva: a solução é construída, elemento a elemento (ou utilizando um grupo de elementos), respeitando algum critério de otimização para escolha de tais elementos, obtendo ao final da execução da heurística uma solução viável;

- heurísticas de melhoramento (ou de busca em vizinhança): a partir de uma solução inicial viável, busca-se melhorá-la iterativamente através de operações de troca, remoção e/ou inserção de elementos, repetindo-se o procedimento, até que não se consiga mais melhorar a solução corrente, ou outro critério de parada seja satisfeito;

- métodos de decomposição: o problema original é dividido em sub-problemas que são mais simples de se resolver, cuja solução obtida é uma solução viável para o problema original.

Pode-se citar como exemplo de heurística construtiva o procedimento guloso, onde em cada iteração um elemento é adicionado à solução, visando obter o maior benefício possível segundo algum critério. 
Outro exemplo de heurística construtiva é o procedimento relax-and-fix, descrito com mais detalhes neste capítulo. Com relação a busca em vizinhança, um exemplo, é a heurística de busca local, cuja solução corrente é revisitada com o intuito de se obter uma melhoria e, ainda, garantindo que a solução permaneça viável. Outro exemplo de heurística de melhoria, são as heurísticas fix-and-optimize, também abordadas neste capítulo.

\subsection{MIP-heurísticas: relax-and-fix e fix-and-optimize}

Esta seção traz diferentes abordagens para os procedimentos relax-and-fix e fix-and-optimize. Propomos 10 abordagens diferentes, sendo 5 para as heurísticas relax-and-fix e mais 5 para fix-and-optimize. Inicialmente, verificamos o desempenho de cada uma das estratégias utilizando as instâncias de pequena dimensão definidas no Capítulo 4 (P_1_5_1 a P_4_20_1) e, na sequência, fizemos associações destas heurísticas de forma a obter os procedimentos, denominados de Proc_Crescente e Proc_Decrescente, utilizando a combinação dos métodos que obtiveram bons desempenhos. As subseções que seguem a seguir descrevem como foi obtido cada um destes procedimentos.

\subsubsection{Heurísticas relax-and-fix}

A heurística relax-and-fix é um procedimento fundamentado na resolução iterativa de problemas MIPs (Wolsey, 1998). As variáveis inteiras do problema são divididas em $|C|$ subconjuntos disjuntos (este valor define o número de iterações da heurística). Cada subconjunto $C_{c}(\operatorname{com} c=1, \ldots,|C|)$, agrupa um número de variáveis inteiras (para o modelo TOLM-GLSP, tem-se $Y_{o l t}^{I}$ e $Y_{o m i t}^{I I}$; em um abuso de notação, chamaremos de $Y)$. Para cada iteração $c\left(Y=Y_{c=1}^{f} \cup Y_{c=2}^{f} \cup \ldots \cup Y_{c=k}^{f} \cup \ldots \cup Y_{c=|C|}^{f}\right)$, somente as variáveis pertencentes a $C_{c}(c \in\{1, \ldots,|C|\})$ são definidas como inteiras; as demais variáveis do problema são relaxadas (ou estão fixadas). O subproblema MIP resultante é então resolvido, porém se este for inviável, o método é interrompido. Caso seja viável, as variáveis do subconjunto $C_{c}\left(Y_{c}^{f}\right)$ são fixadas em seu valor corrente (ou parte delas). Este procedimento se repete enquanto os sub-MIPs forem viáveis e todos os $|C|$ subconjuntos não possuírem suas variáveis fixadas.

Quando o procedimento inclui overlapping ( $Y_{c}^{o}$, sendo $Y=Y_{1}^{o} \cup Y_{2}^{o} \cup \ldots \cup Y_{c}^{o} \cup \ldots \cup Y_{|C|}^{o}$ ), os subconjuntos que terão seu domínio reiterado para inteiro (a partir das partições relaxadas) e os subconjuntos que terão seus valores fixados $\left(Y_{k}^{f}\right)$ podem ter diferentes tamanhos. O conjunto das variáveis que serão fixadas $\left(Y_{c}^{f}\right)$ é um subconjunto de variáveis que terão o domínio reiterado para inteiro $\left(Y_{c}^{o}\right)$. Em outras palavras, considere $Y$ o conjunto de variáveis inteiras do modelo, sendo este conjunto dividido em subconjuntos $Y_{c}^{o}$ e $Y_{c}^{f}$, define-se:

$$
\begin{gathered}
\text { (i) } Y_{c}^{o} \cap Y_{c^{\prime}}^{o}=\emptyset \text { e } Y_{c}^{f} \cap Y_{c^{\prime}}^{f}=\emptyset \quad\left(c \neq c^{\prime} ; \forall c, c^{\prime} \in\{1, \ldots,|C|\}\right. \\
\text { (ii) } Y=Y_{1}^{f} \cup Y_{2}^{f} \cup \ldots \cup Y_{c}^{f} \cup \ldots \cup Y_{|C|}^{f}=Y_{1}^{o} \cup Y_{2}^{o} \cup \ldots \cup Y_{c}^{o} \cup \ldots \cup Y_{|C|}^{o} \\
\text { (iii) } Y_{1}^{f} \subseteq Y_{1}^{o} ; Y_{2}^{f} \subseteq Y_{1}^{o} \cup Y_{2}^{o} ; \ldots ; Y_{c}^{f} \subseteq Y_{1}^{o} \cup \ldots \cup Y_{c}^{o} .
\end{gathered}
$$

$\mathrm{O}$ algoritmo geral de uma heurística relax-and-fix com overlapping encontra-se definido em Algoritmo 2. 


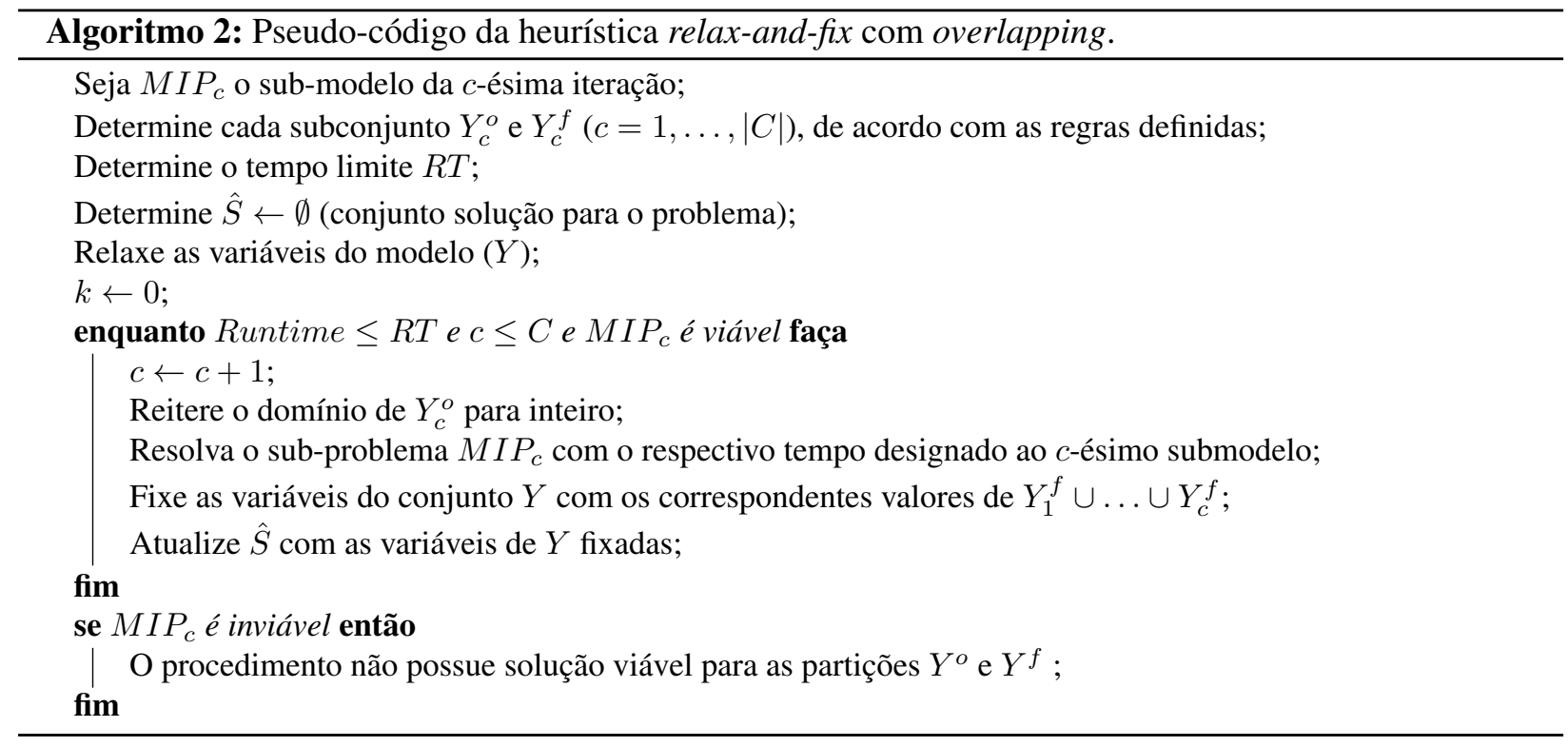

\section{Relax-and-fix: partição por períodos (RF_Forw, RF_Forw_II-I e RF_Back)}

Propomos três estratégias diferentes para se obter as partições necessárias para a execução da heurística relax-and-fix utilizando o horizonte de planejamento, mais precisamente os períodos. A primeira delas para a heurística relax-and-fix forward com overlapping (RF_Forw, representada na Figura 5.1) que tem suas partições $Y^{f}$ e $Y^{o}$ definidas por meio da divisão do horizonte de planejamento, onde cada partição tem um tamanho correspondente a duração do tempo de fermentação e maturação (min e max $\Delta_{l}$ ). As partições que definem os conjuntos $Y^{o}$ e $Y^{f}$ são estabelecidas progressivamente no horizonte de planejamento, ou seja, desde o início até o final do horizonte. O tamanho de cada subconjunto $Y^{o}$ é dado por $\max _{\forall l \in L} \Delta_{l}$ e cada subconjunto $Y^{f}$ é $\min _{\forall l \in L} \Delta_{l}$. Nos casos em que $\max _{\forall l \in L} \Delta_{l}$ difere de $\min _{\forall l \in L} \Delta_{l}$, incorre-se em overlapping. Por consequência, os tamanhos das partições são baseados nas características de cada instância. Esta abordagem relax-and-fix visa construir uma solução viável para o problema analisando o horizonte de planejamento progressivamente no tempo, decompondo-o em subproblemas menores e mais fáceis de serem resolvidos, considerando prioritárias as decisões envolvidas no início do horizonte, respeitando simultaneamente as restrições presentes nos estágios I e II (preparação do líquido e envase).

A segunda, a heurística relax-and-fix backward com overlapping (RF_Back), Figura 5.2, possui as mesmas definições para o tamanho dos subconjuntos $Y^{o}$ e $Y^{f}$ que RF_Forw, entretanto as partições são definidas do final seguindo ao início do horizonte de planejamento. Ou seja, esta abordagem, assim como RF_Forw, avalia conjuntamente as restrições presentes no estágios I e II; entretanto, contrariamente a RF_Forw, considera prioritária as decisões relacionadas ao final do horizonte de planejamento.

A terceira heurística relax-and-fix hibridiza as duas estratégias para a divisão e obtenção dos $|C|$ subconjuntos. As partições utilizadas em RF_Forw também são utilizadas para esta heurística. Entretanto, ambos os estágios são desvinculados, sendo processado primeiramente o estágio II e depois o estágio I. Ou seja, os conjuntos $Y_{k}^{o}$ e $Y_{k}^{f}$ relacionam apenas o estágio II na iteração k, enquanto que na iteração $k+1$ associa-se apenas o estágio I ( $Y_{k+1}^{o}$ e $Y_{k+1}^{f}$ ) e a junção das partições $k$ e $k+1$ correspondem a uma partição de RF_Forw. Esta heurística é denotada por RF_Forw_II-I. O intuito desta heurística é estabelecer uma programação da produção explorando progressivamente o horizonte de planejamento, analisando os estágios I e II de maneira desacoplada; ou seja, primeiro, estabelece-se o programa de produção às envasadoras 
levando em consideração a demanda dos itens e, depois, programa-se os tanques de forma a abastecer as envasadoras, suprindo a demanda de líquidos.

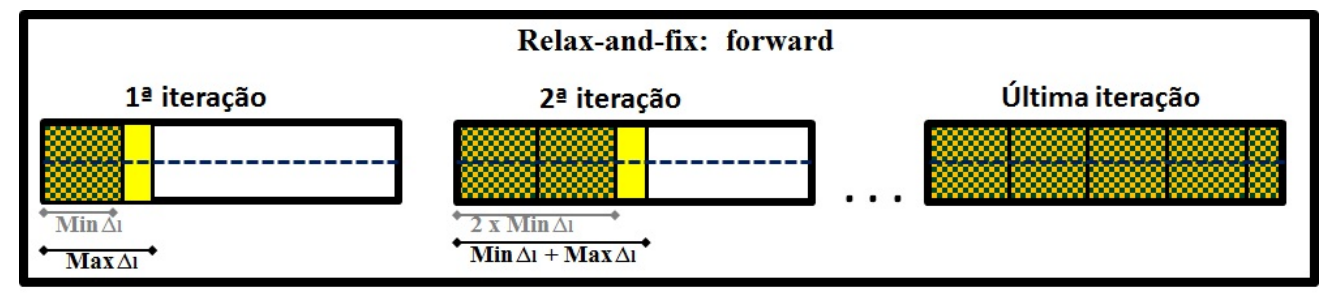

Figura 5.1: Ilustração das iterações da heurística relax-and-fix forward.

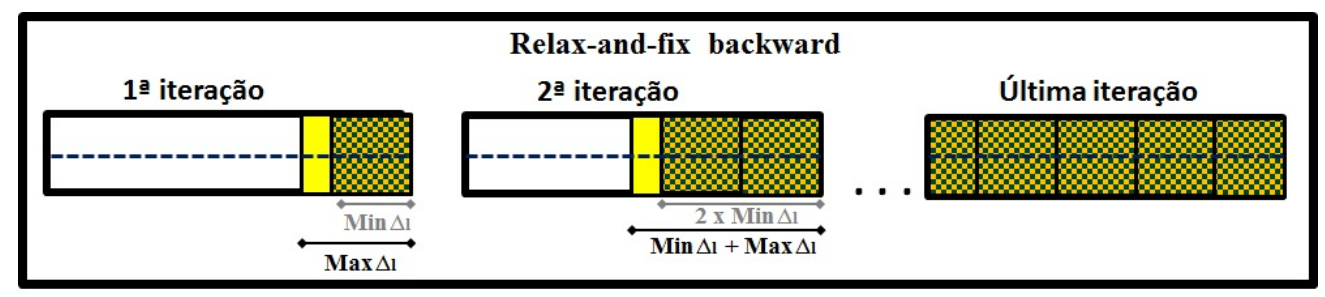

Figura 5.2: Ilustração das iterações da heurística relax-and-fix backward.

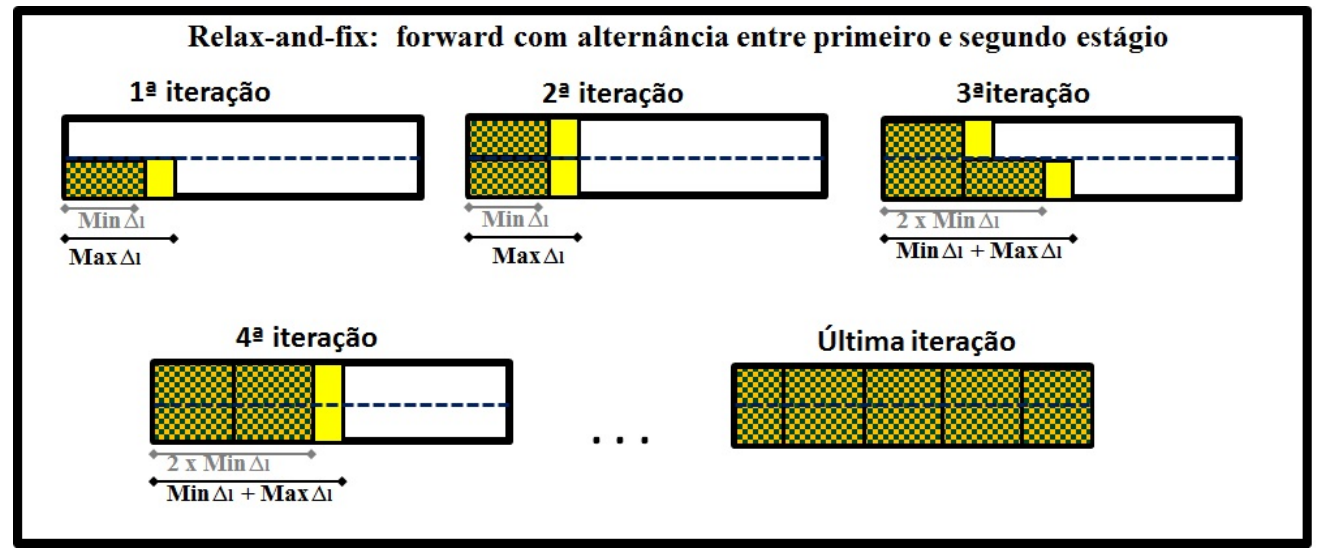

Figura 5.3: Ilustração das iterações da heurística relax-and-fix forward por estágios.

\section{Relax-and-fix: partição por tanques (RF_Tank)}

Esta heurística, assim como a próxima, não tem suas partições associadas ao horizonte de planejamento. A heurística aqui descrita tem suas partições definidas por meio da ordenação dos tanques, em ordem decrescente em relação a sua capacidade. Os subconjuntos $Y^{o}$ e $Y^{f}$ são do mesmo tamanho, ou seja, $\left|Y_{1}^{o}\right|=\left|Y_{1}^{f}\right|$ definido pelo maior tanque, $\left|Y_{2}^{o}\right|=\left|Y_{2}^{f}\right|$ definido pelo segundo maior tanque, e assim por diante. Esta estratégia é denominada RF_Tank. Um resumo de cada iteração deste procedimento encontra-se na Figura 5.4. onde na primeira iteração, as variáveis relacionadas ao maior tanque tem seu domínio reiterado e se o sub-MIP for factível, fixam-se estas variáveis nos respectivos valores fornecidos pela resolução do subMIP, e, assim por diante. Esta estratégia visa, de maneira gulosa, alocar os tanques, um a um, de modo a 
obter uma programação viável aos tanques e, consequentemente, quais as respectivas linhas de envase são abastecidas por ele(s).

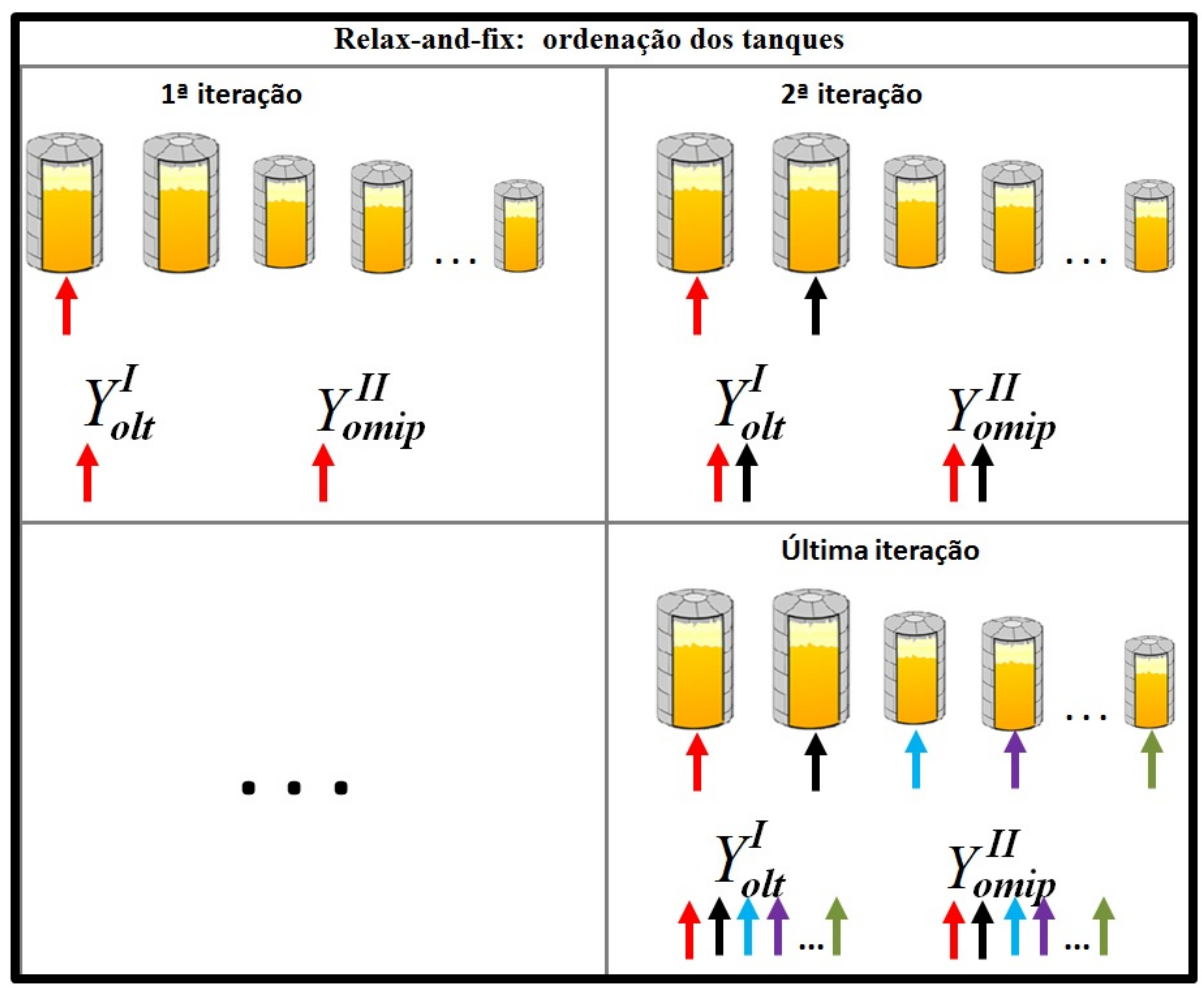

Figura 5.4: Ilustração das iterações da heurística relax-and-fix por tanques.

\section{Relax-and-fix: partição por líquidos (RF_Demand)}

Esta última heurística relax-and-fix (RF_Demand) define as partições $Y^{f}$ e $Y^{o}$ a partir da demanda de líquido, sendo cada conjunto definido pela ordenação da demanda de líquido de maneira decrescente. Ou seja, o líquido que possui maior demanda no decorrer do horizonte de planejamento define a primeira partição (consequentemente, os respectivos itens que utilizam este líquido, visto que cada item é composto de apenas um líquido). A segunda partição é definida pelo líquido de segunda maior procura, como, também, os itens oriundos deste líquido. E, assim, sucessivamente. A Figura 5.5 ilustra a cada iteração a ideia da heurística. Esta é uma estratégia gulosa, que analisa os líquidos (um a um), priorizando o(s) líquido(s) mais demandado(s), tendo o propósito de alocar o(s) tanque(s) e a(s) linha(s) de envase responsáveis para a preparação e produção, respectivamente, do líquido e de seu(s) item(ns). 


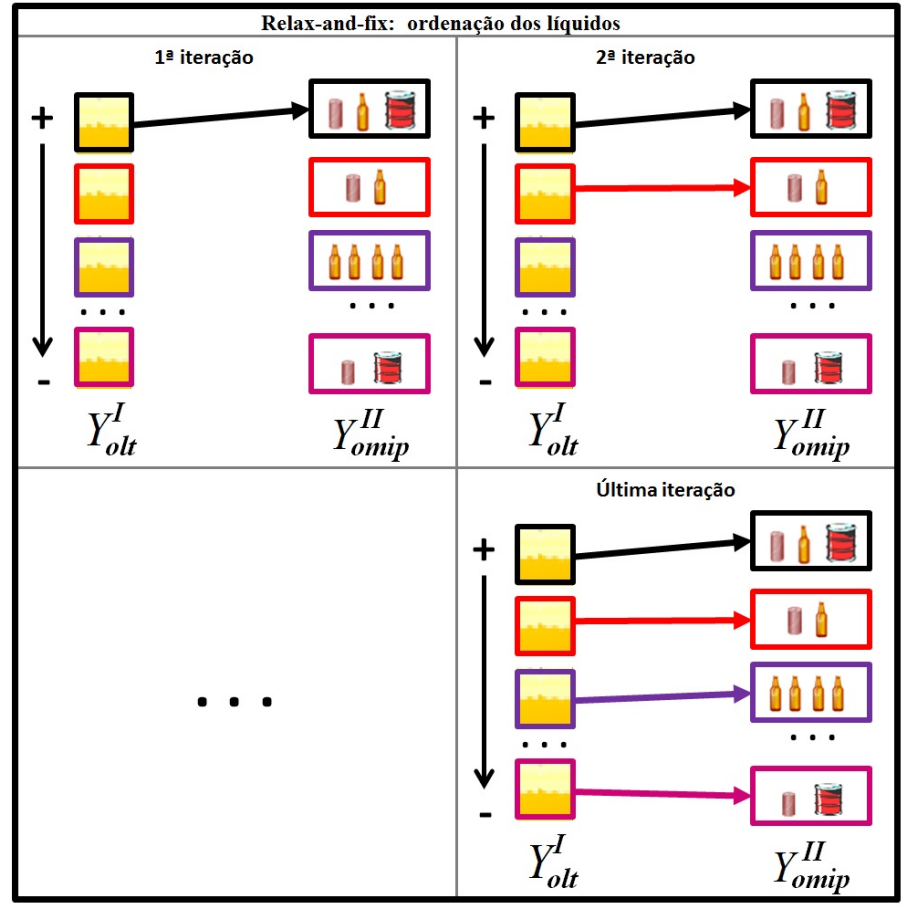

Figura 5.5: Ilustração das iterações da heurística relax-and-fix por líquidos e itens.

\subsubsection{Heurísticas de melhoria: fix-and-optimize (Opt_Forw, Opt_Back, Opt_Forw_II- I, Opt_Tank e Opt_Demand)}

O procedimento fix-and-optimize parte de uma solução viável do problema (veja $\hat{S}$ do Algoritmo 3 ) e tenta, de forma iterativa, melhorá-la. A solução incumbente $\hat{S}$ contém valores inteiros para as variáveis $Y$, que são denominados por $\hat{Y}$. O procedimento fix-and-optimize decompõe as variáveis de $\hat{Y}$ em subconjuntos disjuntos. Assim, a cada iteração do método, dois passos básicos são necessários: em primeiro lugar, um subconjunto de variáveis é selecionado para ter seus valores liberados para serem otimizados novamente (consequentemente, podendo assumir novos valores), e as demais variáveis tem seus valores fixos no valor corrente. Assim, o novo sub-MIP é resolvido até a otimalidade (ou até um limite de tempo). Se a função objetivo da nova solução for melhor, então as variáveis $\hat{Y}$ são redefinidas para o valor corrente; caso contrário, o valor da melhor solução encontrada até o momento $(\hat{S})$ é mantido. Este passo é repetido até que todos os subconjuntos sejam visitados pelo menos uma vez e enquanto o procedimento é capaz de encontrar melhores soluções dentro do limite de tempo de execução. O processo de melhoria (fix-and-optimize) também pode ser usado com overlapping. Em nossos experimentos, as cinco estratégias de decomposição utilizadas nas heurísticas relax-and-fix são utilizadas para os procedimentos fix-and-optimize. Portanto, as partições $Y^{o}$ e $Y^{f}$ definidas para cada estratégia relax-and-fix são usadas para o procedimento de melhoria ( $\hat{Y}^{o}$ e $\hat{Y}^{f}$ ), cujas denominações para os procedimentos são dadas por:

- Opt_Forw: partições definidas semelhantes a RF_Forw;

- Opt_Back: partições análogas a RF_Back;

- Opt_Forw_II-I: partições similares a RF_Forw_II-I 
- Opt_Tank: partições equivalentes a RF_Tank

- Opt_Demand: partições conforme RF_Demand.

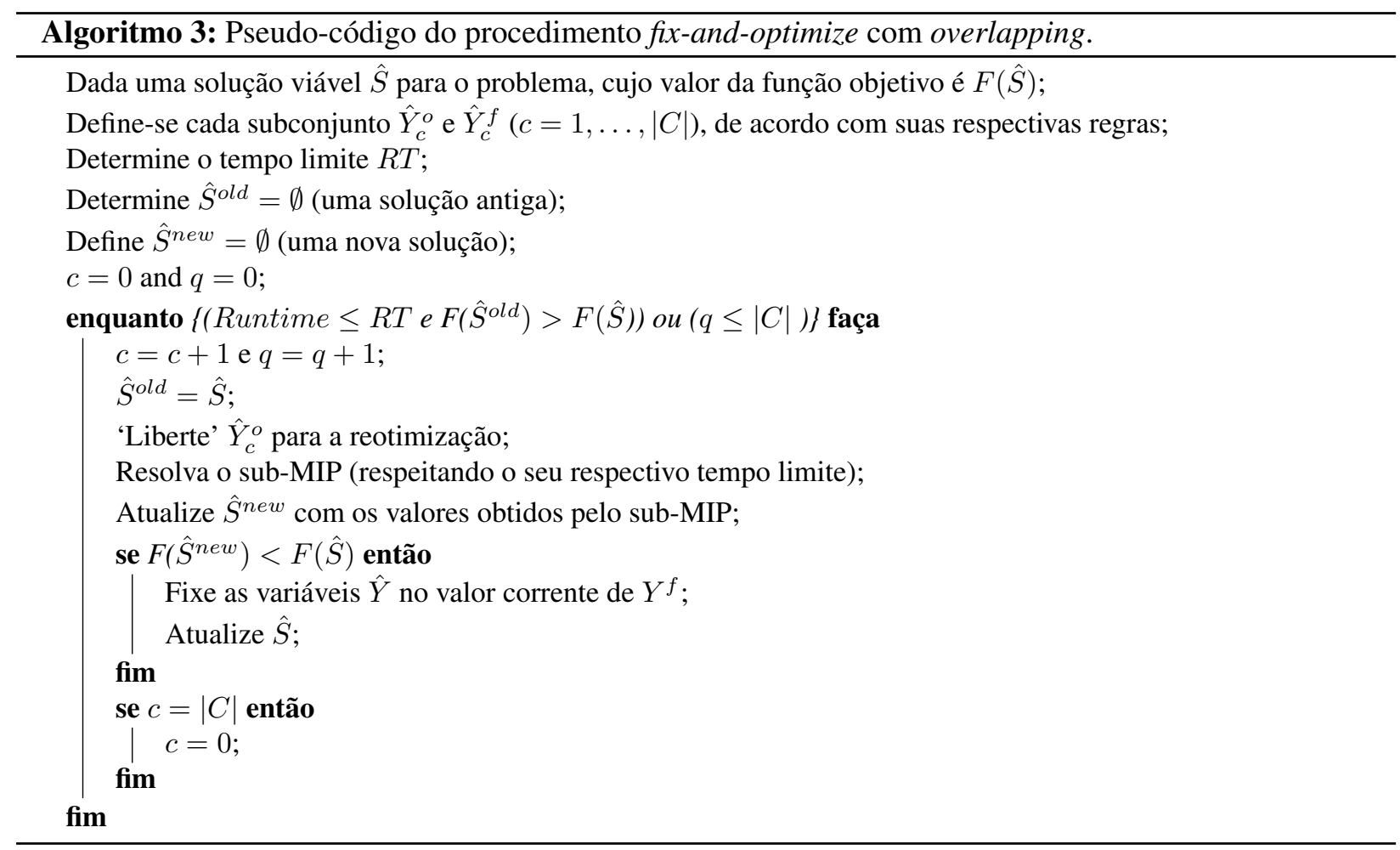

\subsubsection{Testes (iniciais) computacionais: MIP-heurísticas relax-and-fix e fix-and- optimize}

Devido ao grande número de combinações possíveis para se resolver o problema utilizando os procedimentos relax-and-fix e fix-and-optimize apresentados nas seções anteriores, utilizamos algumas estratégias para classificar as melhores heurísticas e combiná-las, buscando um método competitivo com os resultados da resolução do modelo TOLM-GLSP pelo CPLEX. Os métodos de resolução Proc_Crescente e Proc_Decrescente, propostos neste trabalho baseiam-se na geração de uma boa solução inicial utilizando a relax-and-fix e melhorando-a por meio das estratégias fix-and-optimize.

Para os testes preliminares, utilizou-se as mesmas configurações definidas no Capítulo 4 (Seção 4.2.5); ou seja, todos os procedimentos foram implementados utilizando a linguagem de programação $\mathrm{C}++$, conjuntamente com a biblioteca Concert do software de otimização CPLEX (versão 12.4), utilizou-se uma máquina com processador Intel(R) i7 2600 com quatro núcleos (2 threads cada) de $3.4 \mathrm{GHz}$ cada e 16GB de RAM. Porém, para resolver cada instância, limitou-se a utilização em 4 threads. O sistema operacional foi o Windows 7. A execução dos algoritmos foi limitada a um tempo de 3600 segundos para cada instância.

Para estes testes computacionais utilizou-se as 7 instâncias menores (definidos no Capítulo 4, Seção 4.2.4 - Tabela 4.6, ou seja, as instâncias P_1_5_1 a P_4_20_1. Inicialmente, testamos todas as heurísticas relax-and-fix e as comparamos com relação ao GAP obtido (definido pela equação 4.16) e tempo de execução. Os resultados também foram comparados com os obtidos por meio da resolução do modelo utilizando o software de otimização CPLEX. Os resultados estão na Tebela 5.1 . 
Observe na Tabela 5.1 que na resolução do modelo TOLM-GLSP, o CPLEX utilizou todo o tempo na resolução para a instâncias, porém com menor GAP para algumas delas. A heurística RF_Forw obteve um melhor desempenho para todas as instâncias quando comparada as demais estratégias relax-and-fix. As heurísticas relax-and-fix RF_Forw_II-I, RF_Tank e RF_Demand, de maneira geral, não obtiveram um bom desempenho, logo não são mais citadas. Vários testes foram realizados, dentre eles destacamos as relax-and-fix onde apenas as variáveis que reiteraram seu domínio para inteiro $(Y)$, durante a execução dos procedimentos, foram fixadas a cada iteração (veja a (A) na Tabela 5.1). Outro teste foi considerar também as variáveis reais $Q_{\text {olt }}$ limitadas inferiormente pelos valores obtidos na(s) partição(ões) anterior(es) (veja a (B) na Tabela 5.1p e, por fim, fixando $Q_{\text {olt }}$, utilizando o primeiro valor encontrado. Este último não apresentou um bom desempenho, resultando em muitos atrasos na entrega da demanda, por isso não o reportamos.

O melhor GAP médio dentre as MIP-heurísticas relax-and-fix foi obtido pela RF_Forw (veja A e B na Tabela 5.1. Portanto, esta é utilizada para gerar a solução inicial do nosso método Proc_Crescente e Proc_Decrescente. Observe que o GAP médio na Tabela 5.1 em A e B, para RF_Forw, tem valores próximos, mas B obteve um melhor GAP médio. Logo, optou-se pela estratégia B, ou seja, a cada iteração, além de fixarmos as variáveis $Y$, também limitamos inferiormente as variáveis reais $Q_{\text {olt }}$ pelos valores obtidos nas iterações anteriores. Após definida a heurística que irá gerar a solução inicial, precisa-se definir como será aplicado o procedimento de melhoria.

Para encontrar qual (ou quais) fix-and-optmize será(ão) utilizado nos métodos finais (Proc_Crescente e Proc_Decrescente), também realizamos testes preliminares com as mesmas 7 instâncias do teste anterior (P_1_5_1 a P_4_20_1). Primeiramente, utilizou-se o método Populate (disponível no software de otimização CPLEX) para gerar a solução inicial e aplicou-se os respectivos procedimentos de melhoria. Os resultados foram tabelados (veja a Tabela 5.2) e os GAPs calculados, como também, o GAP médio de cada procedimento. Note que os procedimentos de melhoria, de maneira geral, obtêm bons resultados, diminuindo consideravelmente o GAP da solução inicial encontrada pelo Populate.

Sendo assim, para o nosso método final, utilizamos todos os procedimentos de melhoria fix-and-optmize. Estes são aplicados de duas maneiras diferentes: na primeira o procedimento começa com o fix-and-optimize que obteve o menor GAP até o de maior GAP médio (veja a Tabela 5.2), ou seja, nesta ordem: OPT_Forw, OPT_Back, OPT_Demand, OPT_Forw_II-I e OPT_Tank, denominada de Proc_Decrescente. Na segunda maneira, as heurísticas de melhoria foram utilizadas na ordem do maior GAP médio para o menor, ou seja, nesta sequência OPT_Tank, OPT_Forw_II-I, OPT_Demand, OPT_Back e OPT_Forw, Proc_Crescente.

Gostaríamos de destacar algumas considerações importantes, principalmente em relação à escolha da heurística para obter a solução inicial. Foram feitos vários testes variando o tempo limite de execução das heurísticas e do Populate. Quando o tempo é superior a 900 segundos, concluímos que para 100\% dos casos a heurística RF_Forw superou o método Populate. Por isso não cogitamos a possibilidade de utilizar o Populate em nossos procedimentos Proc_Crescente e Proc_Decrescente. 

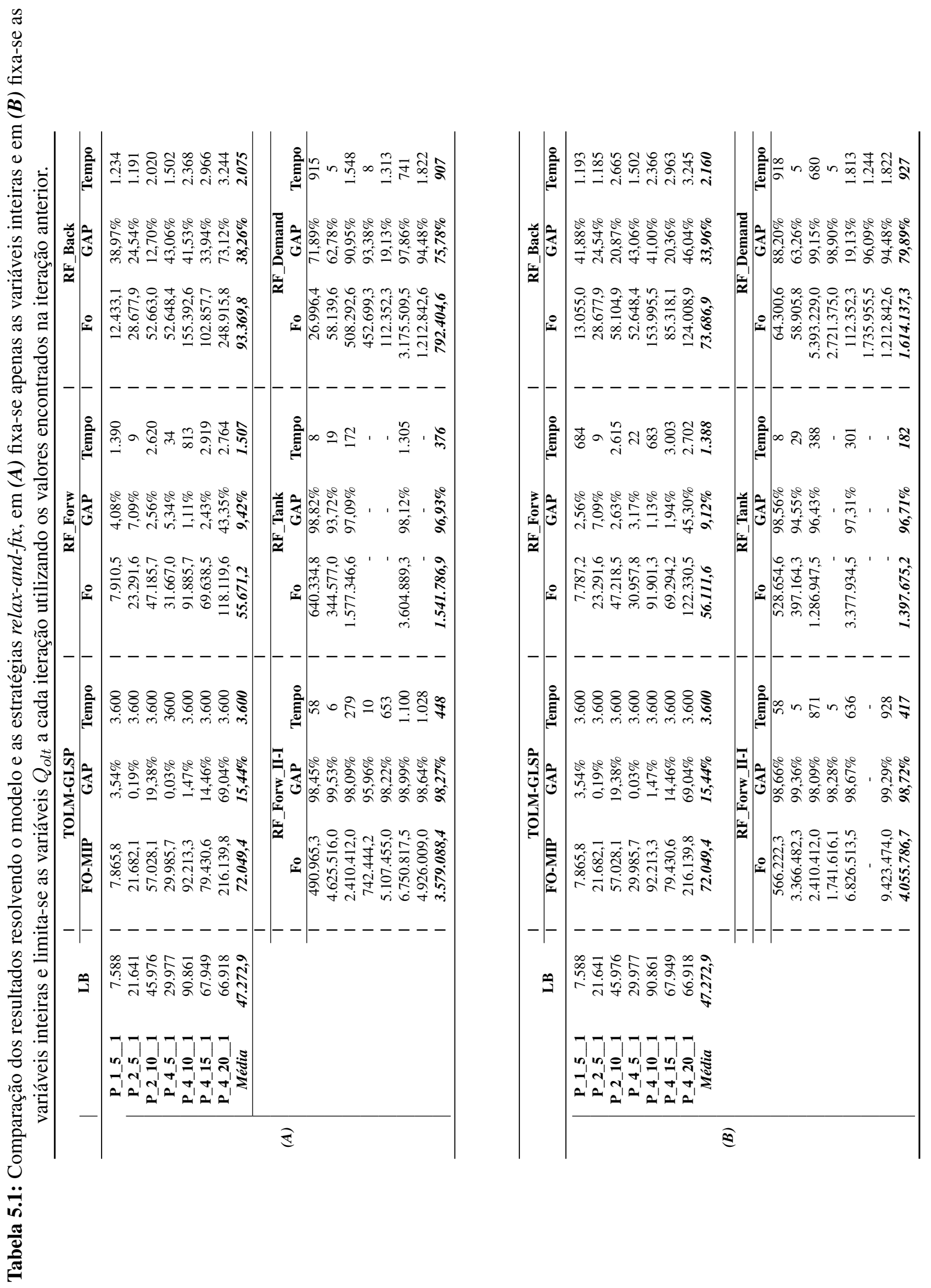


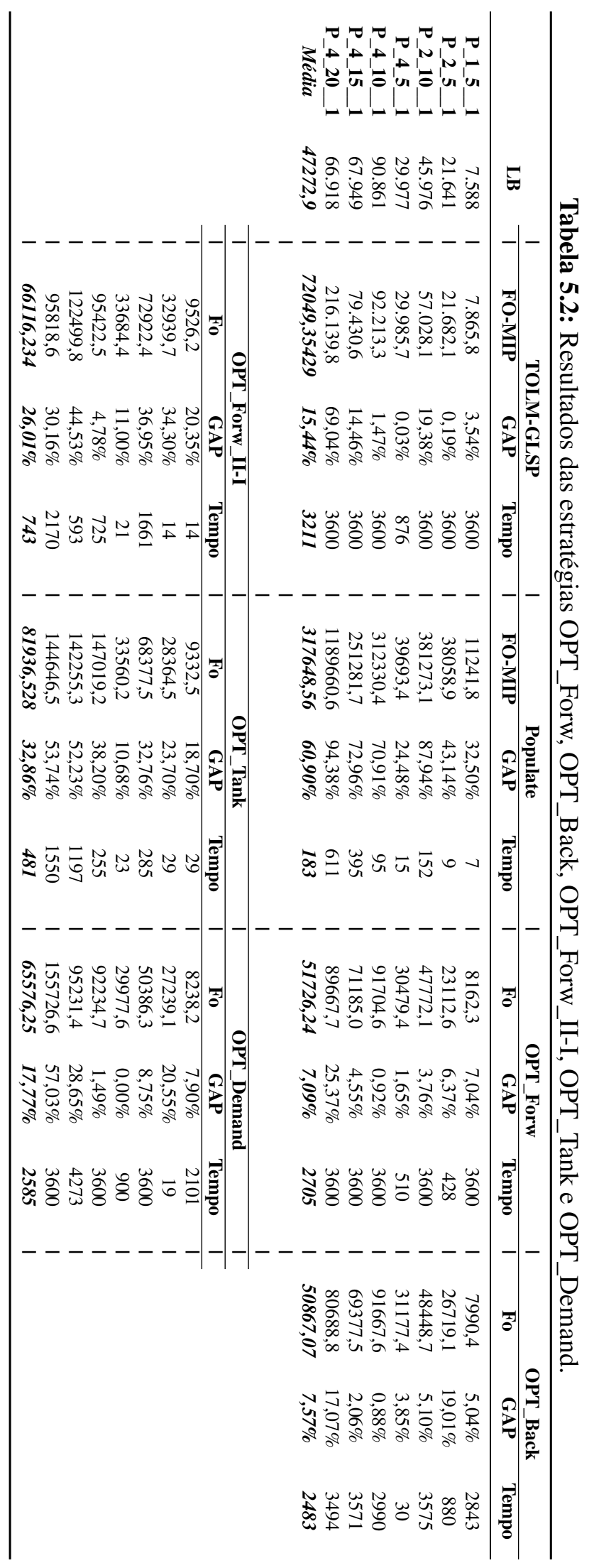




\subsection{MIP-heurística: decomposição por estágios}

A decomposição por estágios consiste na resolução de cada um dos estágios envolvidos durante o processo produtivo de maneira desacoplada. Primeiramente, resolve-se o estágio I e, na sequência, o estágio II. Este último recebe informações obtidas pela resolução do anterior e estas devem ser respeitadas. O estágio I fornece ao estágio II qual líquido, qual período e a respectiva quantidade deste líquido está pronta em cada um dos tanques durante o decorrer do horizonte de planejamento (veja a Figura 3.2 do Capítulo 3).

Algumas restrições foram inseridas ao estágio I, com o intuito de que os líquidos não fiquem todos prontos ao mesmo tempo e sobrecarreguem as linhas de envase. Consequentemente, também evitando a infactibilidade, pois com esta sobrecarga nas linhas, resultava no não esvaziamento completo dos tanques, implicando na situação inviável em que o próximo líquido a ser inserido ao tanque conflitasse com o líquido anterior.

Um tanque demora (em média) 1 período e meio para ser esvaziado quando abastece uma única envasadora ( $\varpi=1,5$, onde $\varpi$ representa o número de períodos necessários para esvaziar um tanque por uma única envasadora). Ou seja, durante quase dois períodos, uma máquina fica dedicada a este tanque. Sendo assim, esta restrição foi incorporada ao estágio I $\left(\sum_{o \in O} \sum_{l \in L} \sum_{t^{\prime}=0}^{\lceil\varpi\rceil} Y_{o l t+t^{\prime}}^{I} \leq|M|, t \in T\right)$. Para evitar atrasos, adianta-se a demanda de líquido em $\lfloor\varpi\rfloor$ períodos (ou seja, em um dia), excluindo a possibilidade da demanda de itens ocorrer no mesmo período que o líquido fica pronto. Assim, inclui-se a restrição $\sum_{t^{\prime}=0}^{t+\lfloor\varpi\rfloor} \sum_{i \in \gamma_{l} \cap \mu_{m}} r_{l i} d_{i, t^{\prime}} \leq \sum_{t^{\prime}=0}^{t} \sum_{o \in O} X_{o l t}^{I}, l \in L ; t \in T$.

As demais restrições seguem a mesma definição do problema original. Considere as novas variáveis descritas a seguir.

\section{Variáveis:}

\section{Estágio I}

$K_{\text {olt }}^{-}$: quantidade faltante de líquido $l$ pronto no tanque $o$ no período $t$

$K_{o l t}^{+}$: quantidade em estoque de líquido $l$ pronto no tanque $o$ no período $t$;

$X_{o l t}^{I}$ : demanda de líquido $l$ atendida pelo tanque $o$ no período $t$.

\section{Estágio I}

\section{Minimizar}

$$
\sum_{i \in N} \sum_{l \in L} \sum_{t \in T}\left(K_{o l t}^{-}+\frac{K_{o l t}^{+}}{C a p_{\max }^{o}}\right)
$$


Sujeito a:

$$
\begin{array}{cl}
\sum_{o \in O} \sum_{l \in L} \sum_{t^{\prime}=0}^{\lceil\varpi\rceil} Y_{o l t+t^{\prime}}^{I} \leq|M| & t \in T \\
\sum_{t^{\prime}=0}^{t+\lfloor\varpi\rfloor} \sum_{i \in \gamma_{l} \cap \mu_{m}} r_{l i} d_{i, t^{\prime}} \leq \sum_{t^{\prime}=0}^{t} \sum_{o \in O} X_{o l t}^{I} & l \in L ; t \in T \\
\sum_{t \in T} \sum_{i \in \gamma_{l} \cap \mu_{m}} r_{l i} d_{i, t}=\sum_{t \in t} \sum_{o \in O} X_{o l t}^{I} & l \in L \\
K_{o l t}^{+}+K_{o l, t-1}^{-}=K_{o l, t-1}^{+}+K_{o l, t}^{-}-X_{o l t}^{I}+Q_{o l t} & o \in O ; l \in L ; t \in T \\
\sum_{l^{\prime}=1}^{L} \sum_{t^{\prime}=1}^{\Delta_{l}+1} K_{o l^{\prime}, t-t^{\prime}}^{+} \leq B\left(1-Y_{o l t}^{I}\right) & o \in O ; l \in L ; t \in T
\end{array}
$$

Restrições (4.27)-(4.28)

A função objetivo (5.1) visa minimizar a falta de líquido nos tanques, penalizando esta falta, e também evitar que o líquido fique estocado dentro dos tanques, entretanto com uma penalidade menor. As restrições 5.2) garantem, que durante $\lceil\varpi\rceil$ períodos consecutivos, não pode haver mais que $|M|$ tanques com líquidos ficando pronto, pois todas as envasadoras estarão ocupadas. As restrições 5.3 e e 5.2 ) calculam a demanda de líquido necessária para cada período.

Após a resolução do estágio I, resolve-se o estágio II. Para resolução do estágio II, utilizamos os resultados obtidos para as variáveis $Q_{\text {olt }}=Q$ copia ${ }_{\text {olt }}$ e para as variáveis $Y_{\text {olt }}^{I}=Y$ copia $a_{\text {olt }}^{I}$, que agora denominemos de Qcopia $_{\text {olt }}$ e $Y$ copia $I_{\text {olt }}^{I}$ para diferenciarmos da variável do estágio anterior, dado que são parâmetros no estágio II.

\section{Estágio II}

\section{Função objetivo}

Função objetivo do modelo TOLM-GLSP 4.17).

Sujeito a:

$$
\begin{aligned}
& K_{\text {olt }}=K_{o l, t-1}-\sum_{m} \sum_{i \in \gamma_{l} \cap \mu_{m}} \sum_{p \in \lambda_{t}} r_{l i} X_{\text {omip }}+Q_{\text {copia }} \quad \forall o, l, t \\
& K_{o l, t-1} \leq \operatorname{Cap}_{\text {max }}^{o}\left(1-Y \text { copia }_{\text {olt }}^{I}\right) \quad \forall o, l, t
\end{aligned}
$$

Restrições (4.22) - (4.29).

As restrições (5.7) e (5.7) são semelhantes as 4.18) e (4.19), respectivamente. 


\subsection{Resultados das MIP-heurísticas}

Os procedimentos Proc_Crescente, Proc_Decrecente e Decomposição por estágios propostos nas seções anteriores foram implementados utilizando a linguagem de programação $\mathrm{C}++$, conjuntamente com a biblioteca Concert do software de otimização CPLEX (versão 12.4), assim como os demais procedimentos apresentados anteriormente. Estes foram executados utilizando as mesmas condições de teste definidas no Capítulo 4 (Seção 4.2.5). As instâncias utilizadas estão definidas neste mesmo capítulo, na Seção 4.2.4Tabela 4.6 .

Todas as MIP-heurísticas obtiveram melhores GAPs médios, definidos pela equação [4.16], quando comparadas ao modelo TOLM-GSP. O tempo computacional foi bastante elevado para todos os procedimentos, atingindo o tempo limite de execução (3600 segundos) para a grande maioria dos exemplares testados. Observe na Tabela 5.3 que todas as MIP-heurísticas obtiveram menores GAPs que o CPLEX ao resolver o modelo TOLM-GLSP, para as instâncias de grande dimensão (D_5_35_1 a D_5_40_10). Ao analisarmos as instâncias menores, as MIP-heurísticas mostraram-se competitivas ao CPLEX, com destaque para Proc_Crescente obtendo soluções melhores que CPLEX para 85,7\% dos exemplares. Note que o GAP obtido por Proc_Crescente e Proc_Decrescente para a instância $P \_4 \_5 \_1$ podem ser considerados ótimos. Ao compararmos as abordagens, nota-se que são competitivas, entretanto Proc_Crescente e Proc_Decrescente tem desempenho superiores. No geral, tem-se que Proc_Crescente apresenta melhor desempenho que as demais MIP-heurísticas ao compararmos os GAPs médios, obtendo 26,13\%, enquanto que Proc_Decrescente e Decomposição por estágios 45,64\% e 55,82\%, respectivamente. 


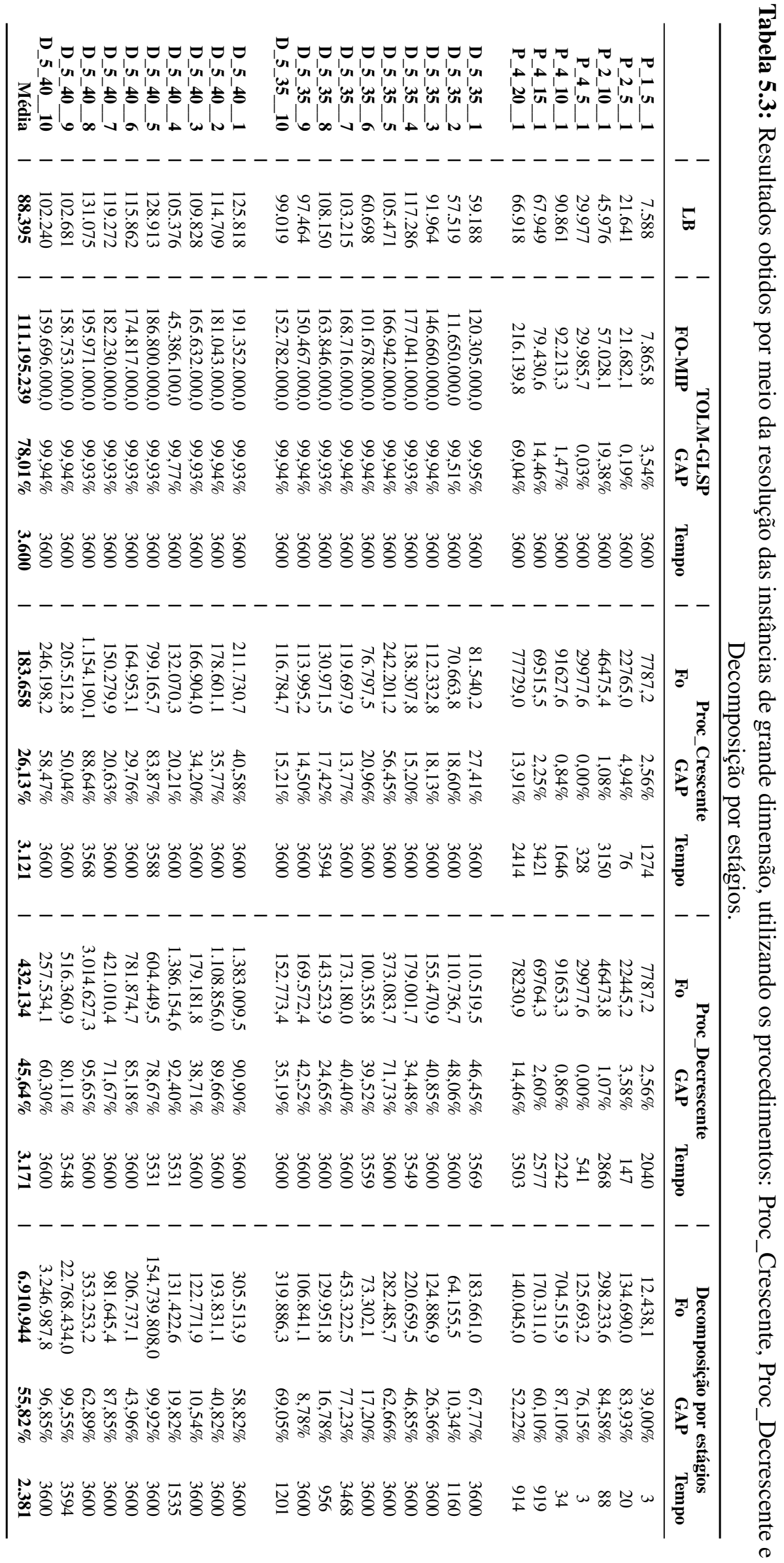




\subsection{Análise de sensibilidade}

De maneira geral, as MIP-heurísticas obtiveram um bom desempenho quando comparadas aos resultados obtidos pelo modelo matemático TOLM-GLSP. Destacando-se Proc_Crescente e, na sequência, Proc_Decrescente. Nesta seção, testes computacionais são realizados com o intuito de analisar a sensibilidade do modelo e das soluções MIP-heurísticas ao realizar perturbações em alguns parâmetros das instâncias testes de maiores dimensões. Por exemplo, qual a influência exercida nas soluções caso ocorra a compra de novos tanques de fermentação/maturação, ou ainda, a utilização de algum recurso que propicie a aceleração do tempo de fermentação e maturação? Sendo assim, novas instâncias foram geradas alterando-se o número original de tanques $\left(\left|O^{\text {original }}\right|\right)$ ou a quantidade de dias necessários para se completar o tempo de fermentação e maturação dos líquidos ( $\Delta_{l}^{\text {original }}$ ) das 20 instâncias de maiores dimensões definidas no Capítulo 4 (Seção 4.2.4 - Tabela 4.6, instâncias D_5_35_1 a D_5_40_10). As variações destes parâmetros estão definidas a seguir:

- diminuição do número de dias necessários para a completude do tempo de fermentação/maturação dos líquidos em $10 \%\left(\Delta_{l}=\left\lfloor 0,9 \times \Delta_{l}^{\text {original }}\right\rfloor, \forall l \in L\right)$,

- aumento da quantidade de tanques em $5 \%\left(|O|=\left\lceil 1,05 \times\left|O^{\text {original }}\right|\right\rceil\right)$,

- aumento da quantidade de tanques em $10 \%\left(|O|=\left\lceil 1,10 \times\left|O^{\text {original }}\right|\right\rceil\right)$.

Os novos conjuntos de instâncias testes foram resolvidos utilizando o modelo TOLM-GLSP e as MIPheurísticas Proc_Crescente e Proc_Decrescente. O tempo de execução foi limitado em 3600 segundos. Considera-se, para as MIP-heurísticas, um limite máximo de tempo de 900 segundos para a execução da RF_Forw (solução inicial) e o tempo restante para a heurística de melhoria (fix-and-optimize), semelhante as condições utilizadas para os testes da Tabela 5.3. Analisou-se o valor da função objetivo (Fo), o GAP (calculado utilizando a equação (4.16) ) e o tempo de execução despendido ao resolver cada nova instância proposta.

Todos os procedimentos utilizaram praticamente $100 \%$ do tempo para a resolução das instâncias e os resultados encontram-se nas Tabelas 5.4 (A)-(C). A Tabela 5.4(A) apresenta os valores obtidos por meio da resolução das instâncias geradas ao reduzir o número de dias necessários para a completude do estágio de fermentação e maturação $\left(\Delta_{l}=\left\lfloor 0,9 \times \Delta_{l}^{\text {original }}\right\rfloor, \forall l \in L\right)$. As Tabelas 5.4 (B) e (C) mostram os resultados das instâncias geradas com o aumento do número de tanques $\left(|O|=\left\lceil 1,05 \times\left|O^{\text {original }}\right|\right\rceil\right.$ e $|O|=\left\lceil 1,10 \times\left|O^{\text {original }}\right|\right\rceil$, respectivamente) .

Analisando-se os resultados da Tabela 5.4 (A), o modelo apresenta dificuldade em encontrar uma boa solução, quando comparado a Proc_Crescente e Proc_Decrescente, com GAP superior a 97\% para todos os exemplares e GAP médio superior a 99\%. Ao analisarmos as MIP-heurísticas, Proc_Crescente apresenta GAPs com valores menores que Proc_Decrecente para a maior parte das instâncias e um GAP médio igual a $31,87 \%$ e $64,28 \%$, respectivamente.

Para as instâncias geradas com o aumento do número de tanques $\left(|O|=\left\lceil 1,05 \times\left|O^{\text {original }}\right|\right\rceil\right.$ e $|O|=$ $\left\lceil 1,10 \times\left|O^{\text {original }}\right|\right\rceil$ ), observa-se novamente a superioridade de Proc_Crescente e Proc_Decrescente em relação as soluções obtidas pelo modelo (veja as Tabelas 5.4 (C) e (D)). Nota-se que Proc_Decrescente obteve um melhor desempenho médio para as instâncias geradas a partir de $|O|=\left\lceil 1,05 \times\left|O^{\text {original }}\right|\right\rceil$, quando analisa-se o GAP. Proc_Decrescente foi melhor para $|O|=\left\lceil 1,10 \times\left|O^{\text {original }}\right|\right\rceil$. 
Resumidamente, ao analisarmos o $G A P$, observa-se a superioridade em qualidade de solução das MIPheurísticas, comparadas ao modelo. Para todos os testes realizados, apenas em $|O|=\left\lceil 1,10 \times\left|O^{\text {original }}\right|\right\rceil$ Proc_Decrescente apresentou-se superior a Proc_Crescente, quando considera-se o valor médio do GAP; porém, note que Proc_Crescente conseguiu encontrar uma solução melhor para 50\% dos exemplares deste conjunto de instâncias, apresentando um valor médio de GAP não tão discrepante de Proc_Decrescente (Tabela 5.4(C)). Quando comparamos o GAP médio dos demais testes, nota-se um melhor desempenho de Proc_Crescente e uma diferença razoável dos valores médios obtidos entre as heurísticas. Ao analisarmos os resultados obtidos nesta seção com os das instâncias originais (Tabelas $5.4 \mathrm{e} 5.3$, respectivamente), nota-se que o desempenho do modelo, independente da alteração dos parâmetros, manteve-se praticamente semelhante; diferentemente das MIP-heurísticas, que para a grande maioria das novas instâncias, apresentaram uma melhoria no valor do $G A P$ e da função objetivo. 
Tabela 5.4: Resultados da análise de sensibilidade do modelo e das MIP-heurísticas.

(A) $\quad \Delta_{l}=\left\lfloor 0,9 \times \Delta_{l}^{\text {original }} \mid, \forall l \in L\right.$

\begin{tabular}{|c|c|c|c|c|c|c|c|c|c|c|c|c|c|c|}
\hline & \multirow{2}{*}{$\begin{array}{l}1 \\
1\end{array}$} & \multirow[b]{2}{*}{ LB } & \multirow{2}{*}{$\begin{array}{l}1 \\
1\end{array}$} & \multicolumn{3}{|c|}{ TOLM-GLSP } & \multirow{2}{*}{$\begin{array}{l}1 \\
1\end{array}$} & \multicolumn{3}{|c|}{ Proc_Crescente } & \multirow{2}{*}{$\begin{array}{l}1 \\
1\end{array}$} & \multicolumn{3}{|c|}{ Proc_Decrescente } \\
\hline & & & & FO-MIP & GAP & Tempo & & Fo & GAP & Tempo & & Fo & GAP & Tempo \\
\hline D_5_35 1 & I & 59.172 & I & $2.556 .010,8$ & $97,68 \%$ & 3600 & I & 73098,6 & $19,05 \%$ & 3600 & 1 & 69827,0 & $15,26 \%$ & 3600 \\
\hline D_5_35_2 & I & 57.517 & I & $124.440 .288,0$ & $99,95 \%$ & 3600 & I & 72955,7 & $21,16 \%$ & 3514 & 1 & 69286,9 & $16,99 \%$ & 3600 \\
\hline D_5_35_3 & I & 91.964 & I & $146.660 .336,0$ & $99,94 \%$ & 3600 & I & 102374,5 & $10,17 \%$ & 3600 & I & 616060,4 & $85,07 \%$ & 3600 \\
\hline D_5_35_4 & I & 117.286 & I & $177.040 .928,0$ & $99,93 \%$ & 3600 & I & 186811,3 & $37,22 \%$ & 3600 & I & 373325,3 & $68,58 \%$ & 3585 \\
\hline D_5_35_5 & I & 105.471 & I & $166.942 .096,0$ & $99,94 \%$ & 3600 & I & 119077,8 & $11,43 \%$ & 3600 & I & 148329,4 & $28,89 \%$ & 3600 \\
\hline D_5_35_6 & I & 60.712 & I & $12.329 .240,0$ & $99,51 \%$ & 3600 & I & 74144,6 & $18,12 \%$ & 3600 & I & 124058,5 & $51,06 \%$ & 3526 \\
\hline D_5_35_7 & I & 103.273 & I & $31.245 .312,0$ & $99,67 \%$ & 3600 & I & 114445,0 & $9,76 \%$ & 3600 & I & 926323,0 & $88,85 \%$ & 3600 \\
\hline D_5_35_8 & I & 108.150 & I & $15.450 .486,0$ & $99,30 \%$ & 3600 & I & 119881,1 & $9,79 \%$ & 3600 & I & 129373,9 & $16,41 \%$ & 3600 \\
\hline D_5_35_9 & I & 97.467 & I & $10.411 .625,0$ & $99,06 \%$ & 3600 & I & $109.588,8$ & $11,06 \%$ & 3600 & 1 & $458.218,9$ & $78,73 \%$ & 3600 \\
\hline D_5_35_10 & I & 99.021 & I & $152.782 .304,0$ & $99,94 \%$ & 3600 & I & $111.276,2$ & $11,01 \%$ & 3600 & I & $359.165,7$ & $72,43 \%$ & 3550 \\
\hline & I & & I & & & & I & & & & 1 & & & \\
\hline D_5_40_1 & I & 125.818 & I & $184.869 .152,0$ & $99,93 \%$ & 3600 & I & $201.459,7$ & $37,55 \%$ & 3600 & I & $1.827 .716,3$ & $93,12 \%$ & 3600 \\
\hline D_5_40_2 & I & 114.709 & I & $22.814 .854,0$ & $99,50 \%$ & 3600 & I & $248.678,5$ & $53,87 \%$ & 3520 & I & $1.033 .855,1$ & $88,90 \%$ & 3552 \\
\hline D_5_40_3 & I & 109.836 & I & $159.653 .632,0$ & $99,93 \%$ & 3600 & I & $172.722,3$ & $36,41 \%$ & 3510 & I & $561.310,8$ & $80,43 \%$ & 3600 \\
\hline D_5_40_4 & I & 105.375 & I & $159.143 .200,0$ & $99,93 \%$ & 3600 & I & $135.642,7$ & $22,31 \%$ & 3600 & I & $155.486,9$ & $32,23 \%$ & 3600 \\
\hline D_5_40_5 & I & 128.913 & I & $186.799 .808,0$ & $99,93 \%$ & 3600 & I & $244.231,1$ & $47,22 \%$ & 3600 & I & $185.107,2$ & $30,36 \%$ & 3600 \\
\hline D_5_40_6 & I & 115.863 & I & $174.816 .544,0$ & $99,93 \%$ & 3600 & I & $280.111,1$ & $58,64 \%$ & 3534 & I & $849.649,3$ & $86,36 \%$ & 3600 \\
\hline D_5_40_7 & I & 119.325 & I & $24.164 .846,0$ & $99,51 \%$ & 3600 & I & $171.907,4$ & $30,59 \%$ & 3600 & I & $1.936 .527,8$ & $93,84 \%$ & 3600 \\
\hline D_5_40_8 & I & 131.075 & I & $195.970 .736,0$ & $99,93 \%$ & 3600 & I & $508.119,7$ & $74,20 \%$ & 3600 & I & $806.981,8$ & $83,76 \%$ & 3600 \\
\hline D_5_40_9 & I & 102.697 & I & $32.082 .416,0$ & $99,68 \%$ & 3600 & I & $249.643,0$ & $58,86 \%$ & 3600 & I & $3.737 .433,3$ & $97,25 \%$ & 3600 \\
\hline D_5_40_10 & I & 102.244 & I & $19.167 .416,0$ & $99,47 \%$ & 3600 & I & $249.535,3$ & $59,03 \%$ & 3600 & 1 & $447.360,3$ & $77,15 \%$ & 3600 \\
\hline Média & I & 102.794 & I & 99.967.061 & $99,63 \%$ & 3600 & I & 177.285 & $31,87 \%$ & 3584 & I & 740.770 & $64,28 \%$ & 3591 \\
\hline
\end{tabular}

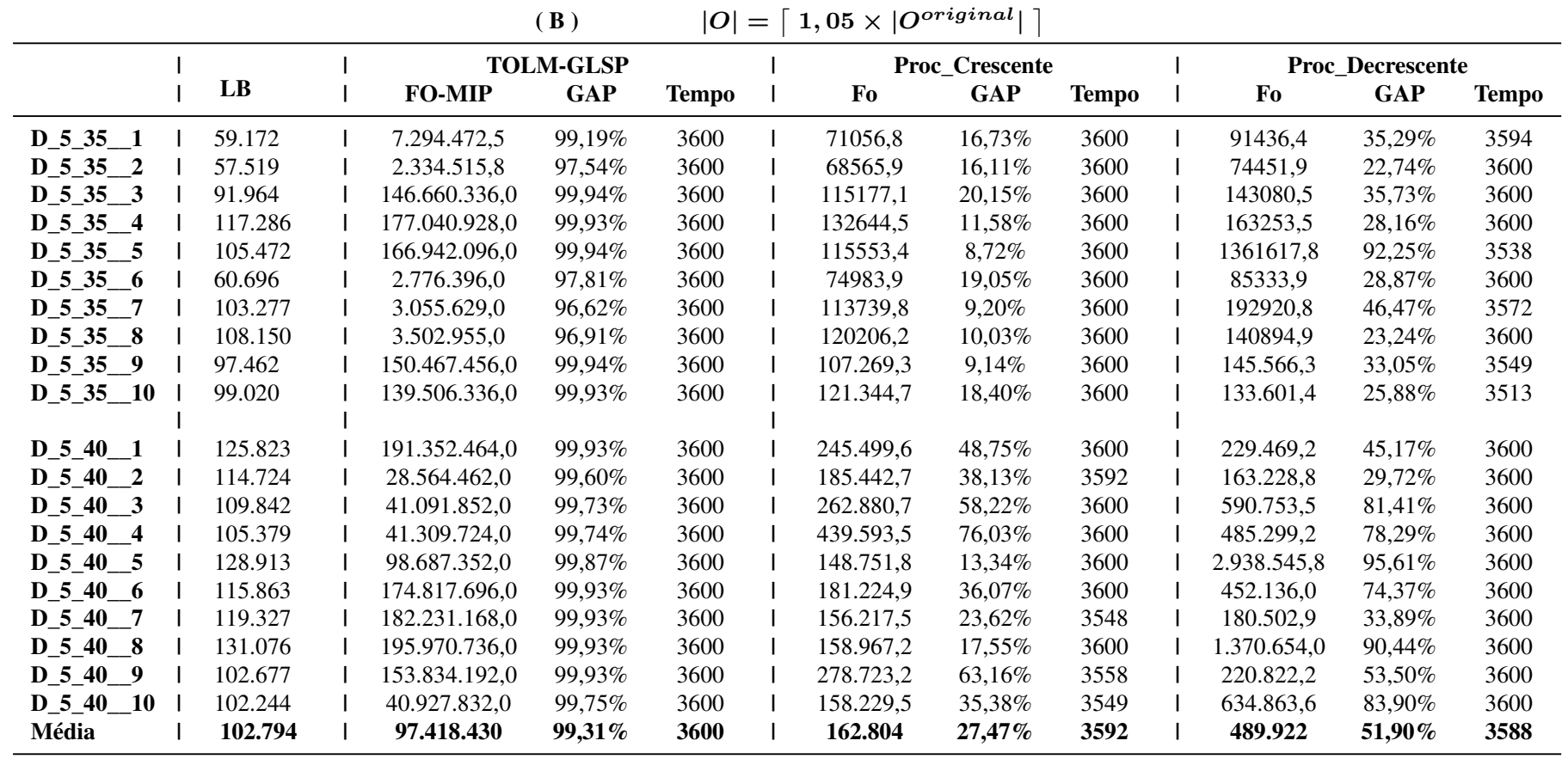

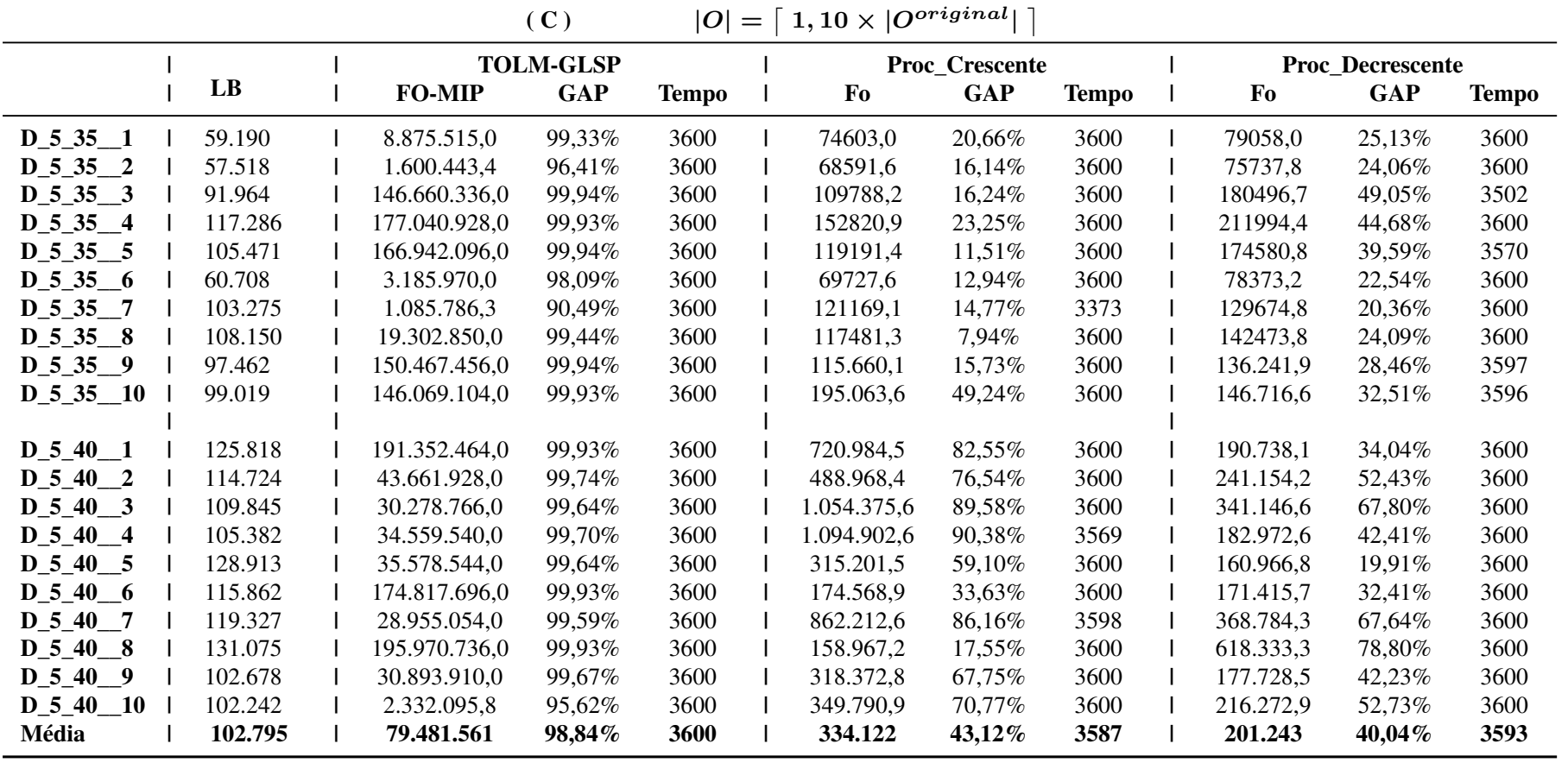



As meta-heurísticas são muito utilizadas para resolver problemas de otimização combinatória, pois fornecem soluções de boa qualidade utilizando um tempo razoável para resolver problemas difíceis e complexos. Segundo Talbi (2009), o termo metaheuristic foi utilizado pela primeira vez em Glover (1986), e representa uma família de técnicas algorítmicas aproximadas de otimização que ganhou popularidade nas últimas duas décadas. Para Talbi (2009), métodos de busca meta-heurística podem ser definidos como templates que podem auxiliar na concepção de estratégias heurísticas para resolver problemas de otimização específicos. Em outras palavras, uma meta-heurística pode ser vista como uma estrutura algorítmica geral que pode ser aplicada a diferentes problemas de otimização podendo, com poucas modificações, adaptar-se a problemas específicos.

Na literatura, há diversas meta-heurísticas utilizadas para a resolução dos mais diversos problemas de otimização, por exemplo: algoritmo genético (Goldberg, 1989), busca tabu (Glover et al., 2000), GRASP (Feo \& Resende, 1989), entre muitas outras. Neste trabalho optamos por utilizar a meta-heurística GRASP.

A meta-heurística GRASP (Greedy Randomized Adaptive Search Procedure) foi proposta para a resolução de problemas de recobrimento de nós (Feo \& Resende, 1989). Em Feo \& Resende (1995), o GRASP teve suas definições formalizadas e, também, suas propriedades apresentadas para o problema de designação quadrática. A partir de então, vários algoritmos da literatura surgiram baseados nesta meta-heurística, como mostram, por exemplo, os trabalhos de Festa et al. (2002), Festa \& Resende (2009a b) e Resende \& Ribeiro (2010). Alguns exemplos de trabalhos que utilizam a meta-heurística GRASP para a resolução de problemas de planejamento e programação da produção aparecem em Nascimento et al. (2010), Mateus et al. (2010), Binato et al. (2000) e Aiex et al. (2003). Em Nascimento et al. (2010) utiliza-se a meta-heurística GRASP para a resolução do problema multi-plantas de dimensionamento de lotes com limitações de capacidade. Mateus et al. (2010) abordam o problema de dimensionamento e sequenciamento de lotes, sendo a meta-heurística utilizada para obtenção do sequenciamento da produção. Outros trabalhos que utilizam o GRASP para o sequenciamento (job-shop) são Binato et al. (2000) e Aiex et al. (2003). 
O GRASP consiste basicamente de duas etapas, sendo estas, construção de uma solução (fase construtiva) e melhoria desta (fase de busca local) (Feo \& Resende, 1989, 1995). Na fase construtiva, elemento a elemento é incluído à solução, sendo este selecionado randomicamente a partir de uma lista de candidatos obtida pela ordenação dos elementos seguindo uma relação à uma função gulosa. Sendo assim, a fase construtiva gera uma solução viável para o problema, com o intuito de obter uma vizinhança que é visitada durante a fase de busca local, encontrando um mínimo local. Estas fases são executadas durante um limite máximo de iterações, ou quando algum critério de parada é atingido. A cada iteração, a melhor solução encontrada (inclusive em outras iterações) é mantida como resultado.

\subsection{Meta-heurística GRASP proposta}

A meta-heurística GRASP proposta nesta tese para a resolução do problema de dimensionamento de lotes e programação da produção em indústrias cervejeiras tem a implementação de suas etapas descritas no Algoritmo 4. O algoritmo é executado até que se atinja o tempo limite $(R T)$, ou o número máximo de iterações seja alcançado (max_iteração), ou a melhor solução encontrada atinja IT iterações sem que se obtenha uma solução melhor.

Para a execução do Algoritmo 4 necessita-se de dois parâmetros: a semente e $\partial$, estes são utilizados na heurística construtiva gulosa (Heurística_Construtiva(semente, $\partial$ ), Algoritmo 5). O primeiro parâmetro é utilizado na inicialização do gerador de número aleatório e o segundo $\partial$ indica o percentual de aleatoriedade utilizada na construção da solução inicial. A solução gerada pela heurística construtiva gulosa é utilizada como parâmetro para fase de busca local (Heurística_Busca_Local( $\hat{S})$, Algoritmo 6 ).

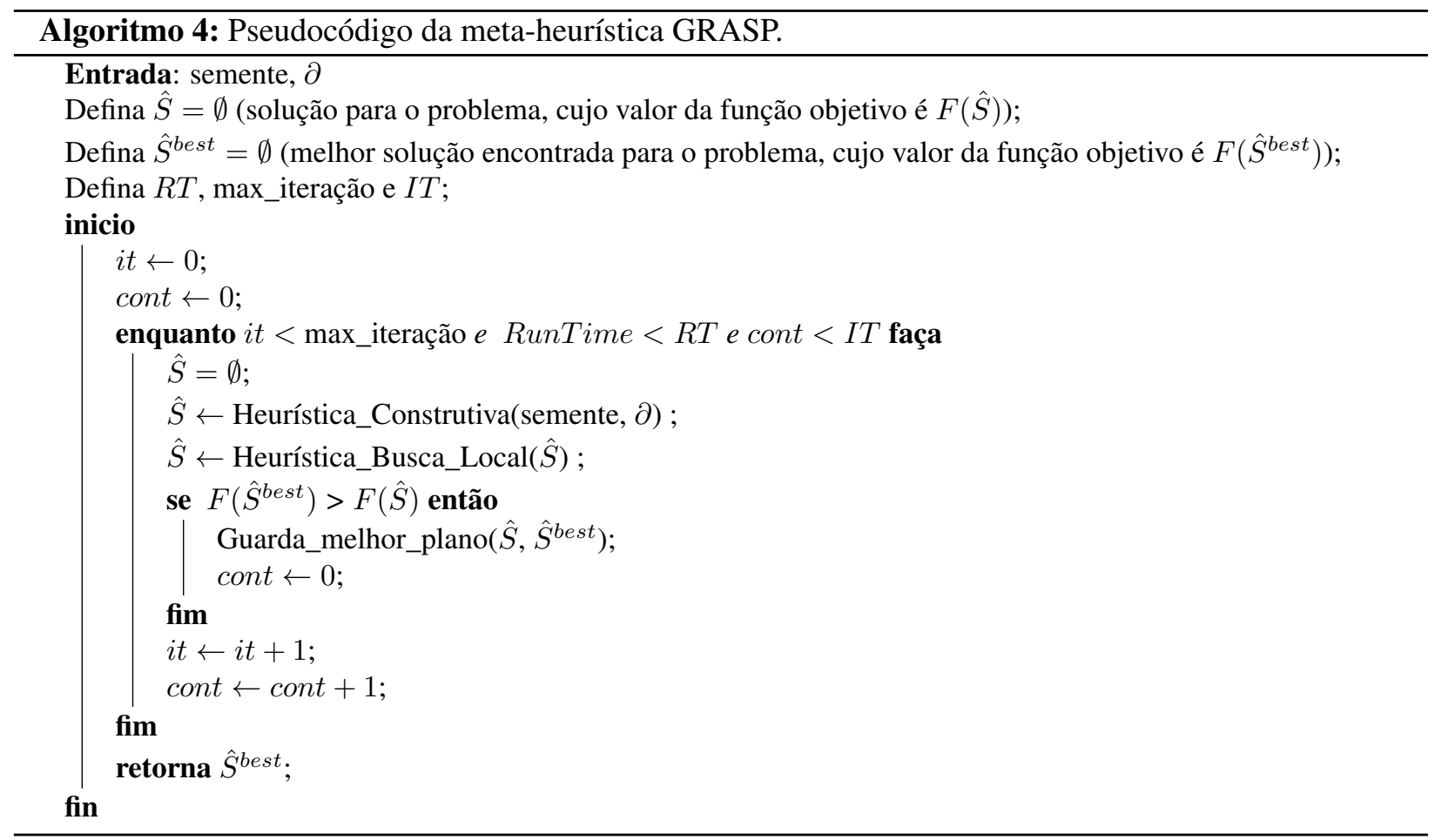

As próximas seções descrevem a heurística construtiva gulosa e a heurística de busca local. Para facilitar o entendimento destas heurísticas, utiliza-se um exemplo numérico ilustrativo cujos dados encontram-se nas Tabelas 6.1 e 6.2. A Tabela 6.1 fornece as informações sobre a quantidade de itens $(|N|)$, custo de estoque 
de cada item $\left(h_{i}\right)$, quantidade de líquidos diferentes $(|L|)$, o tempo necessário para completar o período de fermentação e maturação de cada líquido $\left(\Delta_{l}\right)$, a quantidade total de períodos do horizonte de planejamento ( $|T|$, sendo os $\left|T_{1}\right|$ primeiros períodos detalhados), a quantidade de envasadoras $(|M|)$, a quantidade de tanques $(|O|)$, a capacidade máxima de cada tanque $\left(\right.$ Cap $_{\max }$, lembrando que $C_{a p_{\min }}=0,1 \times$ Cap $\left._{\max }\right)$, tempo de setup entre itens que compartilham a mesma envasadora $\left(b_{m j i}\right)$, tempo de processamento do produto nas envasadoras $\left(a_{m i}\right)$ e quantidade de líquido que compõem cada item $\left(r_{l i}\right)$. A Tabela 6.2 descreve a demanda dos itens durante o horizonte de planejamento.

Tabela 6.1: Dados referentes ao exemplo numérico ilustrativo utilizado para a explicação da meta-heurística GRASP.

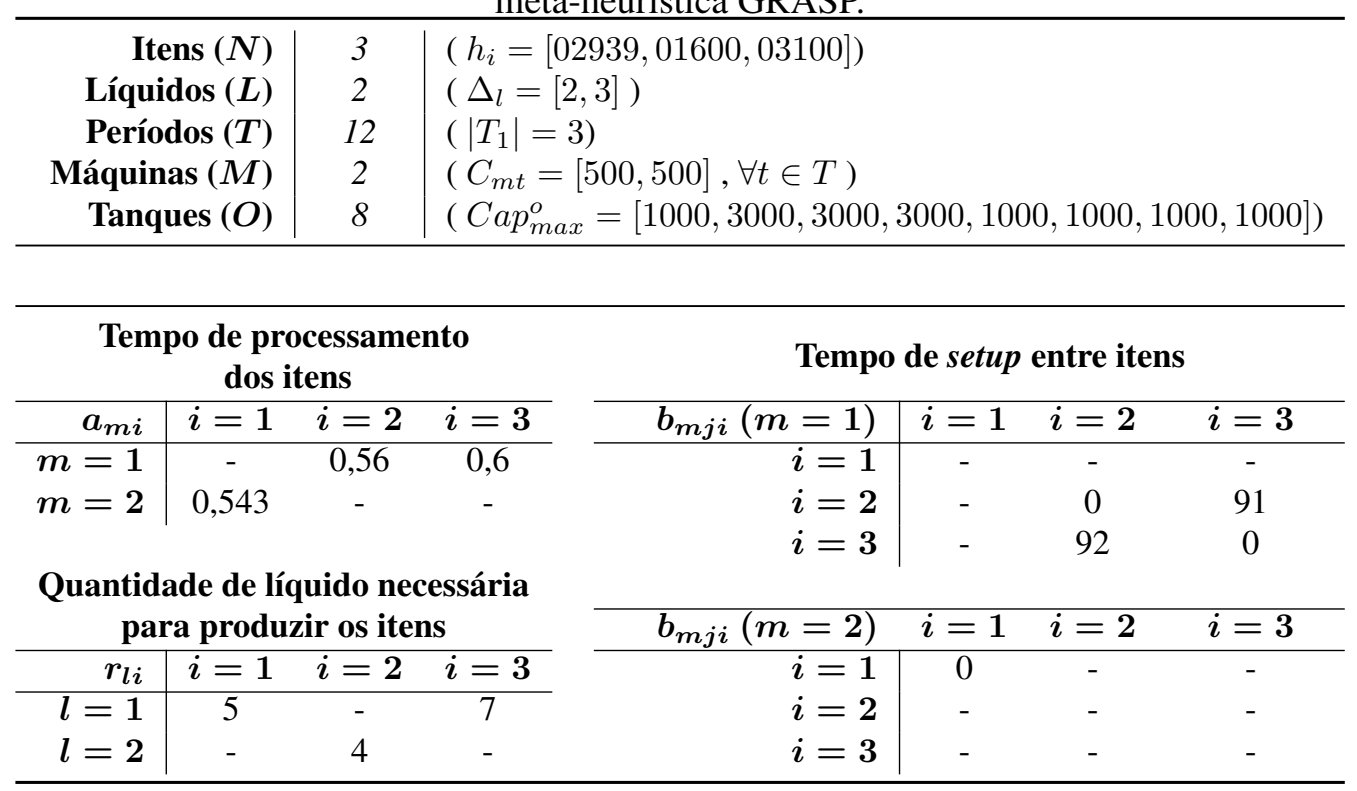

Tabela 6.2: Demanda dos itens do exemplo numérico ilustrativo utilizado para a explicação da meta-heurística GRASP

\begin{tabular}{r|cccccccccccc}
\hline $\boldsymbol{d}_{\boldsymbol{i t}}$ & $\boldsymbol{t}=\mathbf{1}$ & $\boldsymbol{t}=\mathbf{2}$ & $\boldsymbol{t}=\mathbf{3}$ & $\boldsymbol{t}=\mathbf{4}$ & $\boldsymbol{t}=\mathbf{5}$ & $\boldsymbol{t}=\mathbf{6}$ & $\boldsymbol{t}=\mathbf{7}$ & $\boldsymbol{t}=\mathbf{8}$ & $\boldsymbol{t}=\mathbf{9}$ & $\boldsymbol{t}=\mathbf{1 0}$ & $\boldsymbol{t}=\mathbf{1 1}$ & $\boldsymbol{t}=\mathbf{1 2}$ \\
\hline $\boldsymbol{i}=\mathbf{1}$ & 100 & 200 & 500 & 0 & 0 & 500 & 0 & 0 & 0 & 500 & 0 & 500 \\
$\boldsymbol{i}=\mathbf{2}$ & 0 & 50 & 100 & 0 & 0 & 700 & 0 & 0 & 0 & 500 & 0 & 800 \\
$\boldsymbol{i}=\mathbf{3}$ & 0 & 250 & 700 & 200 & 0 & 0 & 0 & 800 & 0 & 800 & 0 & 1000 \\
\hline
\end{tabular}

\subsubsection{Heurística Construtiva}

O Algoritmo 5 consiste em um procedimento guloso que visa à obtenção de uma solução viável para o problema, cujo objetivo é produzir cada item requerido no decorrer do horizonte de planejamento o mais cedo possível, assim, evitando o atraso na entrega da demanda. Para a execução do Algoritmo 5, necessitase de dois parâmetros, isto é, a semente para inicialização do gerador de números aleatórios e o percentual de aleatoriedade $(\partial)$. $\mathrm{O} \partial$ está relacionado com a aleatoriedade na escolha dos itens, ou seja, a ordem em que a demanda de cada item é processada no decorrer do horizonte de planejamento. Ambos os parâmetros são utilizados em Ordena_Demanda(semente, $\partial$ ).

A execução da heurística tem início com o enchimento dos tanques (Tanques $\forall t \in T \leftarrow$ Enche_Tanques (semente)). Assume-se que todos os tanques tenham líquido disponível ao início do horizonte de planejamento, porém precisa-se estabelecer quais líquidos estão preparados e prontos. Essa definição é feita 


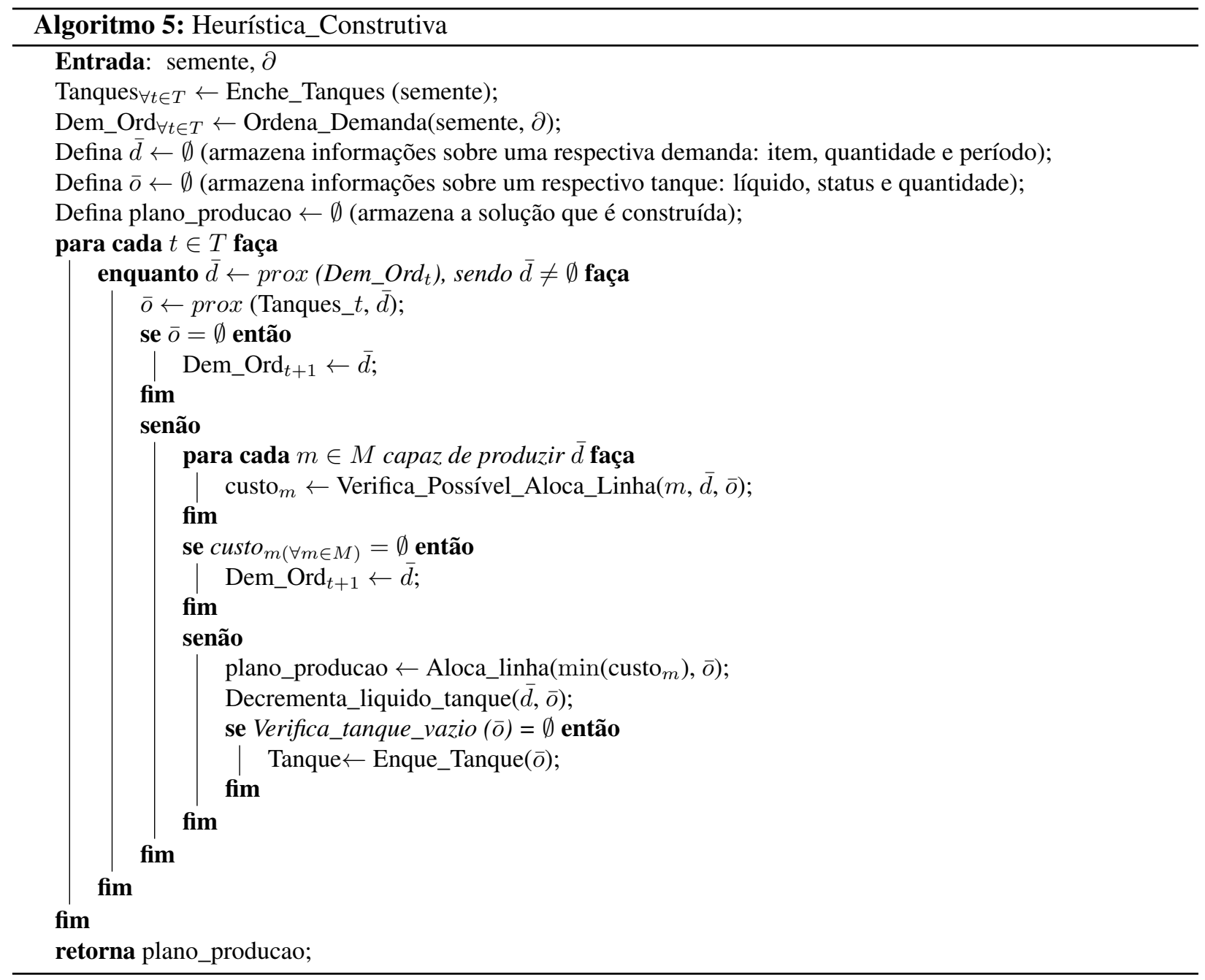

considerando a demanda existente. Deste modo, calcula-se o percentual das demandas dos líquidos. Por exemplo, se o líquido 1 corresponde a $81 \%$ das demandas e o líquido 2 por $19 \%$, tem-se que $81 \%$ dos tanques iniciam o horizonte de planejamento contendo o líquido 1 e $19 \%$ o líquido 2 . A escolha de quais tanques recebem líquido 1 ou 2 é feita de maneira aleatória, obviamente, respeitando a proporção estabelecida. Para o exemplo numérico considerado, tem-se os tanques cheios de líquido pronto como descrito na Tabela 6.3. Quando um tanque encontra-se vazio durante a execução do algoritmo, este recebe líquido impreterivelmente ao final do mesmo período. A escolha do líquido para abastecer o tanque é feita de acordo com o percentual de demanda de líquido que ainda precisa ser suprida, sendo escolhido o líquido de maior valor demandado.

Após o enchimento dos tanques, estabelece-se uma ordem de processamento das demandas (Dem_Ord $\forall t \in T$ $\leftarrow$ Ordena_Demanda(semente, $\partial$ ) ). Esta ordem é utilizada para definir como ocorre a produção, influenciando na escolha do tanque responsável por abastecer a linha de envase, como também da envasadora responsável pela produção. Para definir a ordem de processamento das demandas (Dem_Ord), busca-se o primeiro período que apresenta demanda positiva. Ou seja, o primeiro período $(t)$ que apresentar demanda tem as informações desta inserida no conjunto Dem_Ord $t$ e é a primeira demanda candidata a ser produzida. Caso haja mais de um item com demanda positiva no mesmo período $t$, ordenam-se estes itens de acordo com o líquido mais demandado, ou seja, os itens que são compostos pelo líquido de maior demanda total 
Tabela 6.3: Inicialização dos tanques.

\begin{tabular}{ccc}
\hline Tanque $(o)$ & Cap $_{\max }$ & Líquido $(l)$ \\
\hline 1 & 1000 & \\
2 & 3000 & \\
3 & 3000 & $1(81 \%)$ \\
4 & 3000 & \\
5 & 1000 & \\
6 & 1000 & $2(19 \%)$ \\
7 & 1000 & \\
\hline 8 & 1000 & \\
\hline
\end{tabular}

são os primeiros a serem processados (inseridos) em Dem_Ord $t$. Se necessário, utiliza-se o custo de estoque como critério de desempate, sendo os primeiros os de menor valor.

Observe a Tabela 6.2, para $t=1$ há apenas a demanda do item $i=1\left(d_{1,1}=100\right)$, de modo que esta é a primeira a ser inserida em Dem_Ord $t_{t=1}$, como mostra a Tabela 6.4. Para $t=2$ há procura de todos os itens, logo os itens compostos pelo líquido de maior demanda são os primeiros analisados, ou seja, $i=1$ e $i=3$, que utilizam o líquido 1. Como são dois itens, utiliza-se o segundo critério de desempate, ou seja, como o custo de estoque do item $i=1$ é mais baixo, então este é o item a ser inserido em Dem_Ord ${ }_{t=2}$, seguido da demanda do item $i=3 \mathrm{e}$, por último, $i=2$. Faz-se esta análise durante todo o decorrer do horizonte de planejamento, obtendo Dem_Ord $t(\forall t \in T)$ de acordo com a Tabela 6.4 .

A descrição anterior de Ordena_Demanda(semente, $\partial$ ) não considera a aleatoriedade na escolha dos itens, ou seja, seria como se $\partial=0$. Porém, quando tem-se $\partial>0$ ocorre mudanças apenas nos períodos onde há mais de um item com demanda positiva, sendo que a escolha da ordem de processamento dos itens ganha um fator aleatório. Assim, os itens demandados no respectivo período são ordenados seguindo o critério: líquido que possui maior procura e, caso seja necessário, utiliza-se o custo de estoque como critério de desempate. Em nosso exemplo, em $t=2$ temos a ordem de candidatos a Dem_Ord $t=2$, tal como, $i=1, i=3$ e $i=4$, com a possibilidade de escolha entre os $\partial$ (valor entre 0 e 100\%) primeiros itens a serem inseridos a priori. Ou seja, tem-se 3 itens ordenados (100\% dos candidatos à nossa lista), supondo $\partial=65 \%$ (o que corresponde aos 2 primeiros itens), tem-se a possibilidade de escolher aleatoriamente entre: $i=1$ e $i=3$. O item sorteado é o próximo incluso em Dem_Ord ${ }_{t=2}$. Se $\partial=100 \%$, todos os itens teriam a mesma probabilidade de serem escolhidos como o próximo inserido em Dem_Ord ${ }_{t=2}$. Lembrando que a execução do nosso exemplo ilustrativo considera $\partial=0$ (Tabela 6.4).

Na sequência faz-se as inicializações dos parâmetros $\bar{d} \leftarrow \emptyset$ como vazias, assim como também, $\bar{o} \leftarrow \emptyset$ e plano_producao $\leftarrow \emptyset$, finalizando a etapa inicial da heurística construtiva, dando início a montagem do conjunto solução a cada iteração de $t \in T$.

A cada período do horizonte de planejamento consulta-se Dem_Ord ${ }_{t}$, obtendo a demanda candidata a ser produzida $\left(\bar{d} \leftarrow \operatorname{prox}\left(\operatorname{Dem}_{-} \operatorname{Ord}_{t}\right)\right)$, e depois, analisa-se qual tanque pode fornecer líquido o mais cedo possível para a sua produção $(\bar{o} \leftarrow \operatorname{prox}$ (Tanques_t $t)$ ). Após estabelecido qual tanque fornece líquido, precisase verificar a disponibilidade das linhas de envase. Caso haja mais de uma linha disponível para fabricar esta demanda, escolhe-se a que conseguir produzir mais cedo (custo $m \leftarrow$ Verifica_Possível_Aloca_Linha $(m, \bar{d}$, $\bar{o})$, ou seja, a envasadora que apresentar o menor $\operatorname{custo}_{m}(m \in M)$. O valor de custo $_{m}(m \in M)$ é mensurado da seguinte maneira: seja $t$ o período em que pode-se alocar a produção na máquina $m, \operatorname{logo}$, quanto 
maior o valor de $t$, mais distante do início do horizonte a produção está alocada, possuindo um valor maior de custo $_{m}$; em outras palavras, quanto mais distante do início do horizonte de planejamento estiver alocada a produção, maior o valor de custo $_{m}$. Caso haja truncamento na produção da demanda, ou seja, parte produzida em um período e outra parte em outro sendo abastecido pelo mesmo tanque, há uma penalização, de forma a priorizar a produção em um mesmo período (desde que não haja atraso na entrega da demanda). Se houver empate na escolha do tanque ou da linha, o primeiro entre eles a ser analisado é o escolhido.

Todas as informações relativas a produção da demanda são inseridas no plano_producao. Entretanto, se em algum período $t$ não houver tanque com líquido pronto ou linha de envase disponível para a produção da demanda, esta é reinserida em Dem_Ord, porém no período $t+1\left(\right.$ Dem_Ord $\left._{t+1}\right)$, sendo analisada no próximo período.

Tabela 6.4: Demanda de líquidos por períodos e respectiva ordem de processamento das demandas

(Dem_Ord $t$ )

\begin{tabular}{|c|c|c|c|c|}
\hline \multicolumn{5}{|c|}{ Demanda liquidos por períodos $\left(\right.$ Dem_Ord $\left._{t}\right)$} \\
\hline Período & Líquido & Qtde líquido & & $i, t$ \\
\hline 1 & 1 & 500 & $\left(d_{1,1}=100,00\right)$ & \\
\hline 2 & $\begin{array}{l}1 \\
2\end{array}$ & $\begin{array}{l}2750 \\
200\end{array}$ & $\begin{array}{c}\left(d_{1,2}=200,00\right) \\
\left(d_{2,2}=50,00\right)\end{array}$ & $\left(d_{3,2}=250,00\right)$ \\
\hline 3 & $\begin{array}{l}1 \\
2\end{array}$ & $\begin{array}{c}7400 \\
400\end{array}$ & $\begin{array}{l}\left(d_{1,3}=500,00\right) \\
\left(d_{2,3}=100,00\right)\end{array}$ & $\left(d_{3,3}=700,00\right)$ \\
\hline 4 & 1 & 1400 & $\left(d_{3,4}=200,00\right)$ & \\
\hline 6 & $\begin{array}{l}1 \\
2\end{array}$ & $\begin{array}{l}2500 \\
2800\end{array}$ & $\begin{array}{l}\left(d_{1,6}=500,00\right) \\
\left(d_{2,6}=700,00\right)\end{array}$ & \\
\hline 8 & 1 & 5600 & $\left(d_{3,8}=800,00\right)$ & \\
\hline 10 & $\begin{array}{l}1 \\
2\end{array}$ & $\begin{array}{l}8100 \\
2000\end{array}$ & $\begin{array}{l}\left(d_{1,10}=500,00\right) \\
\left(d_{2,10}=500,00\right)\end{array}$ & $\left(d_{3,10}=800,00\right)$ \\
\hline 12 & $\begin{array}{l}1 \\
2\end{array}$ & $\begin{array}{l}9500 \\
3200\end{array}$ & $\begin{array}{l}\left(d_{1,12}=500,00\right) \\
\left(d_{2,12}=800,00\right)\end{array}$ & $\left(d_{3,12}=1000,00\right)$ \\
\hline
\end{tabular}

A seguir, executamos as primeiras iterações da heurística construtiva (Algoritmo 5) utilizando nosso exemplo numérico ilustrativo. Os resultados encontram-se nas Tabelas 6.5 e 6.6. O resultado final que determina a relação de produção de itens $(i)$ por períodos $(t)$ encontra-se na Tabela 6.7. A execução das primeiras iterações da heurística construtiva, para $t \in T$ :

$\mathbf{1}^{a}$ iteração $(t=1)$ :

- Executa-se $\bar{d} \leftarrow$ prox (Dem_Ord ${ }_{t=1}$ ), ou seja, $\bar{d}$ recebe as informações referentes ao primeiro item de $\operatorname{Ord}_{t=1}$, isto é, o primeiro item demandado $\left(i=1, d_{1,1}=100\right)$, veja a Tabela 6.4,

- Verifica-se qual (ou quais) tanque(s) pode(m) abastecer a linha de envase para fabricação do item $1\left(d_{1,1}=100\right.$, necessita-se de 500 unidades de líquido 1 para suprir esta demanda). Os tanques 
$o \in\{1, \ldots, 7\}$ podem fornecer líquido pronto no primeiro período (Tabela 6.3). Escolhe-se o primeiro tanque que contém 1000 unidades de líquido. Então, $\bar{o} \leftarrow$ prox (Tanques_t$t$ ) contém informações do tanque 1.

- Executa-se custo $m \leftarrow$ Verifica_Possível_Aloca_Linha $(m, \bar{d}, \bar{o})$. Na Tabela 6.1 temos que apenas $m=2$ consegue fabricar o item 1 . Assim, esta demanda é inserida ao plano de produção de $m=2$ em $t=1$ (plano_producao $\leftarrow$ Aloca_linha $\left(\min \left(\operatorname{custo}_{m}\right), \bar{o}\right)$ ), cujo líquido é fornecido pelo tanque 1, decrementando a quantidade de líquido utilizada no abastecimento de $m=1$ (Decrementa_liquido_tanque $(\bar{d}, \bar{o})$ ). Neste caso utiliza-se $r_{11} \times d_{1,1}=5 \times 100=500$ unidades do líquido 1, restando agora 500 unidades de líquido no tanque 1. Como ainda há líquido no tanque 1, segue-se para a próxima iteração.

- O resultado final desta iteração pode ser visto na Tabela 6.5, onde para $m=2$ e $t=1$ não há preparação da linha de envase $(T P=0)$. A envasadora 2 , ao final do período $t=1$, encontra-se preparada para a produção do item $1($ prep $=1)$, com capacidade de tempo disponível igual a 445,7 ( Disp $=445,7)$, pois foi utilizada 54,3 da capacidade de tempo da máquina para produzir o item 1 ( $\left.\operatorname{Prod}=a_{21} \times d_{11}=0,543 \times 100=54,3\right)$. Ou seja, ao final desta iteração são produzidas 100 unidades do item 1 (1->100), com o líquido fornecido pelo tanque 1 , correspondente a 500 unidades de líquido ([o=1-500]). Interpreta-se tal fato na Tabela 6.5, na linha: $(1->100[\mathrm{o}=1-$ 500]).

$\mathbf{2}^{a}$ iteração $(t=2)$ :

- Não há mais demanda em $\operatorname{Ord}_{t=1}$, ou seja, em $t=1$ (veja Tabela 6.4). Analisa-se o próximo período $\operatorname{Ord}_{t=2}$. A primeira demanda a ser analisada é do item $i=1\left(d_{1,2}=200\right)$.

- Verifica-se a disponibilidade de tanque com líquido pronto para produzir $d_{1,2}=200$. Há $o \in$ $\{1, \ldots, 7\}$ (Tabela 6.3). Utiliza-se o restante do líquido 1 do tanque 1 e parte do tanque 2. Deste modo, $\bar{o} \leftarrow$ prox (Tanques_t ) contém informações dos tanques 1 e 2 .

- Executa-se custo $m \leftarrow$ Verifica_Possível_Aloca_Linha $(m, \bar{d}, \bar{o})$ e apenas $m=2$ consegue produzir o item 1 (Tabela 6.1). Assim, este item é fabricado por $m=2 \mathrm{em} t=1$ (plano_producao $\leftarrow$ Aloca_linha $\left.\left(\min \left(\operatorname{custo}_{m}\right), \bar{o}\right)\right)$.

- Decrementa-se a quantidade de líquido utilizado (Decrementa_liquido_tanque $(\bar{d}, \bar{o})$ ). Foram necessárias $r_{11} \times d_{1,1}=1000$ unidades de líquido 1 . No tanque 1 havia 500 unidades deste líquido, conseguindo suprir metade da demanda dos itens, e o restante é suprido pelo tanque 2. Logo, ao final desta iteração, o tanque 1 está vazio e o tanque 2 tem 2500 unidades de líquido.

- Como tanque 1 está vazio, este recebe líquido para que possa fermentar/maturar e estar disponível novamente em períodos posteriores. Como o líquido que possui maior demanda é o líquido 1 (mesmo com a produção destas demandas e decrementando a quantidade de líquido presente nos demais tanques), o tanque 1 recebe líquido 1 , ficando disponível apenas em $t=4$ ( $t=1$ + fermentação/maturação $=1+2=3$; terminando o período de fermentação/maturação em $t=3$, logo disponível apenas em $t=4$ ).

- Ao final da $2^{\text {a }}$ iteração, podemos notar que para $t=1$, a máquina 2 continua pronta para a produção do item 1, cujo tempo disponível baixou para 337,1 (Disp = 337,1) e o tempo utilizado para a produção de $i=1$ é de $162,9(\operatorname{Prod}=162,9)$, sendo produzido 300 unidades 
de item 1 (1->300), cujos tanques que abastecem a linha de envase para produção são $o=1 \mathrm{e}$ $o=2$, utilizando 1000 e 500 unidades de líquido de cada tanque ( $[\mathrm{o}=1-500 \mathrm{o}=1-500 \mathrm{o}=2-500]$ ), respectivamente. Na Tabela 6.5 consegue-se visualizar esta situação na linha (1->300 [o=1-500 $\mathrm{o}=1-500 \mathrm{o}=2-500])$.

$\mathbf{3}^{a}$ iteração $(t=2)$ :

- Ainda em $t=2$, há demanda para os itens $i=3$ e $i=2$, como pode-se observar em Dem_Ord ${ }_{t=2}$ (Tabela 6.4). A próxima demanda a ser analisada é a do item $i=3$, cujo valor da demanda é $d_{3,2}=250\left(\bar{d} \leftarrow\right.$ prox $\left(\right.$ Dem_Ord $\left.\left._{t=2}\right)\right)$.

- Verifica-se a disponibilidade de tanque com líquido pronto para produzir o item 3, há $o \in$ $\{2, \ldots, 7\}$, logo utiliza-se o líquido do tanque $o=2$, pois tem líquido suficiente para suprir esta demanda. Assim, $\bar{o} \leftarrow \operatorname{prox}$ (Tanques_t $t$ ) contém informações do tanque 2.

- Executa-se custo $_{m} \leftarrow$ Verifica_Possível_Aloca_Linha $(m, \bar{d}, \bar{o})$. Apenas $m=1$ consegue produzir o item 3, assim, este item é fabricado por $m=1$ em $t=1$ (plano_producao $\leftarrow$ Aloca_linha $\left(\min \left(\right.\right.$ custo $\left.\left.\left._{m}\right), \bar{o}\right)\right)$, decrementando a quantidade de líquido utilizada (Decrementa_liquido_tanque $(\bar{d}$, $\bar{o})$ ). Ou seja, tem-se restando $2500-250 \times 7=2500-1750=750$ unidades de líquido no tanque 2.

- A atualização da Tabela 6.5 para $m=1$ e $t=1$ mostra que a máquina continua pronta para a produção do item 3 ao final deste período ( $p r e p=3$ ), a máquina 1 tem tempo disponível igual a $350($ Disp $=350)$ e o tempo utilizado para a produção do item 3 é de $150(\operatorname{Prod}=150)$, sendo produzido neste período 250 unidades. O tanque que abastece a linha de envase para produção nesta iteração é $o=2$, utilizando 1750 unidades de líquido, esta situação está representada na Tabela 6.5 para $m=1$ e $t=1$ tem-se (3->250 [o=2-1750]).

$4^{a}$ iteração $(t=2)$ :

- Continuando em $t=2$, há demanda para $i=2\left(d_{2,2}=50\right)$, veja Dem_Ord ${ }_{t=2}$ (Tabela6.4), que é apenas fabricado pelo líquido 2 (Tabela 6.1).

- Veja na Tabela 6.3, apenas o tanque 8 possui líquido 2. Deste modo, utiliza-se o líquido deste tanque para suprir a produção de $d_{2,2}=50$.

- Executa-se custo $_{m} \leftarrow$ Verifica_Possível_Aloca_Linha $(m, \bar{d}, \bar{o})$. Apenas $m=1$ consegue fabricar o item 2. Assim, esta demanda é inserida ao plano de produção da envasadora 1 em $t=1$ (plano_producao $\leftarrow$ Aloca_linha $\left(\min \left(\right.\right.$ custo $\left.\left._{m}\right), \bar{o}\right)$ ). Decrementando do tanque 8 a quantidade de líquido utilizada (Decrementa_liquido_tanque $(\bar{d}, \bar{o})$ ), ou seja, resta $1000-50 \times 4=$ $1000-200=800$ unidades de líquido no tanque 8 .

- A envasadora $m=1$ estava preparada para produzir o item $i=3$, logo tem que realizar um setup cujo tempo corresponde a 92 (Tempo de setup->92), veja Tabela 6.1. Ao final desta produção, a máquina $m=1$ está preparada para o item $2($ prep $=2)$. O tempo disponível para produção e preparação ao final de $t=2$ é de $230(D i s p=230)$ e o tempo total de máquina utilizado para produção é de 178 ( $\operatorname{Prod}=178)$. Produzindo neste período 50 unidades de item 2, cujo tanque que abastece a linha de envase para produção é $o=8$, utilizando 200 unidades de líquido. 
- A atualização de plano_producao pode ser observada na Tabela 6.6 .

$\mathbf{5}^{a}$ iteração $(t=3)$ 1.

- Não há mais demanda em $t=2$. Logo, analisa-se $t=3$ (Dem_Ord $t=3$, veja Tabela 6.4). Tem-se demanda para todos os itens, sendo $d_{1,3}=500\left(\bar{d} \leftarrow\right.$ prox $\left(\right.$ Dem_Ord $\left.\left._{t=1}\right)\right)$ a próxima a ter sua produção alocada.

- Os tanques 2 e 3 vão abastecer as envasadora para a produção do item 1 (Tabela 6.3), dado que necessita-se de $500 \times 5=2500$ unidades de líquido para suprir esta demanda, consumindo todo o tanque 2 (750 unidades) e utilizando parte do tanque 3 (1750 unidades).

- Executa-se custo $_{m} \leftarrow$ Verifica_Possível_Aloca_Linha $(m, \bar{d}, \bar{o})$. Apenas $m=2$ consegue produzir o item 1 (Tabela 6.1). A produção é abastecida pelo tanque 2 no período $t=1$ (plano_producao $\leftarrow$ Aloca_linha $\left(\min \left(\operatorname{custo}_{m}\right), \bar{o}\right)$ ). Entretanto, note que para o tanque 3, o valor de custo $_{m}$ é menor se a produção for totalmente alocada a $t=2$, sem truncamento no abastecimento do líquido. Assim, o item 1 é fabricado por $m=2 \mathrm{em} t=1$, sendo abastecido pelo tanque 2, e em $t=2$, pelo tanque 3 (plano_producao $\leftarrow$ Aloca_linha $\left(\min \left(\right.\right.$ custo $\left.\left._{m}\right), \bar{o}\right)$ ).

- Decrementa-se a quantidade de líquido utilizada (Decrementa_liquido_tanque $(\bar{d}, \bar{o})$ ). Foram necessárias $r_{11} \times d_{1,3}=2500$ unidades de líquido 1 . No tanque 2 havia 750 unidades deste líquido, conseguindo suprir parte da demanda dos itens e o restante é suprido pelo tanque 3. Logo, ao final desta iteração, o tanque 2 está vazio e o tanque 3 tem 1250 unidades de líquido 1.

- Como tanque 2 está vazio, este recebe líquido 1 , ficando disponível apenas em $t=4$ ( $t=1$ + fermentação/maturação $=1+2=3$; terminando o período de fermentação/maturação em $t=3$, disponível apenas em $t=4$ ).

- A atualização do plano_producao pode ser observada na Tabela 6.6, para $m=1$ e $t=1$, a máquina 2 tem tempo total disponível igual a 255,7 (Disp $=255,7)$ e o tempo utilizado para a produção do item 1 é de 244,3 ( $\operatorname{Prod}=244,3)$, sendo produzido neste período mais 150 unidades deste item (somando um total de 450 unidades no período), utilizando 750 unidades de líquido 1 do tanque 2. E, ainda, tem-se que para $m=2$ e $t=2$, cujo tempo disponível é igual a 310 (Disp $=310)$ e o tempo utilizado para a produção do item 1 é de $189(\operatorname{Prod}=189)$, sendo produzido neste período 350 unidades deste item supridos pelo líquido do tanque 3 .

$\mathbf{6}^{a}$ iteração $(t=3)$ :

- A próxima demanda é $d_{3,3}=700$ (Dem_Ord ${ }_{t=3}$, veja na Tabela6.4).

- Restam 1250 unidades de líquido disponível em $o=3$. Entretanto, não são suficientes para produzir toda demanda de item 3. Esta necessita de $700 \times 7=4900$ unidades de líquido 1 . Utiliza-se, também, todo líquido de $o=4 \mathrm{e}$, parcialmente, o líquido de $o=5$ (restando neste tanque 350 unidades). O líquido fornecido por $o=3$ foi utilizado no período $t=1$, produzindo

\footnotetext{
${ }^{1}$ Notou-se um melhor desempenho da meta-heurística (devido a fase de busca local) quando evita-se o truncamento de abastecimento de líquido entre períodos, ou seja, como neste caso, parte da demanda poderia ser produzida em $t=1$ e o restante em $t=2$, sendo abastecida pelo mesmo tanque. Logo, é melhor alocar a produção toda para o mesmo período. Sendo esta estratégia aplicada a todos os casos que ocorrem trucamento da demanda com possibilidade de alocação de toda a produção em um mesmo período sem ocorrência de atraso.
} 
o item $i=3$ na máquina $m=1$. Aloca-se o restante da produção para o período $t=2$ sendo abastecida pelo líquido 1 de $o=4$ e o=5, entretanto, faz-se um setup (91 unidades de tempo) no início do período $t=3$, pois a máquina estava preparada para o item 2 .

- Como os tanques $o=3$ e $o=4$ estão vazios, estes recebem o líquido 1. Dando início ao processo de fermentação e maturação.

$7^{a}$ iteração $(t=3)$ : A última demanda do período $t=3$ é do item $i=2\left(d_{2,3}=100\right)$. Esta é suprida, durante a produção, pelo tanque $o=8$ e alocada ao período $t=1$, aproveitando a preparação existente neste período para este item. Há produção deste item suprida pelo tanque $8 \mathrm{e}$, também, há tempo de máquina disponível, logo a produção é aloca a este período.

$\vdots$

Última iteração : A última demanda a ser produzida é $d_{2,12}=800$ e, ao final da iteração, obtém-se a solução final que pode ser vista na Tabela 6.7

Ao final da execução do Algoritmo 5 ( Heurística_Construtiva(semente, $\partial$ )), cujo tempo consumido para a conclusão do procedimento foi de 3 segundos, obtém-se um plano de produção factível, como mostra a Tabela 6.7. O custo deste plano de produção é de aproximadamente 3048.

\footnotetext{
${ }^{2}$ Nesta iteração, poderíamos utilizar todo o tempo disponível da máquina $m=1 \mathrm{em} t=1$, porém, já houve uma troca de itens neste período e há 3 tanques diferentes sendo utilizados (lembremos das restrições dos modelos matemáticos), logo não pode-se alocar o líquido de $o=4$ para a produção de $i=3 \mathrm{em} t=1$
} 


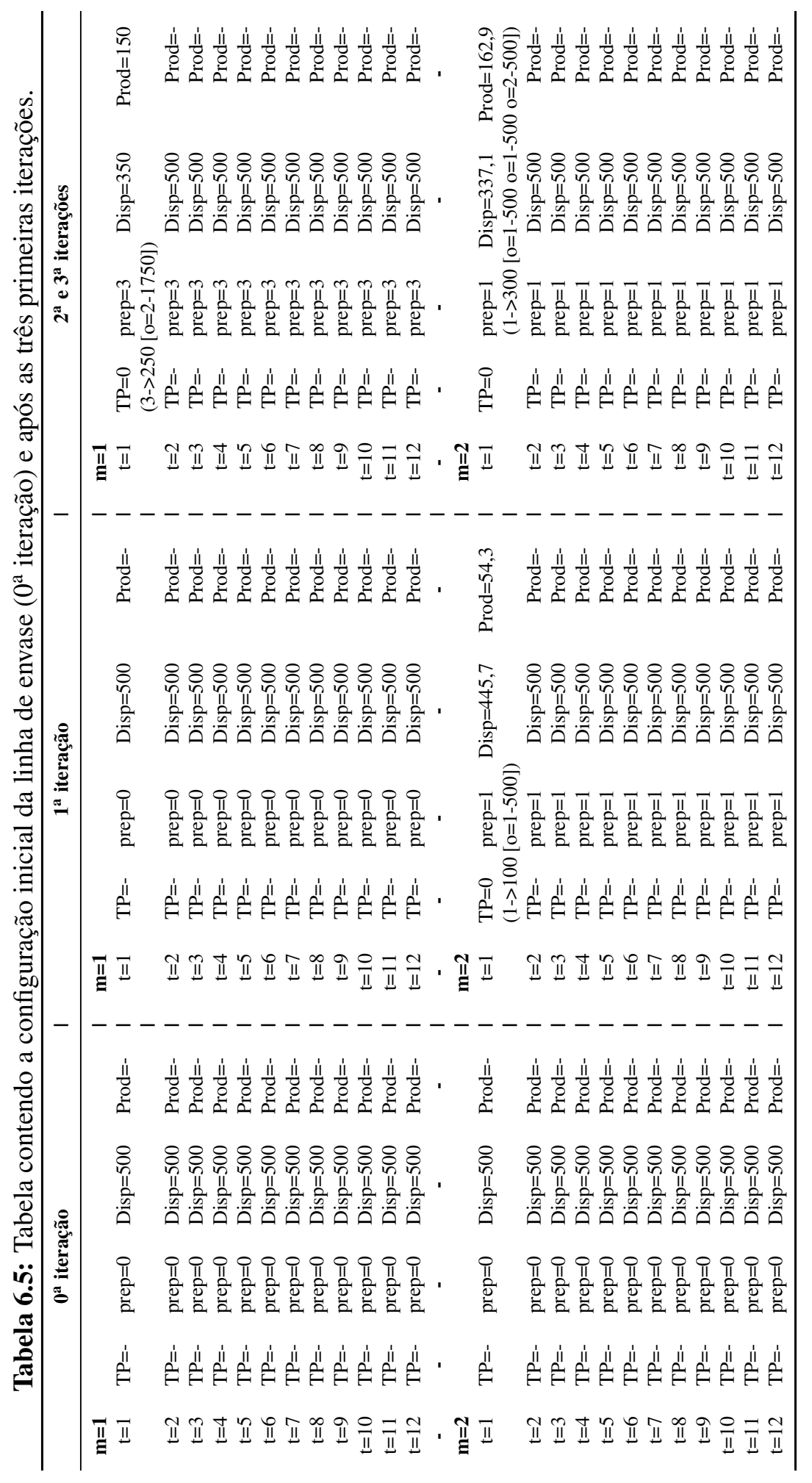




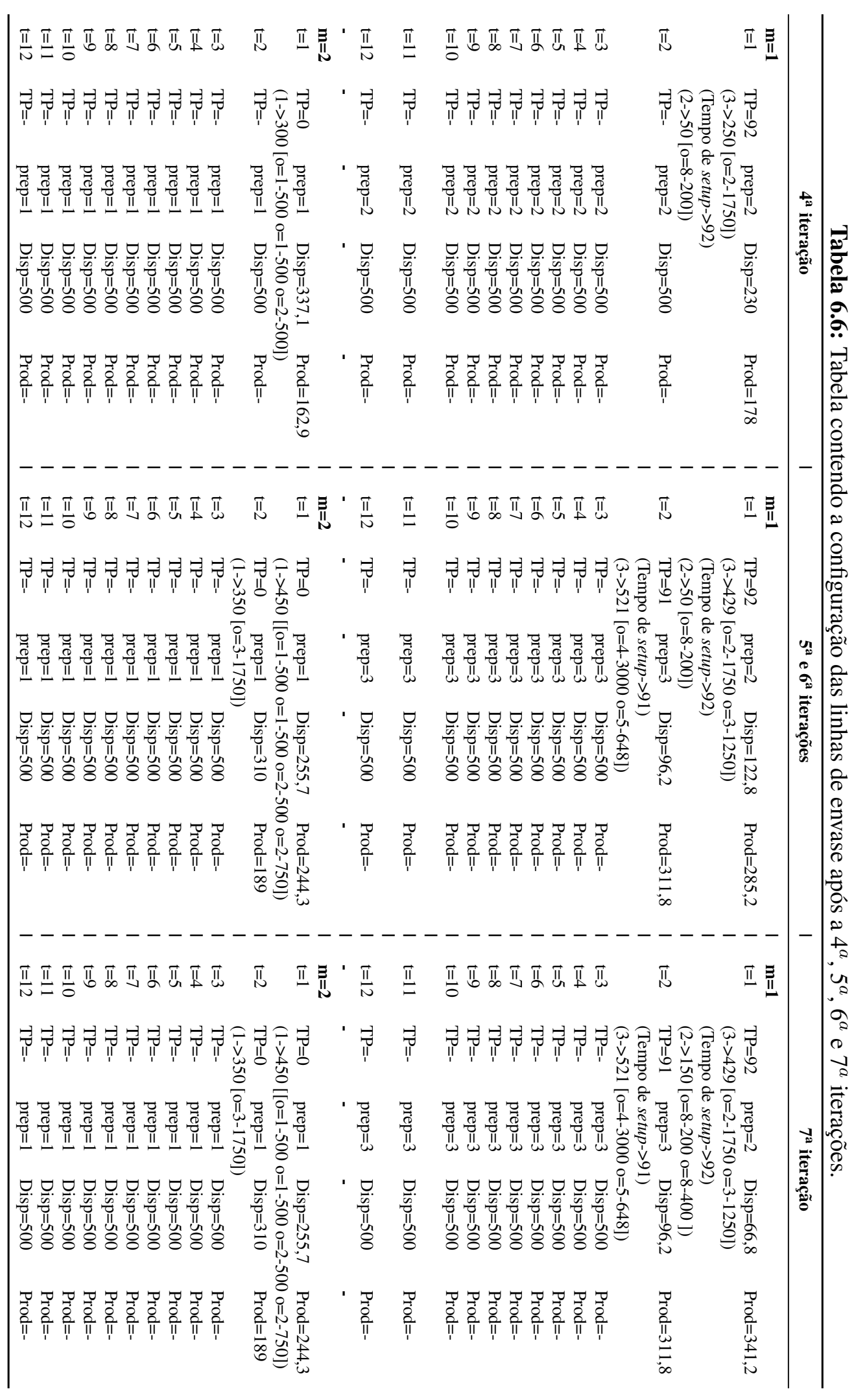


Tabela 6.7: Plano de produção fornecido por meio da execução da heurística construtiva para o exemplo (Algoritmo).

\begin{tabular}{|c|c|c|c|c|c|c|c|c|c|c|c|c|}
\hline $\mathrm{i}=1$ & $t=1$ & $t=2$ & $t=3$ & $t=4$ & $t=5$ & $t=6$ & $t=7$ & $t=8$ & $t=9$ & $t=10$ & $\mathrm{t}=11$ & $\mathrm{t}=12$ \\
\hline Estoque & 350 & 691 & 191 & 500 & 1.000 & 500 & 500 & 500 & 651 & 151 & 500 & - \\
\hline Atraso & - & - & - & - & - & - & - & - & - & - & - & - \\
\hline Demanda & 100 & 200 & 500 & - & - & 500 & - & - & - & 500 & - & 500 \\
\hline Produção & 450 & 541 & - & 309 & 500 & - & - & - & 151 & - & 349 & - \\
\hline$i=2$ & $t=1$ & $\mathrm{t}=2$ & $t=3$ & $\mathrm{t}=4$ & $t=5$ & $t=6$ & $t=7$ & $t=8$ & $t=9$ & $t=10$ & $\mathrm{t}=11$ & $t=12$ \\
\hline Estoque & 250 & 200 & 100 & 100 & 100 & - & - & - & 400 & 150 & 800 & - \\
\hline Atraso & - & - & - & - & - & 600 & 600 & 350 & - & - & - & - \\
\hline Demanda & - & 50 & 100 & - & - & 700 & - & - & - & 500 & - & 800 \\
\hline Produção & 250 & - & - & - & - & - & - & 250 & 750 & 250 & 650 & - \\
\hline $\mathrm{i}=3$ & $t=1$ & $t=2$ & $t=3$ & $t=4$ & $t=5$ & $t=6$ & $t=7$ & $t=8$ & $t=9$ & $t=10$ & $\mathrm{t}=11$ & $\mathrm{t}=12$ \\
\hline Estoque & 429 & 750 & 200 & 494 & 1.136 & 1.422 & 1.994 & 1.765 & 1.800 & 1.000 & 1.000 & - \\
\hline Atraso & - & - & - & - & - & - & - & - & - & - & - & - \\
\hline Demanda & - & 250 & 700 & 200 & - & - & - & 800 & - & 800 & - & 1.000 \\
\hline Produção & 429 & 572 & 150 & 494 & 643 & 286 & 571 & 571 & 35 & - & - & - \\
\hline
\end{tabular}

\subsubsection{Heurística de busca local}

A heurística de busca local utiliza a solução fornecida pela heurística construtiva. Sua execução iniciase analisando os períodos finais do horizonte de planejamento, seguindo em direção aos do início. A cada período, avalia-se cada uma das envasadoras, verificando a possibilidade de deslocamento da produção dos itens com o intuito de pagar menos estoque. Lembre-se que o critério guloso utilizado pela heurística construtiva é produzir o mais próximo possível ao início do horizonte de planejamento, não considerando o custo de estoque. Agora, na heurística de busca local, analisa-se a possibilidade de deslocamento da produção dos itens para incorrer em um menor custo de estoque. Entretanto, também é necessário analisar se o tanque consegue continuar fornecendo líquido. Assim, se houver possibilidade de deslocamento da produção, pagando-se menos estoque e, ainda, o mesmo tanque suprindo a envasadora, ocorre, portanto, o deslocamento da produção para períodos posteriores (Veja Algoritmo6).

O Algoritmo 6 tem como parâmetro de entrada uma solução inicial $(\hat{S})$. Ao começar a execução, os demais parâmetros utilizados durante as iterações são iniciados ( $\operatorname{prod} \leftarrow \emptyset \mathrm{e} \overline{t_{o}} \leftarrow \emptyset$ ). Percorre-se o horizonte de planejamento a partir do final, período a período, até o período $t=1$. Analisa-se cada uma das envasadoras a cada período. Caso ocorra produção $(\operatorname{prod} \leftarrow \operatorname{último}(\hat{S}, m)$ e $\operatorname{prod} \neq \emptyset)$, verifica-se qual o período de ocorrência da demanda $\left(t^{\prime} \leftarrow\right.$ Período_Demanda $(p r o d)$ ) e, também, quais os períodos em que o tanque pode continuar abastecendo de líquido a produção deste item $\left(\overline{t_{o}} \leftarrow\right.$ Período_Líquido_Disponível $($ prod $\left.)\right)$. Se a tentativa em realocar a produção resultar em menor custo de estoque, é necessário verificar se a solução permanece viável caso ocorra este rearranjo (Tentar_Realocar_Produção(prod, $\left.t^{\prime \prime}\right)=$ verdadeiro). Em caso afirmativo, a produção é realocada (Realoca_Produção $\left.\left(\operatorname{prod}, t^{\prime \prime}\right)\right)$ e as informações do tanque são atualizadas (Ajeita_Tanque).

Ao final da execução da heurística de busca local para o exemplo numérico, obtém-se o plano de produção apresentado na Tabela 6.8, cujo valor da função objetivo é de aproximadamente 3.033, ou seja, um pouco melhor que a solução da heurística construtiva (3048). 


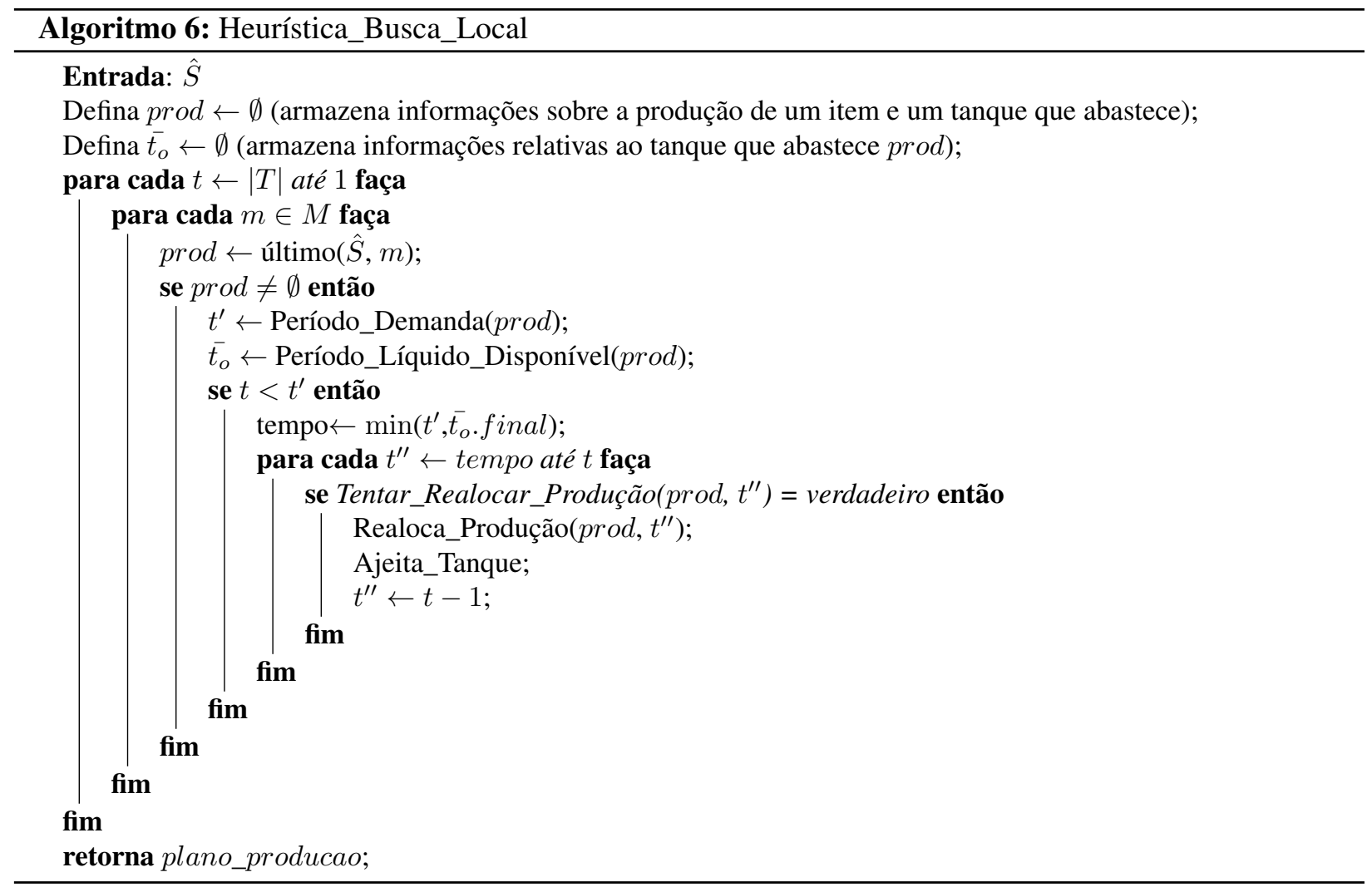

Tabela 6.8: Plano de produção fornecido ao final da execução da heurística de busca local para o exemplo (Algoritmo).

\begin{tabular}{|c|c|c|c|c|c|c|c|c|c|c|c|c|}
\hline $\mathrm{i}=1$ & $\mathrm{t}=1$ & $t=2$ & $t=3$ & $t=4$ & $t=5$ & $t=6$ & $t=7$ & $t=8$ & $\mathrm{t}=9$ & $t=10$ & $\mathrm{t}=11$ & $t=12$ \\
\hline Estoque & 350 & 500 & 191 & 500 & 1.000 & 500 & 1.000 & 1.000 & 1.000 & 500 & 500 & - \\
\hline Atraso & - & - & - & - & - & - & - & - & - & - & - & - \\
\hline Demanda & 100 & 200 & 500 & - & - & 500 & - & - & - & 500 & - & 500 \\
\hline Produção & 450 & 350 & 191 & 309 & 500 & - & 500 & - & - & - & - & - \\
\hline$i=2$ & $\mathrm{t}=1$ & $t=2$ & $t=3$ & $t=4$ & $\mathrm{t}=5$ & $t=6$ & $\mathrm{t}=7$ & $t=8$ & $\mathrm{t}=9$ & $t=10$ & $\mathrm{t}=11$ & $t=12$ \\
\hline Estoque & 250 & 200 & 100 & 100 & 100 & - & - & - & 140 & 150 & 150 & - \\
\hline Atraso & - & - & - & - & - & 600 & 600 & 350 & - & - & - & - \\
\hline Demanda & - & 50 & 100 & - & - & 700 & - & - & - & 500 & - & 800 \\
\hline Produção & 250 & - & - & - & - & - & - & 250 & 490 & 510 & - & 650 \\
\hline$i=3$ & $\mathrm{t}=1$ & $t=2$ & $t=3$ & $t=4$ & $t=5$ & $t=6$ & $\mathrm{t}=7$ & $t=8$ & $\mathrm{t}=9$ & $t=10$ & $\mathrm{t}=11$ & $t=12$ \\
\hline Estoque & 429 & 750 & 200 & 494 & 1.136 & 1.422 & 1.636 & 1.408 & 1.408 & 751 & 1.000 & -0 \\
\hline Atraso & - & - & - & - & - & - & - & - & - & - & - & - \\
\hline Demanda & - & 250 & 700 & 200 & - & - & - & 800 & - & 800 & - & 1.000 \\
\hline Produção & 429 & 572 & 150 & 494 & 643 & 286 & 214 & 571 & - & 143 & 249 & - \\
\hline
\end{tabular}




\subsection{Resultados}

A meta-heurística GRASP foi implementada em linguagem de programação $\mathrm{C}$, executada empregando as mesmas condições de teste, ambiente computacional, como também, as instâncias utilizadas nos capítulos anteriores.

Inicialmente, realizou-se uma comparação dos resultados variando-se os valores de $\partial$ na execução da meta-heurística, como pode ser observado na Tabela 6.9. Para a interpretação desta tabela, considere na primeira linha as variações de $\partial$ entre os valores $0 \%, 10 \%, 50 \%, 90 \%$ e $100 \%$, respectivamente. Ressaltando que para $\partial=0 \%$ temos uma solução determinística. Para cada valor de $\partial$ apresenta-se o GAP obtido pela solução da heurística construtiva (coluna HC) e o da heurística de busca local (coluna HBL), referente a solução obtida de melhor valor da função objetivo durante a execução da meta-heurística. A última coluna apresentada para cada $\partial$ fornece o tempo total de execução (em segundos) utilizado pela meta-heurística GRASP. Os valores dos GAPs são calculados por meio da equação (4.16), apresentada no Capítulo 4. A equação (4.16) precisa de dois parâmetros para seu cálculo, sendo $F o$ o valor da função objetivo obtido pela solução da meta-heurística e Best o melhor limitante inferior encontrado para o problema, sendo este valor obtido pelo CPLEX ao resolver o modelo TOLM-GLSP. Entretanto, diferentemente dos testes computacionais realizados anteriormente, os tanques estão cheios de líquido ao início do horizonte de planejamento. Nos capítulos anteriores, incumbia-se aos modelos decidirem como fazer esta programação inicial. Agora, para que o GRASP tenha seus resultados comparáveis de uma maneira mais fidedigna, realizou-se os testes computacionais do modelo matemático TOLM-GSLP considerando os tanques cheios no início do horizonte de planejamento. Esta inicialização é feita de maneira idêntica ao Algoritmo 5, na etapa Tanques $\forall t \in T \leftarrow$ Enche_Tanques (semente).

Dentre os valores testados para $\partial$, nota-se que $\partial=0,5, \partial=0,9$ e $\partial=1$ obtêm melhores resultados em comparação aos $\partial \leq 0,1$. Para $\partial=0,5$, são obtidos os melhores valores de GAP para aproximadamente $22 \%$ dos exemplares de teste, enquanto que para $\partial=1$, apresentam-se melhores resultados para aproximadamente $25 \%$. E com um melhor percentual, $\partial=0,9$ para aproximadamente $51 \%$ de todas as instâncias testes. Sendo assim, utilizamos os resultados obtidos por $\partial=0,9$ para compararmos com os resultados do modelo TOLM-GLSP e da MIP-heurística Proc_Crescente, que obtiveram os melhores desempenhos, entre e as MIP-heurísticas, como apresentado nos capítulos anteriores.

Para os próximos testes computacionais, além da resolução do modelo TOLM-GLSP, a MIP-heurística Proc_Crescente também teve seus testes computacionais executados considerando a inicialização dos tanques de maneira idêntica a realizada no Algoritmo 5, analisando-se os resultados obtidos por TOLM-GLSP, Proc_Crescente e meta-heurística GRASP $(\partial=0,9)$, com relação ao valor da função objetivo $(F o)$, ao GAP e ao tempo de execução dos procedimentos em segundos (Tempo), veja a Tabela 6.10 O cálculo do GAP é feito de maneira semelhante ao da Tabela 6.9 .

Ao analisarmos os valores dos GAPs obtidos, Proc_Crescente apresentou um melhor desempenho relativo para mais de $81 \%$ das instâncias, a meta-heurística foi responsável por quase $15 \%$ e o modelo TOLM-GLSP por menos de 4\% dos melhores GAPs encontrados. Ou seja, para a maioria dos resultados, Proc_Crescente obteve um melhor desempenho. No entanto, com relação a instância P_4_15_1, o modelo obteve melhor valor de GAP. Com relação as 3 últimas instâncias maiores, D_40_5_7 a D_40_5_10, a meta-heurística foi superior. Assim, de maneira geral, pode-se dizer que Proc_Crescente mostrou-se superior, porém a meta-heurística apresenta-se promissora para instâncias de maiores dimensões. 


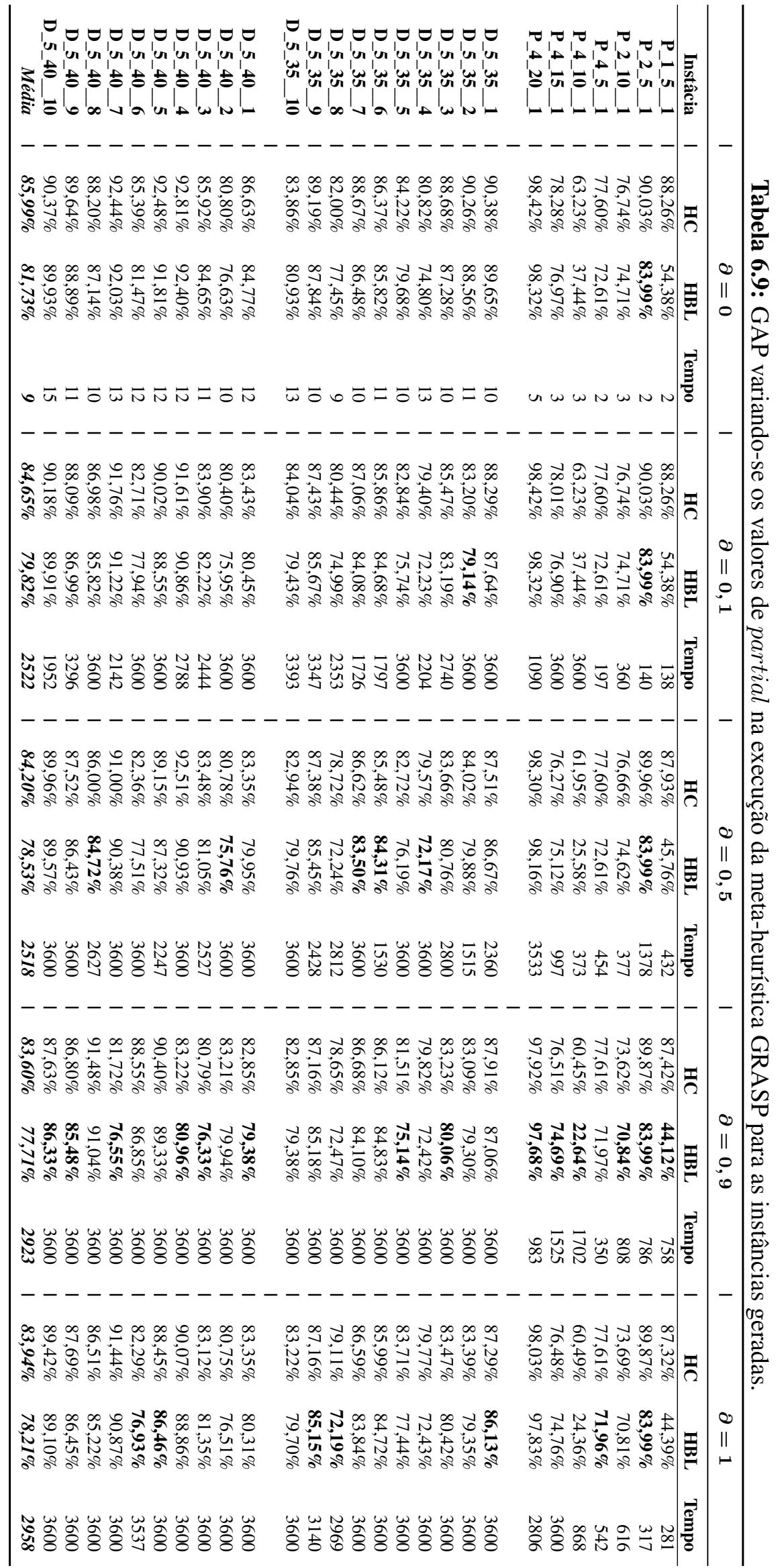




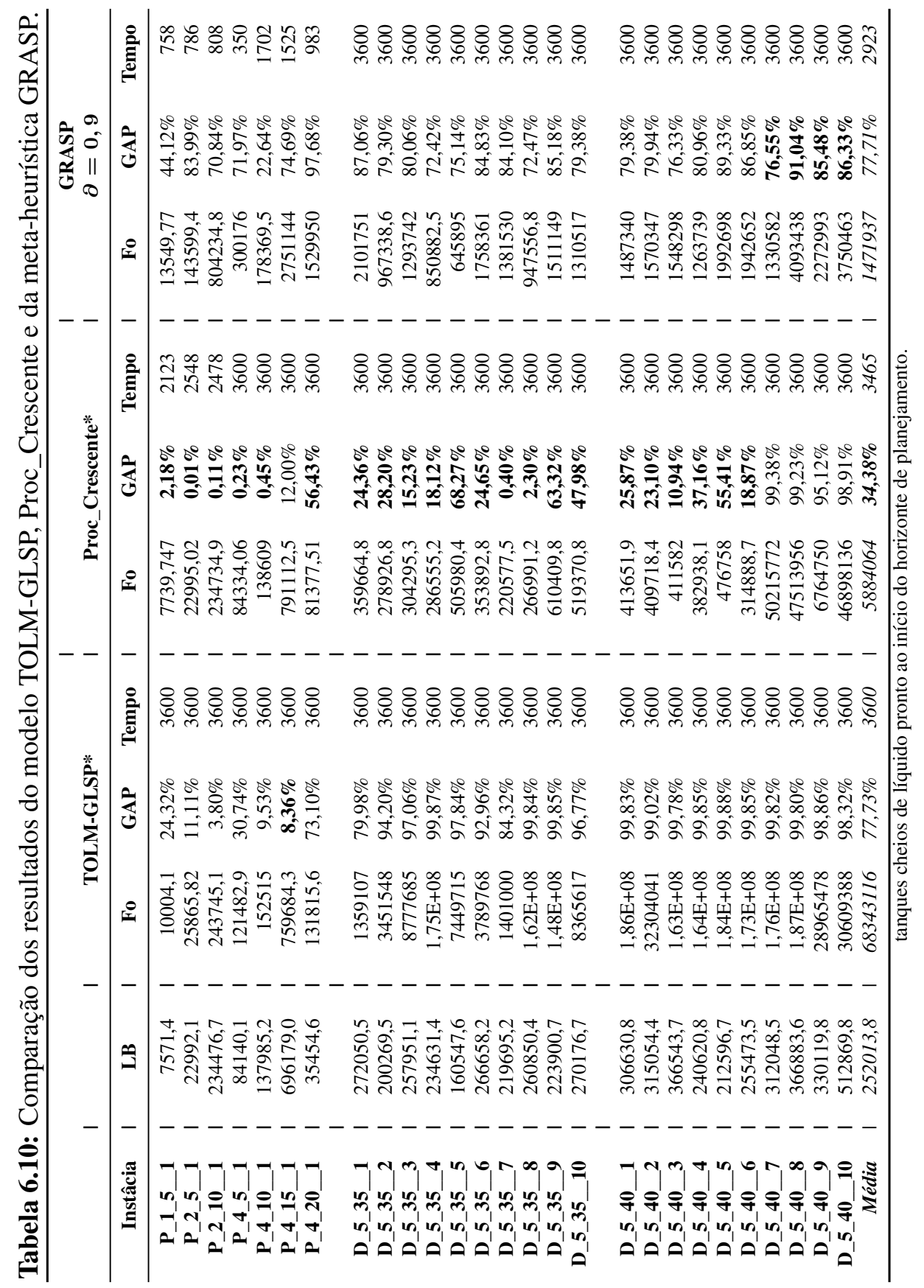





\section{Conclusões}

O objetivo desta tese foi estudar e caracterizar o problema de dimensionamento de lotes e programação da produção em indústrias cervejeiras e propor abordagens de otimização baseadas em modelagem matemática do problema e no desenvolvimento de métodos de solução para resolvê-lo em situações práticas. Sendo assim, este capítulo tem o intuito de apresentar as principais conclusões desta pesquisa, como também discutir possíveis perspectivas para trabalhos futuros.

\subsection{Conclusões}

Esta pesquisa foi motivada pelo problema de planejamento e programação da produção multiestágio presente no processo de produção em indústrias cervejeiras. Trata-se de uma pesquisa quantitativa, empírica, axiomática e normativa, seguindo as orientações de classificação em Bertrand \& Fransoo (2002) e Morabito \& Pureza (2010). Foram realizadas várias visitas a cervejarias no Brasil e em Portugal, que foram importantes para o entendimento, na prática, de detalhes do processo produtivo e, também, das dificuldades para o planejamento de produção, sob o ponto de vista das indústrias. Basicamente, o processo de produção de cerveja por ser dividido em dois principais estágios: preparação do líquido (estágio I) e envase (estágio II). As empresas visitadas fazem o planejamento e a programação da produção de cada um dos estágios de maneira desacoplada, onde primeiramente há o planejamento do estágio I e depois a programação do estágio II. Esta estratégia de desmembrar os estágios simplifica as soluções para o problema encontrado na prática. Porém, podendo perder oportunidades importantes de melhorar as soluções, visto que qualquer decisão em um dos estágios, pode interferir diretamente no outro. Logo, ao considerar o problema de maneira integrada, trata-se estas decisões de forma conjunta. $\mathrm{O}$ intuito deste trabalho foi apresentar modelos e métodos de solução que consideram ambos os estágios simultaneamente para gerar planos de produção efetivos para apoiar as decisões neste processo produtivo. 
Os gargalos de produção presentes nos estágios I e II foram o foco deste trabalho, visto que, obter planos de produção viáveis para os demais processos envolvidos na produção de cerveja são facilmente deriváveis a partir dos planos de produção estabelecidos para esses processos. O gargalo da produção no estágio I é o processo que ocorre dentro dos tanques (fermentação/maturação), pois os tanques ficam ocupados durante vários dias até a cerveja ficar pronta e disponível para o envase. Com relação ao estágio II, o gargalo do processo encontra-se no envase e a velocidade em que as embalagens são enchidas com líquidos influencia diretamente na liberação (ou não) dos tanques.

Para a elaboração dos modelos, procedimentos MIP-heurísticos e (meta)heurísticos foram propostos nesta pesquisa, assumimos que:

- os líquidos podem ficar estocados dentro dos tanques enquanto esperam para ser envasados, diferindose, por exemplo, dos processos de produção em indústrias de refrigerantes e outras bebidas;

- devido ao curto período de tempo em que o líquido pronto permanece estocado, não são considerados os custos de estoque dos líquidos dentro dos tanques;

- os tanques precisam ser limpos e o tempo consumido é suposto conhecido previamente e independe da sequência; portanto, o tempo necessário para limpeza dos tanques estão inclusos na definição de tempos de fermentação/maturação utilizados nos modelos e métodos de solução;

- não se considera a possibilidade dos líquidos serem filtrados e esperarem em outros tanques (buffers).

Para este estudo, uma ampla revisão bibliográfica também foi realizada e observou-se que este problema de planejamento e programação da produção em indústrias cervejeiras é pouco explorado na literatura (a autora desconhece o desenvolvimento de outros trabalhos na mesma linha de pesquisa desta tese). Sendo assim, para representar adequadamente o problema alguns modelos de programação linear inteira mista foram desenvolvidos e métodos de solução foram elaborados com o intuito de obter planos de produção factíveis e efetivos. Os modelos de programação matemática desenvolvidos foram:

- T1LM: trata-se de um modelo de otimização linear inteira mista, em que o estágio II foi elaborado com base no problema CSLP, conhecido da literatura. Algumas restrições foram elaboradas embasadas no trabalho de Ferreira (2007) para as indústrias de refrigerantes, que propõe um modelo baseado no problema GSLP. O modelo T1LM considera apenas um tanque e múltiplas linhas de envase, sendo, portanto, uma simplificação dos processos de produção de cerveja das empresas visitadas. Notou-se a dificuldade de resolução de instâncias que exigiam um número maior de variáveis, por possuírem mais linhas de envase e líquidos, fazendo com que a extensão deste modelo fosse repensada, surgindo assim o segundo modelo TOLM-GSLP.

- TOLM-GLSP: também é um modelo de otimização linear inteira mista, que considera vários tanques e linhas de envase, como é mais usual nos processos de produção de cervejarias maiores, inclusive como as duas empresas visitadas. Este modelo foi elaborado com base no problema GLSP. Considera o horizonte de planejamento dividido em duas partes disjuntas, sendo a primeira parte do horizonte mais detalhada (i.e., com mais subperíodos) do que a segunda. Uma nova interpretação das principais variáveis de decisão envolvidas no estágio I do modelo T1LM foi realizada. O modelo TOLM-GLSP apresentou-se eficaz, ao encontrar pelo menos uma solução factível para todas as instâncias aqui testadas; embora, em alguns casos, esta solução envolvesse altos custos de atrasos e faltas (backlogging). 
- TOLM-SPL: este modelo é uma reformulação do modelo TOLM-GLSP, utilizando estratégias dos modelos do problema SPL, também conhecido da literatura. O modelo TOLM-SPL representa o problema de dimensionamento de lotes e sequenciamento da produção em indústrias cervejeiras assumindo que toda a demanda deve ser atendida até o final do horizonte de planejamento. Ambos estágios (I e II) foram reescritos embasados no problema SPL. Entretanto, devido ao elevado número de variáveis resultante desta reformulação, como também a restrição de atender toda a demanda dentro do horizonte de planejamento, o modelo não apresentou um bom desempenho para boa parte dos exemplares, principalmente para os de maiores dimensões (mais itens, linhas de envase, tanques, etc).

- TOLM-CLSD: o modelo TOLM-GLSP foi reformulado baseado em CLSD, também conhecido da literatura. Para resolvê-lo, a possibilidade de subciclos foi eliminada explorando-se duas estratégias de eliminação de subtours (TOLM-CLSD_MTZ e TOLM-CLSD_W). Embora os modelos tenham apresentado um bom desempenho ao resolver as instâncias menores, para as instâncias de grandes dimensões não conseguiram encontrar soluções viáveis para muitos exemplares dentro do limite de tempo computacional pré-estabelecido.

Os métodos heurísticos propostos para a resolução do problema, baseiam-se em MIP-heurísticas e, também, uma meta-heurística GRASP. Sendo estes descritos a seguir:

- Pro_Crescente e Proc_Decrescente: são procedimentos MIP-heurísticos resultantes da combinação da melhor heurística relax-and-fix testada para o problema (RF_Forw), combinada com todos os procedimentos de melhoria fix-and-optimize apresentados. A Proc_Crescente mostrou-se o melhor procedimento para a resolução de instâncias de grande dimensão.

- Decomposição por estágios: consiste na resolução de cada um dos estágios envolvidos durante o processo produtivo de maneira desacoplada. Primeiramente, resolve-se o estágio I e, na sequência, o estágio II. Este último recebe informações obtidas pela resolução do anterior e estas devem ser respeitadas. O estágio I informa ao II qual líquido, qual período e a respectiva quantidade deste líquido que está pronta em cada um dos tanques durante o decorrer do horizonte de planejamento. Esta abordagem também mostrou-se competitiva, obtendo bons resultados.

- Meta-heurística GRASP: a fase construtiva desta meta-heurística tem por objetivo produzir o mais cedo possível a demanda, evitando o atraso na entrega. Após a construção de uma solução viável, esta passa por uma fase de melhoria por meio de uma heurística de busca local, que visa deslocar a produção no horizonte de planejamento, com o intuito de diminuir os custos de estoques derivados da política gulosa da solução inicial. Para a comparação dos resultados computacionais, utilizou-se o modelo e a MIP-heurística de melhores desempenhos (TOLM-GSLP e Proc_Crescente, respectivamente). Para estes, alterou-se a condição inicial dos tanques começando o horizonte de planejamento cheios de líquido pronto, semelhantes ao GRASP. Em relação aos resultados, de maneira geral, Proc_Crescente apresentou um melhor desempenho; entretanto, a meta-heurística mostra-se promissora para as instâncias maiores.

Experimentos computacionais foram realizados utilizando os modelos, as MIP-heurísticas e a metaheurística GRASP. Os modelos e as MIP-heurísticas foram implementados em linguagem de programação 
C++ , conjuntamente com a biblioteca Concert do software de otimização CPLEX (versão 12.4). A metaheurística GRASP foi implementada em linguagem de programação C. Instâncias de teste foram geradas baseadas em dados reais para a realização dos experimentos computacionais. Sendo assim, um gerador de instâncias para o problema foi desenvolvido, cujas informações consideradas baseiam-se em grande parte em dados reais. Para os testes computacionais dos procedimentos, foram geradas instâncias de pequeno (P_1_5_1 a P_4_20_1) e grande porte (D_5_35_1 a P_5_40_10), considerando as situações reais das indústrias cervejeiras. Os resultados mostraram que os modelos são coerentes e representam adequadamente o problema proposto.

De maneira geral, os modelos TOLM-CLSD_W e TOLM-CLSD_MTZ apresentaram melhores resultados para instâncias de teste com menores dimensões (P_1_5_1 a P_4_20_1), conseguindo encontrar a solução ótima para algumas delas. Entretanto, para instâncias de maiores dimensões, o modelo TOLMGLSP obtém um melhor desempenho, pois consegue encontrar uma solução viável em todas as instâncias, mesmo que para algumas delas tenha-se um custo elevado de atraso e falta. Com relação aos procedimentos MIP-heurísticos, destaca-se Proc_Crescente, obtendo melhores resultados e encontrando uma boa solução para quase todas as instâncias, sendo estas, na grande maioria dos casos, melhores que as encontradas pelos modelos. Com o intuito de comparar o desempenho da meta-heurística, o modelo TOLMGLSP e a MIP-heurística Proc_Crescente foram resolvidos utilizando os mesmos parâmetros iniciais do GRASP. Proc_Crescente apresentou um melhor desempenho relativo para mais de $81 \%$ das instâncias, a meta-heurística foi responsável por quase $15 \%$ e o modelo TOLM-GLSP por menos de $4 \%$ dos melhores GAPs encontrados. Proc_Crescente mostrou-se mais uma vez superior.

\subsection{Pesquisas futuras}

Por tratar-se de um problema ainda pouco explorado na literatura, várias perspectivas interessantes para pesquisas futuras podem ser exploradas. Dentre as principais ideias a serem trabalhadas no futuro encontram-se:

- Aplicar as abordagens desenvolvidas em um estudo de caso prático: uma pesquisa futura importante seria aplicar efetivamente os modelos e métodos propostos em situações reais, verificando e analisando suas vantagens e desvantagens em relação às soluções praticadas pelas empresas.

- Estoque de segurança: devido a sazonalidade da demanda, principalmente na indústria portuguesa, uma extensão interessante das abordagens aqui propostas seria acoplar ao modelo matemático o estoque de segurança;

- Horizonte rolante: a estrutura do horizonte de planejamento utilizada pelos modelos TOLM foi inspirada nos problemas de horizonte rolante. Logo, uma adaptação destes modelos acoplando-se o horizonte rolante poderia fornecer um detalhamento maior para mais períodos do horizonte de planejamento.

- Incluir nos modelos os tanques buffers: na empresa portuguesa não há a possibilidade do líquido ser filtrado e imediatamente envasado, pois não existe sincronia direta entre as linhas de envase e os tanques de fermentação e maturação. Neste aspecto, difere-se da empresa brasileira, pois a velocidade 
de escoamento do líquido pode ser sincronizada com as linhas de envase. Entretanto, os tanques buffers, para as empresas brasileiras, são utilizados como tanques intermediários para armazenagem de líquido filtrado, com o intuito de liberar o mais rápido possível os tanques de fermentação/maturação. Uma abordagem interessante seria acoplar a possibilidade de utilização de tanques buffers ao modelo e verificar se este recurso interfere e ameniza o problema do gargalo de recursos do estágio I presentes nas cervejarias.

- Adaptação e extensão dos modelos para outras empresas de bebidas: ao estudar o trabalho de Guimarães et al. (2012), nota-se que há empresas que produzem não apenas cerveja, como também outras bebidas carbonatadas. Logo, o desenvolvimento de modelos e métodos de solução que considerassem simultaneamente as decisões de produção de cerveja e das demais bebidas, seria uma pesquisa futura interessante para tratar o problema no caso destas empresas.

- Validade de líquido dentro dos tanques: embora não explorado explicitamente nos modelos desta pesquisa, o tempo de validade dos líquidos dentro dos tanques está presente nos problemas reais e é considerado importante principalmente para itens com baixa demanda. Logo, estudar os modelos e métodos de solução para incorporar estes tempos de validade dos líquidos seria uma pesquisa futura interessante para certas empresas cervejeiras.

- Melhoria da meta-heurística GRASP: explorar outras estratégias para buscar uma melhor vizinhança durante a fase de busca local da meta-heurística GRASP, pode melhorar de forma relevante o desempenho e, também, está na agenda de pesquisa futura.

- Desenvolvimento de outras meta-heurísticas: desenvolvimento de outra meta-heurística, como por exemplo, o algoritmo genético, que apresentou-se eficiente para a indústria de refrigerantes (Toledo et al. 2009), também seria uma pesquisa futura interessante.

- Decomposição de Dantzig-Wolfe, geração de colunas e procedimento de factibilização: a decomposição de Dantzig \& Wolfe (1960) consiste em reescrever algumas variáveis do problema como combinação convexa de pontos extremos (e raios extremos, se existirem), utilizando um subconjunto do conjunto de restrições do problema original (problema mestre). Assim, as demais restrições são trabalhadas em subproblemas. Com a conjunção dos subproblemas e do problema mestre, tem-se um problema equivalente ao original, entretanto, relaxado. Para um mesmo problema, há várias possibilidades de decomposição que podem ser aplicadas. As diferentes decomposições podem influenciar no desempenho do algoritmo de geração de colunas.Uma proposta interessante para pesquisa futura seria explorar possibilidades de decomposição de Dantzig-Wolfe para o problema de dimensionamento e sequenciamento de lotes de produção para a indústria cervejeira, tais como:

- considerar as restrições de acoplamento dos estágios alocadas ao problema mestre; logo, resultam dois subproblemas, um para cada estágio.

- considerar as restrições do estágio I alocadas ao problema mestre, obtendo $|M|$ subproblemas, um para cada envasadora.

A utilização da decomposição de Dantzig-Wolfe, não garante que a solução encontrada seja ótima (resolve uma relaxação do problema original), o que justificaria a utilização de um procedimento 
heurístico para aproximar a solução encontrada na geração de colunas a uma solução inteira factível para o problema, ou ainda, a utilização do método branch-and-price para a obtenção da solução inteira.

- Remodelar o problema utilizando estratégias multi-commodity flow (Eppen \& Martin, 1987): uma das reformulações estudadas durante a revisão da literatura para o problema de dimensionamento e sequenciamento de lotes consiste em reescrever o problema utilizando estratégias do problema de muti-fluxo (multi-commodity flow (Eppen \& Martin 1987)), como em Wolsey (2002). Problemas de multi-commodity flow visam roteirizar os fluxos commodities (individuais). Cada commodity possui origem e destino especificados e são roteirizados por meio de uma rede. A origem e o destino são representados como nós da rede e os recursos compartilhados são as capacidades dos arcos desta rede. Assim, a ideia de reescrever os modelos do problema de programação da produção em indústrias cervejeiras consiste em focalizar na variável $Z_{m j i t}$, que representaria o fluxo do nó $j$ do período $t-1$ para o nó $i$ no período $t\left(i, j \in N\right.$ e $\left.t \in T_{1}\right)$, lembrando das restrições $\sum_{i \in \mu_{m}} Z_{m j i t}=Y_{m i t}$ $\left(\forall j \in \mu_{m} ; m \in M ; t \in T_{1}\right)$ e $\sum_{j \in \mu_{m}} Z_{m j i t}=Y_{m i(t-1)}\left(\forall i \in \mu_{m} ; m \in M ; t \in T_{1}\right)$. Sendo assim, poderia-se pensar numa pesquisa futura explorando a definição de start up $q_{m i t}$ sendo escritas em função das variáveis de setup, algo como $q_{m i t}=Y_{m i t}-Z_{m i i t}=\sum_{j \in \mu_{m} ; j \neq i} Z_{m j i t}$, e variáveis switch off sendo $w_{m i t}=Y_{m i t}-Z_{m i i(t+1)}=\sum_{j \in \mu_{m} ; j \neq i} Z_{m j i(t+1)}$, o que também faz parte da minha agenda de pesquisa futura. 
Afentakis, P.; Gavish, B.; Karmarkar, U. Computationally efficient optimal solutions to the lotsizing problem in multistage assembly systems. Management Science, v. 30, n. 2, p. 222-239, 1984.

Aiex, R.; Binato, S.; Resende, M. Parallel \{GRASP\} with path-relinking for job shop scheduling. Parallel Computing, v. 29, n. 4, p. 393 - 430, parallel computing in numerical optimization, 2003.

Almada-lobo, B.; Klabjan, D.; Ant’o onia Carravilla, M.; Oliveira, J. F. Single machine multi-product capacitated lot sizing with sequence-dependent setups. International Journal of Production Research, v. 45, n. 20, p. 4873-4894, 2007.

Almada-Lobo, B.; Oliveira, J. F.; Carravilla, M. A. Production planning and scheduling in the glass container industry: A VNS approach. International Journal of Production Economics, v. 114, n. 1, p. $363-375,2008$.

AmBev (último acesso em 01 de outubro de 2013). 2013.

Disponível em http://www.ambev.com.br/nossas-marcas/cervejas/cervejas

Araujo, S.; Arenales, M.; Clark, A. Joint rolling-horizon scheduling of materials processing and lot-sizing with sequence-dependent setups. Journal of Heuristics, v. 13, n. 4, p. 337-358, 2007.

Araujo, S. A.; Arenales, M. N. Problema de dimensionamento de lotes monoestágio com restrição de capacidade: modelagem, método de resolução e resultados computacionais. Pesquisa Operacional, v. 20 , p. $287-306,2000$.

Araujo, S. A.; Arenales, M. N.; Clark, A. R. Lot sizing and furnace scheduling in small foundries. Computers \& Operations Research, v. 35, n. 3, p. 916 - 932, 2008.

BALDo, T. A. Geração de colunas para o problema de dimensionamento de lotes de produção com limitações de capacidade. Dissertação de Mestrado, Universidade de São Paulo, São Carlos, 2009.

Baldo, T. A.; Santos, M. O.; Almada-Lobo, B.; Morabito, R. An optimization approach for the lot sizing and scheduling problem in the brewery industry. Computers \& Industrial Engineering, v. 72, p. $58-71,2014$. 
Berretta, R.; FrançA, P.; ARmentano, V. Metaheuristic approaches for the multilevel resourceconstrained lot-sizing problem with setup and lead times. Asia-Pacific Journal of Operational Research, v. 22, n. 02, p. 261-286, 2005.

Disponível em http://www.worldscientific.com/doi/abs/10.1142/ S0217595905000510

Bertrand, J. W. M.; Fransoo, J. C. Modelling and simulation - operations management research methodologies using quantitative modeling. International Journal of Operations \& Production Management, 2002.

Billington, P. J.; McClain, J. O.; Thomas, L. J. Mathematical programming approaches to capacity-constrained mrp systems: Review, formulation and problem reduction. Management Science, v. 29 , p. $1126-1141,1983$.

Billington, P. J.; McClain, J. O.; Thomas, L. J. Heuristics for multilevel lot-sizing with a bottleneck. Management Science, v. 32, n. 8, p. 989-1006, 1986.

Binato, S.; Hery, W.; Loewenstern, D. M.; Resende, M. G. C. A grasp for job shop scheduling. In: Essays and Surveys on Metaheuristics, Kluwer Academic Publishers, 2000, p. 59-79.

Bitran, G. R.; YAnasse, H. H. Computational complexity of the capacitated lot size problem. Management Science, v. 28, n. 10, p. 1174-1186, 1982.

BŁażewicz, J.; Domschke, W.; Pesch, E. The job shop scheduling problem: Conventional and new solution techniques. European Journal of Operational Research, v. 93, n. 1, p. 1-33, 1996.

CHARNPRASITPHON, A. Modeling and analysis of the batch production scheduling problem for perishable products with setup times. Tese de Doutorado, Geogia Institute of Technology, 2007.

Clark, A.; Morabito, R.; Toso, E. A. V. Production setup-sequencing and lot-sizing at an animal nutrition plant through atsp subtour elimination and patching. Journal of Scheduling, v. 13, n. 2, p. 111$121,2010$.

Clark, A. R.; Armentano, V. A. A heuristic for a resource-capacitated multi-stage lot-sizing problem with lead times. Journal of the Operational Research Society, v. 46, p. 1208-1222, 1995.

Dantzig, G. B.; Wolfe, P. Decomposition principle for linear programs. Operations Research, v. 8, n. 1, p. 101-111, 1960.

DreXL, A.; KIMMS, A. Lot sizing and scheduling - survey and extensions. European Journal of Operational Research, v. 99, n. 2, p. 221-235, 1997.

Eppen, G. D.; Martin, R. K. Solving multi-item capacitated lot-sizing problems using variable redefinition. Operations Research, v. 35, n. 6, p. 832-848, 1987.

Feo, T.; Resende, M. A probabilistic heuristic for a computationally difficult set covering problem. Operations Research Letters, v. 8, p. 67-71, 1989.

FEO, T.; RESEndE, M. Greedy randomized adaptive search procedures. Journal of Global Optimization, v. 6, p. 109-133, 1995. 
FERREIRA, D. Abordagens para o problema integrado de dimensionamento e sequenciamento de lotes da produção de bebidas. Tese de Doutorado, Universidade Federal de São Carlos, 2007.

Ferreira, D.; Clark, A. R.; Almada-Lobo, B.; Morabito, R. Single-stage formulations for synchronised two-stage lot sizing and scheduling in soft drink production. International Journal of Production Economics, v. 136, n. 2, p. 255-265, 2012.

Ferreira, D.; França, P. M.; Kimms, A.; Morabito, R.; Rangel, S.; Toledo, C. M. F. Heuristics and meta-heuristics for the lot-sizing and scheduling in the soft drinks industry: a comparison study (cap. 8), em: Metaheuristics for scheduling in industrial and manufacturing applications. Springer, 2008a.

Ferreira, D.; Morabito, R.; RAngel, S. Um modelo de otimização inteira mista e heurísticas relax and fix para a programação da produção de fábricas de refrigerantes de pequeno porte. Produção, v. 18, n. 1 , p. $76-88,2008$ b.

Ferreira, D.; Morabito, R.; RAngel, S. Solution approaches for the soft drink integrated production lot sizing and scheduling problem. European Journal of Operational Research, v. 196, n. 2, p. 697-706, 2009.

Festa, P.; Mauricio; Resende, G. C. Grasp: An annotated bibliography. In: Essays and surveys in metaheuristics, Kluwer Academic Publishers, 2002, p. 325-367.

Festa, P.; Resende, M. G. C. An annotated bibliography of grasp - part i: Algorithms. International Transactions in Operational Research, v. 16, n. 1, p. 1-24, 2009a.

Festa, P.; Resende, M. G. C. An annotated bibliography of grasp-part ii: Applications. International Transactions in Operational Research, v. 16, n. 2, p. 131-172, $2009 \mathrm{~b}$.

Figueira, G.; Santos, M. O.; Almada-Lobo, B. A hybrid VNS approach for the short-term production planning and scheduling: A case study in the pulp and paper industry. Computers \& Operations Research, v. 40, n. 7, p. $1804-1818,2013$.

FleischmanN, B. The discrete lot-sizing and scheduling problem with sequence-dependent setup costs. European Journal of Operational Research, v. 75, n. 2, p. 395 - 404, 1994.

Fleischmann, B.; Meyr, H. The general lotsizing and scheduling problem. Operations-ResearchSpektrum, v. 19, n. 1, p. 11-21, 1997.

Florian, M.; Lenstra, J. K.; KAn, A. H. G. R. Deterministic production planning: Algorithms and complexity. Management Science, v. 26, n. 7, p. 669-679, 1980.

França, P. M.; Armentano, V. A.; Berretta, R. E.; Clark, A. R. A heuristic method for lotsizing in multi-stage systems. Computers \& Operations Research, v. 24, n. 9, p. $861-874,1997$.

Glover, F. Future paths for integer programming and links to artificial intelligence. Computers \& Operations Research, v. 13, n. 5, p. 533-549, 1986.

Glover, F.; LAGUnA, M.; MARTí, R. Fundamentals of scatter search and path relinking. CONTROL AND CYBERNETICS, v. 39, p. 653-684, 2000. 
GoldberG, D. E. Genetic algorithms in search, optimization and machine learning. 1st ed. Boston, MA, USA: Addison-Wesley Longman Publishing Co., Inc., 1989.

Guimarães, L.; Klabjan, D.; Almada-Lobo, B. Annual production budget in the beverage industry. Engineering Applications of Artificial Intelligence, v. 25, n. 2, p. 229 - 241, 2012.

Guimarães, L. F. R. S. Production planning and scheduling in supply chain Unicer Bebidas,S.A.. Dissertação de Mestrado, Faculdade de Engenharia da Universidade do Porto, 2009.

HAASE, K. Capacitated lot-sizing with sequence dependent setup costs. Operations-Research-Spektrum, v. 18 , n. 1 , p. 51-59, 1996.

HARris, F. W. How many parts to make at once. Factory, The Magazine of Management, v. 10, n. 2, p. 135-136,152, 1913.

JANS, R. Capacitated lot sizing problems: New applications, formulations and algorithms. Tese de Doutorado, Faculteit Economische en Toegepaste Economische Wetenschappen - Katholieke Universiteit Leuven, Belgium, 2002.

JAns, R.; Degraeve, Z. Meta-heuristics for dynamic lot sizing: A review and comparison of solution approaches. European Journal of Operational Research, v. 177, n. 3, p. 1855 - 1875, 2007.

Johnson, L. A.; Montgomery, D. C. Operations research in production planning, scheduling, and inventory control. New York: John Wiley \& Sons, 1974.

Johnson, R.; Pilcher, M. G. The traveling salesman problem, edited by e.l. lawler, j.k. lenstra, a.h.g. rinnooy kan, and d.b shmoys, john wiley \& sons, chichester, 1985, 463 pp. Networks, v. 18, n. 3, p. 253-254, 1988.

KARimi, B.; FATEMi GHOMI, S. M. T.; Wilson, J. M. The capacitated lot sizing problem: a review of models and algorithms. Omega, v. 31, n. 5, p. 365-378, 2003.

KIRIN Global beer production by country in 2011. Kirin Institute of Food and Lifestyle Report, v. Vol.36, 2012.

Kuik, R.; Salomon, M.; van Wassenhove, L. N. Batching decisions: structure and models. European Journal of Operational Research, v. 75, n. 2, p. 243-263, 1994.

LANG, J. C.; SHEN, Z.-J. M. Fix-and-optimize heuristics for capacitated lot-sizing with sequencedependent setups and substitutions. European Journal of Operational Research, v. 214, n. 3, p. 595 $-605,2011$.

Lehnert, R.; Brányik, T.; Vicente, A. A.; Dostálek, P.; A.TeiXeira, J. Preliminary optimization study of alcohol-free beer production in continuous immobilized cell reactor system. In: International Congress of Chemical and Process Engineering - CHISA, 2006.

Luche, J. R. D.; Morabito, R.; Pureza, V. Combining process selection and lot sizing models for production scheduling of electrofused grains. Asia-Pacific Journal of Operational Research, v. 26, n. 3, p. 421-443, 2009. 
Maes, J.; McClain, J. O.; Wassenhove, L. N. V. Multilevel capacitated lotsizing complexity and LP-based heuristic. European Journal Of Operational Research, v. 53, p. 131-148, 1991.

Manne, A. S. Programming of economic lot sizes. Management Science, v. 4, n. 2, p. 115-135, 1958.

Martín, R.; Reinelt, G. Heuristic methods. In: The Linear Ordering Problem, v. 175 de Applied Mathematical Sciences, Springer Berlin Heidelberg, p. 17-40, 2011.

Mateus, G. R.; Ravetti, M. G.; Souza, M. C.; Valeriano, T. Capacitated lot sizing and sequence dependent setup scheduling: an iterative approach for integration. Journal of Scheduling, v. 13, n. 3, p. 245-259, 2010.

MENDES, A. S. O framework np-opt e suas aplicações a problemas de otimização. Tese de Doutorado, UNICAMP, 2003.

Meyr, H.; ManN, M. A decomposition approach for the general lotsizing and scheduling problem for parallel production lines. European Journal of Operational Research, v. 229, n. 3, p. 718 - 731, 2013.

Morabito, R.; Pureza, V. Metodologia de pesquisa em engenharia de produção e gestão de operações, cáp. Modelagem e simulação Editora Campus/Elsevier, Rio de Janeiro, p. 165-194, 2010.

Morado, R. Larousse da cerveja. Larousse do Brasil, 2009.

Nascimento, M. C.; Resende, M. G.; Toledo, F. M. \{GRASP\} heuristic with path-relinking for the multi-plant capacitated lot sizing problem. European Journal of Operational Research, v. 200, n. 3, p. $747-754,2010$.

Pimentel, C. M. O. Algoritmos de partição e geração de colunas para dimensionamento de lotes de produção. Dissertação de Mestrado, Escola de Engenharia - Universidade do Minho, Portugal, 2005.

Pinedo, M. Scheduling: theory, algorithms, and systems. Springer, 1995.

Pochet, Y.; Wolsey, L. Production planning by mixed integer programming. Springer Series in Operations Research And Financial Engineering. S Springer, 2006.

RESENDE, M.; RIBEIRO, C. Greedy randomized adaptative search procedures: advances and applications. Springer (2nd ed), 2010.

Rosling, K. Optimal lot-sizing for dynamic assembly system. in: Axsäter, S.; Schneeweilj, C.; Silver, E. (eds.): Multi-stage production planning and inventory control. Springer, Berlin, p. 119-131, 1986.

SAlomon, M. Deterministic lotsizing models for production planning, v. 355. Berlin, 1991.

Salomon, M.; Kroon, L. G.; Kuik, R.; Wassenhove, L. N. V. Some extensions of the discrete lotsizing and scheduling problem. Management Science, v. 37, n. 7, p. 801-812, 1991.

Salomon, M.; Solomon, M. M.; Wassenhove, L. N. V.; Dumas, Y.; DauZer-Peres, S. Solving the discrete lotsizing and scheduling problem with sequence dependent setup costs and setup times using the travelling salesman problem with time windows. European Journal of Operational Research, v. 100, n. 3, p. $494-513,1997$. 
SAntos, M. O. Dimensionamento de lotes em máquinas paralelas com restrições de capacidade em sistemas multiestágios. Tese de Doutorado, ICMC-USP, Brasil, 2000.

Santos, M. O.; AlmadA-Lobo, B. Integrated pulp and paper mill planning and scheduling. Computers \& Industrial Engineering, v. 63, n. 1, p. $1-12,2012$.

Seeanner, F.; Almada-Lobo, B.; Meyr, H. Combining the principles of variable neighborhood decomposition search and the fix\&amp;optimize heuristic to solve multi-level lot-sizing and scheduling problems. Computers \& Operations Research, v. 40, n. 1, p. $303-317,2013$.

SINDCERV Sindicerv - sindicato nacional da indústria da cerveja. Tipos de cervejas (último acesso em 25 de novembro de 2013), 2013.

Disponível em http://www.sindicerv.com.br/tipo-cerveja.php

Slack, N.; Chambers, S.; Johston, R. Administração da produção. Tradução: Maria Teresa Corrêa de Oliveira, Fábio Alher. Revisão Técnica: Henrique Corrêa., 2002.

StaggmeIer, A. T.; Clark, A. R. A survey of lot-sizing and scheduling models. In: Anais do XXXIII SBPO, 2001, p. 938-947.

SUERIE, C. Basic models in lot-sizing - time continuity in discrete time models. Springer Berlin Heidelberg (Lecture Notes in Economics and Mathematical Systems), 2005.

TAlBI, E.-G. Metaheuristics: From design to implementation. Wiley Publishing, 2009.

Tempelmeier, H.; Derstroff, M. A lagrangean-based heuristic for dynamic multilevel multi-item constrained lotsizing with setup times. Management Science, v. 42, n. 5, p. 738-757, 1996.

Toledo, C.; FrançA, P.; Morabito, R.; Kimms, A. Multi-population genetic algorithm to solve the synchronized and integrated two-level lot sizing and scheduling problem. International Journal of Production Research, v. 47, n. 11, p. 3097-3119, 2009.

Toledo, C. F.; FranÇA, P.; Morabito, R.; Kimms, A. Um modelo de otimização para o problema integrado de dimensionamento de lotes e programação da produção em fábricas de refrigerantes. Pesquisa Operacional, v. 27, n. 1, p. 155-186, 2007.

Toledo, C. F. M.; De Oliveira, R. R. R.; FrançA, P. M. A hybrid multi-population genetic algorithm applied to solve the multi-level capacitated lot sizing problem with backlogging. Computers \& Operations Research, v. 40, n. 4, p. 910 - 919, 2013.

Toledo, C. F. M.; Da Silva Arantes, M.; FrançA, P. M.; Morabito, R. A memetic framework for solving the lot sizing and scheduling problem in soft drink plants. In: CHIONG, R.; WeISE, T.; MichalewiCZ, Z., eds. Variants of Evolutionary Algorithms for Real-World Applications, Springer, p. 59-93, 2012.

Toledo, F. M. B.; Armentano, V. A. A lagrangian-based heuristic for the capacitated lot-sizing problem in parallel machines. European Journal of Operational Research, v. 175, n. 2, p. 1070 - 1083, 2006. 
TONAKI, V. S.; TOLEDo, F. M. B. An approach for solving the lot-sizing problem of a market-driven foundry. Journal of the Operational Research Society, v. 61, n. 1, p. 108-114, 2010.

Toso, E. A. V.; Morabito, R.; Clark, A. R. Combinação de abordagens glsp e atsp para o problema de dimensionamento e sequenciamento de lotes de produção de suplementos para nutrição animal. Pesquisa Operacional, v. 28, n. 3, p. 423-450, 2008.

Toso, E. A. V.; Morabito, R.; Clark, A. R. Lot sizing and sequencing optimisation at an animal-feed plant. Comput. Ind. Eng., v. 57, n. 3, p. 813-821, 2009.

Trigeiro, W. W.; Thomas, L. J.; MCClain, J. O. Capacitated lot sizing with setup times. Management Science, v. 35, n. 3, p. 353-366, 1989.

Wagner, H. M.; Whitin, T. M. Dynamic version of the economic lot size model. Management Science, v. 5 , n. 1 , p. 89-96, 1958.

Wolsey, L. A. Mip modelling of changeovers in production planning and scheduling problems. European Journal of Operational Research, v. 99, n. 1, p. 154-165, 1997.

Wolsey, L. A. Integer programming. Wiley, New York, 1998.

WOLSEY, L. A. Solving multi-item lot-sizing problems with an MIP solver using classification and reformulation. Management Science, v. 48, n. 12, p. 1587-1602, 2002.

Wu, T.; ZhANG, C.; LiAng, Z.; LeUng, S. C. A lagrangian relaxation-based method and models evaluation for multi-level lot sizing problems with backorders. Computers \& Operations Research, v. 40, n. 7 , p. $1852-1863,2013$. 